INSTITUTO DE PESQUISAS ENERGÉTICAS E NUCLEARES

AUTARQUIA ASSOCIADA À UNIVERSIDADE DE SÃO PAULO

\title{
AVALIAÇÃO DA CITOTOXICIDADE DO DIETILTOLUAMIDA (DEET) EM MEXILHÕES Perna perna (Linnaeus, 1758) IRRADIADOS E NÃO IRRADIADOS COM RADIAÇÃO GAMA DE ${ }^{60} \mathrm{Co}$
}

\section{GISELA DE ASSIS MARTINI}

Dissertação apresentada como parte dos requisitos para obtenção do Grau de Mestre em Ciências na Área de Tecnologia Nuclear - Aplicações

Orientador:

Prof. Dr. José Roberto Rogero

Versão Corrigida

Versão Original se encontra no IPEN

SÃO PAULO

2013 
Dedico este trabalho aos meus pais, amo vocês! 


\section{AGRADECIMENTOS}

Aos meus pais pela confiança em mim depositada, pelo apoio de todas as maneiras possíveis, e por todo o amor! Vocês são minha referência de vida, obrigada por tudo!!!

Às minhas irmãs, que acreditaram no meu potencial e sempre estiveram ao lado, amo vocês! Aos meus queridos avós e padrinhos, que sempre estiveram me apoiando e acompanhando toda a minha trajetória!

Ao meu orientador Dr. José Roberto Rogero, pela oportunidade de realizar esse projeto, pela confiança, paciência, por toda a contribuição, aprendizado e amizade! À Msc. Sizue Ota Rogero minha "co-orientadora" muito obrigada pelo apoio, amizade, por todas as contribuições e ajuda nos momentos difíceis no decorrer desse projeto!

Ao Instituto de Pesquisas Energéticas e Nucleares e ao Centro de Química e Meio Ambiente pela infraestrutura disponibilizada para o desenvolvimento deste trabalho.

À Marina Victoretti, por toda a ajuda na parte experimental, pelo apoio e bom convívio, muito obrigada!

À Edgar França por toda a ajuda nas coletas, grande apoio em todo o projeto, pelo carinho e amizade!

À Renan Azevedo, por toda a ajuda, amizade, paciência, carinho e parceria!

À Fabio Pusceddu, por todas as contribuições e amizade!

À Thiago Gomes, pela ajuda, amizade e companhia!

À Rodrigo Viana, por todas as contribuições, carinho, atenção e companhia!

À Giovanna Gimiliani e Vanessa Lameira, por toda a ajuda, contribuições e amizade.

Agradeço às minhas queridas amigas: Camila, Bia, Laís, Rafa, Carol, Isa e Bárbara, por todo carinho, amizade, parceria e por sempre apoiarem meus sonhos e estarem presentes na minha vida!

Aos funcionários do Centro de Tecnologia das Radiações - CTR: Beth, Carlos e Hélio, pela realização das irradiações no GammaCell, por todo o interesse e ajuda. 
À todos os funcionários do CQMA que contribuíram para o desenvolvimento desse projeto, um especial agradecimento à Lurdinha, que me auxiliou em muitas limpezas após as quedas de energia!

Aos funcionários do transporte do IPEN, sem os quais as minhas coletas não seriam possíveis! E o meu obrigada especial ao Eduardo, Fábio e Marcelo, por toda a colaboração!

Aos amigos "pós-graduandos": Flávia Junqueira, Juliana Cristina, Bruna Rafaela, Tharcilla Collachite, Gustavo Gobatto obrigada pela amizade e apoio!

À Lucilena Rebelo Monteiro, por toda a ajuda e pelas trocas de ideias!

À Bruna Roque e Fernanda Oliveira, por toda a ajuda e pelas boas conversas! À CNEN pelo apoio financeiro. 
Somos um grande barco navegando ao redor de um sol incandescente no universo. Mas cada um de nós é um barco em si mesmo, um barco carregado de genes navegando pela vida. Se conseguirmos levar esta carga ao porto mais próximo, nossa vida não terá sido em vão. (Jostein Gaarder) 


\section{Avaliação da citotoxicidade do Dietiltoluamida (DEET) em mexilhões Perna perna (Linnaeus, 1758) irradiados e não irradiados com radiação gama de ${ }^{60} \mathrm{Co}$}

\section{Gisela de Assis Martini}

\section{RESUMO}

Estudos recentes têm identificado a presença de diversos poluentes emergentes em ambientes aquáticos. A ocorrência em diferentes matrizes ambientais tem sido continuamente relatada, o que evidencia a necessidade de estudos de toxicidade. O DEET ( $N, N$-dietil-meta-toluamida) é o princípio ativo mais utilizado em repelentes de insetos e está presente em diversas formulações comercialmente disponíveis. Além dos poluentes químicos, os organismos aquáticos estão sujeitos à exposição da radiação ionizante proveniente de fontes naturais ou em proximidades de instalações de usinas nucleares. O presente estudo avaliou a toxicidade do DEET em organismos irradiados e não irradiados com radiação gama de ${ }^{60} \mathrm{Co}$, e os efeitos que a radiação causa sob os lisossomos de hemócitos do mexilhão Perna perna. Para isso, foram realizados ensaios de toxicidade aguda para identificar a concentração de DEET e a dose de radiação gama passíveis de causar mortalidade, e posteriormente ensaios de citotoxicidade avaliando a estabilidade da membrana lisossômica em organismos expostos ao DEET e radiação ionizante. De acordo com os resultados obtidos nos ensaios de toxicidade aguda, a concentração de DEET que causa mortalidade em $50 \%$ dos organismos expostos (CL50) é de 114,27 $\mathrm{mg} \mathrm{L}^{-1}$, e a dose de radiação que causa mortalidade (DL50) é de 1068 Gy. Nos os ensaios de citotoxicidade obteve-se a concentração de efeito não observado (CENO) para organismos irradiados e não irradiados de $0,0001 \mathrm{mg} \mathrm{L}^{-1}$ e a concentração de efeito observado (CEO) em concentrações acima desta. A Cl25(72h) para organismos não irradiados foi de $0,0003 \mathrm{mg} \mathrm{L}^{-1}$ e a Cl50 $(72 h)$ foi de $0,0008 \mathrm{mg} \mathrm{L}^{-1}$ para organismos irradiados e não irradiados. Apesar das concentrações de efeito encontradas no presente estudo terem sido mais altas que as ambientais, estão na mesma ordem de grandeza e também deve-se levar em consideração os possíveis efeitos sinérgicos do DEET com outros contaminantes presentes em ambiente aquático.

Palavras-chave: Ecotoxicidade; Dietiltoluamida; Radiação gama; Mexilhão Perna perna. 


\title{
Cytotoxicity evaluation of Diethyltoluamide (DEET) in Perna perna (Linnaeus, 1758) mussels non-irradiated and irradiated with ${ }^{60} \mathrm{Co}$ gamma radiation
}

\section{Gisela de Assis Martini}

\begin{abstract}
Recent studies have identified the presence of several emerging pollutants in aquatic environments. The occurrence in different environmental matrices has been continuously reported, highlighting the need for toxicity studies. The DEET ( $\mathrm{N}, \mathrm{N}$-diethyl-meta-toluamide) is the active ingredient used in most insect repellents, and is present in many commercially available formulations. Apart from chemical pollutants, aquatic organisms are subject to exposure of ionizing radiation from natural sources or in the vicinity of nuclear power plants. The present study evaluated the toxicity of DEET in organisms irradiated and nonirradiated with ${ }^{60} \mathrm{Co}$ gamma radiation, and the effects that radiation causes in lysosomes of hemocytes of Perna perna mussel. For this purpose, assays were performed to identify the acute toxicity of DEET concentration and the dose of gamma radiation able to cause mortality. Subsequently, cytotoxicity assays were carried out to assess the stability of the lysosomal membrane in organisms exposed to ionizing radiation and DEET. According to the results obtained in acute toxicity tests, the concentration of DEET that causes mortality of $50 \%$ exposed organisms (LC50) is $114,27 \mathrm{mg} \mathrm{L}^{-1}$, and the radiation dose that causes mortality (LD50) is 1068 Gy. In the cytotoxicity assays, the concentration of the nonobserved effect (NOEC) for irradiated and non-irradiated organisms $0.0001 \mathrm{mg} \mathrm{L}^{-1}$ and observed effect concentration (LOEC) at concentrations above this. The IC25 (72h) for non-irradiated organisms was $0.0003 \mathrm{mg} \mathrm{L}^{-1}$ and IC50 (72h) was 0.0008 $\mathrm{mg} \mathrm{L}^{-1}$ for irradiated and non-irradiated organisms. Despite of the concentrations of effect found in this study were higher than in the environment, both measurements are in the same order of magnitude and should be also take into account the possible synergistic effects of DEET with other contaminants in the aquatic environment.
\end{abstract}

Key words: Ecotoxicity; Diethyltoluamide; Gamma radiation; Perna perna mussel. 


\section{SUMÁRIO}

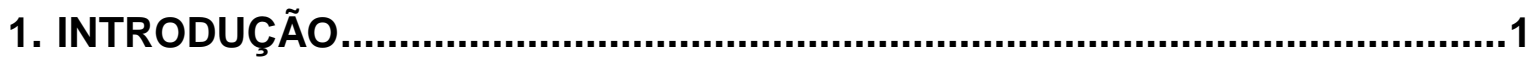

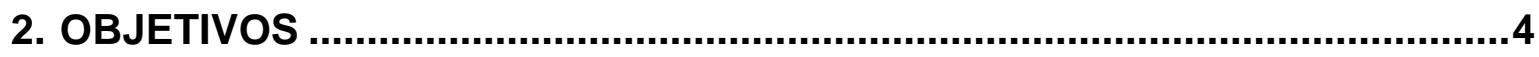

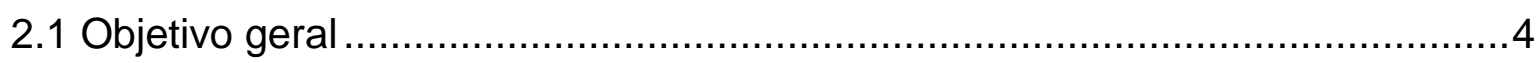

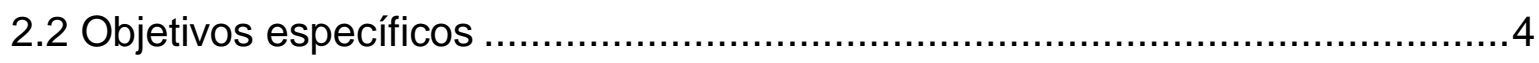

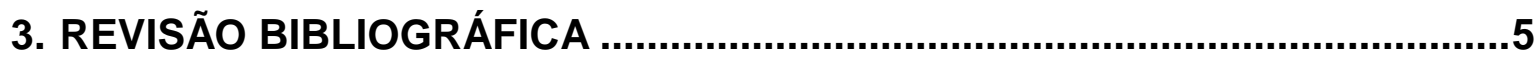

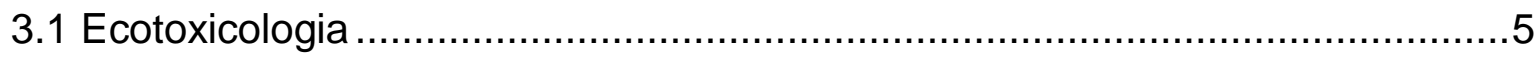

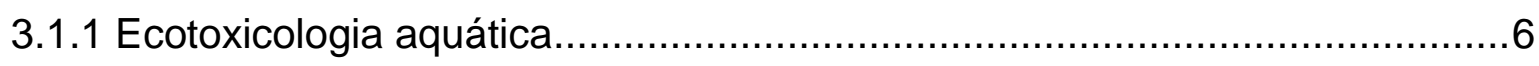

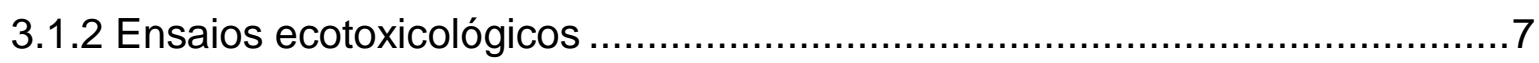

3.1.3 Ensaios de toxicidade com organismos marinhos ....................................

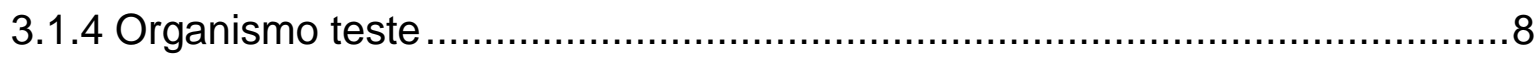

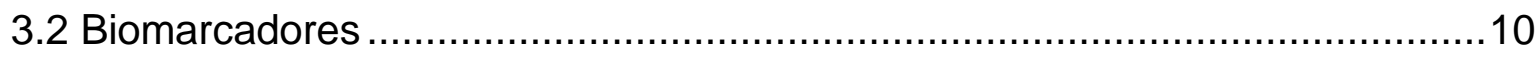

3.3 DEET (N,N-dietil-m-toluamida)..........................................................13

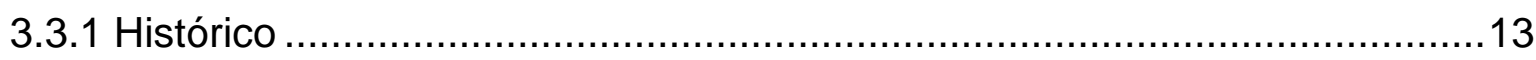

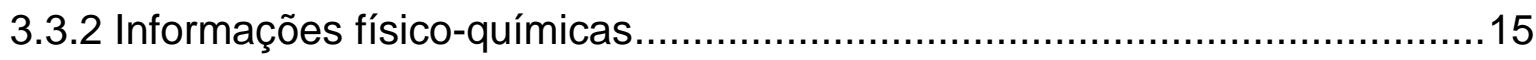

3.3.3 Avaliação ambiental do DEET ...........................................................16

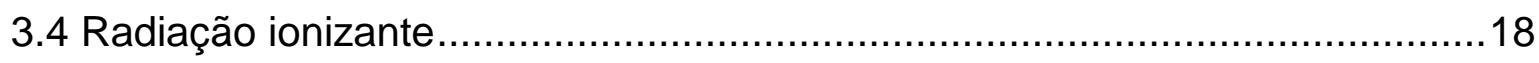

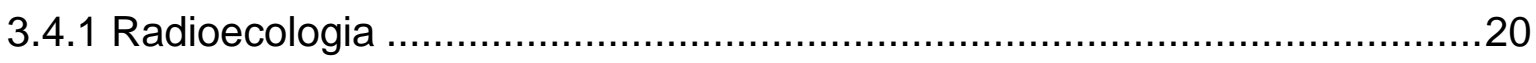

3.4.2 Exposição dos organismos aquáticos às fontes de radiação ionizante ........21

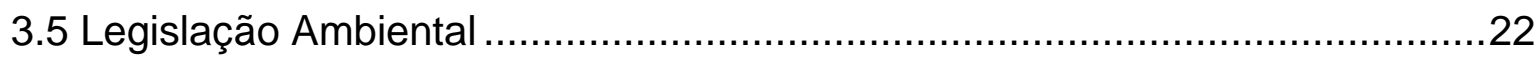

4. METODOLOGIA

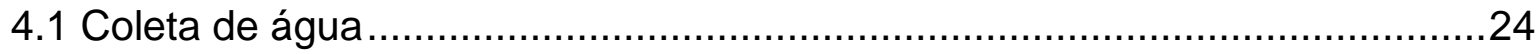

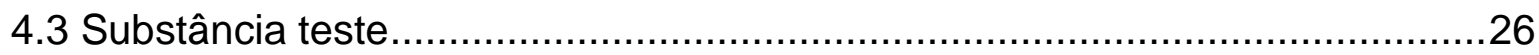


4.4 Irradiação dos organismos .27

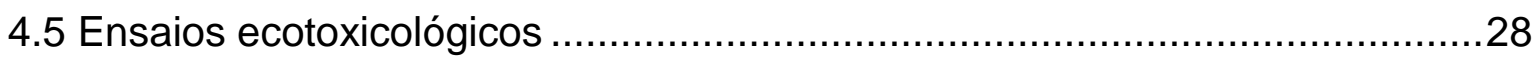

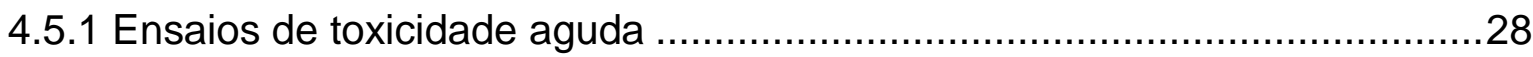

4.5.1.1 Ensaios de toxicidade aguda com DEET ………..............................29

4.5.1.2 Ensaios de toxicidade aguda em organismos irradiados com radiação

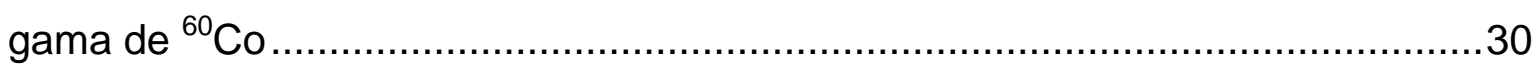

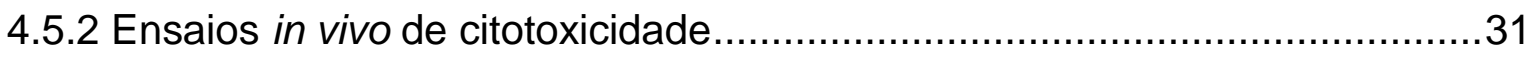

4.5.2.1 Ensaio do tempo de retenção do corante vermelho neutro ......................32

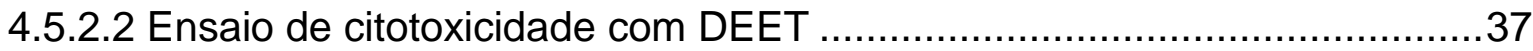

4.5.2.3 Ensaios de citotoxicidade do DEET em organismos irradiados ................38

4.5.2.4 Ensaios de citotoxicidade em organismos irradiados...............................39

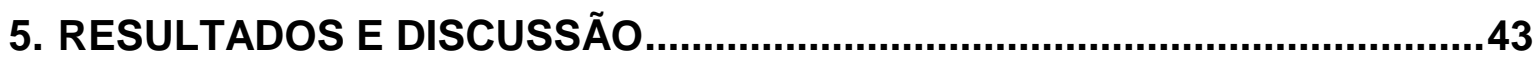

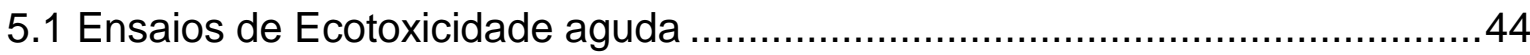

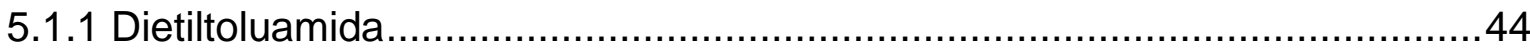

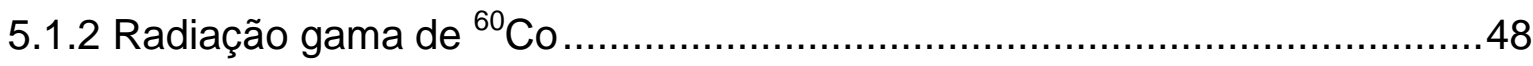

5.2 Ensaios de citotoxicidade com Perna perna (Mollusca, Bivalvia)....................53

5.2.1 Ensaios preliminares de citotoxicidade do DEET com organismos não irradiados

5.2.2 Ensaios definitivos de citotoxicidade do DEET em organismos não irradiados

5.2.3 Ensaios preliminares de citotoxicidade do DEET em organismos irradiados.

5.2.4 Ensaios definitivos de citotoxicidade do DEET em organismos irradiados ..71

5.2.5 Exposição dos organismos à radiação ionizante .77 
5.2.6 Comparação dos resultados dos ensaios de citotoxicidade do DEET com organismos irradiados e não irradiados com radiação gama de ${ }^{60} \mathrm{Co}$....................78

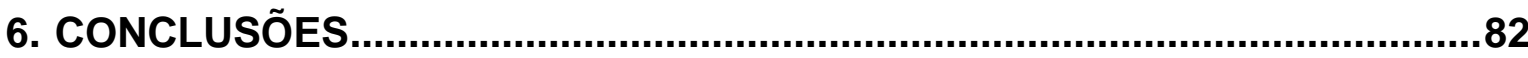

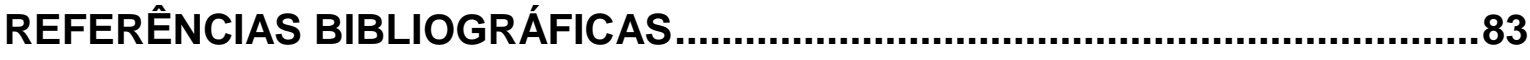

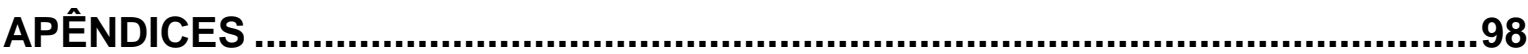




\section{LISTA DE FIGURAS}

FIGURA 1 - Associação dos efeitos de poluentes em organismos e seus hábitats (baseado em Blaise, 1984)

FIGURA 2 - Esquematização externa (a) e interna (b) de um mexilhão Perna perna com identificação de algumas características morfológicas (FERREIRA, J. F., 1987)

FIGURA 3 - Tipos de biomarcadores. Adaptado de Schlenk (1999). 10

FIGURA 4 - Representação de uma célula com ampliação à direita do lisossomo

FIGURA 5 - Representação esquemática de um lisossomo, com ampliação da bicamada lipídica (http://educacaoalemdaescola.blogspot.com.br)

FIGURA 6 - Ação direta e indireta da radiação ionizante na molécula de ácido nucleico. .19

FIGURA 7 - Localização da Praia da Cocanha, Caraguatatuba - SP. .24

FIGURA 8 - Fazenda de Mexilhões na llha da Cocanha, Caraguatatuba - SP. Identificação também da Praia da Cocanha e da Sede da MAPEC. .25

FIGURA 9 - (a) Mexilhões Perna perna recém retirados do cultivo, (b) Mexilhões Perna perna limpos, (c) Mexilhões Perna perna no processo de lavagem no laboratório 26

FIGURA 10 - Representação da cadeia química do Dietiltoluamida DEET .27

FIGURA 11 - (a) Irradiador Gamma-Cell 200, (b) Mexilhões Perna perna em frascos de polipropileno .28

FIGURA 12 - Etapas realizadas no ensaio de tempo de retenção do corante vermelho neutro descrito por Lowe (1995).

FIGURA 13 - Extração da hemolinfa .34

FIGURA 14 - Incubação do conjunto de lâminas em câmara escura e úmida .....35 
FIGURA 15 - Observação das lâminas em microscópio .35

FIGURA 16 - (a) Células saudáveis, (b) Células estressadas. .36

FIGURA 17 - Ensaio de Citotoxicidade com DEET .38

FIGURA 18 - Mexilhões Perna perna acondicionados nos frascos de polipropileno para irradiação 39

FIGURA 19 - Fluxograma com as etapas para análise estatística e determinação dos valores de CE ou CL50 e intervalo de confiança a 95\%

FIGURA 20 - Fluxograma com as etapas para análise estatística e determinação dos valores de CENO, CEO e Cl ( adaptado USEPA, 2002).

FIGURA 21 - Fluxograma das etapas realizadas no presente estudo. . .43

FIGURA 22 - Taxa de mortalidade em função das concentrações de DEET a que os organismos foram expostos.

FIGURA 23 - Taxa de mortalidade em função das doses de radiação gama de ${ }^{60} \mathrm{Co}$ a que os organismos foram expostos 49

FIGURA 24 - Representação gráfica do tempo de retenção do corante VN em função das concentrações de DEET para o mexilhão Perna perna. .54

FIGURA 25 - Representação gráfica do tempo de retenção do corante VN em função das concentrações de DEET para o mexilhão Perna perna. .55

FIGURA 26 - Representação gráfica do tempo de retenção do corante VN em função das concentrações de DEET para o mexilhão Perna perna. .57

FIGURA 27 - (a, b) Representação gráfica do tempo de retenção do corante VN em função das concentrações de DEET para o mexilhão Perna perna. .58

FIGURA 28 - Toxicidade do DEET em hemócitos do molusco bivalve Perna perna (Ensaio I)

FIGURA 29 - Toxicidade do DEET em hemócitos do molusco bivalve Perna perna (Ensaio II) 
FIGURA 30 - Toxicidade do DEET em hemócitos do molusco bivalve Perna perna (Ensaio III)

FIGURA 31 - Toxicidade do DEET em hemócitos de Perna perna irradiados (3Gy) .68

FIGURA 32 - Toxicidade do DEET em hemócitos de Perna perna irradiados .....69 FIGURA 33 - Toxicidade do DEET em hemócitos de Perna perna irradiados .....70 FIGURA 34 - Toxicidade do DEET em hemócitos de Perna perna irradiados (Ensaio I) 72

FIGURA 35 - Toxicidade do DEET em hemócitos de Perna perna irradiados (Ensaio II). .73

FIGURA 36 - Toxicidade do DEET em hemócitos de Perna perna irradiados (Ensaio III) 74

FIGURA 37 - Tempo de retenção do corante vermelho neutro do molusco bivalve Perna perna irradiados em comparação com o controle. 77

FIGURA 38 - Tempo de retenção do corante VN em função da concentração de DEET para organismos irradiados e não irradiados (24h). 79

FIGURA 39 - Tempo de retenção do corante VN em função da concentração de DEET para organismos irradiados e não irradiados (48h) .80

FIGURA 40 - Tempo de retenção do corante VN em função da concentração de DEET para organismos irradiados e não irradiados (72h) 81 


\section{LISTA DE TABELAS}

TABELA 1 - Características físico-químicas do DEET

TABELA 2 - Parâmetros e condições dos ensaios de toxicidade aguda com o mexilhão Perna perna

TABELA 3 - Parâmetros e condições dos ensaios de toxicidade aguda com mexilhão Perna perna irradiados

TABELA 4 - Parâmetros e condições dos ensaios de citotoxicidade com mexilhão Perna perna .32

TABELA 5 - Critérios de avaliação de hemócitos .36

TABELA 6 - Percentual de mortalidade obtido nos ensaios de toxicidade aguda de DEET para o mexilhão Perna perna

TABELA 7 - Valores da CL50, intervalos de confiança, média, desvio padrão e coeficiente de variação para os ensaios de ecotoxicidade aguda do DEET para mexilhões Perna perna.

TABELA 8 - Toxicidade aguda do DEET para diversas espécies em diferentes ensaios (Adaptado de RAND e BRAUSCH, 2011) .46

TABELA 12 - Valores médios do tempo de retenção do corante VN (minutos), desvio padrão (DP) e coeficiente de variação $(\mathrm{CV})$ para as leituras do $1^{\circ}$ ensaio de citotoxicidade .55

TABELA 13 - Valores médios do tempo de retenção do corante VN (minutos), desvio padrão (DP) e coeficiente de variação (CV) para as leituras do $2^{\circ}$ ensaio de citotoxicidade .56

TABELA 15 - Valores médios do tempo de retenção do corante VN (minutos), desvio padrão (DP) e coeficiente de variação (CV) para as leituras do $4^{\circ}$ ensaio de citotoxicidade .58 
TABELA 16 - Valores médios do tempo de retenção do corante VN (minutos), desvio padrão (DP) e coeficiente de variação (CV) para as leituras do $5^{\circ}$ ensaio de citotoxicidade

TABELA 15 - Valores médios do tempo de retenção do corante VN (minutos), desvio padrão (DP) e coeficiente de variação (CV)

TABELA 16 - Valores médios do tempo de retenção do corante VN (minutos), desvio padrão (DP) e coeficiente de variação (CV)

TABELA 17 - Valores médios do tempo de retenção do corante VN (minutos), desvio padrão (DP) e coeficiente de variação (CV) .63

TABELA 18 - Valores calculados para a $\mathrm{Cl} 25_{(48 h)}$ 63

TABELA 19 - Valores calculados para a $\mathrm{Cl}_{2} 5_{(72 h)}$ 64

TABELA 20 - Valores calculados para a $\mathrm{Cl}^{5} 0_{(24 h)}$ 64

TABELA 21 - Valores calculados para a $\mathrm{Cl}_{50}(48 \mathrm{~h})$ .64

TABELA 22 - Valores calculados para a $\mathrm{Cl}_{50}(72 h)$ .65

TABELA 23 - Valores médios do tempo de retenção do corante VN (minutos), desvio padrão* e coeficiente de variação** .68

TABELA 24 - Valores médios do tempo de retenção do corante VN, desvio padrão* e coeficiente de variação** 69

TABELA 25 - Valores médios do tempo de retenção do corante $\mathrm{VN}$, desvios padrão* e coeficientes de variação**

TABELA 26 - Valores médios do tempo de retenção do corante VN, desvio padrão* e coeficiente de variação** em organismos irradiados com 11 Gy. .72

TABELA 27 - Valores da média, desvio padrão* e coeficiente de variação** em organismos irradiados com $11 \mathrm{~Gy}$..... .73

TABELA 28 - Valores médios do tempo de retenção do corante VN, desvio padrão* e coeficiente de variação** em organismos irradiados com $11 \mathrm{~Gy}$ .74 
TABELA 29 - Valores calculados para a $\mathrm{Cl}_{50}(24 \mathrm{~h}) \mathrm{em}$ organismos irradiados ......75

TABELA 30 - Valores calculados para a $\mathrm{Cl}_{50}(48 \mathrm{~h})$ em organismos irradiados ......75

TABELA 31 - Valores calculados para a $\mathrm{Cl}_{50}(72 \mathrm{~h})$ em organismos irradiados ......75

TABELA 32 - Valores médios do tempo de retenção do corante, desvio padrão* e coeficiente de variação** de organismos irradiados com 11 Gy e controle .78

TABELA 33 - Valores médios do tempo de retenção do corante, desvio padrão* e coeficiente de variação** de organismos irradiados e não irradiados $(24 \mathrm{~h})$. .79

TABELA 34 - Valores médios do tempo de retenção do corante, desvio padrão* e coeficiente de variação** de organismos irradiados e não irradiados (48h) .80

TABELA 35 - Valores médios do tempo de retenção do corante, desvio padrão* e coeficiente de variação** de organismos irradiados e não irradiados $(72 h)$ .81 


\section{INTRODUÇÃO}

Anualmente novas substâncias químicas são sintetizadas e a maioria atinge direta ou indiretamente os ecossistemas aquáticos (SOUSA, 2000). A introdução desses compostos em concentrações acima das naturais e a presença de compostos sintéticos podem causar alterações no meio ambiente, podendo configurar eventos de contaminação. Visando à proteção da biota aquática, tornase desejável progredir na identificação e quantificação da presença desses contaminantes para uma avaliação de sua biodisponibilidade e efeitos nocivos ao ecossistema aquático.

A identificação e ocorrência desses compostos em diferentes matrizes ambientais têm sido continuamente relatadas, o que evidencia a necessidade de avaliações de risco ambiental. Mesmo que presentes em baixas concentrações, esses compostos podem causar efeitos adversos sobre a biota, agindo de forma isolada ou a partir da interação com outras substâncias.

Dentre os compostos mundialmente utilizados destaca-se o DEET (N,Ndiethyl-meta-toluamide $-\mathrm{C}_{12} \mathrm{H}_{17} \mathrm{NO}$ ) que é o principio ativo mais utilizado na formulação de repelentes de insetos, e está sendo comercializado há mais de 50 anos (USEPA, 1998). Já foi evidenciada a presença do DEET em diversas matrizes ambientais, mostrando que este composto apresenta característica persistente (SINGH, 2010).

Além disso, no meio ambiente em regiões próximas as instalações nucleares, na maioria das vezes litoral, e em regiões com maior nível de radiação de fundo, muitos organismos aquáticos podem estar sujeitos a níveis elevados de radiação, ficando mais sucetíveis à exposição a outros contaminantes.

Diversos organismos marinhos podem bioacumular radioisótopos em concentrações milhares de vezes superiores aos níveis encontrados no ambiente (FOWLER,2003). Portanto, é de extrema importância verificar o comportamento destes compostos no ambiente, bem como, avaliar os efeitos da radiação sobre sistemas biológicos. 
Após submissão à doses de radiação os organismos podem apresentar efeitos biológicos que desencadeiam mudanças desde o nível molecular até altos níveis de organização biológica, podendo afetar toda uma comunidade, ou até mesmo um nicho ecológico.

Estudos ecotoxicológicos podem ser utilizados para estimar os efeitos de substâncias desde níveis bioquímicos e moleculares até níveis mais elevados de organização, como comunidades e ecossistemas (WALKER, 1996).

Diferentes métodos podem ser utilizados para estimar os efeitos causados pelos contaminantes, tais como testes de toxicidade, determinação de anomalias genéticas, utilização de biomarcadores, entre outros (PEDROSA et al.,2001; ZARONI et al., 2001).

No presente estudo optou-se pela utilização de biomarcadores que, de acordo com Walker (1996), são indicadores bioquímicos, fisiológicos ou histológicos de exposição ou efeito de xenobióticos presentes no ambiente, em nível de organismo ou de "sub-organismo".

Dentre as diversas técnicas, foi escolhida a integridade da membrana lisossômica, avaliada por meio do ensaio de tempo de retenção do corante vermelho neutro, devido à sua alta sensibilidade à maioria dos grupos de contaminantes e extrapolação dos danos lisossomais em níveis de maior organização biológica, tais como indivíduo e população.

Esta técnica foi considerada confiável e recomendada para avaliação da qualidade da água, de acordo com os resultados de um programa internacional de monitoramento ambiental (UNEP, 1997).

Mexilhões e outros organismos bivalves têm sido amplamente utilizados como organismos sentinelas no monitoramento da qualidade ambiental em regiões costeiras (IMWC, 1995). No presente estudo o organismo utilizado foi o mexilhão Perna perna (Linnaeus, 1758).

Nesse contexto, o presente estudo avaliou os efeitos ecotoxicológicos do Dietiltoluamida (DEET) em hemócitos de mexilhões Perna perna (Linnaeus, 1758) irradiados e não irradiados com radiação gama de fonte de ${ }^{60} \mathrm{Co}$ por meio do 
ensaio do tempo de retenção do corante vermelho neutro. Com os resultados obtidos, espera-se contribuir para uma melhor avaliação do risco ecológico do composto e para conhecimento dos efeitos da radiação ionizante em invertebrados marinhos. 


\section{OBJETIVOS}

\subsection{Objetivo geral}

O objetivo do presente estudo é avaliar a citotoxicidade do Dietiltoluamida (DEET) por meio da avaliação dos possíveis efeitos adversos causados nos lisossomos de hemócitos de mexilhões Perna perna irradiados e não irradiados com radiação gama de ${ }^{60} \mathrm{Co}$ empregando-se o ensaio do tempo de retenção do corante vermelho neutro.

A fim de se contribuir para a avaliação do risco ecológico desse composto, para conhecimento do possível efeito causado pela radiação ionizante nos mexilhões, bem como o possível efeito sinérgico entre a radiação e o DEET, gerando subsídios para futura regulação de seus descartes no ambiente aquático.

\subsection{Objetivos específicos}

$\checkmark$ Avaliar a sensibilidade do organismo teste à radiação e exposição ao DEET;

$\checkmark$ Determinar a CL50 (concentração letal 50\%) de DEET e DL50 (dose letal $50 \%$ ) de radiação gama de ${ }^{60} \mathrm{Co}$ para mexilhões Perna perna;

$\checkmark$ Determinar a CENO (concentração de efeito não observada) e CEO (concentração de efeito observada) após exposição dos organismos ao DEET;

$\checkmark$ Avaliar os efeitos da radiação gama de ${ }^{60}$ Co sobre a integridade da membrana lisossômica em organismos irradiados e expostos ao DEET;

$\checkmark$ Comparar os efeitos citotóxicos do DEET em organismos irradiados e não irradiados. 


\section{REVISÃO BIBLIOGRÁFICA}

\subsection{Ecotoxicologia}

O termo Ecotoxicologia foi sugerido pela primeira vez em 1969 na reunião do Committee of the International Council of Scientific Unions (ICSU) por René Truhaut (TRUHAUT, 1977).

Desde então, o conceito foi muito discutido, até que em 1976 definiu-se ecotoxicologia como sendo: a ciência que estuda os efeitos das substâncias naturais ou sintéticas sobre os organismos vivos, populações e comunidades, animais ou vegetais, terrestres ou aquáticos, que constituem a biosfera, incluindo assim a interação das substâncias com o meio nos quais os organismos vivem num contexto integrado (PLAA, 1982; CAIRNS \& NIEDERLEHNER, 1995).

A associação dos efeitos dos poluentes aos organismos e a interação desses em seus habitats foi descrita por Blaise (1984) (FIG. 1), e é mostrado no fluxograma abaixo:

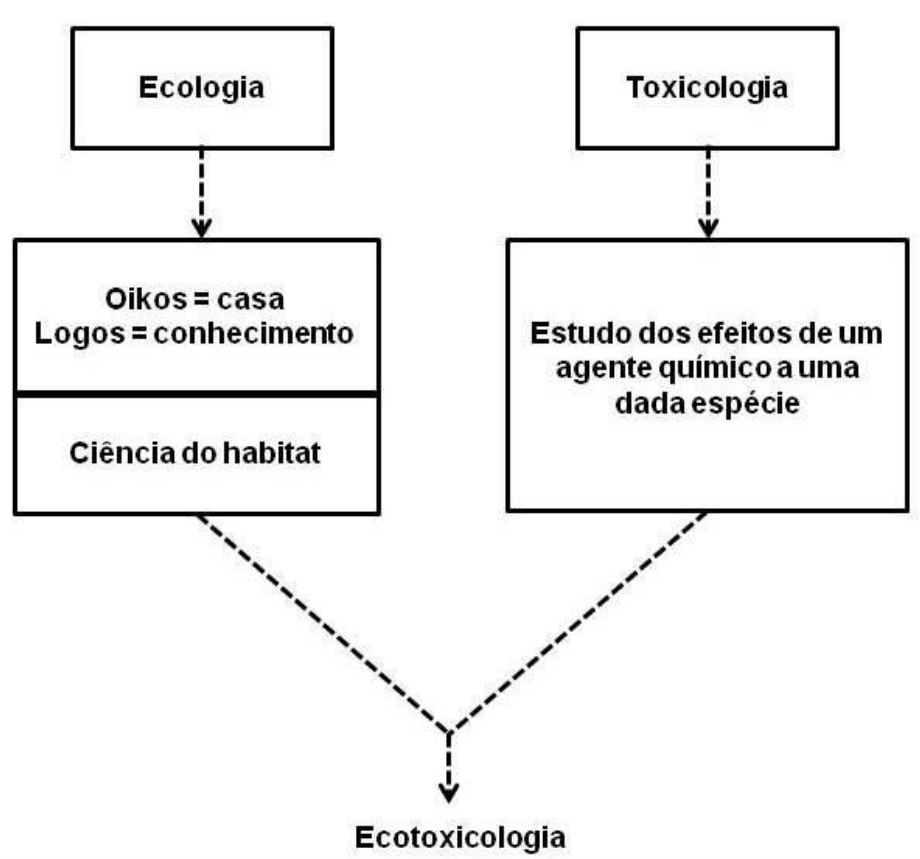

Estudo dos efeitos de uma ou mais substâncias a uma população ou comunidade de organismos

FIGURA 1 - Associação dos efeitos de poluentes em organismos e seus hábitats (baseado em Blaise, 1984) 
De acordo com Rand (1995) o objetivo da ecotoxicologia é proteger populações e comunidades, porém não é possível a utilização de todas as espécies existentes pois o número de organismos é maior e consequentemente, o grau de incerteza na extrapolação dos dados também. Além do que a extrapolação dos dados de toxicidade são mais difíceis devido às variações dos fatores ambientais.

A toxicologia ambiental é uma ciência altamente eclética e multidisciplinar que envolve diversas áreas de estudo como biologia, química (orgânica, analítica e bioquímica), anatomia, genética, fisiologia, microbiologia, ecologia, ciências do solo, água e atmosfera, epidemiologia, estatística, legislação e a ecotoxicologia (HODGSON, E., 2004; YU, M.H., 2005).

\subsubsection{Ecotoxicologia aquática}

A ecotoxicologia aquática tem como objetivo avaliar o efeito de substâncias químicas tóxicas sobre organismos representativos do ecossistema aquático, e a concentração, transporte, transformação e disposição final dos contaminantes dependem de suas características e das propriedades do ambiente a que foi introduzido (RAND, 1995).

A toxicidade de uma substância química depende das propriedades, concentração e do tempo de exposição à que o organismo está sendo exposto.

Os efeitos tóxicos causados pela exposição à diversos contaminantes pode se manifestar em diferentes níveis de organização biológica, desde estruturas celulares até populações e comunidades (ADAMS, W. J., 2003).

Visando a proteção dos ecossistemas aquáticos, testes de toxicidade aquática são bastante utilizados, pois os mesmos constituem os principais receptáculos de contaminantes, sejam eles lançados diretamente nos corpos d'água, emitidos no ar ou depositados nos solos (GHERARDI-GOLDSTEIN, E., et al., 1990; KENDALL, R. J., et al., 2001). 


\subsubsection{Ensaios ecotoxicológicos}

A utilização de ensaios ecotoxicológicos integra os conceitos da ecologia, na diversidade e representatividade dos organismos e seu significado ecológico, e da toxicologia, em relação aos efeitos adversos dos poluentes sobre comunidades biológicas (PLAA, 1982).

O emprego dos ensaios ecotoxicológicos apresenta diversas finalidades, das quais, de acordo com Abessa (2002), destacam-se:

1) o conhecimento da qualidade de águas, sedimentos, solos e do ar;

2) os fins de regulação e a definição de limites máximos permissíveis para o lançamento de efluentes e substâncias químicas;

3) as estimativas do efeito de descargas de contaminantes sobre as populações naturais;

4) a definição de áreas críticas;

5) análises de risco ecológico;

6) como integrantes em programas de monitoramento ambiental;

7) a detecção dos primeiros sinais de impacto devido a compostos químicos ("early warning");

8) o fornecimento do significado biológico para dados de contaminação;

Atualmente, cada vez mais os ensaios de toxicidade e estudos de monitoramento ambiental têm sido empregados com a finalidade de se avaliar e conhecer os efeitos da introdução direta e/ou indireta de compostos químicos emergentes no meio ambiente.

As informações obtidas fornecem dados para comparação da toxicidade entre substâncias, para comparar a sensibilidade de diferentes organismos expostos às mesmas, informações para registros químicos bem como, comparar os valores obtidos com os padrões já estabelecidos. 
A avaliação da toxicidade por meio de ensaios ecotoxicológicos se dá com organismos representativos de ambientes de água doce, estuarina ou marinha.

\subsubsection{Ensaios de toxicidade com organismos marinhos}

O uso de testes de toxicidade como ferramenta em análises de impacto ambiental vêm sendo utilizados no Brasil desde a década de 70, mas somente a partir da década de 80 foram realizados os primeiros ensaios com espécies marinhas e estuarinas, e ainda são necessários estudos que definam quais são os organismos mais indicados a serem utilizados, bem como sua sensibilidade aos distintos agentes impactantes (RESGALLA et al., 2002)

De acordo com Domingues \& Bertoletti (2006) os organismos utilizados em ensaios de toxicidade podem ser coletados em ambientes naturais, obtidos através de produtores especializados ou cultivados em laboratório.

Recomenda-se que os testes de toxicidade sejam realizados com organismos de três diferentes níveis tróficos, porém por razões práticas e econômicas, muitas vezes os testes de toxicidade são realizados com uma única espécie de organismo teste (RIBO, 1997).

Para ser utilizado como organismo teste em ensaios ecotoxicológicos, é de extrema importância que os mesmos apresentem características como: seletividade constante e elevada aos contaminantes, disponibilidade e abundância, uniformidade e estabilidade genética nas populações, representatividade de seu nível trófico, ampla distribuição e importância comercial, facilidade de cultivo e de adaptação às condições de laboratório (RAND, 1995).

\subsubsection{Organismo teste}

A importância da utilização de invertebrados em estudos de monitoramento ambiental se dá pelo fato de que essas espécies constituem 95\% do total de espécies viventes no planeta, e estão presentes em praticamente todos os 
ecossistemas e apresentam-se geralmente em grande abundancia populacional, o que faz com que a coleta dos organismos para análises e experimentos não afetem significativamente sua dinâmica populacional (FOSSI et al., 1998).

De acordo com International Mussel Watch Committee (1995), mexilhões e outros bivalves vêm sendo empregados como organismos sentinelas apropriados para estudos de monitoramento da qualidade ambiental em áreas costeiras, em função de apresentarem hábitos sedentários, valor comercial e habilidade de bioconcentrar poluentes presentes na água e sedimento (PEREIRA et al., 2007).

Mexilhão é o termo utilizado para denominar as diversas espécies de moluscos bivalves da família Mytilidae, sendo os gêneros mais comuns Mytilus, Perna e Mytella. São muito abundantes no litoral brasileiro, vivendo principalmente fixos aos costões rochosos, na região de variação das marés e início do infralitoral (MAGALHÃES \& FERREIRA, 1997).

A espécie Perna perna (FIG. 2) tem a capacidade de resistir a uma ampla variação de salinidade (SALOMÃO et al., 1980) sendo sua faixa ótima entre $34 \%$ $36 \%$, e é também considerada euritérmica, podendo suportar grande variação de temperatura tendo a faixa ótima entre 21 e $28^{\circ} \mathrm{C}$.

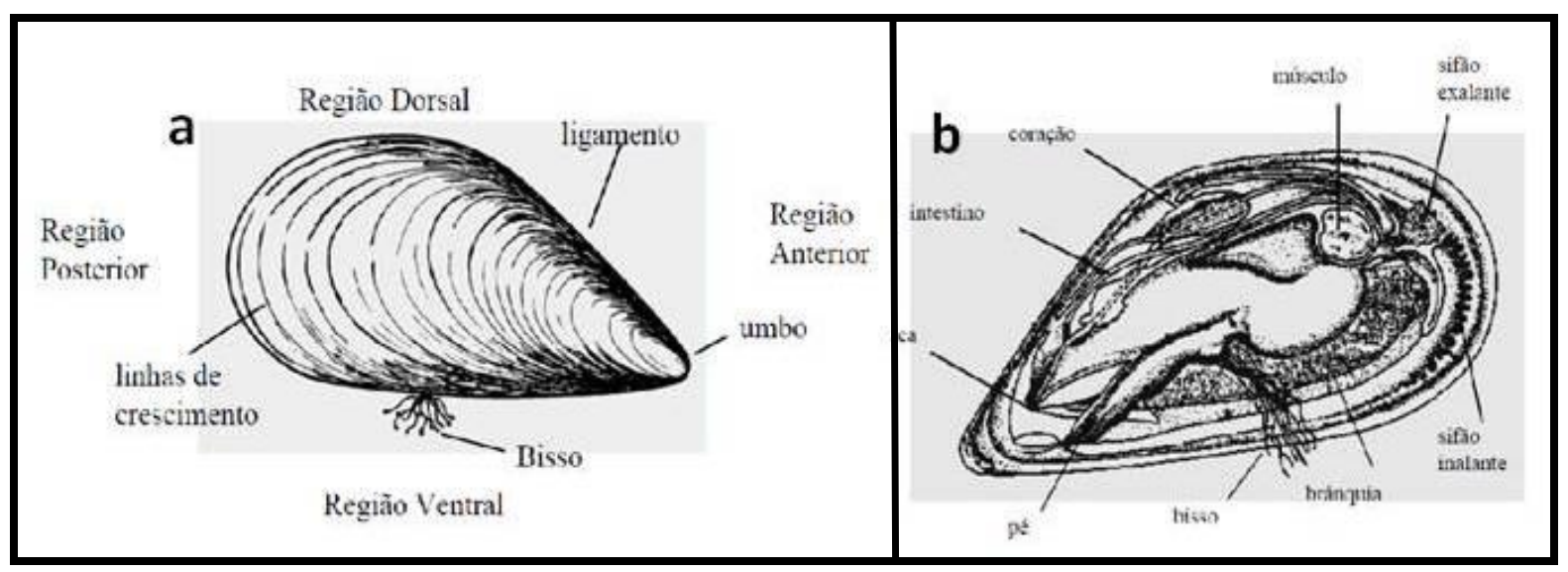

FIGURA 2 - Esquematização externa (a) e interna (b) de um mexilhão Perna perna com identificação de algumas características morfológicas (FERREIRA, J. F., 1987) 


\subsection{Biomarcadores}

Para se avaliar os efeitos causados pelos contaminantes em menores níveis de organização biológica os biomarcadores tem sido muito utilizados.

São respostas a perturbações de processos bioquímicos e moleculares que ocorrem no interior das células causados pela ação dos xenobioticos dando origem aos efeitos em maiores níveis de organização (CHEUNG et al., 1997).

Biomarcadores são definidos como respostas biológicas adaptativas a estressores, evidenciados como alterações bioquímicas, celulares, histológicas, fisiológicas ou comportamentais (DEPLEDGE, 1993).

Leonzio \& Fossi (1993) ampliaram a definição proposta pela National Academy of Sciences, definindo biomarcadores ecotoxicologicos como variações bioquímicas, celulares, fisiológicas ou comportamentais que possam ser medidas em amostras de tecidos ou fluidos orgânicos, em organismos ou populações, que possam evidenciar exposição ou efeitos de um ou mais poluentes químicos ou radiações. Foram propostas definições para três classes de biomarcadores: exposição, efeito, suscetibilidade (FIG. 3).
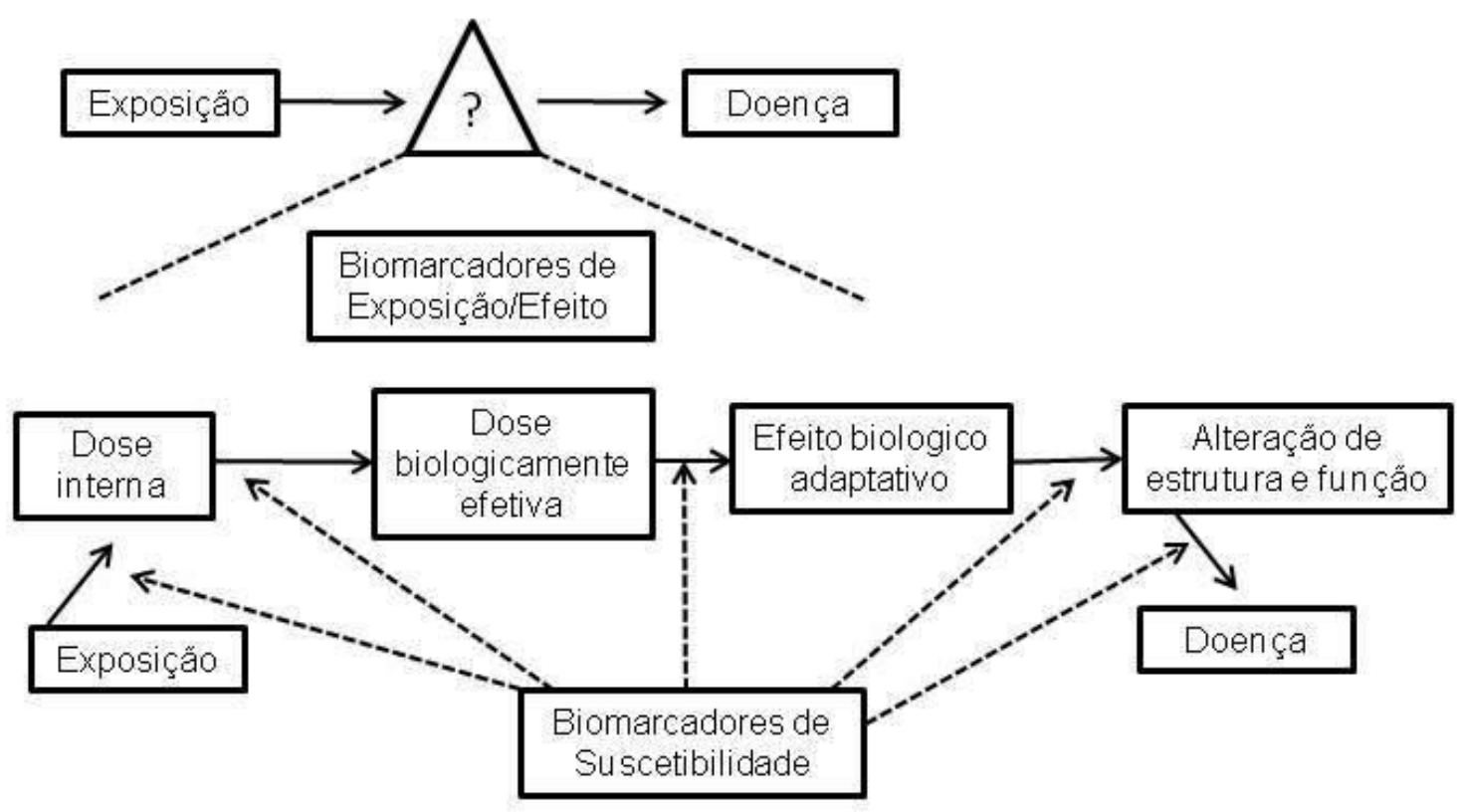

FIGURA 3 - Tipos de biomarcadores. Adaptado de Schlenk (1999). 
Considerando os danos em nível sub-celular uma técnica de avaliação amplamente empregada é o ensaio do tempo de retenção do corante vermelho neutro em hemócitos de bivalves descrito por Lowe (1995).

Essa técnica detecta alterações na permeabilidade da membrana lisossômica, que podem ocorrer em função da exposição a contaminantes ou fatores ambientais, tais como: temperatura, salinidade, hipóxia e depleção alimentar (MOORE et al., 1985; NICHOLSON et al., 2001).

O lisossomo (FIGURA 4, 5) é a organela responsável pelo seqüestro e acumulação de xenobióticos orgânicos e inorgânicos e exerce um papel chave no processo de detoxificação e posterior excreção desses compostos em mexilhões (MOORE, 1985; VIARENGO et al., 1987).

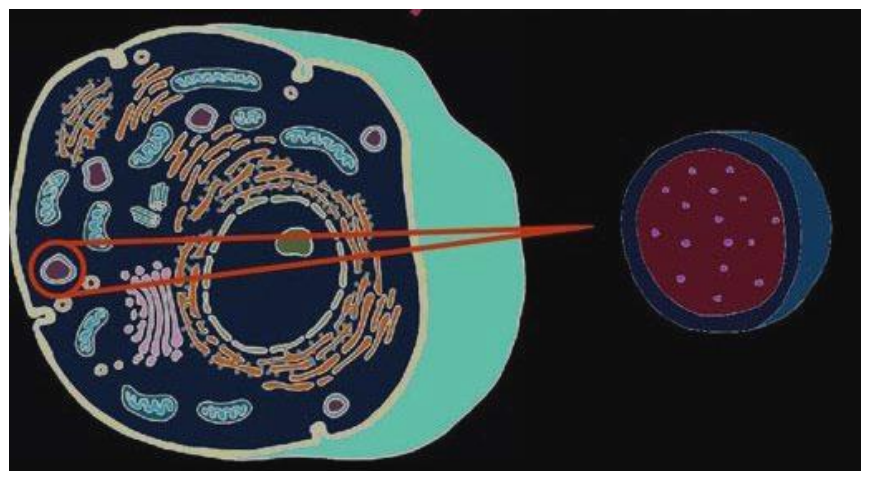

FIGURA 4 - Representação de uma célula com ampliação à direita do lisossomo

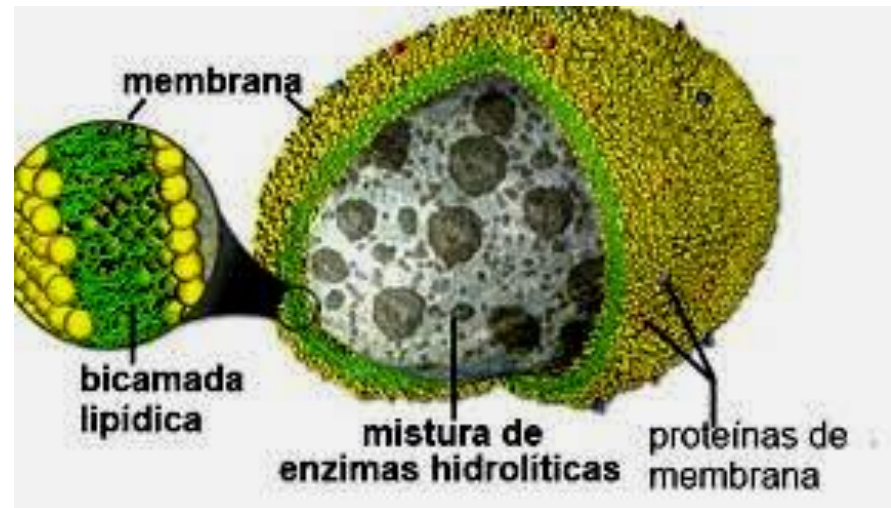

FIGURA 5 - Representação esquemática de um lisossomo, com ampliação da bicamada lipídica (http://educacaoalemdaescola.blogspot.com.br) 
Lisossomos são organelas que desempenham importante função em diversos processos fisiológicos, e possuem importante papel na absorção de substâncias orgânicas e inorgânicas e, devido a capacidade de acumular compostos, essa estrutura tem sido identificada como "organela alvo" dos efeitos causados por diversos contaminantes (Hwang et al, 2002).

Baseia-se no princípio de que lisossomos de células saudáveis conseguem reter o corante por mais tempo, uma vez que membranas lisossômicas são desestabilizadas devido à ação de substâncias citotóxicas.

O corante é seqüestrado pelo lisossomo quando as células vivas são préincubadas com vermelho neutro. $\mathrm{Na}$ visualização por microscópio pode ser avaliado o extravasamento do corante para o citosol da célula, e uma diminuição do tempo de retenção do corante em relação aos organismos saudáveis ou não expostos, caracteriza dano nas membranas lisossomais (FREIRE et al., 2008).

O tempo de extravasamento do corante para o citosol é relacionado com o grau de dano nas membranas (LOWE \& PIPE, 1994).

As reações lisossômicas resultantes de exposição a contaminantes são basicamente: alteração no conteúdo lisossomal, alteração nos processos de fusão do sistema lisossomo-vacuolar e alteração na permeabilidade da membrana lisossômica (MOORE et al., 1987). De acordo com Lowe (1992), as alterações na permeabilidade da membrana lisossômica se devem a perturbações na estrutura da membrana associada a alterações na bomba de próton dependente de ATP (ATPase).

Como resposta ao estresse químico Lowe (1988) sugeriu que os efeitos da desestabilização da membrana lisossômica envolve o aumento de processos autofágicos seguido de degeneração celular. Como consequência dos danos lisossomais a relação entre a ruptura celular e consequente extravazamento de enzimas digestivas está diretamente relacionada à redução da taxa de crescimento em mexilhões (BAYNE et al., 1976). Por esses fatores a integridade da membrana lisossômica tem sido amplamente empregada com biomarcador de estresse químico. 


\subsection{DEET ( $N, N$-dietil-m-toluamida)}

\subsubsection{Histórico}

Dietiltoluamida é o principio ativo mais utilizado em repelente para a prevenção de picadas de insetos, como mosquitos, moscas, pulgas e outros pequenos insetos voadores.

O principio ativo foi desenvolvido pelo exercito dos Estados Unidos em 1946 com a finalidade de proteger soldados nas áreas infestadas por insetos.

Desde 1957, repelentes de insetos contendo DEET foram amplamente utilizados pelo público em geral nos Estados Unidos. E sugere-se que anualmente cerca de $30 \%$ da população utiliza um ou mais produtos repelentes que contenham DEET (USEPA, 1998).

Este composto é considerado até hoje um repelente de padrão ouro devido à sua eficácia contra vários ectoparasitas (BISSINGER \& ROE, 2010).

O DEET é disponível em vários tipos de formulações de produtos com ação de repelência, incluindo loções, líquidos e aerossóis.Também comercializa-se sabonete contendo DEET como ingrediente ativo em algumas regiões do mundo (ROWLAND et al., 2004). Atualmente existem cerca de 225 produtos disponíveis no mercado tendo o DEET como principio ativo (WEEKS et al., 2011)

Alguns estudos e revisões de literatura têm sugerido que o DEET tem melhor eficácia repelente em comparação com outros ingredientes ativos (FRADIN and DAY, 2002).

O mecanismo de ação do DEET não é completamente confirmado. Existem hipóteses que sugerem diferentes tipos de funcionamento. Alguns estudos têm sugerido que o DEET funciona, formando uma barreira de vapor com um odor e sabor que é ofensivo aos insetos (BROWN and HEBERT, 1997).

Dogan (1999) concluiu que os insetos são atraídos para o ácido láctico na pele humana, e o vapor de DEET interfere com sua capacidade de localizar o ácido. Outros estudos têm desafiado esta explicação, encontrando um efeito 
repelente de DEET apenas com dióxido de carbono como o atrativo (HOFFMANN and MILLER, 2003).

Um estudo mais recente forneceu evidências comportamentais que sustentam que a eficácia de repelente do DEET é um resultado de detecção direta do composto em fase vapor por mosquitos (SYED \& LEAL, 2008).

Um repelente de uso tópico ideal deve ser eficiente contra os artrópodes hematófagos em geral, deve possuir as seguintes características: não ser tóxico e nem irritante para o homem, não ser plastificante, isto é, não deve ficar aderido à pele dando um aspecto oclusivo, e possuir um tempo de proteção o mais prolongado possível (HALL, GREEN \& BEROZA, 1957; SHERMAN, 1966).

Os princípios ativos de repelência mais utilizados atualmente são o DEET e a Permetrina. Young \& Evans (1998) relataram que estudos realizados com voluntários das Forças Armadas dos Estados Unidos da América demonstraram que as formulações associando DEET e Permetrina, são bastante eficazes.

Os repelentes podem ser associados a substâncias que têm função sinérgica. Estas substâncias geralmente não são tóxicas para os insetos, mas podem contribuir com a atividade inseticida dos piretróides sintéticos ou facilitar a volatilização do repelente, aumentando o seu raio de ação (MIRANDA, M. C., 2005).

De acordo com o Centro de Controle e Prevenção de Doenças dos Estados Unidos (Centers for Disease Control and Prevention - CDC), a concentração indicada é de 50\% (ANVISA, 2010).

O DEET tem se mostrado muito eficiente na prevenção à picadas de insetos, porém há registros na ANVISA (2010) de que quando usado incorretamente ou em excesso, os repelentes contendo DEET podem apresentar toxicidade para adultos e crianças, tais como toxicidade cutânea, quadros de hipotensão, crises convulsivas, coma, podendo até mesmo atingir o sistema nervoso.

Estudos com esses compostos, ou contaminantes emergentes como diversos autores denominam, são cada vez mais freqüentes nessas últimas 
décadas (BIDWEL et al., 2010; CORDY et al., COSTANZO et al., 2007; 2004; KOLPIN et al., 2004; LAWRENCE, 2009; SINGH et al., 2010; WEIGEL et al., 2004).

Resíduos de DEET têm sido encontrados em águas subterrâneas, águas residuais, continentais e marinhas e até mesmo em águas que já passaram por tratamento convencional, o que mostra sua propriedade persistente (CORDY et al., 2004; COSTANZO et al., 2007; SINGH et al., 2010; TAY et al., 2009).

Estes fatos implicam na necessidade de estudos complementares sobre a toxicidade do composto.

\subsubsection{Informações físico-químicas}

O DEET é uma substância orgânica líquida, volátil sob pressão normal e à temperatura ambiente, sendo praticamente insolúvel em água, embora solúvel em solventes orgânicos.

O composto é membro da família química das N,N-dialkilamidas, sua formula empírica é $\mathrm{C}_{12} \mathrm{H}_{17} \mathrm{NO}$. O DEET é um líquido com odor fraco, distinto e é quase incolor, é praticamente insolúvel em água (> $1,0 \mathrm{~g} \mathrm{~L}^{-1}$ a $\left.25^{\circ} \mathrm{C}\right)$. E é muito solúvel em etanol e isopropanol, que são solventes comuns em formulações de repelentes contendo DEET.

Possui algumas características que são consideradas indesejáveis para o seu uso como repelente: polimerizável (efeito plastificante) e está associado a alguns efeitos tóxicos, quando empregado em concentrações superiores àquelas recomendadas e/ou aplicações sucessivas (GRYBOSKI-WEINSTEIN \& ORDWAY, 1961; MILLER, 1982). Algumas características físico-químicas do DEET estão apresentadas na TAB. 1. 
Tabela 1 - Características físico-químicas do DEET

\begin{tabular}{|c|c|}
\hline Aparência & $\begin{array}{l}\text { Líquido incolor } \\
\text { (Merck, 2010) }\end{array}$ \\
\hline $\begin{array}{l}\text { Coeficiente de partição de adsorção do } \\
\text { solo (Koc) }\end{array}$ & $\begin{array}{c}300 \\
\text { (Handbook of Pesticide } \\
\text { Toxicology, 2010) }\end{array}$ \\
\hline $\begin{array}{l}\text { Coeficiente de partição Octanol/Água } \\
\text { (log Kow) }\end{array}$ & $\begin{array}{c}2.02 \\
\text { (Hansch, C., 1995) }\end{array}$ \\
\hline Constante de Henry & $\begin{array}{c}2.1 \times 10^{-8} \mathrm{~atm}-\mathrm{m}^{3} / \mathrm{mol} \\
\text { (Handbook of Pesticide } \\
\text { Toxicology, 2010) }\end{array}$ \\
\hline Densidade $\left(20^{\circ}\right)$ & $\begin{array}{c}0,997-1,000 \mathrm{~g} / \mathrm{cm} 3 \\
(\text { Merck, 2010) }\end{array}$ \\
\hline Peso molecular & $\begin{array}{c}191,27 \mathrm{~g} \mathrm{~mol}^{-1} \\
\text { (Budavari, S., 1996) }\end{array}$ \\
\hline Pressão de Vapor & $\begin{array}{c}5.6 \times 10^{-3} \mathrm{mmHg} \text { em } 20^{\circ} \mathrm{C} \\
(\text { Little, A. D., 1982) }\end{array}$ \\
\hline
\end{tabular}

\subsubsection{Avaliação ambiental do DEET}

Desde o registro do composto em produtos comercialmente disponíveis, o DEET não foi submetido a uma avaliação de risco ecológico, pois acreditava-se que o composto jamais atingiria os corpos hídricos e a biota aquática (USEPA, 1998). 
A necessidade de monitoramento ambiental para o composto começou quando DEET foi encontrado em amostras de áreas urbanas e agrícolas, efluentes de estações de tratamento de esgoto, sistemas de águas subterrâneas e até mesmo em água potável, mostrando-se persistente aos processos convencionais de tratamento de água (SINGH et al., 2010; TAY et al., 2009; GLASSMEYER et al., 2005; CORDY et al., 2004; WEIGEL et al., 2004; KOLPIN et al., 2002).

A entrada de DEET no ambiente se dá por diversas vias, tais como: diretamente para 0 ar durante a aplicação de aerossóis, para a água superficial através de pulverizações e indiretamente a partir de efluentes das estações de tratamento de esgoto, e para o solo, também a partir de pulverizações ou por aplicação de efluente tratado em agricultura; no solo e das águas superficiais, o DEET degrada a uma moderada taxa, e sua meia-vida é medida em dias ou semanas, sendo o DEET um composto facilmente biodegradável (WEEKS et al., 2011). A USEPA (2000) sugere que a meia-vida do DEET em água seja de 5 dias.

A EU GUIDANCE considera que compostos facilmente biodegradáveis tem meia-vida no ambiente aquático em torno de 15 dias (ECHA, 2010).

Weeks e colaboradores (2011) realizaram uma modelagem matemática para o destino do DEET no ambiente e concluíram que o composto é encontrado em água na proporção de $79 \%$, em solo de $20,7 \%$ e traços no ar $(0,1 \%)$ e no sedimento $(0,2 \%)$; e com base em suas propriedades físico-químicas, o DEET é moderadamente móvel na coluna de solo.

As preocupações ambientais sobre DEET, têm foco em seu potencial de acumulação em águas superficiais e sedimentos e os possíveis perigos para a vida aquática (WEEKS et al., 2011).

O ambiente marinho também recebe aporte de DEET, em menores concentrações que as demais matrizes ambientais citadas. Porém o estudo da ocorrência e distribuição de contaminantes em ecossistemas marinhos é importante principalmente por dois motivos:

(i) a sua presença no mar indica que são suficientemente persistentes para suportar a transformação em seu caminho até os oceanos; 
(ii) condições físico-químicos e biológicas em sistemas aquáticos marinhos são significativamente diferentes por exemplo, salinidade, $\mathrm{pH}$, temperatura, concentrações de compostos orgânicos e atividade biológica (WEIGEL et al., 2002).

\subsection{Radiação ionizante}

A radiação ionizante é definida como a energia propagada capaz de deslocar um ou mais elétrons da molécula (FAJARDO et al., 2001). A incidência dessa radiação em organismos vivos promove danos às células por mecanismos específicos, podendo ser por ação direta e indireta com o meio celular (FIG. 6) (DOWD E TILSON, 1999)

A ação direta consiste na incidência da radiação ionizante diretamente nas macromoléculas biológicas. Na ação indireta ocorrem sucessivas interações da radiação com as moléculas presentes no interior da célula, é o tipo de ação que mais ocorre já que as células possuem em média $75 \%$ de água na sua composição.

O processo da radiólise da água é onde são gerados espécies reativas primárias e produtos moleculares (produtos primários da radiólise da água).

Altamente reativos, os produtos primários interagem com as moléculas presentes no meio ou sofrem recombinações, desencadeando uma série de reações tóxicas para as células que promovem alterações químicas e biológicas (FAJARDO et al., 2001; GETOFF, 1996).

De acordo com Mettler Junior e Upton (1995) a ação indireta é mais frequente devido à abundância de água presente no meio celular, e a radiação gama (radiação ionizante do tipo eletromagnética) possui elevada energia de penetração, e interage mais frequentemente com os organismos vivos pela ação indireta. A radiólise da água pode ser representado pela equação:

$$
\mathrm{H}_{2} \mathrm{O}+\text { radiação } \rightarrow \mathrm{OH}^{\bullet}+\mathrm{H}^{\bullet}+\mathrm{H}_{2} \mathrm{O}_{2}+\overline{\mathrm{e}} \text { aq } \mathrm{H}_{2}+\mathrm{H}_{3} \mathrm{O}^{+}
$$




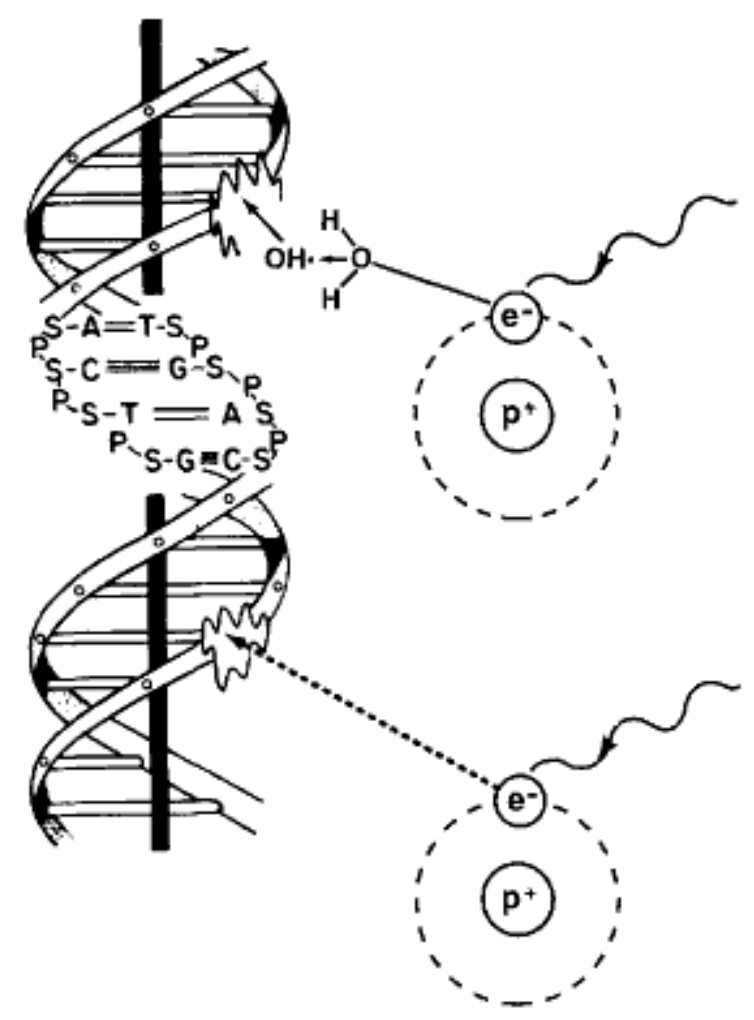

FIGURA 6 - Ação direta e indireta da radiação ionizante na molécula de ácido nucleico.

De acordo com a lei de Bergonie e Tribondeau as células exibem considerável variação na radiosensibilidade (BERGONIE e TRIBONDEAU, 1906; ROSE, 1992). As células são mais radiossensíveis, se forem ativas na mitose e funcionalmente indiferenciadas.

Além disso, os mecanismos celulares de radiação ionizante são complexos, incluindo instabilidade genômica, efeito "bystander" (quando células não irradiadas exibem efeitos de células irradiadas por estarem localizadas próximas umas das outras), respostas adaptativas e processos epigenéticos (BROOKS, 2003; KOTURBASH et al., 2006; MOTHERSILL et al., 2006; HIGLEY, 2007; BIRD, 2007). 


\subsubsection{Radioecologia}

O monitoramento ambiental na área nuclear surgiu para fornecer informações de atividades não declaradas à Agência Internacional de Energia Atômica (AIEA), com o propósito de controlar a utilização de energia nuclear para fins não-pacíficos (DONOHUE, 1998).

E passou a ser considerada uma importante ferramenta a partir da obtenção de dados bastante precisos sobre atividades nucleares em geral, além do que dependendo da dose, da taxa de dose e do tipo, a radiação pode diminuir a tolerância à toxicidade de compostos químicos presentes no ambiente.

A preocupação com a proteção ambiental de substâncias radioativas tem sido muito discutida por organizações internacionais IAEA (International Atomic Energy Agency), ICRP (International Commission on Radiological Protection), OCDE-NEA (Organisation for Economic Co-Operation and Development Nuclear Energy Agengy), órgãos reguladores Environment Canada, USDOE (United States Department of Energy) e cientistas da IUR (International Union of Radioecology) (ANDERSON et al., 2009).

Os impactos das instalações nucleares sobre o ambiente podem incluir: liberação acidental de radionuclídeos nos ecossistemas terrestres e aquáticos a partir da interação dos sistemas de refrigeração do condensador com ecossistemas aquáticos, e, por fontes de liberação de radionuclídeos para o meio ambiente com a operação normal de usinas nucleares e reatores de produção de radioisótopos, acidentes em usinas nucleares e vazamento de resíduos radioativos armazenados.

A radioecologia atualmente apresenta uma linha de estudos que compreende:

(1) proteção ambiental, na qual estão inseridos estudos sobre fluxos e biodisponibilidade das substâncias radioativas ao longo do tempo; ecotoxicologia; harmonização dos métodos de radionuclídeos e outros contaminantes; legislações; técnicas de medição e estratégias de monitoramento; 
(2) avaliação de risco, abordando efeitos biológicos da radiação em humanos e animais;

(3) tratamento de rejeitos radioativos e

(4) aspectos sociais, éticos e econômicos da proteção radiológica (EDITORIAL, 2009).

O estudo da proteção radioecológica está em desenvolvimento, pois alguns aspectos ainda necessitam de mais estudos e definições (PENTREATH, 2009).

\subsubsection{Exposição dos organismos aquáticos às fontes de radiação ionizante}

No meio ambiente, principalmente em regiões de maior incidência de radioatividade ambiental e próximos as instalações nucleares, sendo na maioria das vezes regiões litorâneas, onde existe risco de vazamentos e acidentes nucleares, muitos organismos aquáticos podem estar sujeitos a níveis mais elevados de radiação.

Diversos organismos marinhos podem bioacumular radioisótopos em concentrações milhares de vezes superiores aos níveis encontrados no ambiente (FOWLER,2003).

Portanto, é de extrema importância verificar o comportamento destes compostos no ambiente, bem como, avaliar os efeitos da radiação sobre sistemas biológicos.

Em especial, deve-se olhar os organismos de hábitos sedentários ao redor de instalações nucleares em regiões litorâneas, pois estão continuamente expostos, em contato direto com a radiação durante todo o seu período de vida.

A partir de doses absorvidas durante certo tempo, organismos podem apresentar efeitos biológicos que desencadeiam mudanças desde o nível molecular até altos níveis de organização biológica, podendo afetar toda uma comunidade, ou até mesmo um nicho ecológico. 
A proteção do meio ambiente deve ser claramente demonstrada, independente da presença ou ausência de seres humanos (PENTREATH, 2002).

Os efeitos biológicos das radiações ionizantes na biota foram revistos por numerosos pesquisadores e organizações (e.g.,WHICKER e SCHULTZ, 1982; IAEA, 1992; ROSE, 1992; WOODHEAD, 1993; EISLER, 1994, 2000; WHICKER, 1997; HINTON,1998; MEYERS-SCHONE e TALMAGE, 2003; IRVINE e SAMPLE, 2005; HIGLEY, 2007; GERASKIN et al., 2007).

A radiossensibilidade celular tem se mostrado variar filogeneticamente, apresentando maior sensibilidade em mamíferos e aves, e, baixa sensibilidade em invertebrados (WHICKER e SCHULTZ, 1982; UNSCEAR, 1996).

\subsection{Legislação Ambiental}

Ensaios ecotoxicológicos têm sido empregados para avaliar os efeitos da introdução de contaminantes no ambiente aquático. Ainda que poucos ensaios ecotoxicológicos sejam padronizados no Brasil, existem legislações no âmbito internacional que regulamentam substâncias químicas em diversas matrizes ambientais de forma bastante rigorosa.

$\mathrm{Na}$ Europa, alguns países possuem leis específicas para limites permissíveis de toxicidade estabelecidos para diferentes corpos receptores. De acordo com Zagatto e Bertoletti (2006) o nível de implementação de ensaios ecotoxicológicos no controle da poluição ainda é baixo, mas muitos países da União Européia possuem programas de monitoramento ambiental que utilizam ensaios de toxicidade com microcrustáceos, peixes e algas.

A legislação de substâncias químicas da União Européia foi aprovada pelo Parlamento Europeu e pelo Conselho da Comunidade Européia, originando o regulamento № 1907/2006, definido como REACH (Register, Evaluation, Authorization, Chemicals) aplicando uma política de registro, avaliação, autorização e restrição aos produtos químicos comercializados na Europa.

$\mathrm{Na}$ década de 90 a USEPA desenvolveu os estudos para Avaliação e Redução da Toxicidade (TRE: Toxicity Reduction Evaluation), que tem por 
objetivo identificar e avaliar os agentes responsáveis pela toxicidade de efluentes, implementar ações de controle e confirmar a eficácia das medidas adotadas para a redução da toxicidade.

No Brasil, a revisão da Resolução CONAMA № 20/1986 realizada em 2005 introduziu os ensaios de toxicidade, e na Resolução № 357/2005 exige-se a realização de ensaios ecotoxicológicos na avaliação de corpos hídricos e no controle de efluentes.

Existem ensaios padronizados também pela CETESB a partir da década de 80, mas só foram exigidos por meio da Resolução SMA № 03/2000 (PUSCEDDU, 2009). A Resolução da SMA 03/2000 estabelece os critérios para a realização do controle ecotoxicológico de efluentes líquidos no Estado de São Paulo.

A Legislação Federal - Resolução CONAMA 357/2005 dispõe sobre a classificação dos corpos de água e diretrizes ambientais para o seu enquadramento, bem como estabelece as condições e padrões de lançamento de efluentes, a segunda estabelece as diretrizes gerais e os procedimentos mínimos para a avaliação do material a ser dragado em águas jurisdicionais brasileiras (BRASIL, 2005).

A Resolução CONAMA 357/2005 (BRASIL, 2005), estabelece no parágrafo $1^{\circ}$ do artigo 34 que efluentes líquidos não devem causar ou possuir potencial para causar efeitos tóxicos para organismos aquáticos no corpo receptor, de acordo com os critérios estabelecidos pelo órgão ambiental.

Para os estados, cujos órgãos ambientais estaduais não possuem uma legislação específica para toxicidade, devem seguir as orientações da nova resolução CONAMA 430/2011. 


\section{METODOLOGIA}

\subsection{Coleta de água}

A água utilizada nos ensaios de toxicidade aguda e de citotoxicidade com o mexilhão Perna perna foi coletada na Praia da Cocanha, localizada no município de Caraguatatuba, SP (FIGURA 7); foi acondicionada em barris de 50L transportadas e mantidas em laboratório à temperatura de $24^{\circ} \mathrm{C}$. Para realização dos ensaios a água foi filtrada em rede de zooplâncton com malha de $150 \mu \mathrm{m}$.

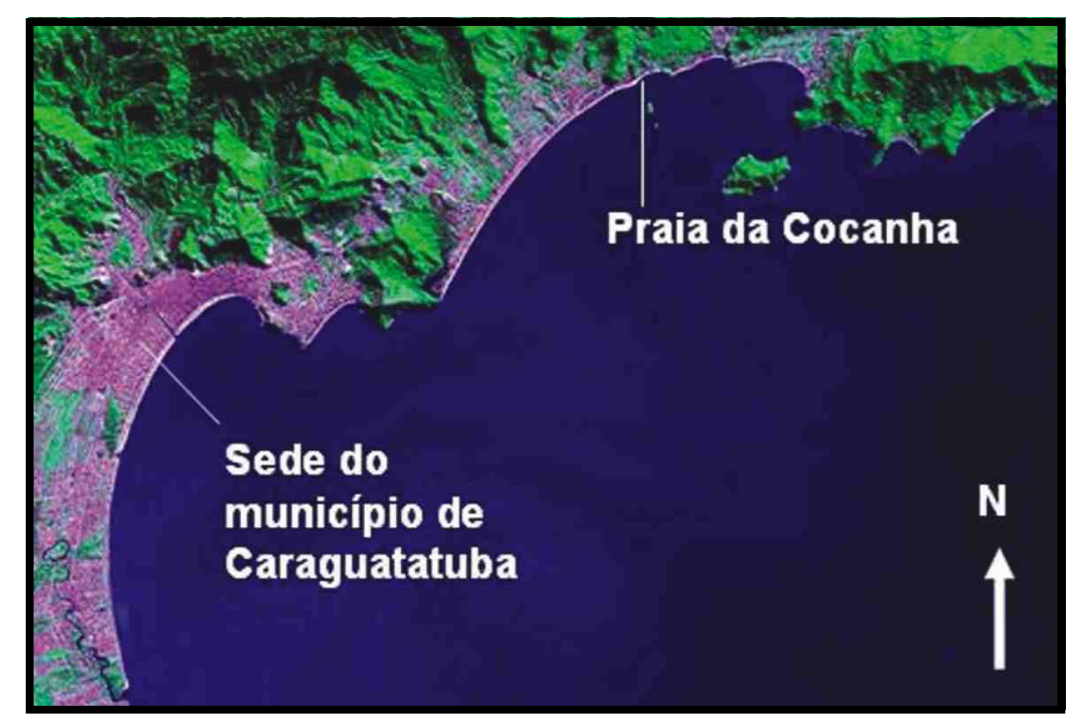

FIGURA 7 - Localização da Praia da Cocanha, Caraguatatuba - SP

Fonte: Imagem LANDSAT, Instituto Nacional de Pesquisas Espaciais.

Escala: 1: 50.000

\subsection{Obtenção e manutenção do organismo teste}

Domingues e Bertoletti (2006) ressaltam que a escolha dos organismos-teste deve seguir os seguintes princípios básicos: sensibilidade a uma diversidade de agentes químicos, tendo como requisito o conhecimento prévio da biologia das espécies; pequeno porte e ciclo de vida não muito longo; facilidade na manutenção/cultivo; disponibilidade dos organismos ao longo do ano, possibilitando o cultivo contínuo em laboratório; espécies autóctones ou 
representativas do ecossistema em estudo; ampla distribuição geográfica e estabilidade genética, o que implica na obtenção de lotes uniformes de organismos. Seguindo essas considerações o organismo teste utilizado no presente estudo foi o mexilhão Perna perna (Linnaeus, 1758).

Os organismos foram obtidos em área de cultivo localizado na llha da Cocanha Grande (FIG. 8). A Praia da Cocanha está localizada na região norte do município de Caraguatatuba, em área de ocupação baixa a média e intensa atividade de maricultura desenvolvida principalmente próximo às llhas da Cocanha Grande (Massaguaçu) e da Cocanha Pequena (CETESB, 2007).

Essa área foi escolhida como ponto de obtenção dos organismos em função de sua boa qualidade ambiental, registrada nos últimos relatórios de balneabilidade divulgados pela CETESB (2006, 2007, 2008, 2009), quando se constatou boa qualidade da água na maior parte do ano, com classificação "Boa". Os mesmos relatórios da CETESB não identificaram toxicidade em amostras de água e sedimento coletados nessa praia. Nos relatórios mais recentes da CETESB dos anos de 2010 e 2011 a qualidade da água foi classificada como "Regular", pois houve um aumento do período em que a praia esteve imprópria.

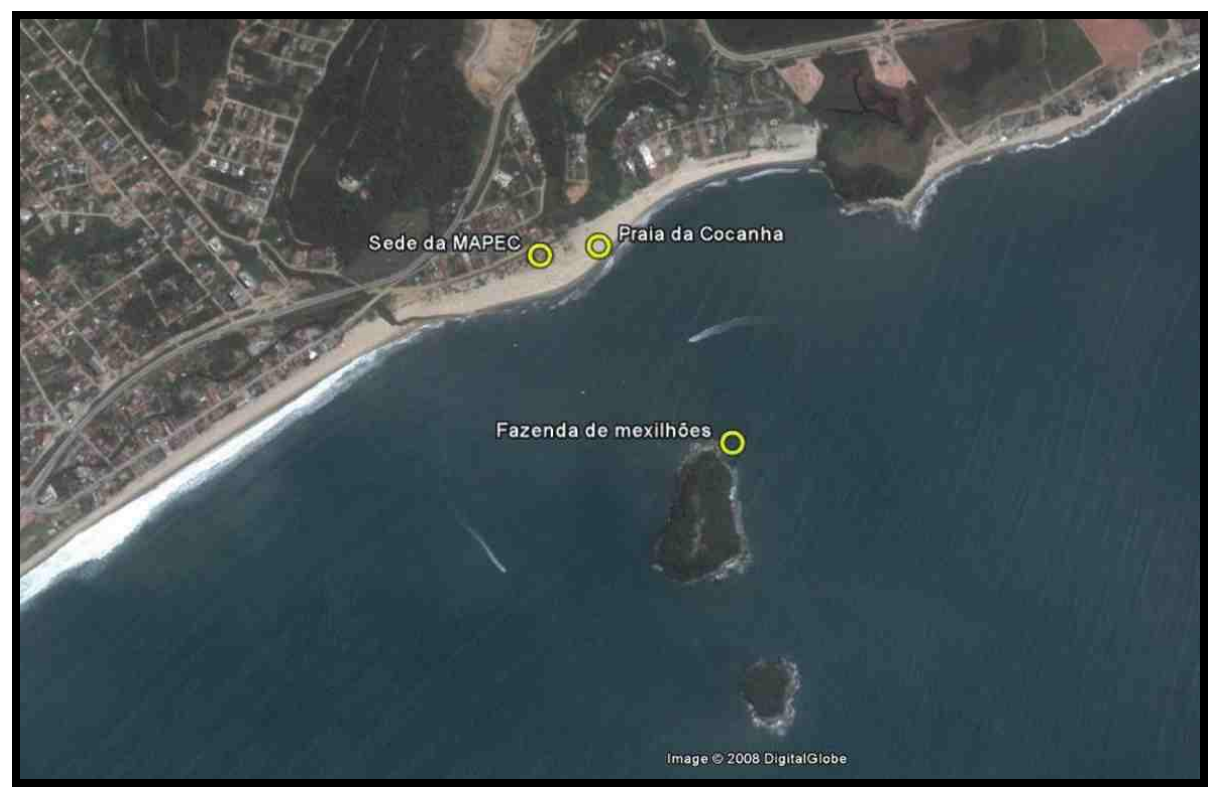

FIGURA 8 - Fazenda de Mexilhões na llha da Cocanha, Caraguatatuba - SP. Identificação também da Praia da Cocanha e da Sede da MAPEC

(Centro de Maricultores e Pescadores da Praia da Cocanha) 
Para realização dos experimentos foram utilizados organismos adultos com tamanho médio de $4-5 \mathrm{~cm}$ de comprimento, após terem sito coletados do cultivo os organismos foram limpos, acondicionados em caixa térmica e transportados para o laboratório. Na figura $9 a$ e $9 b$ está representado o procedimento realizado nos organismos no local de coleta e na figura 9c o procedimento inicial realizado no laboratório.

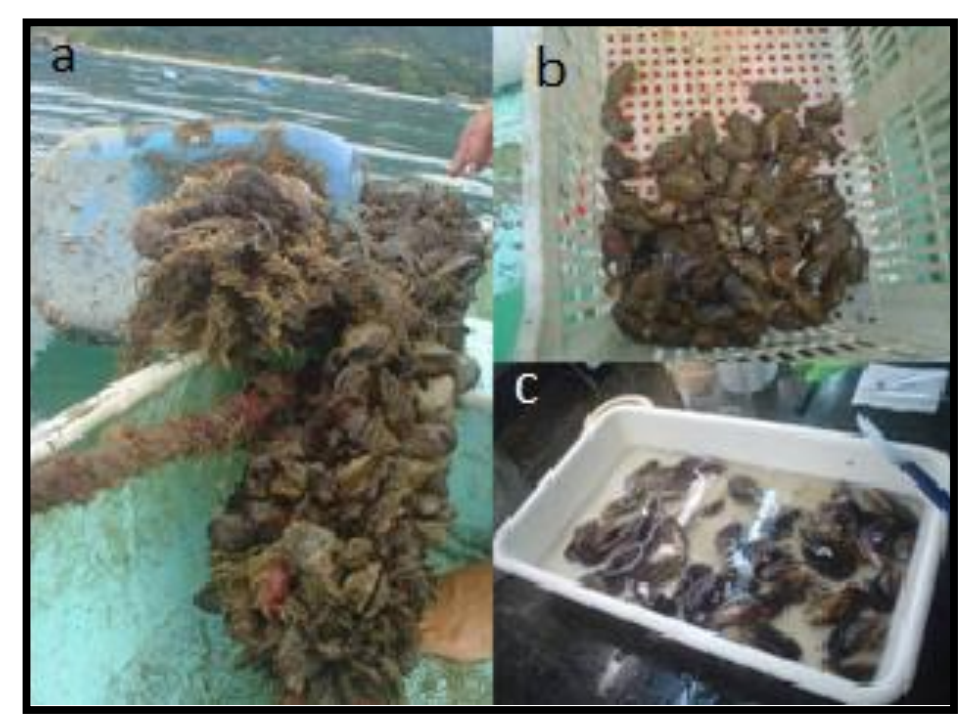

FIGURA 9 - (a) Mexilhões Perna perna recém retirados do cultivo, (b) Mexilhões Perna perna limpos, (c) Mexilhões Perna perna no processo de lavagem no laboratório

No laboratório, os organismos foram aclimatados em aquários contendo água do mar filtrada por 24 horas, com aeração e temperatura de $25^{\circ} \mathrm{C}$ até o momento da realização dos ensaios. A água para a montagem dos experimentos, para utilização no controle e para a aclimatação dos organismos foi coletada em Caraguatatuba, no mesmo local de obtenção dos organismos.

\subsection{Substância teste}

O princípio ativo DEET ( $\mathrm{N}, \mathrm{N}$-diethyl-meta-toluamide $-\mathrm{C}_{12} \mathrm{H}_{17} \mathrm{NO}$ ) (FIG. 10) da Sigma-Aldrich ${ }^{\circledR}$ é relativamente estável, tende a absorver água e possui sensibilidade quando exposto à luz. Insolúvel em água a $20^{\circ} \mathrm{C}$ e em glicerina, 
porém solúvel em vários solventes orgânicos. Possui $95 \%$ de meta isômero, sendo este o princípio ativo do composto (USEPA, 1998). O composto é formado por amida, classe química muito utilizada em repelentes de inseto (PALUCH et al., 2010).

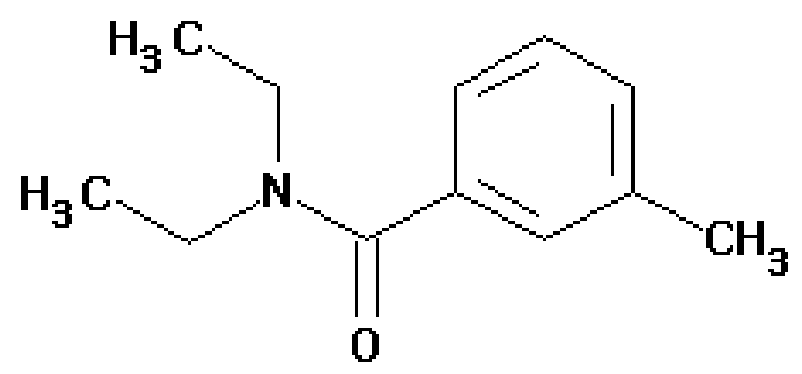

FIGURA 10 - Representação da cadeia química do Dietiltoluamida DEET (MERCK, 2010).

\subsection{Irradiação dos organismos}

Considerando que as instalações nucleares geralmente encontram-se em regiões litorâneas, podendo assim existir o risco de vazamentos e acidentes para o ambiente marinho, o presente trabalho teve como objetivo o estudo dos efeitos de radiação ionizante sobre a biota aquática.

A exposição à radiação ionizante nos mexilhões foi realizada a fim de se verificar os efeitos biológicos causados sobre a membrana lisossômica de hemócitos do organismo teste.

Para irradiação foi utilizada radiação gama da fonte de ${ }^{60} \mathrm{Co}$ GammaCell 200 (FIGURA 11a). Os organismos foram colocados em frascos de polipropileno contendo $750 \mathrm{~mL}$ de água marinha (FIGURA 11b), para serem submetidos à doses da radiação gama de ${ }^{60} \mathrm{Co}: 0,250 ; 500 ; 750$ e 1000 Gy (Gray) com uma taxa de dose de aproximadamente 1,64 KGy/hora. 


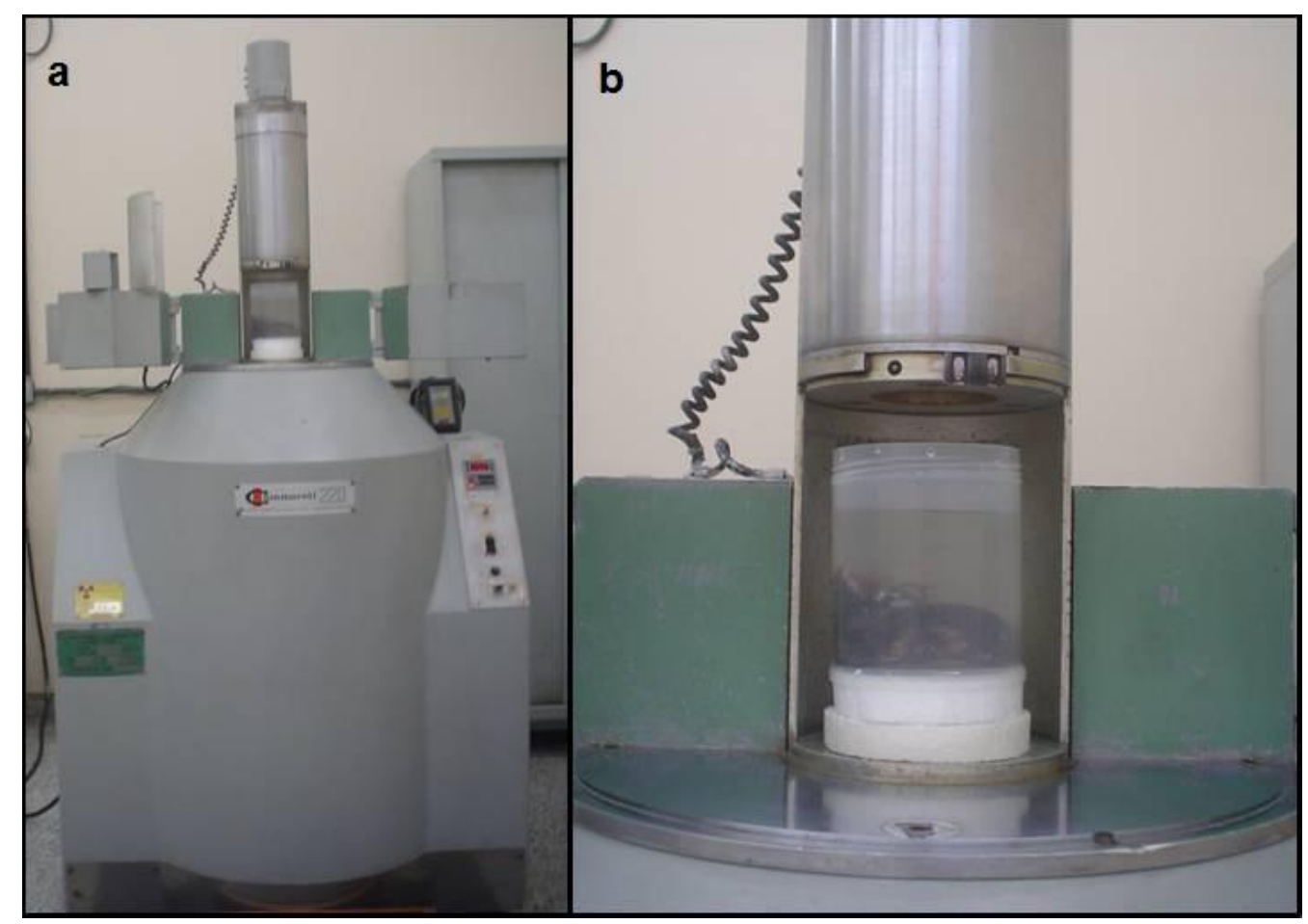

FIGURA 11 - (a) Irradiador Gamma-Cell 200, (b) Mexilhões Perna perna em frascos de polipropileno

\subsection{Ensaios ecotoxicológicos}

Testes de toxicidade são ensaios laboratoriais, realizados sob condições experimentais específicas e controladas, utilizados para estimar a toxicidade de substâncias, efluentes industriais e amostras ambientais (OLIVI et al., 2008).

\subsubsection{Ensaios de toxicidade aguda}

Os ensaios de toxicidade aguda avaliam os efeitos, em geral severos e rápidos, sofridos pelos organismos expostos ao agente químico em um curto período de tempo. O critério de avaliação dos ensaios de ecotoxicidade aguda é a mortalidade ou imobilidade dos organismos-teste (ARAGÃO e ARAÚJO, 2006). No presente estudo os ensaios de toxicidade aguda foram empregados para se avaliar a mortalidade de $50 \%$ (CL50) dos organismos quando expostos a agentes químicos (DEET) ou fisicos (radiação ionizante). 


\subsubsection{Ensaios de toxicidade aguda com DEET}

Primeiramente foram realizados ensaios de toxicidade aguda com o princípio ativo para encontrar a concentração capaz de causar mortalidade em $50 \%$ dos organismos expostos ao DEET. O tempo de exposição definido foi de $72 \mathrm{~h}$, pois o ensaio de citotoxicidade, onde avaliou-se o tempo de retenção do corante vermelho neutro consistiu na exposição dos organismos ao composto por um período de $72 \mathrm{~h}$. As concentrações testadas foram baseadas na literatura onde algumas espécies expostas ao DEET tiveram concentração letal próxima a 100 $\mathrm{mg} \mathrm{L-}{ }^{1}$.

De acordo com Michael and Grant (1974) a concentração letal 50\% para Gambusia affinis foi 235,0 $\mathrm{mg} \mathrm{L}^{-1}$ após 24 e 48 horas de exposição ao DEET. A CL50 encontrada para Daphnia magna foi $160,0 \mathrm{mg} \mathrm{L}^{-1}$ após 48 horas e 108,0 mg $\mathrm{L}^{-1}$ após 96 horas de exposição ao DEET (SEO et al., 2005); e para Gammarus fasciatus a concentração letal $50 \%$ foi de $100 \mathrm{mg} \mathrm{L}^{-1}$ após 96 horas de exposição (MAYER and ELLERSICK, 1986).

Portanto no presente estudo os organismos foram expostos à concentrações de DEET na faixa de $75-400 \mathrm{mg} \mathrm{L}^{-1}$. Na TAB. 2 encontram-se os parâmetros e condições estabelecidos para os ensaios de toxicidade aguda com DEET para o mexilhão Perna perna. 
TABELA 2 - Parâmetros e condições dos ensaios de toxicidade aguda com o mexilhão Perna perna

\begin{tabular}{ll}
\hline PARÂMETROS & CONDIÇÕES \\
\hline Sistema de teste & Estático \\
Duração & $72 \mathrm{~h}$ \\
Substância teste & DEET \\
Temperatura & $22 \pm 2^{\circ} \mathrm{C}$ \\
Organismo teste & Perna perna \\
Fotoperíodo & $12 \mathrm{~h}$ luz/escuro \\
Frasco-teste & Aquários \\
Volume da concentração-teste & 30 Litros \\
№ de soluções-teste & 3 e controle água/solvente \\
Alimentação durante o teste & Não \\
Critério de avaliação de efeito & Mortalidade \\
Expressão dos resultados & Quantitativo: DL50 \\
Critério de aceitação do teste & Mortalidade $<10 \%$ no controle \\
\hline
\end{tabular}

$\mathrm{DL} 50=$ dose letal $50 \%$ dos organismos expostos

\subsubsection{Ensaios de toxicidade aguda em organismos irradiados com radiação gama de ${ }^{60} \mathrm{Co}$}

Foram realizados ensaios de exposição dos organismos em diferentes doses de radiação gama proveniente de fonte de ${ }^{60} \mathrm{Co}$ para encontrar a dose capaz de causa mortalidade à $50 \%$ dos organismos que foram expostos a radiação. Os organismos receberam doses que variaram de $250-3000$ Gy e foram observados por $72 \mathrm{~h}$. Na TAB. 3 estão os parâmetros e condições estabelecidos para os ensaios de toxicidade aguda com radiação para o mexilhão Perna perna. 
TABELA 3 - Parâmetros e condições dos ensaios de toxicidade aguda com mexilhão Perna perna irradiados

\begin{tabular}{ll}
\hline PARÂMETROS & \multicolumn{1}{c}{ CONDIÇÕES } \\
\hline Sistema de teste & Estático \\
Doses de radiação & $0 ; 250 ; 500 ; 750 ; 1000 ; 1500 ; 2000 ; 2500$ e 3000 Gy \\
Taxa de dose & 1,58 a 1,71 kGy.h ${ }^{-1}$ \\
Frasco- teste & Frascos de polipropileno 750mL \\
№ de organismos/frasco & 5 \\
Tempo de observação após radiação & $72 \mathrm{~h}$ \\
Alimentação durante o teste & Não \\
Critério de avaliação de efeito & Mortalidade \\
Expressão dos resultados & Quantitativo: DL50 \\
Critério de aceitação do teste & Mortalidade < 10\% no controle \\
\hline
\end{tabular}

DL50 $=$ dose letal $50 \%$ dos organismos expostos

\subsubsection{Ensaios in vivo de citotoxicidade}

Para os ensaios in vivo da citotoxicidade foi utilizado o do tempo de retenção do corante vermelho neutro para se verificar a integridade/estabilidade da membrana lisossômica de hemócitos do mexilhão Perna perna.

A TAB. 4 apresenta os parâmetros e condições estabelecidos para os ensaios de citotoxicidade com mexilhão Perna perna.

O estudo foi dividido em 3 etapas:

1. exposição dos organismos ao DEET;

2. exposição dos organismos à radiação gama;

3. exposição dos organismos à radiação gama seguida à exposição ao DEET. 
TABELA 4 - Parâmetros e condições dos ensaios de citotoxicidade com mexilhão Perna perna

\begin{tabular}{ll}
\hline PARÂMETROS & CONDIÇÕES \\
Sistema de teste & Estático \\
Duração & $72 \mathrm{~h}$ \\
Substância-teste & DEET \\
Concentrações de DEET & $0,02 \mathrm{mg} \mathrm{L}^{-1}, 0,001 \mathrm{mg} \mathrm{L}^{-1}$ e 0,0001 $\mathrm{mg} \mathrm{L}^{-1}$ \\
Temperatura & $22 \pm 2^{\circ} \mathrm{C}$ \\
Fotoperíodo & $12 \mathrm{~h}$ luz/escuro \\
Frasco-teste & Aquários de 30 Litros \\
№ de concentrações-teste & 3 e controles água/solvente \\
№ de organismos/frasco & 15 \\
Troca de soluções & Não \\
Alimentação & Não \\
Critério de avaliação de efeito & Integridade da membrana lisossômica \\
Expressão dos resultados & Quantitativo: CENO; CEO; Cl25 \\
& Qualitativo: tóxico ou não tóxico
\end{tabular}

CENO = concentração de efeito não observado; CEO = concentração de efeito observado; Cl25 = concentração de inibição em 25\%

\subsubsection{Ensaio do tempo de retenção do corante vermelho neutro}

Para avaliação da citotoxicidade empregou-se o ensaio do tempo e retenção do corante Vermelho Neutro em hemócitos de mexilhão Perna perna, de acordo com o procedimento descrito por Lowe et al. (1995) (FIG. 12). Esse método detecta alterações na permeabilidade da membrana lisossômica de hemócitos, promovendo evidências de danos celulares em função da exposição a diferentes contaminantes. 


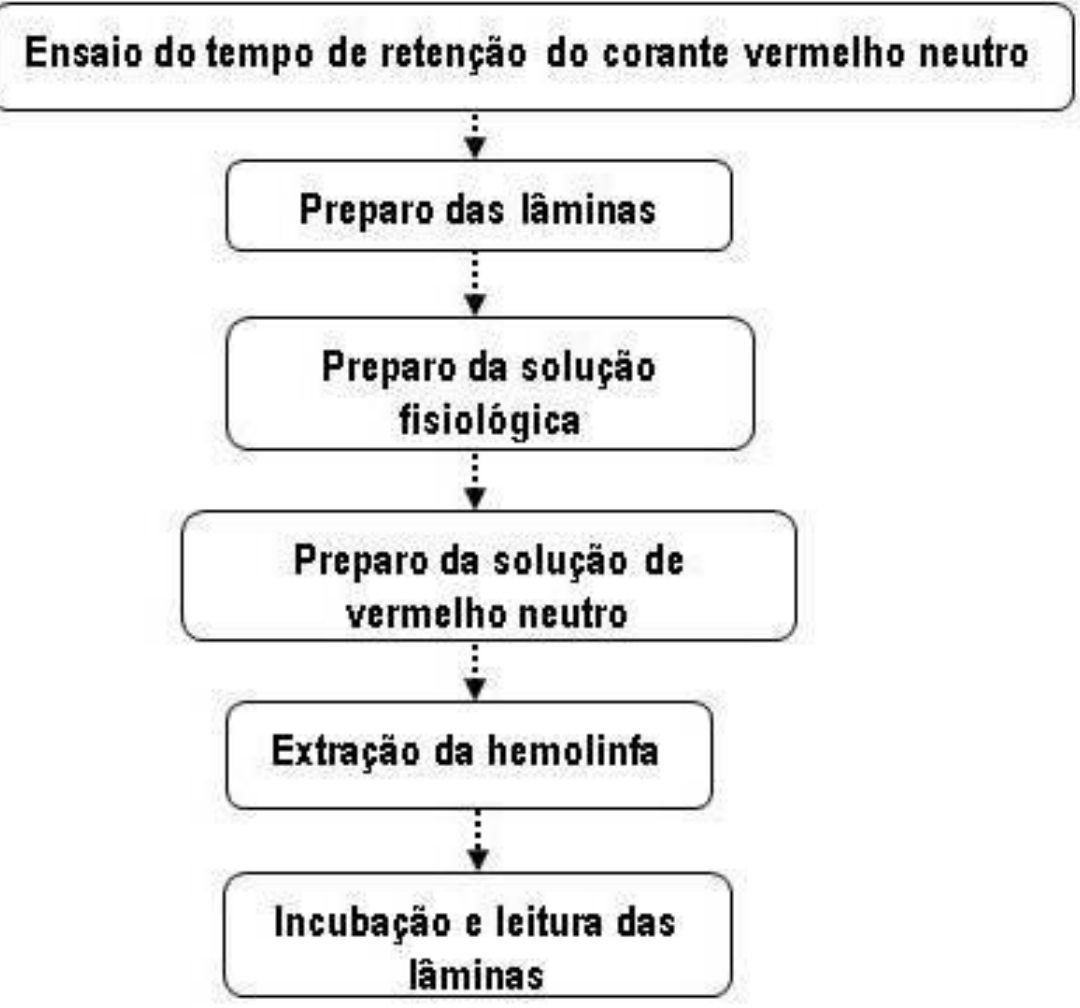

FIGURA 12 - Etapas realizadas no ensaio de tempo de retenção do corante vermelho neutro descrito por Lowe (1995).

Para realização do ensaio do tempo de retenção do corante vermelho neutro as lâminas foram lavadas e preparadas 24 horas antes do experimento, aplicando-se $10 \mu \mathrm{L}$ de uma solução de poly-L-lisina em água destilada, utilizada para melhor fixação das células sobre a lâmina, a solução foi preparada na proporção 1:10 e aplicada sobre cada lâmina com auxílio de uma lamínula foi espalhada para o processo natural de secagem.

Foi preparada uma solução fisiológica para diluir a hemolinfa coletada dos mexilhões (4,77g de HEPES; 25,48 $\mathrm{g}$ de cloreto de sódio; 13,06 $\mathrm{g}$ de sulfato de magnésio; $0,75 \mathrm{~g}$ de cloreto de potássio; $1,47 \mathrm{~g}$ de cloreto de cálcio diluído em água deionizada em balão volumétrico de 1 Litro) . O pH 7,36 foi ajustado com $\mathrm{NaOH}$ ou $\mathrm{HCl}$ impreterivelmente antes de cada uso da solução. Após o preparo, a solução foi estocada em refrigerador, porém utilizada em temperatura ambiente para que o choque térmico não provocasse estresse nos hemócitos. 
Preparou-se uma solução estoque de vermelho neutro utilizando-se 28,8mg do corante em $1 \mathrm{~mL}$ de DMSO (Dimetilsulfóxido). A solução foi conservada em refrigerador ao abrigo de luz, pois este corante é fotossensível. A solução de trabalho foi preparada diluindo-se $10 \mu \mathrm{L}$ da solução estoque em $5 \mathrm{~mL}$ da solução fisiológica e mantida em câmara escura. A cada bateria de lâminas analisada a solução de trabalho foi refeita devido a sua instabilidade.

No processo de extração da hemolinfa as valvas do mexilhão foram levemente separadas e com uma seringa hipodérmica de $1 \mathrm{~mL}$ e agulha padrão 21 retirou-se o líquido do músculo adutor posterior (FIG. 13). O material coletado foi transferido para tubos de microcentrífuga com capacidade de $2 \mathrm{~mL}$, que foram levemente agitados. Em seguida pipetou-se $40 \mu \mathrm{l}$ da solução de hemolinfa sobre cada lâmina tratada previamente com poly-L-lisina.

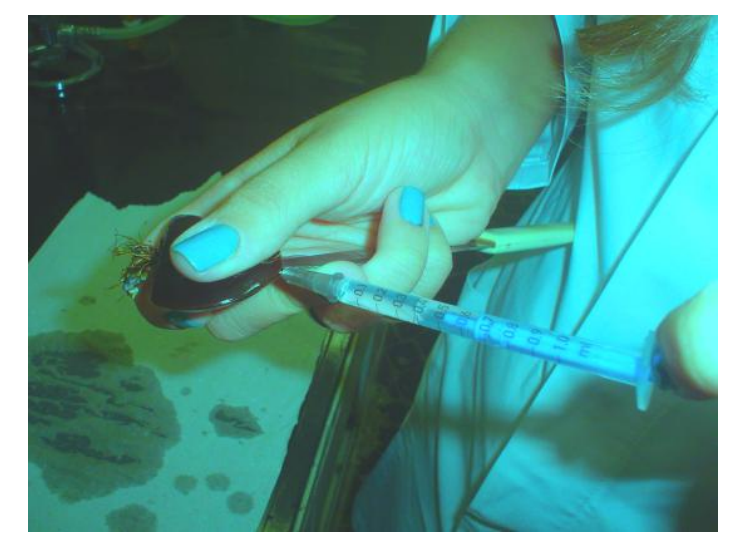

FIGURA 13 - Extração da hemolinfa

As lâminas foram incubadas em câmara escura e úmida por 15 minutos (FIG. 14). Após este período, $40 \mu \mathrm{L}$ de solução de trabalho de vermelho neutro foram adicionados à hemolinfa presente em cada lâmina, e o conjunto novamente incubado por mais 15 minutos. As lâminas foram observadas com auxílio de microscópio óptico (400x) (FIG. 15) em intervalos de 15 minutos, mantendo-se a iluminação mais baixa possível permitindo a visualização dos hemócitos, devido a fotosensibilidade do vermelho neutro. 


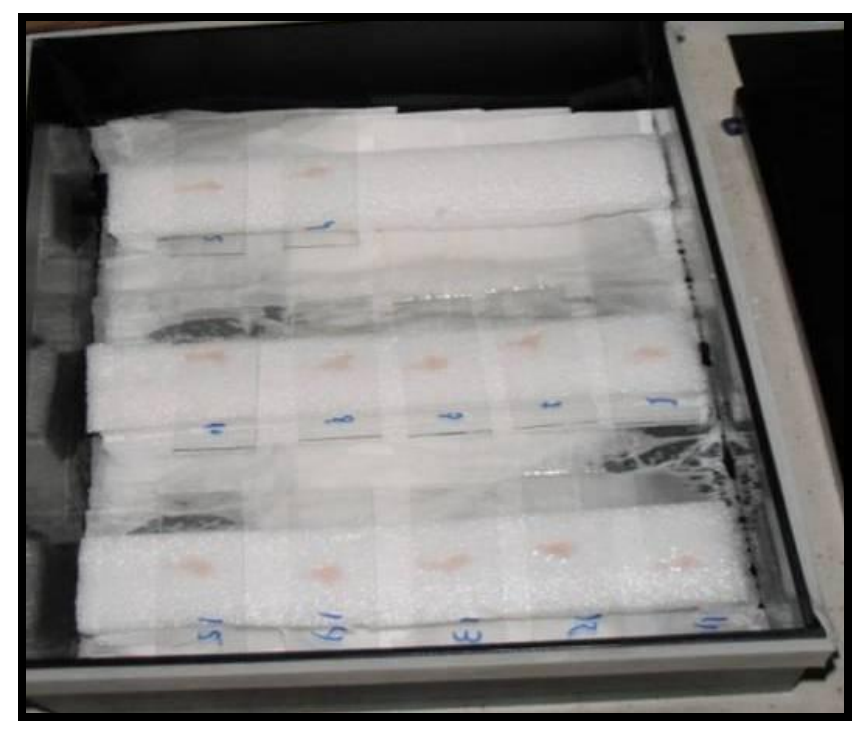

FIGURA 14 - Incubação do conjunto de lâminas em câmara escura e úmida

Nas células (hemócitos) foi analisado o tempo de retenção do corante e as anormalidades estruturais.

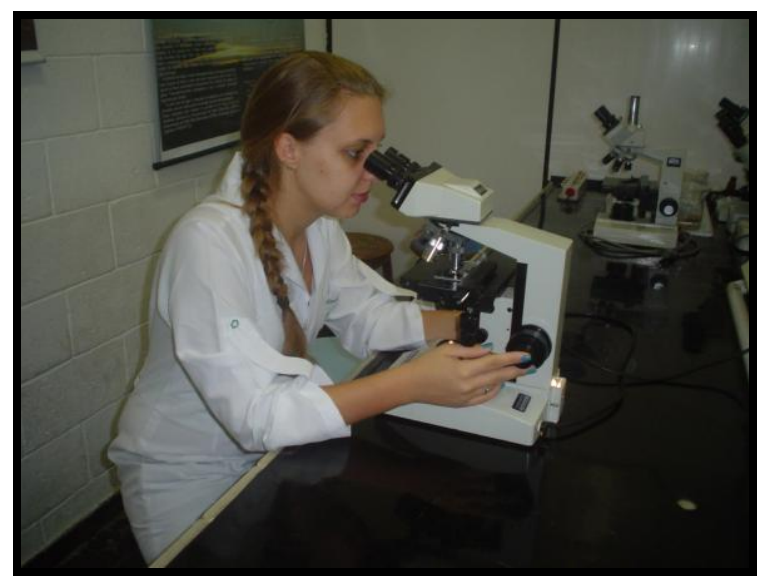

FIGURA 15 - Observação das lâminas em microscópio

O tempo de retenção do corante vermelho neutro é obtido estimando-se a proporção de células que tiveram o corante liberado para o citosol e/ou anormalidades no formato, tamanho e cor dos lisossomos.

A TAB. 5 apresenta os critérios utilizados para diferenciação de células saudáveis e células estressadas, após administração do corante Vermelho Neutro. 
TABELA 5 - Critérios de avaliação de hemócitos

\begin{tabular}{ccc}
\hline Critério & Células saudáveis & Células estressadas \\
\hline Formato das células & Irregular & Arredondado \\
Tamanho das células & Aumentado & Diminuído \\
Número de lisossomos & Aumentado & Diminuído \\
Tamanho dos lisossomos & Menores & Alargados/ Aumentados \\
Cor dos lisossomos & Vermelho pálido/ rosado & Vermelho ou rosa escuro \\
Pseudópodes & Não visíveis & Visíveis \\
Corante extravasado no & Não visíveis & Visíveis \\
\hline citosol & &
\end{tabular}

Hemócitos saudáveis apresentam forma irregular (FIG. 16a) e, uma vez expostos ao vermelho neutro, seus lisossomos podem ser vistos como pequenos pontos rosados aglomerados e o núcleo pode ser visto como uma esfera incolor assim como o citosol. Hemócitos estressados (FIG. 16b) tendem a ser esféricos e menores contendo lisossomos maiores e escuros e o citosol pode aparecer tingido de rosa pela liberação do corante contido nos lisossomos (KING, 2000).

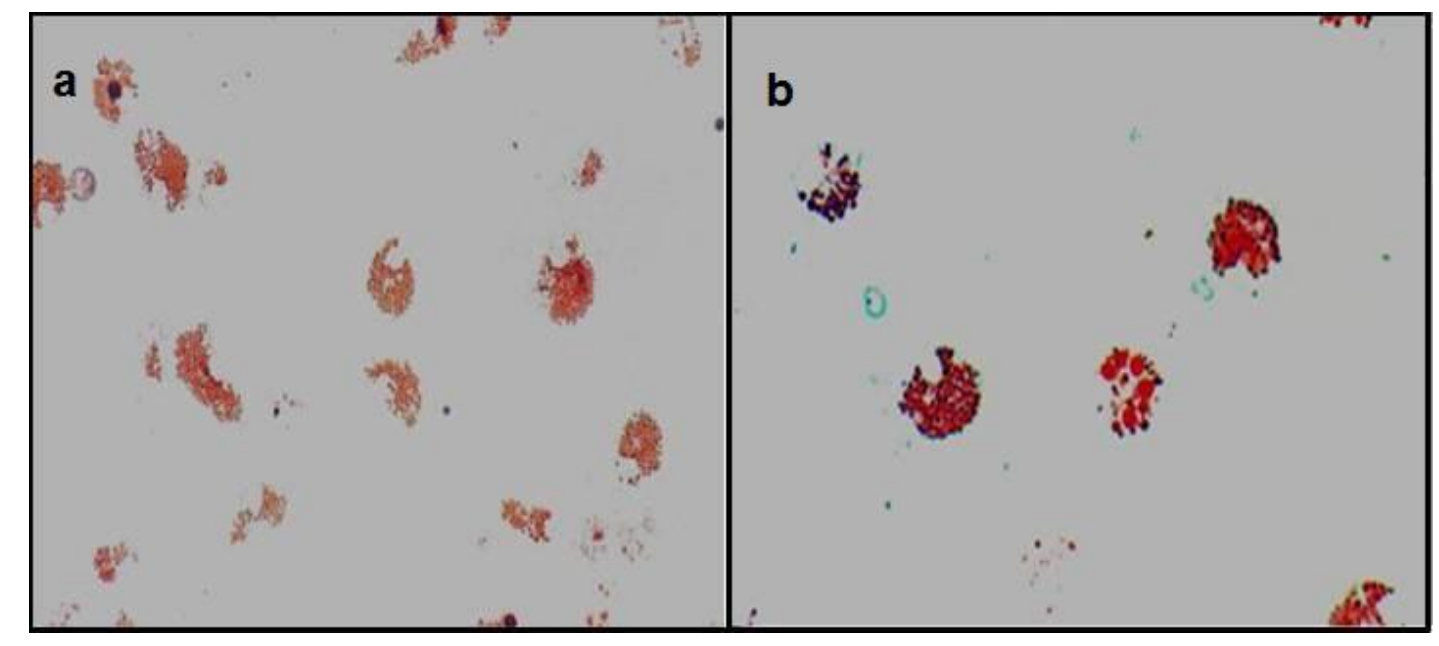

FIGURA 16 - (a) Células saudáveis, (b) Células estressadas 
Foi utilizada uma tabela para controle da avaliação dos hemócitos analisados onde: para mais que $50 \%$ das células observadas sem sinais de stress, usa-se o sinal + (positivo) para o animal examinado. O sinal - (negativo) delimita o "end-point", quando $50 \%$ ou mais das células exibem anomalias estruturais ou vazamento do corante para o citosol (KING, 2000).

O estado de integridade da membrana lisossômica pode ser refletido pelo tempo necessário para que ocorra o extravasamento do corante Vermelho Neutro para o citosol. O tempo de retenção médio para cada concentração é calculado pelo tempo em minutos de cada animal analisado.

\subsubsection{Ensaio de citotoxicidade com DEET}

Nos ensaios preliminares foram utilizados aquários de 15 Litros com 5 organismos para cada solução teste e controles de água e solvente. Todos os experimentos realizados foram estáticos, sem alimentação, com fotoperíodo de $12 \mathrm{~h}$ luz e temperatura controlada de $22^{\circ} \mathrm{C} \pm 2^{\circ} \mathrm{C}$. Os organismos foram retirados para avaliação de hemócitos a cada 24 horas, totalizando 3 leituras para cada experimento. Foram realizados três experimentos, nos quais os organismos foram expostos a diferentes concentrações do composto.

No primeiro experimento, considerado como preliminar, foram testadas as concentrações: $50,0 \mathrm{mg} \mathrm{L}^{-1}, 1,0 \mathrm{mg} \mathrm{L}^{-1}$ e $0,5 \mathrm{mg} \mathrm{L}^{-1}$. A partir dos resultados do teste preliminar foi realizado um segundo experimento onde foram testadas as concentrações: $0,5 \mathrm{mg} \mathrm{L}^{-1}, 0,02 \mathrm{mg} \mathrm{L}^{-1}$ e $0,001 \mathrm{mg} \mathrm{L}^{-1}$. Como foi observado efeito nas duas menores concentrações testadas foram realizados outros três ensaios preliminares com as mesmas concentrações $\left(0,02 \mathrm{mg} \mathrm{L}^{-1}\right.$ e $0,001 \mathrm{mg} \mathrm{L}^{-1}$ e 0,0001 $\left.\mathrm{mg} \mathrm{L}^{-1}\right)$. Para realização dos experimentos foi preparada uma solução estoque de DEET (100 $\mathrm{mg} \mathrm{L}^{-1}$ ) em álcool PA.

A partir dos ensaios preliminares foram definidas as concentrações de DEET para os ensaios definitivos: $0,02 \mathrm{mg} \mathrm{L}^{-1}$ e $0,001 \mathrm{mg} \mathrm{L}^{-1}$ e $0,0001 \mathrm{mg} \mathrm{L}^{-1}$. Foram realizados ensaios estáticos em triplicata, em aquários contendo 30 Litros de água marinha e 15 organismos por aquário (FIGURA 17). 
As leituras foram realizadas a cada 24 horas, e o endpoint do ensaio foi de 72 horas. Os ensaios de citotoxicidade com DEET tem por objetivo encontrar os valores de CENO e CEO para mexilhões Perna perna e para tanto após a realização dos experimentos foi empregado o tratamento estatístico de acordo com o método descrito pela USEPA (2002).

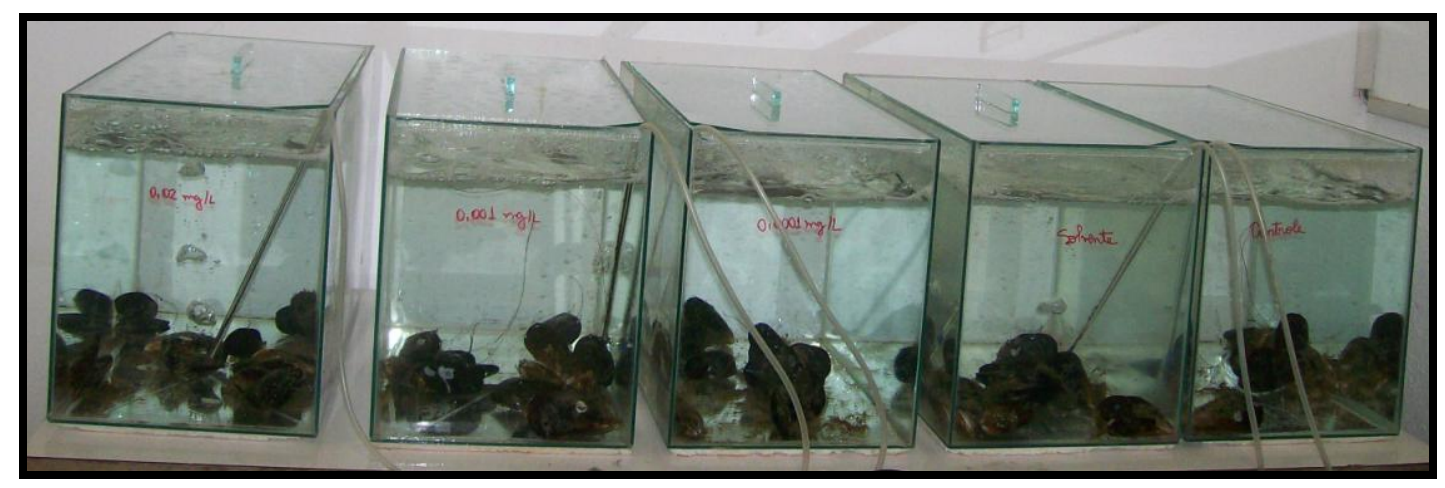

FIGURA 17 - Ensaio de Citotoxicidade com DEET

\subsubsection{Ensaios de citotoxicidade do DEET em organismos irradiados}

Os organismos foram colocados em frascos de polipropileno (FIG. 18) contendo $750 \mathrm{~mL}$ de água marinha e receberam dose de radiação de 11 Gy. Após a irradiação os organismos foram transportados para o laboratório e colocados em aquários contendo 30 Litros de água marinha.

O controle de água e do solvente (etanol) não foram irradiados mas receberam o mesmo procedimento dos organismos irradiados. Os organismos foram colocados em aquários contendo DEET nas concentrações de: $0,02 \mathrm{mg} \mathrm{L}^{-1}$ e $0,001 \mathrm{mg} \mathrm{L}^{-1}$ e $0,0001 \mathrm{mg} \mathrm{L}^{-1}$, e foram realizadas leituras em 24,48 e 72 horas. O endpoint para as leituras é o mesmo dos ensaios anteriores. 


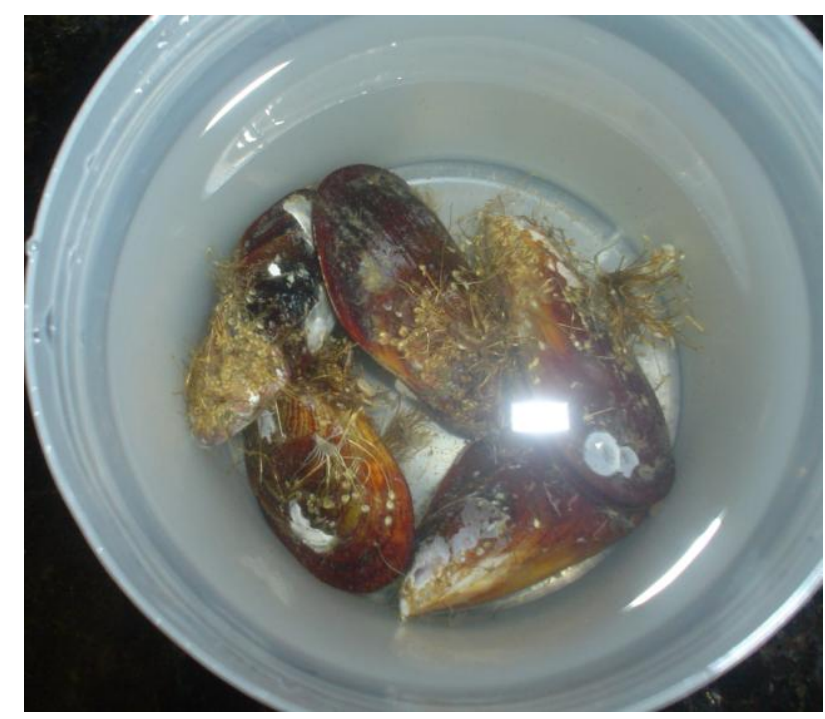

FIGURA 18 - Mexilhões Perna perna acondicionados nos frascos de polipropileno para irradiação

Foram testadas 3 diferentes doses de Radiação gama de fonte de ${ }^{60} \mathrm{Co}$ em combinação com o composto sobre a integridade/estabilidade da membrana lisossômica de mexilhões Perna perna no ensaio do tempo de retenção do corante vermelho neutro.

As doses recebidas pelos organismos foram: 0, 3, 11 e 107 Gy, determinadas pela DL50 $(72 h)$, que correspondem $0 \%, 0,25 \%, 1,0 \%$ e $10 \%$ da DL50 respectivamente. o mesmo procedimento foi aplicado ao controle de água e do solvente. Após a realização dos experimentos foi escolhida a dose de 11 Gy para os ensaios definitivos.

\subsubsection{Ensaios de citotoxicidade em organismos irradiados}

Nessa etapa do trabalho, os organismos receberam a dose de 11 Gy e posteriormente foram colocados em aquários contendo 30 Litros de água marinha, e então foi realizado o ensaio do tempo de retenção do corante vermelho neutro, analisando a integridade/estabilidade da membrana lisossômica em organismos irradiados e não expostos ao DEET. 
Foi observado se houve ou não diminuição no tempo de retenção do corante em comparação aos organismos não irradiados.

\subsection{Tratamento estatístico}

Os dados obtidos foram estatisticamente analisados de acordo com o tipo de ensaio:

\section{Toxicidade Aguda}

No ensaio de toxicidade aguda, com o percentual de mortalidade dos organismos foi calculada a estimativa das concentrações que apresentaram efeito em 50\% dos organismos expostos (FIG. 19), utilizando o método estatístico não paramétrico de Trimmed Spearman-Karber (HAMILTON et al., 1977).

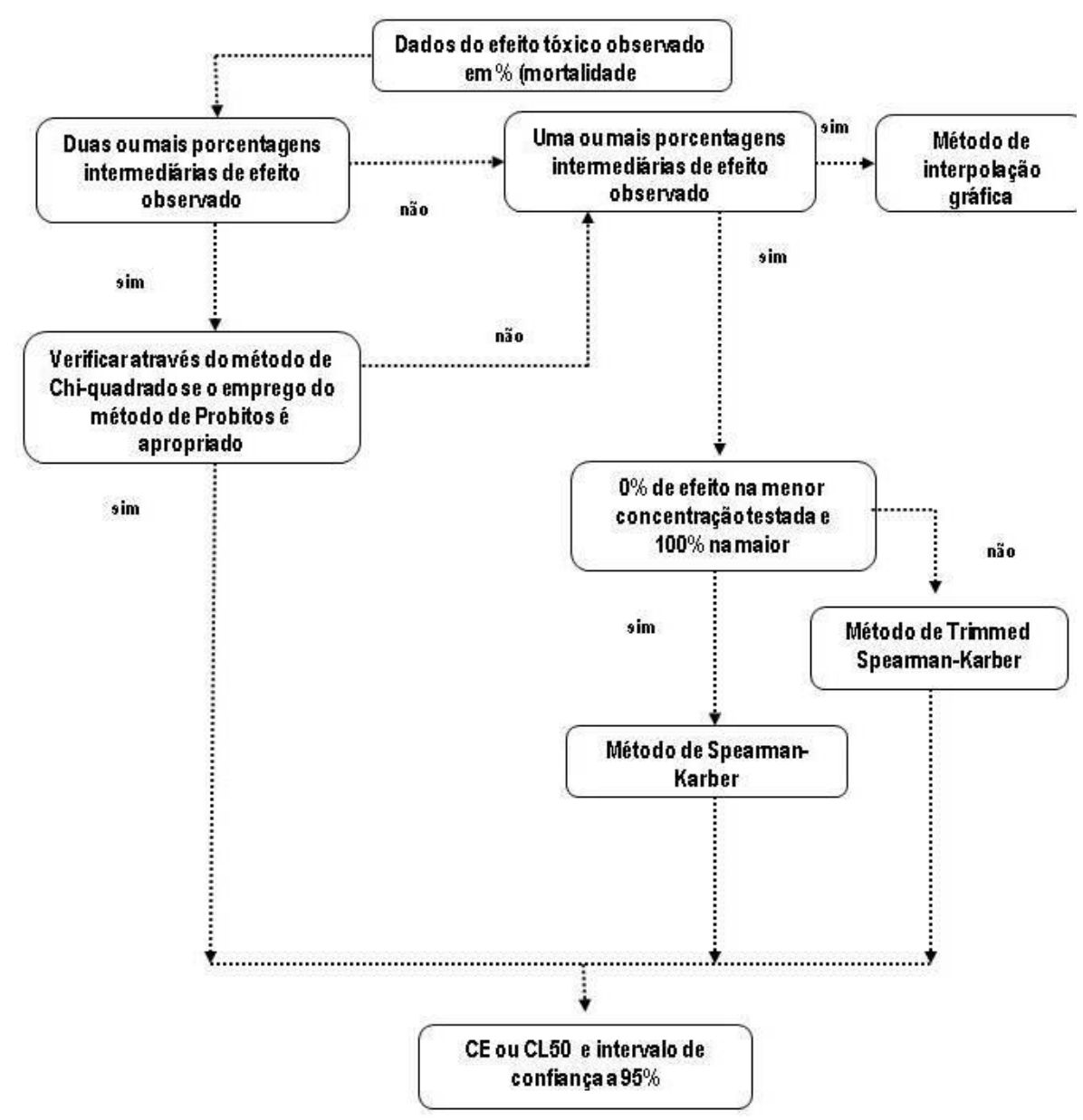

FIGURA 19 - Fluxograma com as etapas para análise estatística e determinação dos valores de CE ou CL50 e intervalo de confiança a 95\% 


\section{Citotoxicidade}

Os efeitos citotóxicos do DEET e da radiação gama em mexilhões Perna perna, assim como devido a exposição ao DEET dos organismos irradiados foi avaliado por analise de variância (ANOVA) e por comparação múltipla nos testes de hipóteses do programa estatístico TOXSTAT 3.4 (WEST \& GULLEY, 1994).

De acordo com Buratini e Bertoletti (2006) a maior concentração de efeito não observado (CENO) e a menor concentração de efeito observado (CEO) são estatisticamente diferentes em relação ao controle. Na FIG. 20 está representado o fluxograma com o procedimento adotado para obter os resultados de efeito citotóxico nos organismos teste (CENO e CEO).

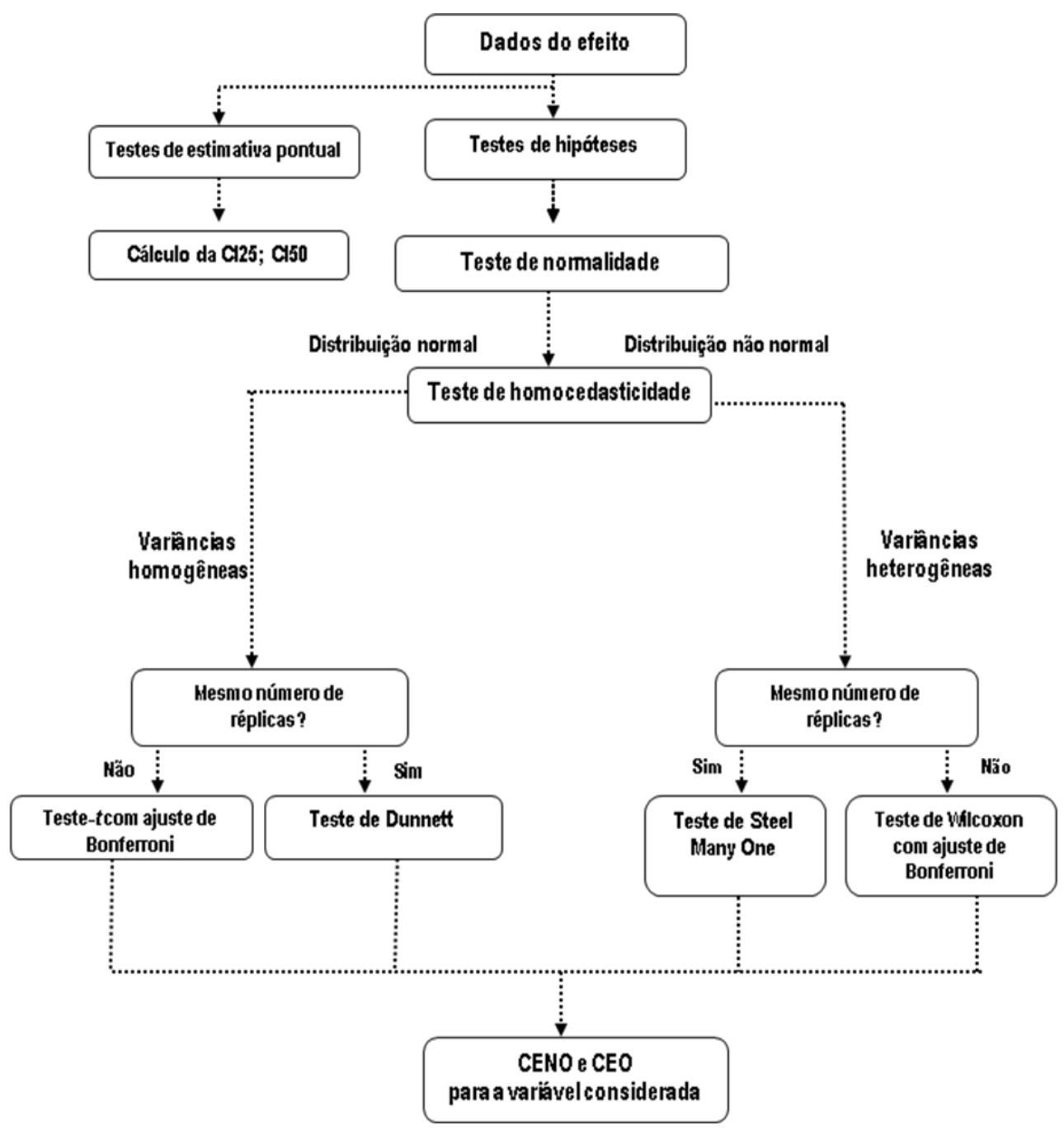

FIGURA 20 - Fluxograma com as etapas para análise estatística e determinação dos valores de CENO, CEO e Cl ( adaptado USEPA, 2002). 
Para a definição da CENO e CEO, os resultados foram analisados quanto à normalidade a partir do Teste de Chi-quadrado $\left(x^{2}\right)$ e quanto à homocedasticidade utilizando-se o Teste de Bartlett. De acordo com a USEPA (2002) o Teste de Chiquadrado $\left(\mathrm{x}^{2}\right)$, estabelece o agrupamento dos dados em classes, comparando sua distribuição à distribuição normal.

Aplica-se o Teste de Bartlett para grupos com número de réplicas igual ou diferente e o Teste de Hartley para grupos com número de réplicas igual ou quando não é muito diferente, e é sensível a dados não normalmente distribuídos (BURATINI e BERTOLETTI, 2006).

Após a verificação da normalidade e homocedasticidade nos resultados do ensaio do tempo de retenção do corante vermelho neutro foi realizada uma análise de variância (ANOVA) entre os grupos para avaliar se as diferenças foram estatisticamente significativas. As diferenças significativas foram determinadas com nível de significância de $\mathrm{p}<0,05$.

Aplicou-se o Teste "t" de Student para detectar diferenças significativas entre os controles, não havendo diferenças foram realizadas análises entre o controle (água) e as soluções teste.

Foram utilizados outros testes como: o teste paramétrico Dunnett quando os dados foram normais e homogêneos e número de réplicas iguais; o teste de Bonferroni no caso de número de réplicas diferentes. Aplicou-se o Teste de Steel Many One quando não houve distribuição normal dos dados e com número de réplicas iguais.

Os resultados também foram submetidos à análise da Concentração de Inibição de $25 \%$ e $50 \%$ pelo método de interpolação linear, ou seja, uma estimativa pontual da concentração que causa efeito em $25 \%$ e $50 \%$ dos organismos expostos. 


\section{RESULTADOS E DISCUSSÃO}

Os resultados dos ensaios de toxicidade aguda (CL50) do DEET e a dose letal de radiação gama de ${ }^{60} \mathrm{Co}$ encontrada para mexilhões Perna perna serão apresentados inicialmente.

Em seguida serão apresentados os resultados obtidos nos ensaios de citotoxicidade (estabilidade da membrana lisossômica) do DEET para organismos irradiados e não irradiados.

Os resultados dos ensaios de toxicidade aguda (CL50 e DL50) foram calculados pelo software Trimmed Spearman-Karber e dos ensaios de citotoxicidade (CENO, CEO, Cl25 e Cl50) obtidos por análise dos softwares TOXSTAT 3.4 e ICP. O fluxograma abaixo (FIG. 21) mostra as etapas realizadas para obtenção dos resultados:

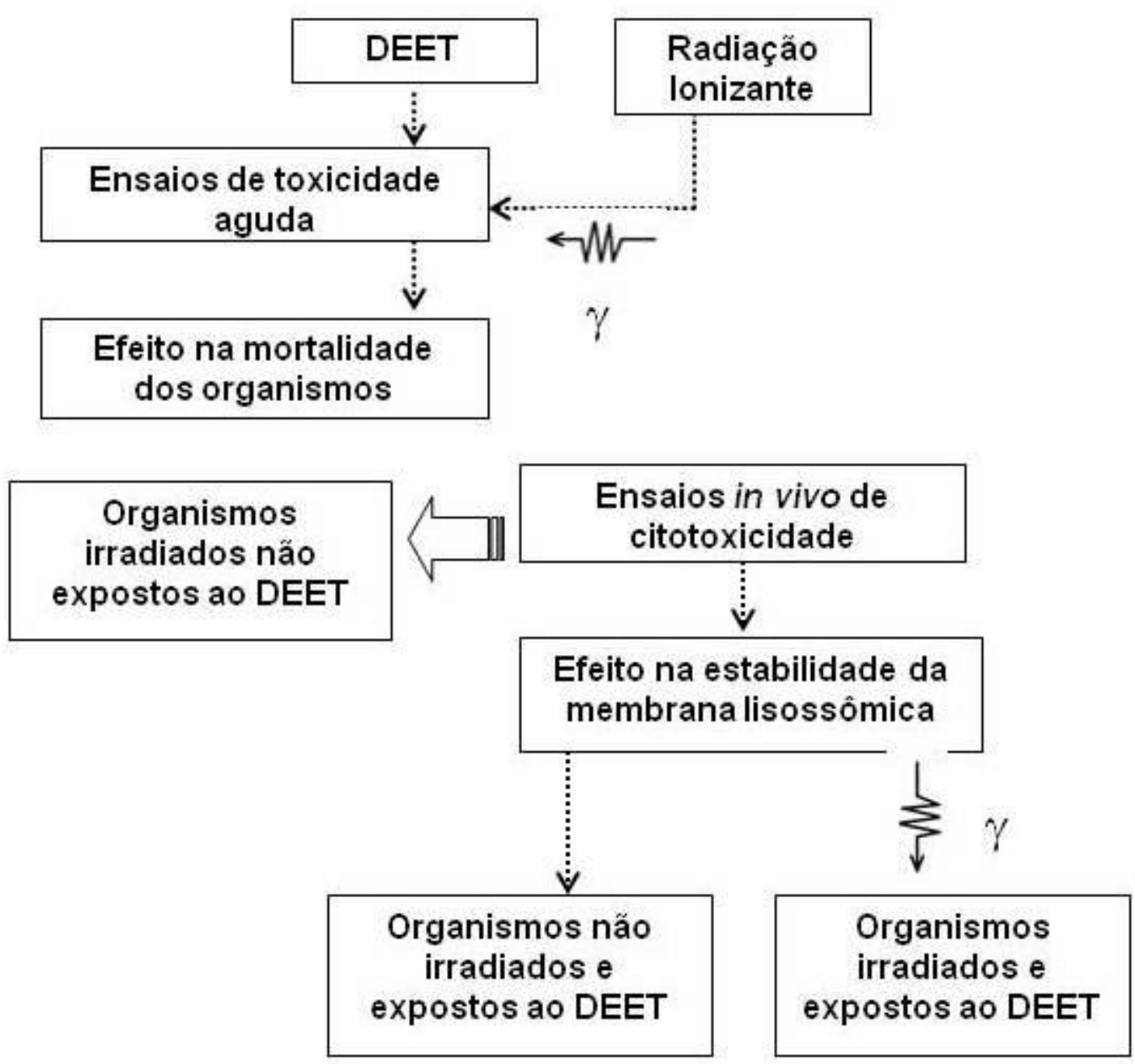

FIGURA 21 - Fluxograma das etapas realizadas no presente estudo. 


\subsection{Ensaios de Ecotoxicidade aguda}

\subsubsection{Dietiltoluamida}

Estes ensaios avaliaram a $\mathrm{CL50}(72)$, concentração capaz de causar mortalidade em $50 \%$ dos organismos após $72 \mathrm{~h}$ de exposição ao DEET.

$O$ valor médio da $\mathrm{CL}(\mathrm{I}) 50 ; 72 \mathrm{~h}$ do DEET obtido nos ensaios de ecotoxicidade aguda $(n=3)$ realizados com o molusco bivalve Perna perna foi de $114,27 \mathrm{mg} \mathrm{L}^{-1}$. O percentual de mortalidade para cada ensaio está apresentado na TAB. 6.

TABELA 6 - Percentual de mortalidade obtido nos ensaios de toxicidade aguda de DEET para o mexilhão Perna perna

\begin{tabular}{cccc}
\hline \multirow{2}{*}{$\begin{array}{c}\text { Concentrações } \\
\left(\mathrm{mg} \mathrm{L}^{-1}\right)\end{array}$} & Ensaio 1 & Ensaio 2 & Ensaio 3 \\
\cline { 2 - 4 } & \multicolumn{3}{c}{ Mortalidade (\%) } \\
\hline Controle & 0 & 0 & 0 \\
Controle (solvente) & 0 & 0 & 0 \\
75 & 0 & 0 & 0 \\
100 & 20 & 40 & 20 \\
150 & 100 & 80 & 100 \\
200 & 100 & 100 & 100 \\
300 & 100 & 100 & 100 \\
400 & 100 & 100 & 100 \\
\hline
\end{tabular}

O valor da CL50 e do intervalo de confiança dos ensaios de ecotoxicidade realizados neste trabalho foram obtidos pelo programa estatístico Trimmed Spearman-Karber (HAMILTON et al., 1977) e a média, o desvio padrão (DP) e o coeficiente de variância (CV) estão apresentados na TAB. 7. 
TABELA 7 - Valores da CL50, intervalos de confiança, média, desvio padrão e coeficiente de variação para os ensaios de ecotoxicidade aguda do DEET para mexilhões Perna perna.

\begin{tabular}{ccc}
\hline Ensaio & $\begin{array}{c}\mathbf{C L 5 0}_{(72)} \\
\left(\mathbf{m g ~ L}^{-1}\right)\end{array}$ & $\begin{array}{c}\text { Intervalo de confiança } \\
\left(\mathbf{m g ~ L}^{-1}\right)\end{array}$ \\
1 & 114,27 & $(100,95-129,36)$ \\
2 & 114,27 & $(93,93-139,02)$ \\
3 & 114,27 & $(100,95-129,36)$ \\
Média & 114,27 & \\
Desvio padrão & 16,98 & \\
Coeficiente de variação $(\%)$ & 15 & \\
\hline
\end{tabular}

A FIG. 22 apresenta a taxa de mortalidade (\%) dos mexilhões para o de DEET $\left(\mathrm{mg} \mathrm{L}^{-1}\right)$.

$\mathrm{CL50}_{(72 \mathrm{~h})}$

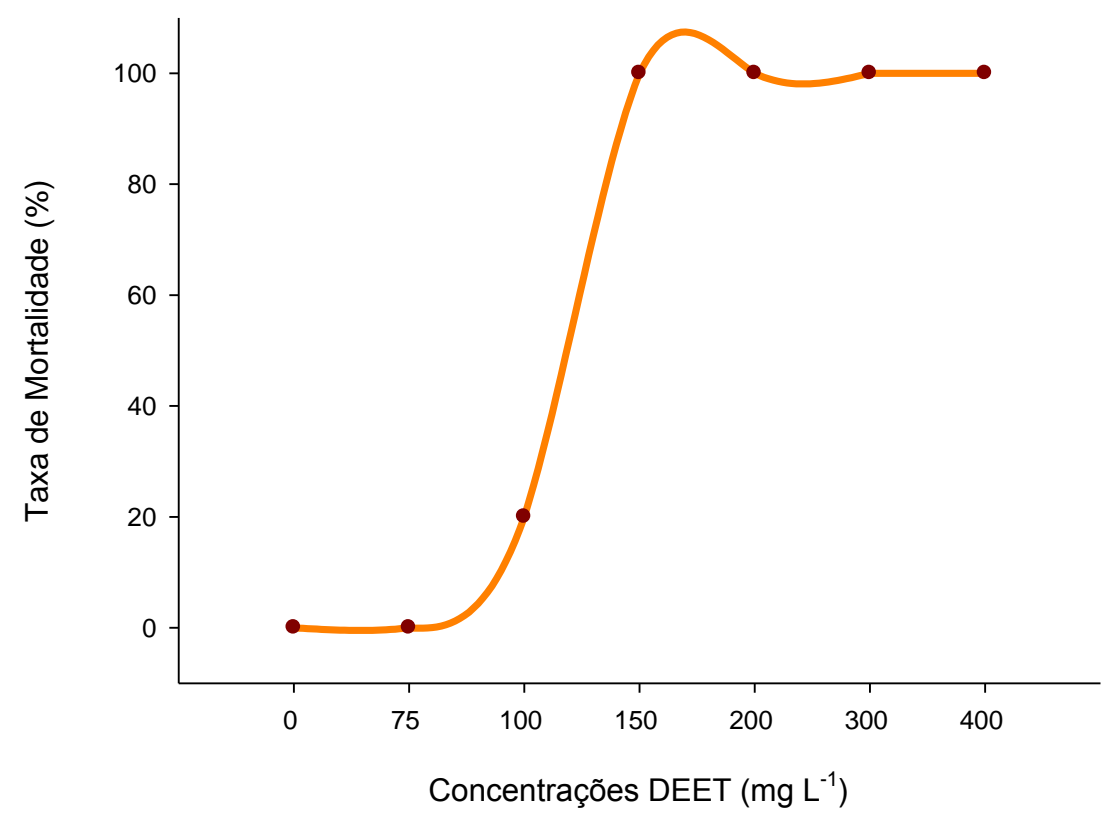

FIGURA 22 - Taxa de mortalidade em função das concentrações de DEET a que os organismos foram expostos.

As concentrações de efeito agudo medido para peixes, invertebrados e algas variaram de $4 \mathrm{mg} \mathrm{L}^{-1}$ a $388 \mathrm{mg} \mathrm{L}^{-1}$, enquanto o intervalo de concentrações calculado pelo programa ECOSAR previu o efeito agudo de $25 \mathrm{mg} \mathrm{L}^{-1}$ a $89 \mathrm{mg} \mathrm{L}^{-1}$ (WEEKS et al., 2011). 
$\mathrm{Na}$ literatura existem poucos dados relativos à toxicidade aguda do DEET para os organismos aquáticos (WEEKS, 2011). E os dados disponíveis indicam que o DEET é ligeiramente tóxico para organismos aquáticos (MICHAEL and GRANT, 1974; OFFICE OF PESTICIDE PROGRAMS, 2000).

Na TAB. 8 estão representados os resultados da CL50 $\left(\mathrm{mg} \mathrm{L}^{-1}\right)$ para várias espécies expostas ao DEET em diferentes endpoints.

TABELA 8 - Toxicidade aguda do DEET para diversas espécies em diferentes ensaios (Adaptado de RAND e BRAUSCH, 2011).

\begin{tabular}{cccccc}
\hline Composto & Categoria & Espécie & Nível trófico & Endpoint/duração & CL50 (mg L $\mathbf{~ L}^{-1}$ ) \\
& & D. magna & Invertebrado & $48 \mathrm{~h}, 96 \mathrm{~h}$ & $160,108^{1}$ \\
$\mathrm{~N}, \mathrm{~N}$-dietil & G. fasciatus & Invertebrado & $96 \mathrm{~h}$ & $100^{2}$ \\
metatoluamida & $\begin{array}{c}\text { Repelente de } \\
\text { insetos }\end{array}$ & P. promelas & Peixe & $96 \mathrm{~h}$ & $110^{3}$ \\
(DEET) & G. affinis & Peixe & $24-48 \mathrm{~h}$ & $235^{4}$ \\
& O. mykiss & Peixe & $96 \mathrm{~h}$ & $71,3^{5}$ \\
& & C. protothecoides & Alga & $24 \mathrm{~h}$ fotossíntese & $388^{6}$ \\
\hline
\end{tabular}

(1) Seo et al. (2005), (2) Mayer and Ellersieck (1986), (3) Brooke et al. (1984), (4) Michael and Grant (1974), (5) Office of Pesticides Program (2000), (6) Costanzo et al. (2007).

O DEET possui um baixo fator de bioconcentração e provavelmente não é acumulado em organismos aquáticos (COSTANZO et al., 2007), o composto foi regularmente detectado em efluentes tratados e águas superficiais em concentrações de $0,2 \mathrm{ng} \mathrm{L}^{-1}$ e $55 \mathrm{ng} \mathrm{L}^{-1}$, respectivamente (WEEKS, 2011)

Embora o composto seja relativamente resistente à degradação e comumente encontrado em águas de superfície, até o presente momento desconhece-se estudos que examinaram a toxicidade crônica da exposição ao DEET para os organismos aquáticos (WEEKS, 2011)

Foi identificado que o DEET inibe a colinesterase em ratos (CHANEY et al., 2000), e é possível que efeitos semelhantes possam ser observados em peixes, apesar de nenhuma pesquisa ter sido conduzida até o presente momento (WEEKS, 2011). 
Além disso, nenhum estudo foi realizado para examinar possíveis efeitos endócrinos em organismos aquáticos, embora estudos nesse âmbito tenham sido conduzidos em ratos.

Os resultados em ratos machos indicaram que DEET não tem efeito sobre o número, morfologia ou viabilidade de espermatozóides após exposição de nove semanas ao composto (LEBOWITZ et al., 1983), partindo desse contexto acredita-se que o composto apresenta baixo potencial de efeito em espécies aquáticas (WEEKS, 2011).

Costanzo et al. (2007) realizaram uma avaliação de risco preliminar para o DEET, e concluíram que o composto não é susceptível de produzir efeitos biológicos em concentrações ambientalmente relevantes nos ecossistemas aquáticos; no entanto, devido à falta de informação sobre a toxicidade crônica uma avaliação definitiva não foi concluída.

A toxicidade crônica do DEET para os organismos aquáticos ainda permanece indeterminada. Foi realizada uma avaliação preliminar de risco semelhante a do DEET, com o repelente de traça 1,4-diclorobenzeno, e invertebrados, especificamente D. magna, que se mostrou mais sensível à exposição de curto prazo enquanto que peixes mostraram-se mais sensíveis à exposição a longo prazo (BOUTONNET et al., 2004).

Com base nas concentrações ambientais de 1,4-diclorobenzeno observadas, efeitos agudos ou crônicos estão ocorrendo para os organismos de água doce e marinhos, além disso, existe um potencial para a bioacumulação do composto e ainda não há nenhuma indicação de que o composto pode causar efeitos endócrinos (BOUTONNET et al., 2004).

Os resultados obtidos nesta etapa do projeto propiciam uma orientação para o início dos ensaios de citotoxicidade com DEET em mexilhões Perna perna e contribuem para informações do potencial tóxico desta substância em mais um organismo aquático, uma vez que não existe uma avaliação de risco ecológica completa deste composto, e o princípio ativo está presente em diversos produtos comercialmente disponíveis sendo amplamente utilizado. 


\subsubsection{Radiação gama de ${ }^{60} \mathrm{Co}$}

Os ensaios de ecotoxicidade aguda avaliaram a DL50 (72), dose capaz de causar mortalidade em $50 \%$ dos organismos $72 \mathrm{~h}$ após a irradiação.

O valor da $\mathrm{DL} \mathrm{0}_{(72)}$ para os ensaios de ecotoxicidade aguda com mexilhões Perna perna irradiados com radiação gama de ${ }^{60} \mathrm{Co}$ foi de $1068 \mathrm{~Gy}$, e o percentual de mortalidade de cada ensaio está representado na TAB. 9.

TABELA 9 - Percentual de mortalidade dos ensaios de toxicidade aguda para organismos irradiados com radiação gama de ${ }^{60} \mathrm{Co}$

\begin{tabular}{cccc}
\hline \multirow{2}{*}{$\begin{array}{c}\text { Doses } \\
(\text { Gy })\end{array}$} & Ensaio 1 & Ensaio 2 & Ensaio 3 \\
\cline { 2 - 4 } & \multicolumn{3}{c}{ Mortalidade (\%) } \\
\hline Controle & 0 & 0 & 0 \\
250 & 0 & 0 & 0 \\
500 & 0 & 0 & 0 \\
750 & 0 & 0 & 0 \\
1000 & 40 & 40 & 60 \\
1500 & 100 & 80 & 100 \\
2000 & 100 & 100 & 100 \\
2500 & 100 & 100 & 100 \\
3000 & 100 & 100 & 100 \\
\hline
\end{tabular}

Utilizou-se o software Trimmed Spearman-Karber para o cálculo da DL50 $(72)$ e dos intervalos de confiança de cada ensaio, tais valores estão apresentados na TAB. 10. Os valores médios da DL50, desvio padrão e coeficiente de variação também constam na mesma. 
TABELA 10 - Valores da DL50, intervalos de confiança, média, desvio padrão e coeficiente de variação para os ensaios de ecotoxicidade aguda para mexilhões Perna perna.

\begin{tabular}{ccc}
\hline Ensaio & $\begin{array}{c}\mathbf{D L 5 0}_{(72)} \\
\left(\mathbf{m g ~ L}^{-1}\right)\end{array}$ & $\begin{array}{c}\text { Intervalo de confiança } \\
\left(\mathbf{m g ~ L}^{-1}\right)\end{array}$ \\
1 & 1066,20 & $(915,98-1241,06)$ \\
2 & 1142,73 & $(939,29-1390,23)$ \\
3 & 994,80 & $(854,64-1157,95)$ \\
Média & 1068 & \\
Desvio padrão & 180 & \\
Coeficiente de variação $(\%)$ & 17 & \\
\hline
\end{tabular}

Na FIG. 23 está representada a taxa de mortalidade (\%) de acordo com as doses (Gy) que os organismos foram submetidos.

$$
\operatorname{DL50}_{(72 h)}
$$

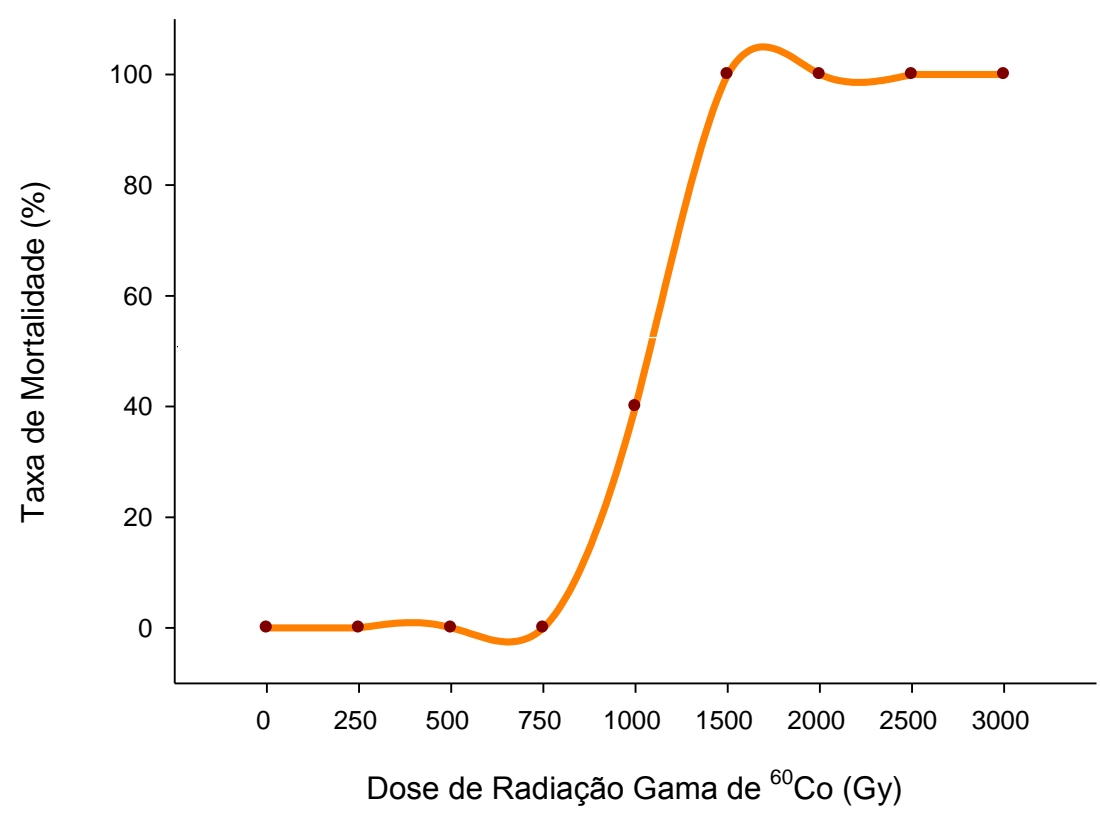

FIGURA 23 - Taxa de mortalidade em função das doses de radiação gama de ${ }^{60} \mathrm{Co}$ a que os organismos foram expostos

A Comissão Internacional de Proteção Radiológica (ICRP) desenvolveu um sistema para proteger seres humanos da radiação ionizante, com recomendação de valores de referência (ICRP, 1991, 2007). Este sistema surgiu inicialmente da necessidade de controlar a exposição de radiação no local de trabalho e em 
práticas médicas, expandindo posteriormente para proteger o público geral de resíduos radioativos associados com armas nucleares, e na geração e produção de energia nuclear (PENTREATH, 2009).

Uma deficiência tem sido a desatenção para um sistema paralelo que avalie os efeitos da radiação ionizante para a biota. A ICRP estabeleceu um novo comitê (Committee 5 for the Protection of the Environment) para realizar trabalhos futuros na área de proteção ambiental às radiações (BALONOV et al., 2005; AIEA, 2005; VOLKLE, 2006).

A proteção do meio ambiente deve ser claramente demonstrada, independente da presença de seres humanos (PENTREATH, 2009).

Os efeitos biológicos das radiações ionizantes na biota têm sido estudados por diversos pesquisadores e organizações (VERGA and SCHULTZ, 1982; AIEA, 1992; ROSA, 1992; WOODHEAD,1993; EISLER, 1994, 2000; UNSCEAR, 1996; VERGA, 1997; HINTON, 1998; MEYERS-SCHONE and TALMAGE, 2003; IRVINE and SAMPLE, 2005; HIGLEY, 2007; GERASKIN et al., 2007).

Vários estudos foram realizados em táxons específicos, incluindo protozoários (WICHTERMAN, 1972), insetos (O'BRIEN and WOLFE, 1964), anfíbios (BRUNST, 1965), répteis (COSGROVE, 1971), aves (MELLINGER and SCHULTZ, 1975), plantas (VERGA and FRALEY, 1974), organismos terrestres (VERGA and HINTON, 1996) e biota aquática (AIEA, 1976, 1979; ANDERSON e HARRISON, 1986; NCRP, 1991; BLAYLOCK et al., 1993).

Estes estudos abordam aspectos dos efeitos radiobiológicos, incluindo semelhanças e diferenças nos seres humanos e na biota, radiossensibilidade, transferência linear de energia (LET), eficácia radiobiológica (RBE), fator de ponderação da radiação (wR), efeitos determinístico versus efeitos estocásticos, exposição aguda versus exposição crônica e endpoints em diversos níveis de organização biológica (DELISTRATY, 2008).

Vias de exposição específicas aumentam a radiossensibilidade (devido a diferenças na toxicocinética, bioacumulação, comportamento) e efeitos secundários podem produzir efeitos biológicos únicos na biota (DELISTRATY, 2008). 
Existem características comuns de efeitos da radiação em todos os organismos vivos, devido às semelhanças no nível molecular, como por exemplo a radiação ionizante pode ionizar átomos e moléculas, que por sua vez, podem produzir radicais livres, quebrar ou formar ligações químicas e moléculas que regulam processos celulares; geralmente esses processos ocorrem pela ação indireta da radiação.

Quando os mecanismos de reparação celular estão saturados, ocorrem danos, e a molécula de DNA é o principal alvo para a indução de efeitos biológicos da radiação em todos os organismos (ICRP, 2003). As quebras na cadeia dupla de DNA são de difícil reparação, portanto é um efeito bastante significativo (ZAHRADKA et al., 2006; DOWNS et al., 2007).

Além de danos diretos do DNA, a radiação ionizante pode interferir com a metilação do DNA ou modificação de histonas, dois principais mecanismos epigenéticos que podem alterar a expressão gênica (QIU, 2006).

A Agência Internacional de Energia Atômica (AIEA) recomenda um limite de dose aguda de 0.1 Gy para plantas terrestres e populações animais, um limite de taxa de dose crônica de $1 \mathrm{mGy} \mathrm{d}^{-1}$ para populações de animais terrestres e um limite de taxa de dose crônica de $10 \mathrm{mGy} \mathrm{d}^{-1}$ para populações aquáticas e populações de plantas terrestres (NCRP, 1991; IAEA, 1992).

De acordo com Irvine e Sample (2005) em uma recente compilação de dados nenhum efeito agudo e crônico adverso foram observados (NOAELs) para a exposição de radiação à biota (TAB. 11), esses resultados sugerem que as orientações da AIEA seriam de medidas preventivas na maioria dos casos.

Porém, foi observado que o critério de exposição de 30 dias a exposições agudas e crônicas (IRVINE and SAMPLE, 2005) é um tanto arbitrário, em relação às definições aguda e crônica especificadas pela AIEA (1992).

Como o nível de organização biológica aumenta, há aumentos em escala espacial e temporal, bem como aumento na magnitude da dose/resposta. Isso reflete em uma cascata hierárquica de respostas biológicas à exposição de contaminantes (POLIKARPOV, 1998; SPURGEON et al., 2005). 
TABELA 11 - Efeitos adversos não observados, expressos em média geométrica da taxa de dose, para exposição aguda e crônica de radiação ionizante em diversos táxons da biota não-humana ${ }^{a}$

\begin{tabular}{|c|c|c|c|c|c|c|}
\hline Taxon & $\begin{array}{l}\text { Taxa de dose a } \\
\text { ( } \leq 30 \text { dias de ex }\end{array}$ & & $\begin{array}{l}\text { Taxa de dose c } \\
\text { (>30 dias de ex }\end{array}$ & & $\begin{array}{l}\text { Dados agudos e crônicos } \\
\text { combinados }\end{array}$ & \\
\hline & $\operatorname{NOAEL}(\mathrm{Gy} / \mathrm{d})$ & $\mathrm{n}^{\mathrm{b}}$ & $\operatorname{NOAEL}(\mathrm{Gy} / \mathrm{d})$ & $\mathrm{n}^{\mathrm{b}}$ & NOAEL (Gy/d) & $\mathrm{n}$ \\
\hline Anfíbios/Répteis & 2,3 & 1 & 0,020 & 1 & 0,21 & 2 \\
\hline Aves & 3,4 & 22 & 0,00020 & 7 & 0,60 & 29 \\
\hline Mamíferos & 0,50 & 13 & 0,033 & 15 & 0,12 & 28 \\
\hline Invertebrados terrestres & 23 & 3 & 64 & 2 & 35 & 5 \\
\hline Plantas terrestres & 2,4 & 4 & 0,027 & 10 & 0,10 & 14 \\
\hline Invertebrados aquáticos & 20 & 12 & 1,3 & 14 & 2,0 & 26 \\
\hline Peixes & 1,1 & 4 & 0,019 & 6 & 0,095 & 10 \\
\hline
\end{tabular}

aguda a uma taxa de dose aguda (quando possível) para facilitar a comparação com a taxa de dose crônica; ${ }^{b} \mathrm{n}=$ número de observações. 
A maioria das pesquisas tem abordado o efeito da radiação ionizante em organismos individuais. $\mathrm{Na}$ avaliação de risco ecológico (ARE), o objetivo é proteger a população, exceto espécies ameaçadas de extinção onde o indivíduo necessita de proteção individual (IAEA,1992).

Além da hipótese inicial de que a biota é protegida de acordo com a radioproteção humana (ICRP, 1991), abordagens mais interessantes têm sido propostas para avaliar os impactos da radiação ionizante diretamente na biota.

Estas estratégias têm sido recomendadas por diversas organizações internacionais, os papéis e as responsabilidades das organizações relevantes foram descritos por IAEA (2005) e ICRP (2003) e forneceram um quadro global de uma perspectiva internacional.

Várias dessas estratégias incluem a aplicação de uma avaliação de risco ecológico, uso de padrões de limite de taxa de dose, desenvolvimento de um conjunto de referência para flora e fauna, e uma abordagem geográfica.

Os resultados dos ensaios de letalidade de radiação gama de ${ }^{60} \mathrm{Co}$ para o mexilhão Perna perna é um dado inédito na literatura. E contribuíram para a denifição das doses utilizadas nos ensaios de citotoxicidade com o DEET, onde foi avaliado o potencial citotóxico da substância em organismos que já tinham sido expostos à uma determinada dose de radiação. $\mathrm{E}$ a interação da radiação com o DEET com a observação de efeito sinérgico ou antagônico.

\subsection{Ensaios de citotoxicidade com Perna perna (Mollusca, Bivalvia)}

\subsubsection{Ensaios preliminares de citotoxicidade do DEET com organismos não irradiados}

As concentrações de DEET utilizadas nos ensaios preliminares de citotoxicidade foram definidas a partir da CL50 encontrada nos ensaios de toxicidade aguda, foram realizados diversos ensaios para encontrar a faixa de efeitos citotóxicos, e partir disso definiu-se concentrações para a obtenção da CEO, CENO, Cl25 e Cl50. 
O primeiro ensaio preliminar de citotoxicidade do DEET com organismos não irradiados não apresentou diferença significativa entre os controles de água e água acrescida de solvente (álcool PA) para $\alpha=0,05$ e $\alpha=0,01$. Foi aplicado o Teste $t$ de Student para avaliar se houve diferença significativa com o solvente utilizado, e a partir disso foi realizada a análise estatística com as concentrações testadas. Todas as análises dos ensaios de citotoxicidade foram realizadas no Software TOXSTAT 3.4.

Observou-se diferença significativa em todas as concentrações testadas $\left(50,0 ; 1,0 ; 0,02 \mathrm{mg} \mathrm{L}^{-1}\right)$. A FIG. 24 representa o tempo de retenção do corante vermelho (VN) em minutos para cada concentração de DEET testada e os controles de água e solvente, em todos os tempos de exposição (24, 48 e 72h). Os valores médios do tempo de retenção do corante, desvio padrão e coeficiente de variação para cada leitura realizada estão apresentados na TAB. 12.

\section{Ensaio Preliminar DEET I}

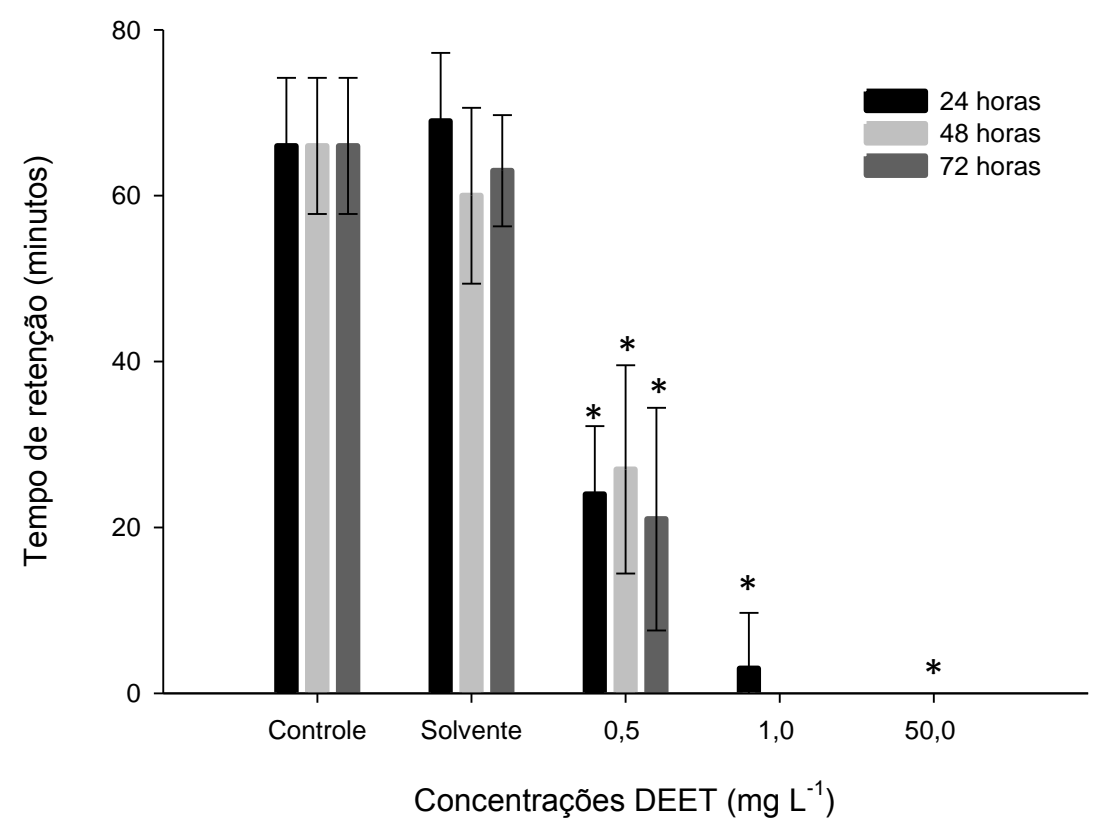

FIGURA 24 - Representação gráfica do tempo de retenção do corante VN em função das concentrações de DEET para o mexilhão Perna perna

$\left(^{\star}\right)$ Diferença significativa em relação ao controle 
TABELA 92 - Valores médios do tempo de retenção do corante VN (minutos), desvio padrão (DP) e coeficiente de variação $(\mathrm{CV})$ para as leituras do $1^{\circ}$ ensaio de citotoxicidade

\begin{tabular}{cccc|ccc|ccc}
\hline & & $\mathbf{2 4 h}$ & \multicolumn{3}{c|}{$\mathbf{4 8 h}$} & \multicolumn{3}{c}{$\mathbf{7 2 h}$} \\
(mg L $^{-1}$ ) & Média & D P & $\mathbf{C ~ V ( \% )}$ & Média & D P & $\mathbf{C ~ V ( \% )}$ & Média & D P & C V(\%) \\
\hline Controle & 66,0 & 8,2 & 12,4 & 66,0 & 8,2 & 12,4 & 66,0 & 8,2 & 12,4 \\
Solvente & 69,0 & 8,2 & 11,9 & 60,0 & 10,6 & 17,6 & 63,0 & 6,7 & 10,6 \\
0,02 & 24,0 & 8,2 & 34,2 & 27,0 & 12,5 & 46,4 & 21,0 & 13,4 & 63,8 \\
1 & 3,0 & 6,7 & 223,6 & 0,0 & 0,0 & 0,0 & 0,0 & 0,0 & 0,0 \\
50 & 0,0 & 0,0 & 0,0 & 0,0 & 0,0 & 0,0 & 0,0 & 0,0 & 0,0 \\
\hline
\end{tabular}

No segundo ensaio foram testadas as concentrações de: $0,001 \mathrm{mg} \mathrm{L}^{-1}$, $0,02 \mathrm{mg} \mathrm{L}^{-1}$ e $0,5 \mathrm{mg} \mathrm{L}^{-1}$. $\mathrm{Na}$ análise estatística pelo Test $t$ de Student não houve diferença significativa entre os controles. Houve diferença significativa em todas as concentrações testadas comparadas com o controle em todos os tempos de exposição. A FIG. 25 mostra os resultados do tempo de retenção do corante vermelho neutro (VN) em função das concentrações que os organismos foram expostos.

Ensaio Preliminar DEET II

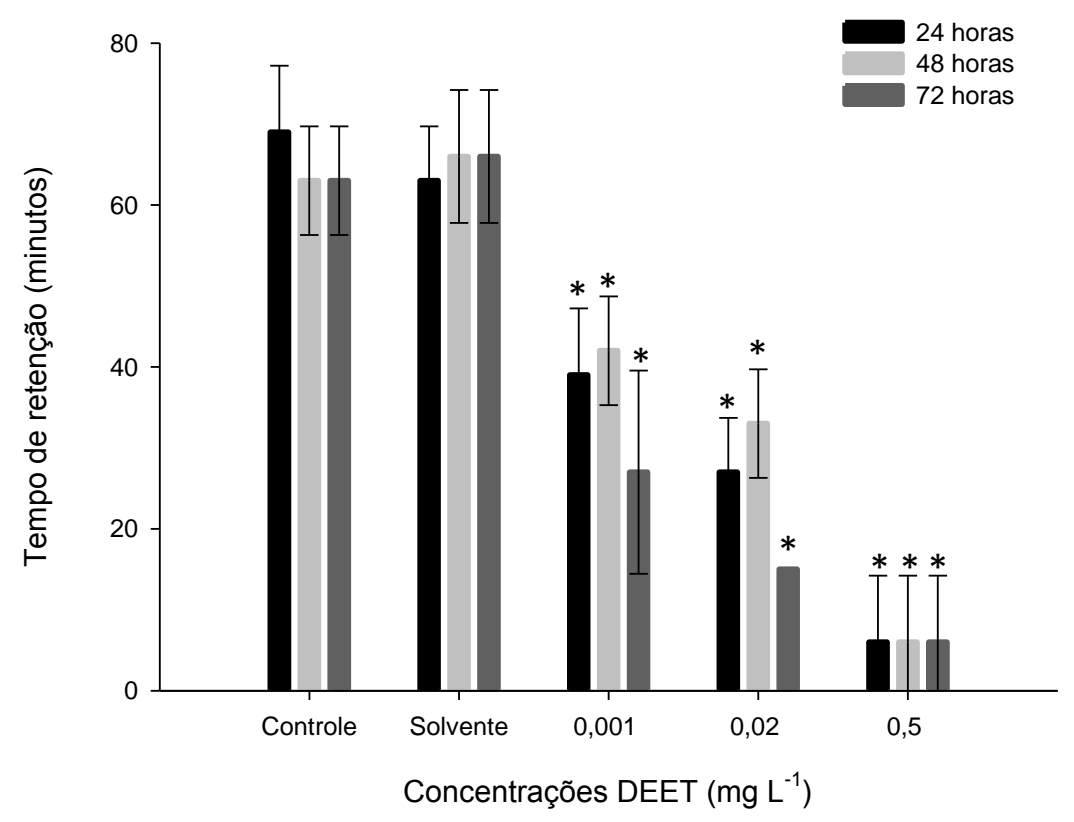

FIGURA 25 - Representação gráfica do tempo de retenção do corante VN em função das concentrações de DEET para o mexilhão Perna perna

(*) Diferença significativa em relação ao controle 
Foram calculados os valores médios do tempo de retenção do corante VN, desvio padrão e coeficiente de variação para as leituras realizadas, tais resultados estão apresentados na TAB. 13.

TABELA 10 - Valores médios do tempo de retenção do corante VN (minutos), desvio padrão (DP) e coeficiente de variação $(\mathrm{CV})$ para as leituras do $2^{\circ}$ ensaio de citotoxicidade

\begin{tabular}{cccc|ccc|ccc}
\hline & & $\mathbf{2 4 h}$ & \multicolumn{3}{c|}{$\mathbf{4 8 h}$} & \multicolumn{3}{c}{$\mathbf{7 2 h}$} \\
(mg L $^{-1}$ ) & Média & D P & $\mathbf{C ~ V ( \% )}$ & Média & D P & $\mathbf{C ~ V ( \% ) ~}$ & Média & D P & C V(\%) \\
\hline Controle & 69,0 & 8,2 & 11,9 & 63,0 & 6,7 & 10,6 & 63,0 & 6,7 & 10,6 \\
Solvente & 63,0 & 6,7 & 10,6 & 66,0 & 8,2 & 12,4 & 66,0 & 8,2 & 12,4 \\
0,001 & 39,0 & 8,2 & 21,0 & 42,0 & 6,7 & 15,9 & 27,0 & 12,5 & 46,4 \\
0,02 & 27,0 & 6,7 & 24,8 & 33,0 & 6,7 & 20,3 & 15,0 & 0,0 & 0,0 \\
0,5 & 6,0 & 8,2 & 136,9 & 6,0 & 8,2 & 136,9 & 6,0 & 8,2 & 136,9 \\
\hline
\end{tabular}

A partir desses resultados foram testadas concentrações mais baixas no terceiro ensaio preliminar $\left(0,0001 \mathrm{mg} \mathrm{L}^{-1}, 0,001 \mathrm{mg} \mathrm{L}^{-1}\right.$ e $\left.0,02 \mathrm{mg} \mathrm{L}^{-1}\right)$.

Os controles foram comparados pelo teste $t$ de Student e não apresentaram diferença significativa.

Nos tempos de 24 e $48 \mathrm{~h}$ as concentrações de 0,001 e $0,02 \mathrm{mg} \mathrm{L}^{-1}$ apresentaram diferença significativa em relação ao controle, e em $72 \mathrm{~h}$ todas as concentrações apresentaram efeito.

Os resultados do tempo de retenção do corante em função das concentrações são apresentados na FIG. 26. 


\section{Ensaio Preliminar DEET III}

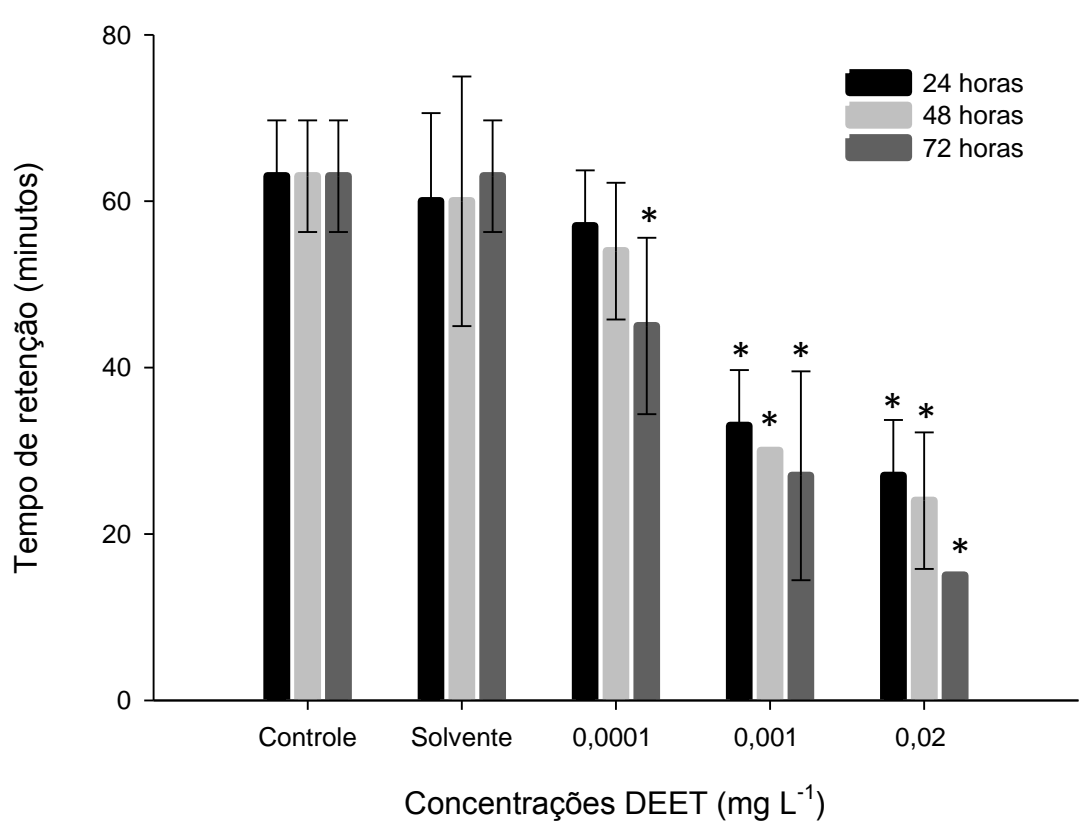

FIGURA 26 - Representação gráfica do tempo de retenção do corante VN em função das concentrações de DEET para o mexilhão Perna perna

$\left({ }^{*}\right)$ Diferença significativa em relação ao controle

Os valores médios do tempo de retenção do corante $\mathrm{VN}$, desvio padrão e coeficiente de variação para este ensaio estão na TAB. 14.

TABELA 14 - Valores médios do tempo de retenção do corante VN (minutos), desvio padrão (DP) e coeficiente de variação (CV) para as leituras do 3 ํㅡㄹ ensio de citotoxicidade

\begin{tabular}{cccc|ccc|ccc}
\hline & \multicolumn{3}{c}{$\mathbf{2 4 h}$} & \multicolumn{3}{|c|}{$\mathbf{4 8 h}$} & \multicolumn{3}{c}{$\mathbf{7 2 h}$} \\
(mg L $^{-1}$ ) & Média & D P & $\mathbf{C ~ V ( \% )}$ & Média & D P & $\mathbf{C ~ V ( \% ) ~}$ & Média & D P & $\mathbf{C ~ V ( \% ) ~}$ \\
\hline Controle & 63,0 & 6,7 & 10,6 & 63,0 & 6,7 & 10,6 & 63,0 & 6,7 & 10,6 \\
Solvente & 60,0 & 10,6 & 17,6 & 60,0 & 15,0 & 25,0 & 63,0 & 6,7 & 10,6 \\
0,0001 & 57,0 & 6,7 & 11,7 & 54,0 & 8,2 & 15,2 & 45,0 & 10,6 & 23,5 \\
0,001 & 33,0 & 6,7 & 20,3 & 30,0 & 0,0 & 0,0 & 27,0 & 12,5 & 46,4 \\
0,02 & 27,0 & 6,7 & 24,8 & 24,0 & 8,2 & 34,2 & 15,0 & 0,0 & 0,0 \\
\hline
\end{tabular}

Para tanto foram realizados outros dois ensaios (FIG. 26) com as mesmas concentrações $\left(0,0001 \mathrm{mg} \mathrm{L}^{-1}, 0,001 \mathrm{mg} \mathrm{L}^{-1}\right.$ e $\left.0,02 \mathrm{mg} \mathrm{L}^{-1}\right)$, onde observou-se diferença significativa em todas as concentrações testadas em um dos ensaios 
FIG. 27 (a), e no outro, diferença significativa apenas nas duas concentrações mais altas $\left(0,02 \mathrm{mg} \mathrm{L}^{-1}\right.$ e $\left.0,001 \mathrm{mg} \mathrm{L}^{-1}\right)$ FIG. 27 (b).

Ensaio Preliminar DEET IV

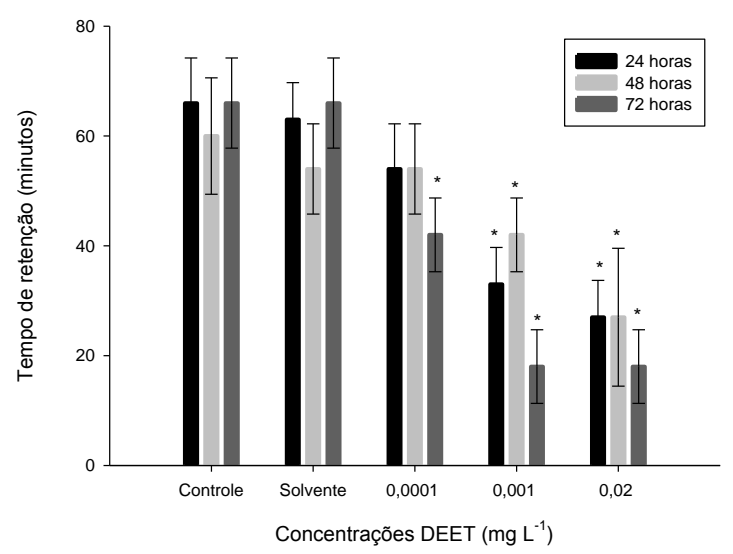

Ensaio Preliminar DEET V

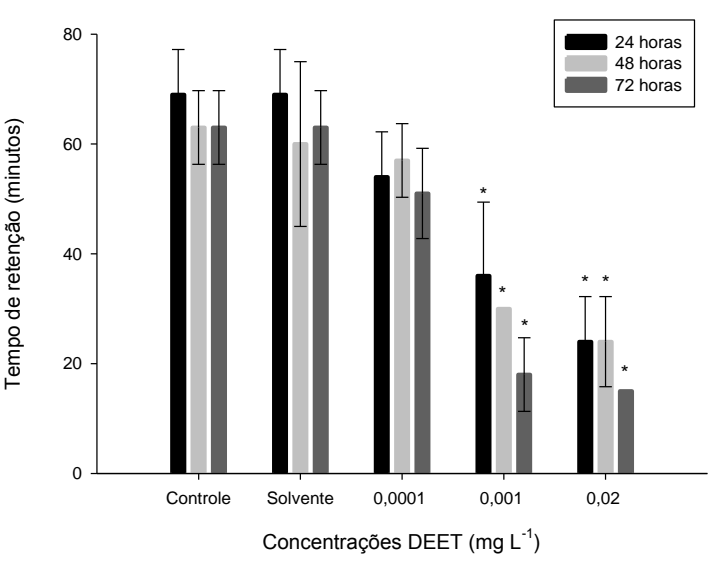

FIGURA 27 - $(a, b)$ Representação gráfica do tempo de retenção do corante VN em função das concentrações de DEET para o mexilhão Perna perna

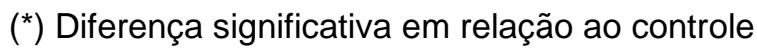

Os valores médios do tempo de retenção do corante VN, desvio padrão e coeficiente de variação dos ensaios representados pelas FIG. 27a e 27b, estão apresentados na TAB. 15 e 16.

TABELA 11 - Valores médios do tempo de retenção do corante VN (minutos), desvio padrão (DP) e coeficiente de variação (CV) para as leituras do $4^{\circ}$ ensaio de citotoxicidade

\begin{tabular}{cccc|ccc|ccc}
\hline & \multicolumn{3}{c}{$\mathbf{2 4 h}$} & \multicolumn{3}{|c|}{$\mathbf{4 8 h}$} & \multicolumn{3}{c}{$\mathbf{7 2 h}$} \\
(mg L $^{-1}$ ) & Média & D P & $\mathbf{C ~ V ( \% )}$ & Média & D P & $\mathbf{C ~ V ( \% ) ~}$ & Média & D P & C V(\%) \\
\hline Controle & 66,0 & 8,2 & 12,4 & 60,0 & 10,6 & 17,6 & 66,0 & 8,2 & 12,4 \\
Solvente & 63,0 & 6,7 & 10,6 & 54,0 & 8,2 & 15,2 & 66,0 & 8,2 & 12,4 \\
0,0001 & 54,0 & 8,2 & 15,2 & 54,0 & 8,2 & 15,2 & 42,0 & 6,7 & 15,9 \\
0,001 & 33,0 & 6,7 & 20,3 & 42,0 & 6,7 & 15,9 & 18,0 & 6,7 & 37,2 \\
0,02 & 27,0 & 6,7 & 24,8 & 27,0 & 12,5 & 46,4 & 18,0 & 6,7 & 37,2 \\
\hline
\end{tabular}


TABELA 12 - Valores médios do tempo de retenção do corante VN (minutos), desvio padrão (DP) e coeficiente de variação $(\mathrm{CV})$ para as leituras do $5^{\circ}$ ensaio de citotoxicidade

\begin{tabular}{|c|c|c|c|c|c|c|c|c|c|}
\hline \multirow[b]{2}{*}{$\left(\mathrm{mg} \mathrm{L}^{-1}\right)$} & \multicolumn{3}{|c|}{$24 \mathrm{~h}$} & \multicolumn{3}{|c|}{$48 \mathrm{~h}$} & \multicolumn{3}{|c|}{$72 \mathrm{~h}$} \\
\hline & Média & D P & C V(\%) & Média & D P & C V(\%) & Média & D P & C V $(\%)$ \\
\hline Controle & 69,0 & 8,2 & 11,9 & 63,0 & 6,7 & 10,6 & 63,0 & 6,7 & 10,6 \\
\hline Solvente & 69,0 & 8,2 & 11,9 & 60,0 & 15,0 & 25,0 & 63,0 & 6,7 & 10,6 \\
\hline 0,0001 & 54,0 & 8,2 & 15,2 & 57,0 & 6,7 & 11,7 & 51,0 & 8,2 & 16,1 \\
\hline 0,001 & 36,0 & 13,4 & 37,2 & 30,0 & 0,0 & 0,0 & 18,0 & 6,7 & 37,2 \\
\hline 0,02 & 24,0 & 8,2 & 34,2 & 24,0 & 8,2 & 34,2 & 15,0 & 0,0 & 0,0 \\
\hline
\end{tabular}

Um estudo realizado por Barber e colaboradores (2013) identificou os 25 compostos orgânicos mais detectados em estações de tratamento de efluentes em algumas localidades norte-americanas no verão e primavera de 2005, dentre os compostos mais encontrados estava o DEET na concentração ambiental média de $0,33 \mu \mathrm{g} \mathrm{L}^{-1}$ em efluentes residuais, e na concentração ambiental média de $0,19 \mu \mathrm{g} \mathrm{L}^{-1}$ nas proximidades das estações de tratamento.

Estes valores foram encontrados a partir de extração continua liquidoliquido de compostos orgânicos neutros. Para os compostos encontrados foi calculado o quociente de perigo (Hazard Quotient), que é o valor estimado do contaminante capaz de causar um risco ambiental potencial.

Para o DEET o valor do quociente em efluente foi de $0,00064 \mu \mathrm{g} \mathrm{L}^{-1}$ e em rio $0,00037 \mu \mathrm{g} \mathrm{L}^{-1}$, esse quociente de perigo $(\mathrm{HQ})$ é calculado a partir da concentração ambiental média pelo valor da concentração letal $50 \%$.

Quando o valor do $\mathrm{HQ}$ é $<1\left(\mu \mathrm{g} \mathrm{L}^{-1}\right)$ considera-se que o composto apresenta baixo risco potencial.

As concentrações testadas nos ensaios de citotoxicidade que apresentaram efeito para 0 mexilhão Perna perna estão na mesma faixa das concentrações ambientais encontradas no estudo realizado por Barber (2013), o que configura a necessidade de se avaliar a toxicidade em concentrações mais baixas, na ordem de $\mu \mathrm{g}$ e $\mathrm{ng} \mathrm{L}^{-1}$ a fim de se manter uma boa qualidade da água e proteger a biota aquática de substâncias com potencial tóxico. 


\subsubsection{Ensaios definitivos de citotoxicidade do DEET em organismos não irradiados}

Para definir as concentrações do DEET passíveis de causar efeito citotóxico no molusco bivalve Perna perna foram realizados ensaios definitivos em triplicata, com maior número de organismos $(n=15)$ utilizando as mesmas concentrações testadas nos últimos ensaios preliminares $\left(0,0001 \mathrm{mg} \mathrm{L}^{-1}, 0,001\right.$ $\mathrm{mg} \mathrm{L}^{-1}$ e 0,02 mg L $\mathrm{L}^{-1}$ ) para os tempos de exposição de 24, 48 e 72h (FIG. 28, 29 e 30).

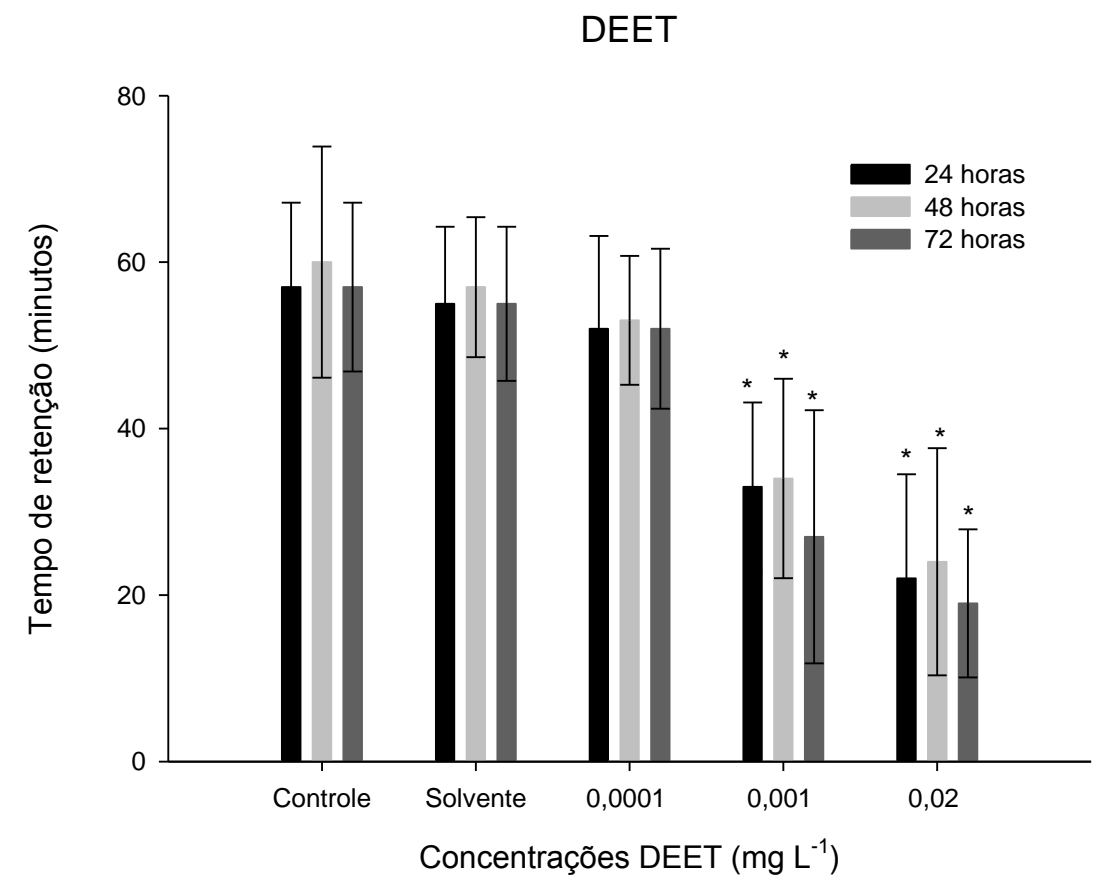

FIGURA 28 - Toxicidade do DEET em hemócitos do molusco bivalve Perna perna (Ensaio I)

$\left(^{*}\right)$ Diferença significativa em relação ao controle

Observou-se efeito na concentrações de 0,001 e 0,02 $\mathrm{mg} \mathrm{L}^{-1}$ para todos os tempos de exposição (24, 48 e $72 \mathrm{~h})$. Nesse ensaio a CENO foi de $0,0001 \mathrm{mg} \mathrm{L}^{-1} \mathrm{e}$ a CEO $0,001 \mathrm{mg} \mathrm{L}^{-1}$.

Os valores médios do tempo de retenção do corante VN (minutos), desvios padrão e coeficiente de variação de cada leitura realizada estão apresentados na tabela abaixo (TAB. 17) 
TABELA 13 - Valores médios do tempo de retenção do corante VN (minutos), desvio padrão (DP) e coeficiente de variação (CV)

\begin{tabular}{cccc|ccc|ccc}
\hline & \multicolumn{3}{c}{$\mathbf{2 4 h}$} & \multicolumn{3}{c|}{$\mathbf{4 8 h}$} & \multicolumn{3}{c}{$\mathbf{7 2 h}$} \\
(mg L $^{-1}$ ) & Média & D P & $\mathbf{C ~ V ( \% )}$ & Média & D P & C V(\%) & Média & D P & C V(\%) \\
\hline Controle & 66,0 & 7,6 & 11,5 & 62,0 & 7,7 & 12,5 & 54,0 & 7,6 & 14,1 \\
Solvente & 64,0 & 8,9 & 13,9 & 60,0 & 11,3 & 18,9 & 50,0 & 7,3 & 14,6 \\
0,0001 & 58,0 & 11,2 & 19,2 & 56,0 & 8,9 & 15,9 & 49,0 & 6,8 & 14,0 \\
0,001 & 36,0 & 9,5 & 26,3 & 38,0 & 7,7 & 20,4 & 24,0 & 11,1 & 46,0 \\
0,02 & 26,0 & 6,8 & 26,4 & 28,0 & 9,6 & 34,3 & 18,0 & 8,4 & 46,7 \\
\hline
\end{tabular}

No segundo ensaio definitivo (FIG. 29) as concentrações mais altas (0,02 e $0,001 \mathrm{mg} \mathrm{L}^{-1}$ ) apresentaram diferença significativa em relação aos controles, sendo portanto a CENO 0,0001 $\mathrm{mg} \mathrm{L}^{-1}$ e a CEO 0,001 $\mathrm{mg} \mathrm{L}^{-1}$.

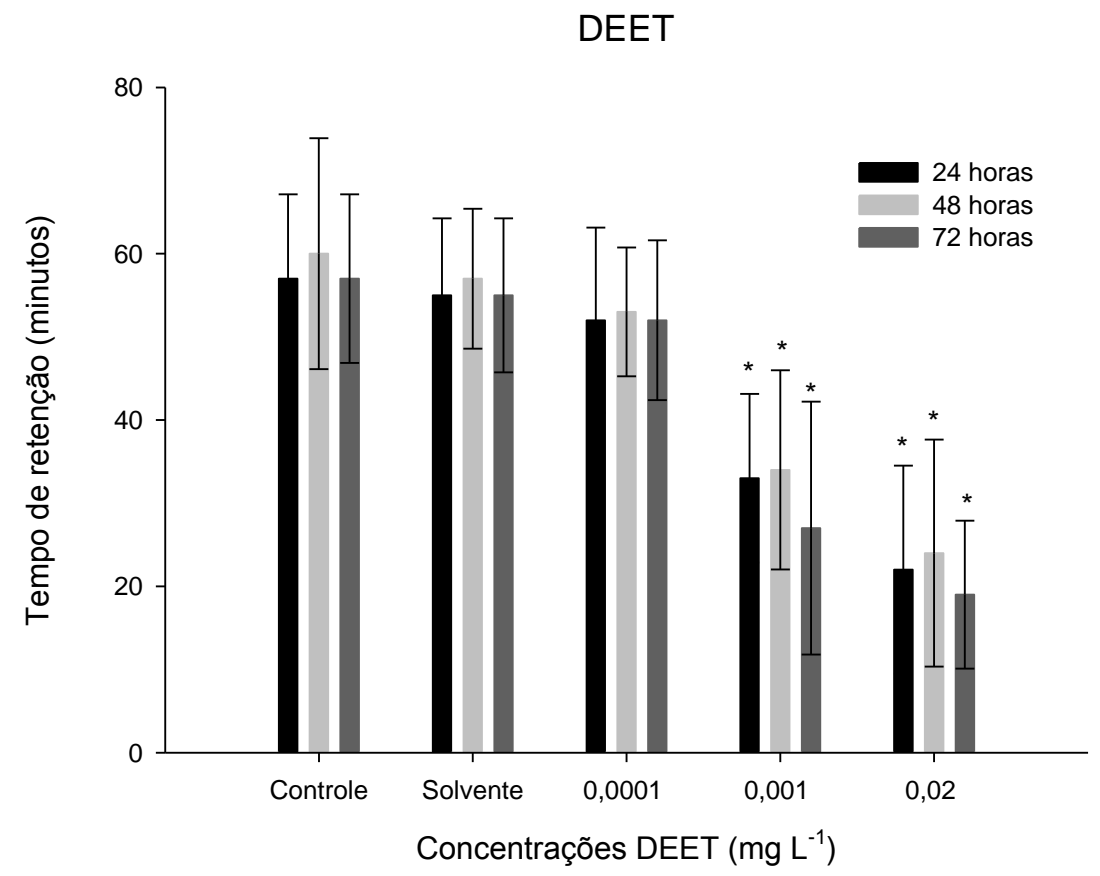

FIGURA 29 - Toxicidade do DEET em hemócitos do molusco bivalve Perna perna (Ensaio II)

(*) Diferença significativa em relação ao controle

Os valores médios do tempo de retenção do corante VN (minutos), desvios padrão e coeficientes de variação de acordo com as leituras realizadas são apresentados na tabela abaixo (TAB. 18) 
TABELA 14 - Valores médios do tempo de retenção do corante VN (minutos), desvio padrão (DP) e coeficiente de variação (CV)

\begin{tabular}{|c|c|c|c|c|c|c|c|c|c|}
\hline \multirow[b]{2}{*}{$\left(\mathrm{mg} \mathrm{L}^{-1}\right)$} & \multicolumn{3}{|c|}{$24 \mathrm{~h}$} & \multicolumn{3}{|c|}{$48 \mathrm{~h}$} & \multicolumn{3}{|c|}{$72 \mathrm{~h}$} \\
\hline & Média & D P & C V(\%) & Média & D P & C V(\%) & Média & D P & C V(\%) \\
\hline Controle & 60,0 & 17,9 & 29,8 & 60,0 & 13,8 & 23,1 & 57,0 & 10,1 & 17,7 \\
\hline Solvente & 58,0 & 16,8 & 29,1 & 57,0 & 8,4 & 14,7 & 55,0 & 9,2 & 16,8 \\
\hline 0,0001 & 52,0 & 11,2 & 21,4 & 53,0 & 7,7 & 14,6 & 52,0 & 9,5 & 18,4 \\
\hline 0,001 & 33,0 & 10,1 & 30,7 & 34,0 & 11,9 & 35,2 & 27,0 & 15,2 & 56,3 \\
\hline 0,02 & 22,0 & 12,5 & 56,8 & 24,0 & 13,6 & 56,8 & 19,0 & 8,9 & 46,8 \\
\hline
\end{tabular}

No último ensaio de citotoxicidade de DEET com organismos não irradiados a CENO foi de $0,0001 \mathrm{mg} \mathrm{L}^{-1}$ e a CEO de $0,001 \mathrm{mg} \mathrm{L}^{-1}$. Os dados estão apresentados na figura abaixo (FIG. 30) e os valores médios do tempo de retenção do corante $\mathrm{VN}$, desvios padrão e coeficientes de variação para este ensaio estão na TAB. 19.

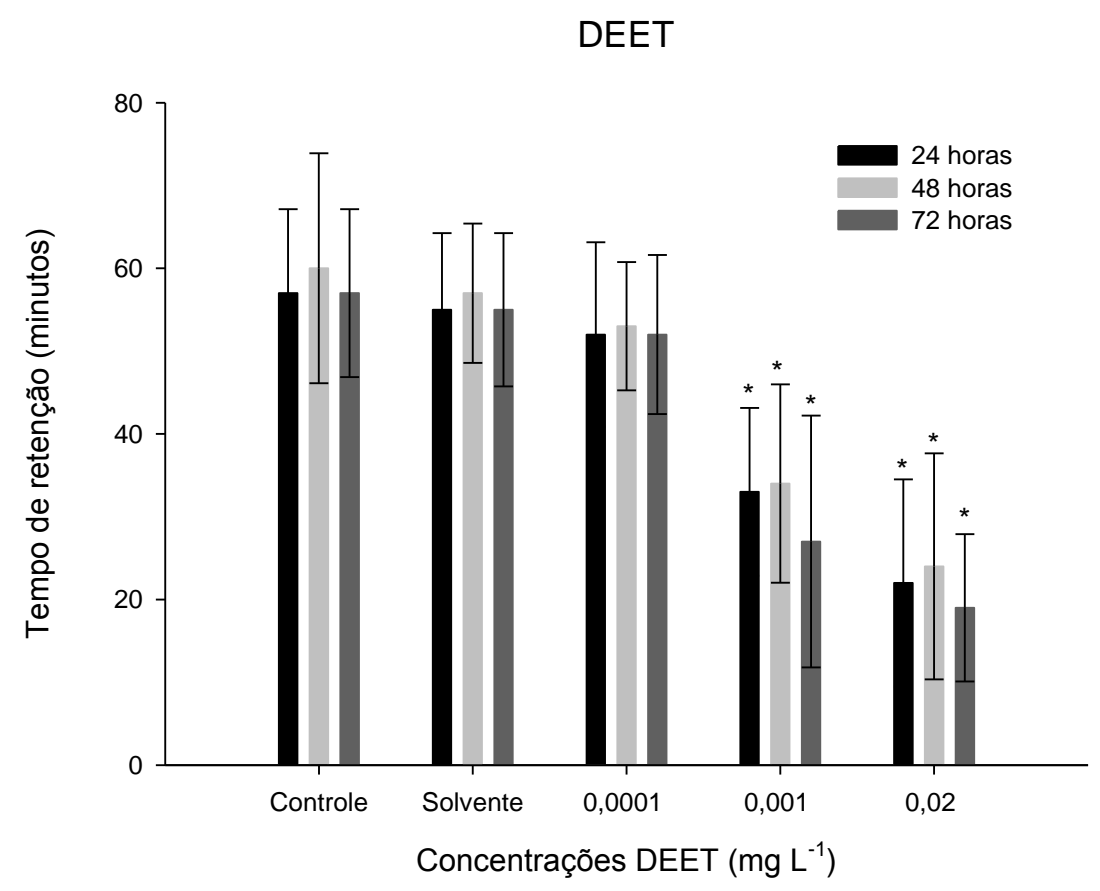

FIGURA 30 - Toxicidade do DEET em hemócitos do molusco bivalve Perna perna (Ensaio III)

$\left(^{\star}\right)$ Diferença significativa em relação ao controle 
TABELA 15 - Valores médios do tempo de retenção do corante VN (minutos), desvio padrão (DP) e coeficiente de variação (CV)

\begin{tabular}{|c|c|c|c|c|c|c|c|c|c|}
\hline \multirow[b]{2}{*}{$\left(\mathrm{mg} \mathrm{L}^{-1}\right)$} & \multicolumn{3}{|c|}{$24 \mathrm{~h}$} & \multicolumn{3}{|c|}{$48 \mathrm{~h}$} & \multicolumn{3}{|c|}{$72 \mathrm{~h}$} \\
\hline & Média & D P & C V(\%) & Média & D P & C V(\%) & Média & D P & C V(\%) \\
\hline Controle & 59,0 & 11,9 & 20,3 & 62,0 & 11,1 & 17,9 & 58,0 & 11,1 & 19,2 \\
\hline Solvente & 60,0 & 13,8 & 23,1 & 61,0 & 11,9 & 19,6 & 55,0 & 9,2 & 16,8 \\
\hline 0,0001 & 54,0 & 7,6 & 14,1 & 53,0 & 7,7 & 14,6 & 49,0 & 8,9 & 18,1 \\
\hline 0,001 & 34,0 & 18,3 & 53,9 & 32,0 & 15,9 & 49,6 & 24,0 & 7,6 & 31,7 \\
\hline 0,02 & 21,0 & 18,6 & 88,7 & 25,0 & 13,5 & 53,9 & 17,0 & 11,1 & 65,6 \\
\hline
\end{tabular}

Para complementar a avaliação da citotoxicidade foi calculada a $\mathrm{Cl} 25$ e Cl50 nos ensaios definitivos. Os resultados com as médias, intervalos de confiança, desvios padrão e coeficientes de variação de todos os ensaios estão apresentados nas TAB. 20, 21 e 22 de acordo com as leituras realizadas (24, 48 e $72 \mathrm{~h})$ para os valores da $\mathrm{Cl} 25$.

TABELA 20 - Valores calculados para a Cl25(24h)

\begin{tabular}{ccc}
\hline Ensaio & $\begin{array}{c}\mathbf{C l 2 5}(24) \\
\left(\mathbf{m g ~ L}^{-1}\right)\end{array}$ & $\begin{array}{c}\text { Intervalo de confiança } \\
\left(\mathbf{m g ~ L}^{-1}\right)\end{array}$ \\
\hline 1 & 0,0004 & $(0,0002-0,0006)$ \\
2 & 0,0005 & $(0,0002-0,0008)$ \\
3 & 0,0005 & $(0,0002-0,0008)$ \\
Média & 0,0005 & \\
Desvio padrão & 0,00 & \\
Coeficiente variação (\%) & 12 & \\
\hline
\end{tabular}

TABELA 16 - Valores calculados para a $\mathrm{Cl} 25_{(48 \mathrm{~h})}$

\begin{tabular}{ccc}
\hline Ensaio & $\begin{array}{c}\mathbf{C l 2 5}(\mathbf{4 8}) \\
\left(\mathbf{m g ~ L}^{-1}\right)\end{array}$ & $\begin{array}{c}\text { Intervalo de confiança } \\
\left(\mathbf{m g ~ L}^{-1}\right)\end{array}$ \\
\hline 1 & 0,0005 & $(0,0003-0,0007)$ \\
2 & 0,0004 & $(0,0002-0,0007)$ \\
3 & 0,0003 & $(0,0002-0,0006)$ \\
Média & 0,0004 & \\
$\begin{array}{c}\text { Desvio padrão } \\
\text { Coeficiente de variação } \\
(\%)\end{array}$ & 0,0001 & \\
\hline
\end{tabular}


TABELA 17 - Valores calculados para a $\mathrm{Cl} 25_{(72 h)}$

\begin{tabular}{ccc}
\hline Ensaio & $\begin{array}{c}\mathrm{Cl}^{25}(\mathbf{7 2 )} \\
\left(\mathbf{m g ~ L}^{-1}\right)\end{array}$ & $\begin{array}{c}\text { Intervalo de } \\
\text { Confiança } \\
\left(\mathbf{m g ~ L}^{-1}\right)\end{array}$ \\
\hline 1 & 0,0004 & $(0,0002-0,0005)$ \\
2 & 0,0004 & $(0,0002-0,0005)$ \\
3 & 0,0002 & $(0,00009-0,00046)$ \\
Média & 0,0003 & \\
Desvio padrão & 0,0001 & \\
Coeficiente de variação $(\%)$ & 35 & \\
\hline
\end{tabular}

Os valores da $\mathrm{Cl} 50$ estão apresentados nas TAB. 23, 24 e 25 para as leituras de 24,48 e $72 \mathrm{~h}$, respectivamente.

TABELA 18 - Valores calculados para a $\mathrm{Cl}_{(24 \mathrm{~h})}$

\begin{tabular}{ccc}
\hline Ensaio & $\begin{array}{c}\mathbf{C l 5 0}_{(24)} \\
\left(\mathbf{m g ~ L}^{-1}\right)\end{array}$ & $\begin{array}{c}\text { Intervalo de } \\
\text { confiança } \\
\left(\mathbf{m g ~ L}^{-1}\right)\end{array}$ \\
\hline 1 & 0,0067 & $(0,0009-0,0110)$ \\
2 & 0,0087 & $(-)$ \\
3 & 0,0075 & $(-)$ \\
Média & 0,0076 & \\
Desvio padrão & 0,0010 & \\
Coeficiente de variação $(\%)$ & 13 & \\
\hline
\end{tabular}

TABELA 19 - Valores calculados para a $\mathrm{Cl}_{50}(48 \mathrm{~h})$

\begin{tabular}{ccc}
\hline Ensaio & $\begin{array}{c}\mathbf{C l 5 0}(48) \\
\left(\mathbf{m g ~ L}^{-1}\right)\end{array}$ & $\begin{array}{c}\text { Intervalo de } \\
\text { confiança } \\
\left(\mathbf{m g ~ L}^{-1}\right)\end{array}$ \\
\hline 1 & 0,0143 & $(-)$ \\
2 & 0,0086 & $(-)$ \\
3 & 0,0009 & $(-)$ \\
Média & 0,0079 & \\
Desvio padrão & 0,0067 & \\
Coeficiente de variação (\%) & 85 & \\
\hline
\end{tabular}


TABELA 20 - Valores calculados para a $\mathrm{Cl}^{5} 0_{(72 \mathrm{~h})}$

\begin{tabular}{ccc}
\hline Ensaio & $\begin{array}{c}\mathbf{C l 5 0}_{(72)} \\
\left(\mathbf{m g ~ L}^{-1}\right)\end{array}$ & $\begin{array}{c}\text { Intervalo de } \\
\text { confiança } \\
\left(\mathbf{m g ~ L}^{-1}\right)\end{array}$ \\
\hline 1 & 0,0008 & $(0,0007-0,0054)$ \\
2 & 0,0009 & $(0,0007-0,0096)$ \\
3 & 0,0008 & $(0,0006-0,0009)$ \\
Média & 0,0008 & \\
Desvio padrão & 0,0001 & \\
Coeficiente de variação (\%) & 7 & \\
\hline
\end{tabular}

Apesar do DEET ser o princípio ativo de repelentes de insetos mais utilizado em âmbito mundial, e estar nas formulações da maioria dos produtos com repelência disponíveis comercialmente, ainda são escassos os dados sobre seu comportamento no meio ambiente, e os processos de degradação do composto após tratamento de águas e efluentes.

Nos últimos anos, a contaminação de DEET tem sido amplamente divulgada, e o composto tem sido detectado em diversas matrizes ambientais aquáticas, incluindo rios, águas subterrâneas, oceano, águas residuais e até mesmo em água tratada por sistemas de tratamento de água convencionais (SANDSTROM, 2005; TAY, 2009; CALZA, 2011).

O DEET pode atingir o ambiente, principalmente por meio de águas residuais e é considerado persistente na hidrólise. Como resultado de seu uso extensivo, o DEET passou a ser classificado como um contaminante emergente, e sua remoção da água é de alta prioridade (ANTONOPOULOU, 2013).

Em um estudo de monitoramento de fármacos e contaminantes emergentes foi identificada a presença de DEET em estações de tratamento de águas residuais da Região Norte do Arizona e na llha de Pittsburg, a menor detecção foi de $23 \mathrm{ng} \mathrm{L}^{-1}$ e a maior de $3000 \mathrm{ng} \mathrm{L}^{-1}$ (WILSON et al., 2013).

Wilson (2013) detectou concentrações de DEET em amostras de água de superfície no rio Colorado na ordem de $\mathrm{ng} \mathrm{L}^{-1}$, a menor concentração detectada foi de 5,5 e a maior de 8,5. Na Baía de Thompson do Lago Havasu também identificou-se DEET com o menor valor detectado de 6,2 e o maior de $12 \mathrm{ng} \mathrm{L}^{-1}$ (WILSON, 2013). 
Também foram monitorados poços na estação de tratamento de águas na Região Norte do Arizona e um ponto na área urbanizada dentro da cidade, os poços possuem de $150-200 m$ de profundidade, e as concentrações de DEET

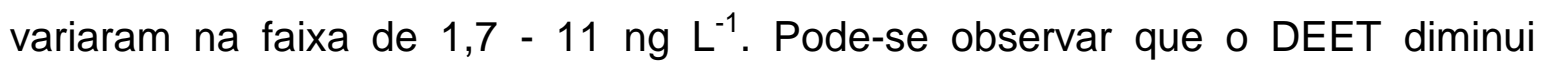
rapidamente em uma média de $700 \mathrm{ng} \mathrm{L^{-1 }}$ em um dos pontos da estação de tratamento para menos de $10 \mathrm{ng} \mathrm{L}^{-1}$ no monitoramento mais próximo (Wilson et al., 2013).

Outros estudos também identificaram a presença de DEET em outra matrizes ambientais, como o estudo realizado por Magnusson (2013), onde foram detectadas concentrações de DEET em sedimentos de rios e estuários de importância econômica ao longo da costa norte de Queensland na Austrália, no rio Herbert foram detectadas $2,7-3,7 \mu \mathrm{g} \mathrm{kg}^{-1}$ de DEET em sedimento e no rio Daintree 4,4 - 5,7 $\mu \mathrm{g} \mathrm{kg}{ }^{-1}$.

Um estudo realizado por Antonopoulou (2013) avaliou o mecanismo de degradação fotocatalítica do DEET em meio aquoso por uma bateria de técnicas analíticas, foram empregadas medições precisas para identificar inúmeros produtos de transformação e a estrutura dos diversos isômeros formados durante a degradação do composto.

A degradação do DEET ocorre através do ataque de radicais $\cdot \mathrm{OH}$, principalmente sobre o anel aromático para formar os radicais hidroxi-metil ciclohexadieno e posteriormente produtos de transformação mono e polihidroxilados, outras rotas de transformação procedem através da adição de radicais superóxidos e finalmente reações de abertura do anel (ANTONOPOULOU, 2013).

A avaliação da toxicidade foi avaliada pelo monitoramento das alterações na bioluminescência de Vibrio fischeri, em uma amostra inicial mostrou um valor de inibição de $20 \%$, depois de uma diminuição inicial para $13 \%$, a toxicidade aumentou e atingiu um máximo de $25 \%$ de inibição em 20 min., após esse tempo, a toxicidade diminuiu e atingiu menos de $5 \%$ em 60 minutos, o que demonstrou eficiência no tratamento fotocatalítico para alcançar a desintoxicação quase completa de amostras contendo DEET (ANTONOPOULOU, 2013).

Com diversos estudos identificando concentrações de DEET na ordem de $\mu \mathrm{g}$ e $\mathrm{ng} \mathrm{L}^{-1}$ em diversas matrizes mostram a importância de se avaliar a toxicidade desse composto em organismos não-alvos, os efeitos adversos causados sobre a 
biota e seu possível potencial de efeito sinérgico em combinação com outras substâncias. O presente estudo encontrou efeito citotóxico do DEET em concentrações acima de $0,1 \mu \mathrm{g} \mathrm{L}^{-1}$ um valor bem próximo das concentrações identificadas no meio ambiente, que evidencia a necessidade de mais estudos sobre a toxicidade, degradação e persistência desse composto no ambiente aquático e na biota.

\subsubsection{Ensaios preliminares de citotoxicidade do DEET em organismos irradiados}

Para a avaliação da citotoxicidade do DEET em organismos irradiados foram escolhidas três doses de radiação gama de ${ }^{60} \mathrm{Co}$ a partir da DL50, com o intuito de se verificar a possibilidade de haver efeitos adversos nos organismos, e a partir disso escolher a melhor dose para ser testada nos ensaios definitivos.

Como a DL50 $(72 h)$ foi de 1068 Gy foram definidas as doses: 3; 11 e 107 Gy para os ensaios de citotoxicidade utilizando as concentrações de $0,0001 \mathrm{mg} \mathrm{L}^{-1}$, $0,001 \mathrm{mg} \mathrm{L}^{-1}$ e $0,02 \mathrm{mg} \mathrm{L}^{-1}$ de DEET.

Na dose de 3 Gy (FIG. 31) observou-se que o tempo de retenção não foi significativamente diferente dos ensaios em que os organismos não foram irradiados, sugerindo que essa dose não tenha sido suficiente para promover algum dano passível de ser observado dentro do período em que o experimento foi realizado. 


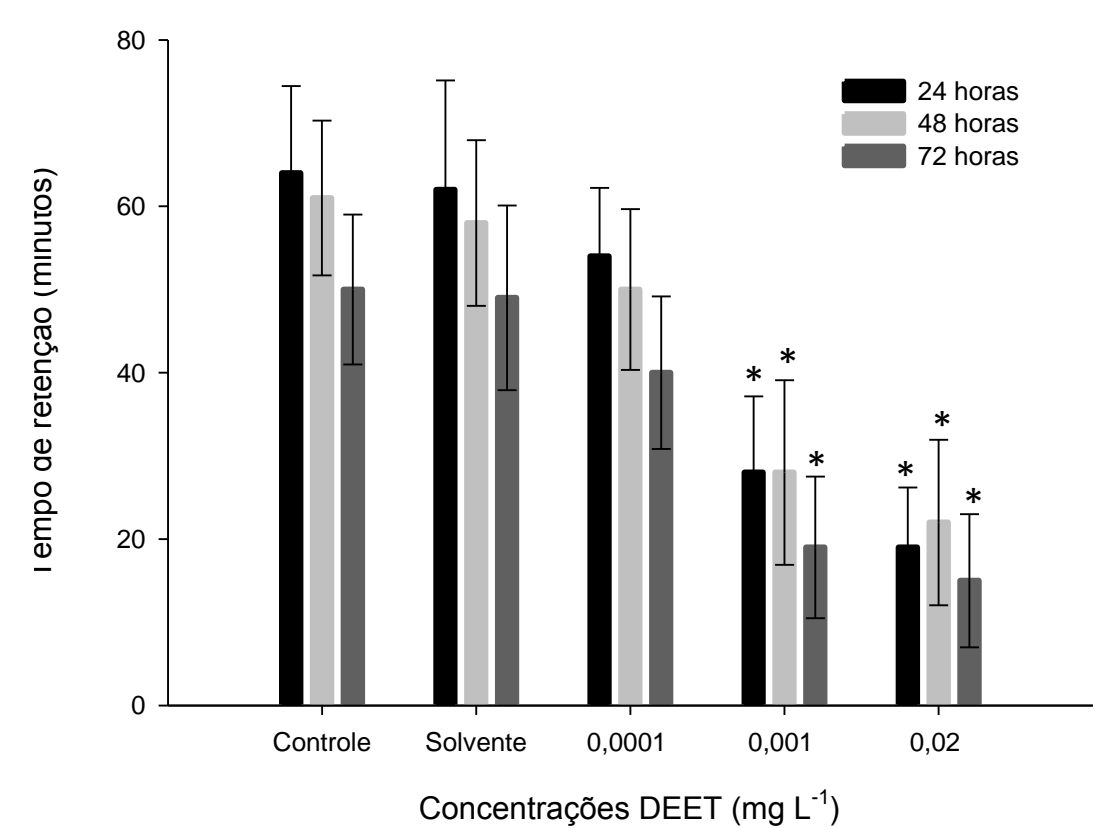

FIGURA 31 - Toxicidade do DEET em hemócitos de Perna perna irradiados (3Gy) (*) Diferença significativa em relação ao controle

Os valores do tempo de retenção do corante VN, desvio padrão e coeficiente de variação de cada leitura realizada no ensaio são apresentadas na TAB. 26.

TABELA 21 - Valores médios do tempo de retenção do corante VN (minutos), desvio padrão* e coeficiente de variação**

\begin{tabular}{|c|c|c|c|c|c|c|c|c|c|}
\hline \multirow[b]{2}{*}{$\left(\mathrm{mg} \mathrm{L}^{-1}\right)$} & \multicolumn{3}{|c|}{$24 h$} & \multicolumn{3}{|c|}{$48 h$} & \multicolumn{3}{|c|}{$72 h$} \\
\hline & Média & ${ }^{*} \mathrm{D} P$ & ${ }^{\star \star *}$ C V (\%) & Média & ${ }^{*} \mathrm{D} P$ & ${ }^{\star \star *} \mathrm{C}$ V (\%) & Média & ${ }^{*} \mathrm{D} P$ & ${ }^{* \star} \mathrm{C}$ V (\%) \\
\hline Controle & 64 & 10,457 & 16,339 & 61 & 9,307 & 15,257 & 50 & 9,012 & 18,025 \\
\hline Solvente & 62 & 13,127 & 21,173 & 58 & 9,954 & 17,163 & 49 & 11,105 & 22,663 \\
\hline 0,0001 & 54 & 8,215 & 15,214 & 50 & 9,660 & 19,321 & 40 & 9,158 & 22,895 \\
\hline 0,001 & 28 & 9,158 & 32,707 & 28 & 11,105 & 39,661 & 19 & 8,510 & 44,790 \\
\hline 0,02 & 19 & 7,210 & 37,951 & 22 & 9,949 & 45,224 & 15 & 8,007 & 53,384 \\
\hline
\end{tabular}

Quando os organismos foram irradiados a 11 Gy (FIG. 32), observou-se uma diminuição no tempo de retenção do corante vermelho neutro em todas as concentrações quando em comparação com os ensaios de organismos não irradiados. 
Pode-se sugerir que a radiação tenha uma ação potencial à toxicidade do composto. Para verificar essa possibilidade foram realizados ensaios definitivos utilizando a dose de 11 Gy, com maior número de organismos $(n=15)$.

\section{Ensaio Preliminar 11 Gy}

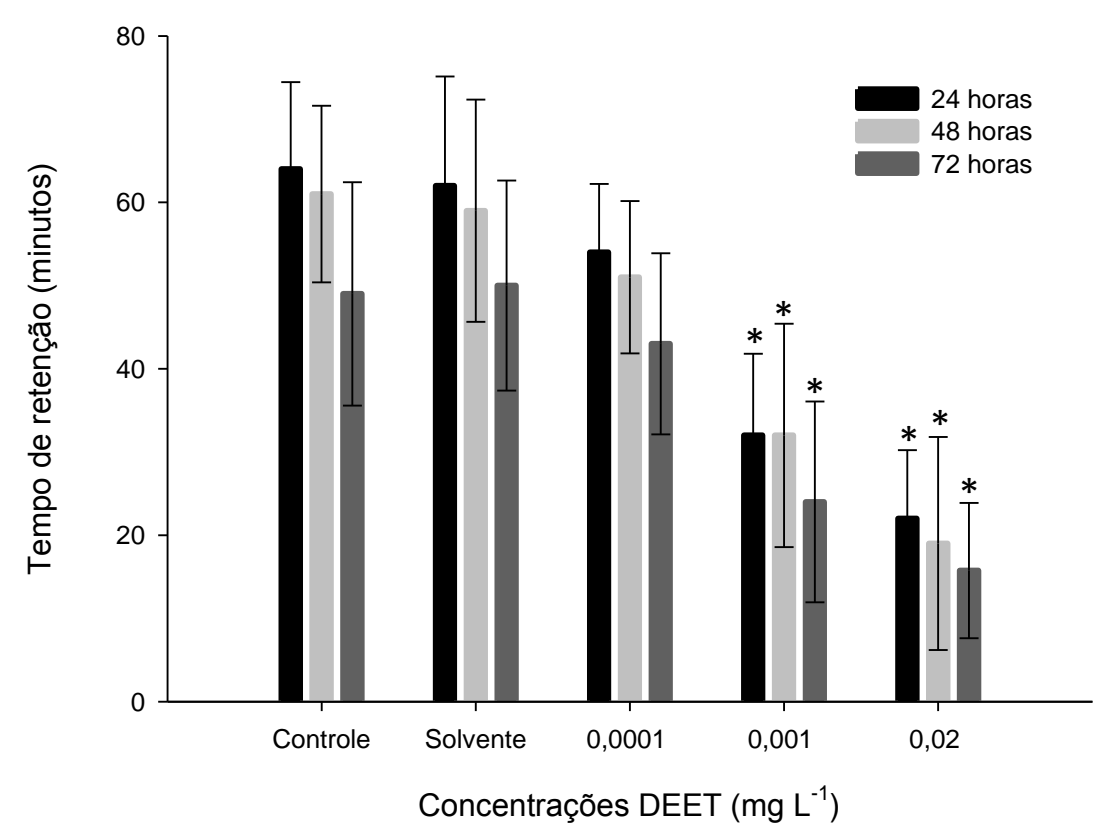

FIGURA 32 - Toxicidade do DEET em hemócitos de Perna perna irradiados (11 Gy)

${ }^{*}$ ) Diferença significativa em relação ao controle

Os valores médios do tempo de retenção do corante VN, desvio padrão (DP) e coeficiente de variação (CV) estão apresentados na TAB. 27.

TABELA 22 - Valores médios do tempo de retenção do corante VN, desvio padrão* e coeficiente de variação**

\begin{tabular}{|c|c|c|c|c|c|c|c|c|c|}
\hline \multirow[b]{2}{*}{$\left(\mathrm{mg} \mathrm{L}^{-1}\right)$} & \multicolumn{3}{|c|}{$24 \mathrm{~h}$} & \multicolumn{3}{|c|}{$48 \mathrm{~h}$} & \multicolumn{3}{|c|}{$72 \mathrm{~h}$} \\
\hline & Média & ${ }^{\star} \mathrm{D} P$ & ${ }^{\star \star}{ }^{*} \mathrm{C} \mathrm{V}(\%)$ & Média & ${ }^{\star} \mathrm{D} P$ & ${ }^{\star \star} \mathrm{C}$ V (\%) & Média & ${ }^{\star} \mathrm{D} P$ & ${ }^{\star \star \star} \mathrm{C} \mathrm{V} \mathrm{( \% )}$ \\
\hline Controle & 64 & 10,457 & 16,339 & 61 & 10,602 & 17,381 & 49 & 13,419 & 27,387 \\
\hline Solvente & 62 & 13,127 & 21,173 & 59 & 13,359 & 22,643 & 50 & 12,622 & 25,245 \\
\hline 0,0001 & 54 & 8,215 & 15,214 & 51 & 9,158 & 17,956 & 43 & 10,891 & 25,329 \\
\hline 0,001 & 32 & 9,809 & 30,655 & 32 & 13,419 & 41,936 & 24 & 12,070 & 50,292 \\
\hline 0,02 & 22 & 8,215 & 37,344 & 19 & 12,793 & 67,333 & 15,75 & 8,125 & 51,589 \\
\hline
\end{tabular}


A dose de 107 Gy (FIG. 33) causou efeito adverso aos organismos, podese observar uma redução significativa no número de células comparando-se com as outras doses testadas, além de ocorrer lise celular na maioria das lâminas analisadas (>80\%).

Também houve uma diminuição no tempo de retenção do corante em $48 \mathrm{~h}$ para as concentrações de 0,001 e $0,02 \mathrm{mg} \mathrm{L}^{-1}$ com aumento em $72 \mathrm{~h}$.

\section{Ensaio Preliminar 107 Gy}

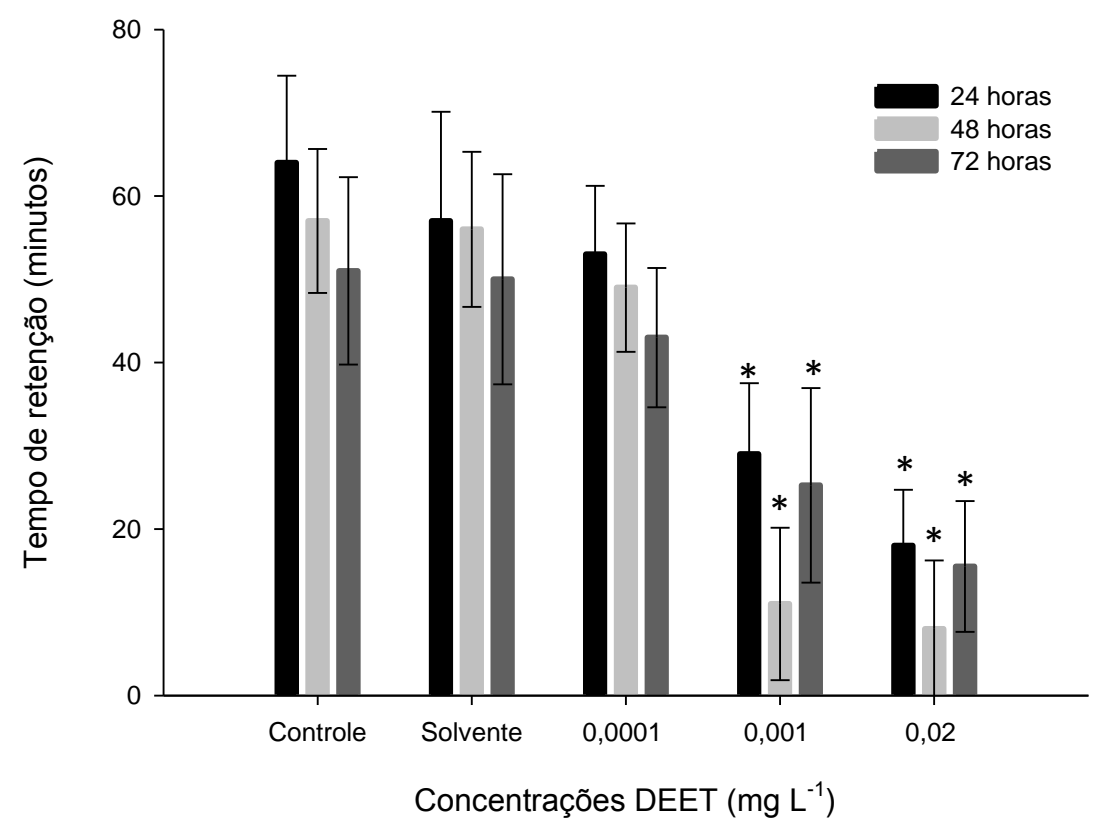

FIGURA 33 - Toxicidade do DEET em hemócitos de Perna perna irradiados

(107 Gy)

$\left(^{*}\right)$ Diferença significativa em relação ao controle

Os valores médios do tempo de retenção do corante $\mathrm{VN}$, desvios padrão (DP) e coeficientes de variação (CV) de cada leitura realizada estão apresentados na TAB. 28. 
TABELA 23 - Valores médios do tempo de retenção do corante VN, desvios padrão* e coeficientes de variação**

\begin{tabular}{|c|c|c|c|c|c|c|c|c|c|}
\hline \multirow[b]{2}{*}{$\left(\mathrm{mg} \mathrm{L}^{-1}\right)$} & \multicolumn{3}{|c|}{$24 \mathrm{~h}$} & \multicolumn{3}{|c|}{$48 \mathrm{~h}$} & \multicolumn{3}{|c|}{$72 \mathrm{~h}$} \\
\hline & Média & ${ }^{*} \mathbf{D} \mathbf{P}$ & ${ }^{* \star} \mathrm{C}$ V (\%) & Média & ${ }^{*} \mathbf{D} \mathbf{P}$ & ${ }^{\star \star *} \mathrm{C} \mathrm{V} \mathrm{( \% )}$ & Média & ${ }^{*} \mathbf{D} \mathbf{P}$ & ${ }^{* \star} \mathrm{C}$ V (\%) \\
\hline Controle & 64 & 10,457 & 16,339 & 57 & 8,655 & 15,184 & 51 & 11,254 & 22,067 \\
\hline Solvente & 57 & 13,127 & 23,030 & 56 & 9,307 & 16,619 & 50 & 12,622 & 25,245 \\
\hline 0,0001 & 53 & 8,215 & 15,501 & 49 & 7,713 & 15,741 & 43 & 8,366 & 19,457 \\
\hline 0,001 & 29 & 8,510 & 29,345 & 11 & 9,158 & 83,254 & 25,25 & 11,683 & 46,270 \\
\hline 0,02 & 18 & 6,708 & 37,267 & 8 & 8,215 & 102,697 & 15,5 & 7,861 & 50,718 \\
\hline
\end{tabular}

Os organismos que receberam 107 Gy de radiação gama de ${ }^{60} \mathrm{Co}$ tiveram um menor tempo de retenção do corante nos lisossomos de hemócitos, sugere-se que nesse caso a radiação cause um efeito de potencialização com o DEET, ou seja, que a toxicidade aumente quando os organismos são irradiados e expostos ao DEET.

Ocorreu mortalidade de organismos que foram irradiados e expostos à 0,001 e $0,02 \mathrm{mg} \mathrm{L}^{-1}$ de DEET, observou-se também uma intensa liberação de gametas nos organismos que receberam essa dose de radiação.

Sugerindo também que a radiação nessa dose, seguida de exposição ao DEET tenha causado alguma alteração no sistema fisiológico dos organismos, e os que não conseguiram se recuperar do efeito vieram a óbito.

Com os resultados desses ensaios preliminares definiu-se a dose de $11 \mathrm{~Gy}$ para os ensaios definitivos, pois foi uma dose que causou diminuição do tempo de retenção, mostrando que a radiação atua de alguma maneira sobre o metabolismo dos mexilhões, porém essa dose não foi passível de causa um efeito maior impedindo a realização do ensaio.

\subsubsection{Ensaios definitivos de citotoxicidade do DEET em organismos irradiados}

Foram realizados ensaios com organismos irradiados $(n=15)$ a 11 Gy e expostos às mesmas concentrações de DEET $\left(0,0001 ; 0,001 ; 0,02 \mathrm{mg} \mathrm{L}^{-1}\right)$ dos ensaios anteriores para avaliar a toxicidade do composto em organismos irradiados. 
Os resultados dos ensaios I, II e III estão apresentados nas FIG. 34, 35 e 36. Para todos os ensaios com organismos irradiados a CENO encontrada foi de $0,0001 \mathrm{mg} \mathrm{L}^{-1}$ e a CEO de $0,001 \mathrm{mg} \mathrm{L}^{-1}$.

\section{DEET com organismos irradiados}

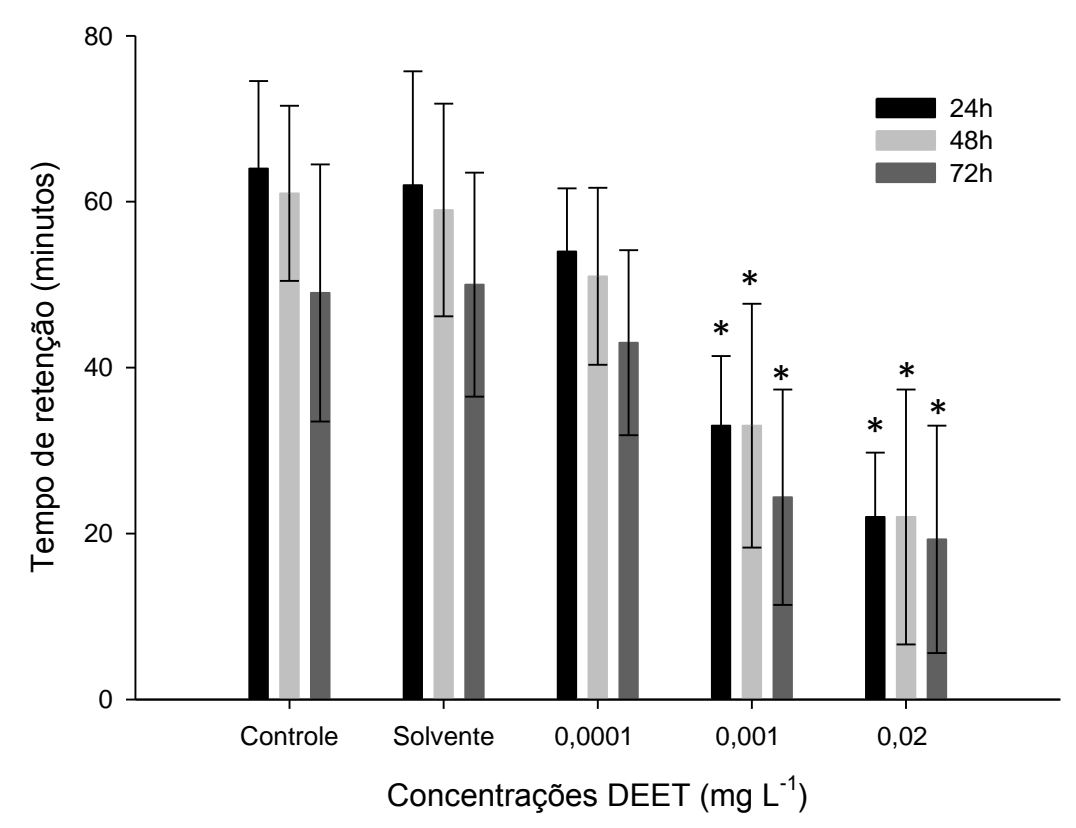

FIGURA 34 - Toxicidade do DEET em hemócitos de Perna perna irradiados (Ensaio I)

(*) Diferença significativa em relação ao controle

Os valores médios do tempo de retenção do corante VN, desvio padrão e coeficiente de variação de cada leitura realizada estão apresentados na tabela abaixo (TAB. 29)

TABELA 24 - Valores médios do tempo de retenção do corante VN, desvio padrão* e coeficiente de variação** em organismos irradiados com 11 Gy

\begin{tabular}{|c|c|c|c|c|c|c|c|c|c|}
\hline \multirow[b]{2}{*}{$\left(\mathrm{mg} \mathrm{L}^{-1}\right)$} & \multicolumn{3}{|c|}{$24 \mathrm{~h}$} & \multicolumn{3}{|c|}{$48 \mathrm{~h}$} & \multicolumn{3}{|c|}{$72 \mathrm{~h}$} \\
\hline & Média & ${ }^{*} \mathrm{D} P$ & ${ }^{\star \star} \mathrm{C} \vee(\%)$ & Média & ${ }^{*} \mathrm{D} P$ & ${ }^{\star \star *}$ C V (\%) & Média & ${ }^{*} \mathrm{DP}$ & ${ }^{* \star} \mathrm{C}$ V (\%) \\
\hline Controle & 64 & 10,556 & 16,493 & 61 & 10,556 & 17,304 & 49 & 15,491 & 31,616 \\
\hline Solvente & 62 & 13,732 & 22,148 & 59 & 12,806 & 21,705 & 50 & 13,496 & 26,992 \\
\hline 0,0001 & 54 & 7,606 & 14,085 & 51 & 10,667 & 20,915 & 43 & 11,148 & 25,926 \\
\hline 0,001 & 33 & 8,409 & 25,482 & 33 & 14,696 & 44,536 & 24,375 & 12,990 & 53,293 \\
\hline 0,02 & 22 & 7,746 & 35,209 & 22 & 15,362 & 69,828 & 19,285 & 13,708 & 71,079 \\
\hline
\end{tabular}


DEET com organismos irradiados

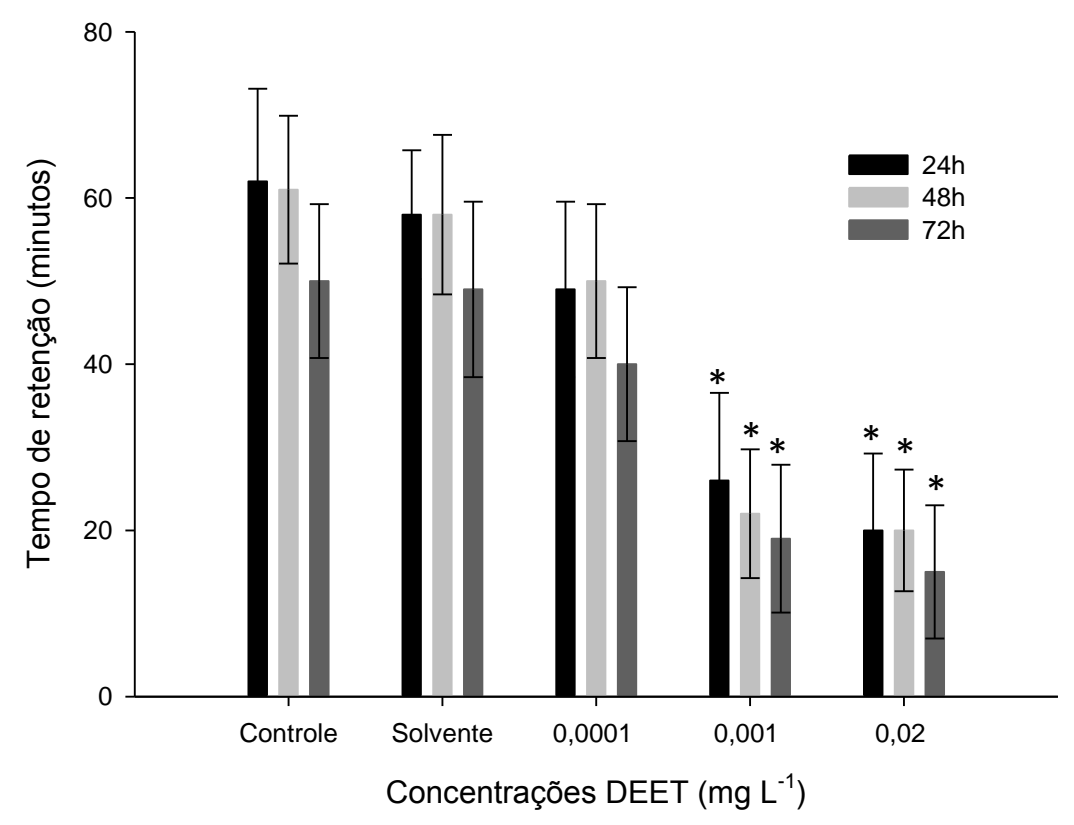

FIGURA 35 - Toxicidade do DEET em hemócitos de Perna perna irradiados (Ensaio II)

$\left(^{*}\right)$ Diferença significativa em relação ao controle

Os valores médios do tempo de retenção do corante $\mathrm{VN}$, desvio padrão e coeficiente de variação de cada leitura realizada estão apresentados na TAB. 30.

TABELA 25 - Valores da média, desvio padrão* e coeficiente de variação** em organismos irradiados com 11 Gy

\begin{tabular}{|c|c|c|c|c|c|c|c|c|c|}
\hline \multirow[b]{2}{*}{$\left(\mathrm{mg} \mathrm{L}^{-1}\right)$} & \multicolumn{3}{|c|}{$24 \mathrm{~h}$} & \multicolumn{3}{|c|}{$48 \mathrm{~h}$} & \multicolumn{3}{|c|}{$72 \mathrm{~h}$} \\
\hline & Média & ${ }^{*} \mathrm{DP}$ & ${ }^{\star \star \star} \mathrm{C} \mathrm{V}(\%)$ & Média & ${ }^{*} \mathrm{D} P$ & ${ }^{\star \star} \mathrm{C} \mathrm{V}(\%)$ & Média & ${ }^{*} \mathrm{D} P$ & ${ }^{\star \star} \mathrm{C} \mathrm{V}(\%)$ \\
\hline Controle & 62 & 11,148 & 17,981 & 61 & 8,904 & 14,597 & 50 & 9,258 & 18,516 \\
\hline Solvente & 58 & 7,746 & 13,355 & 58 & 9,599 & 16,550 & 49 & 10,556 & 21,542 \\
\hline 0,0001 & 49 & 10,556 & 21,542 & 50 & 9,258 & 18,516 & 40 & 9,258 & 23,145 \\
\hline 0,001 & 26 & 10,556 & 40,6 & 22 & 7,746 & 35,209 & 19 & 8,904 & 46,864 \\
\hline 0,02 & 20 & 9,258 & 46,291 & 20 & 7,319 & 36,596 & 15 & 8,017 & 53,452 \\
\hline
\end{tabular}


DEET com organismos irradiados

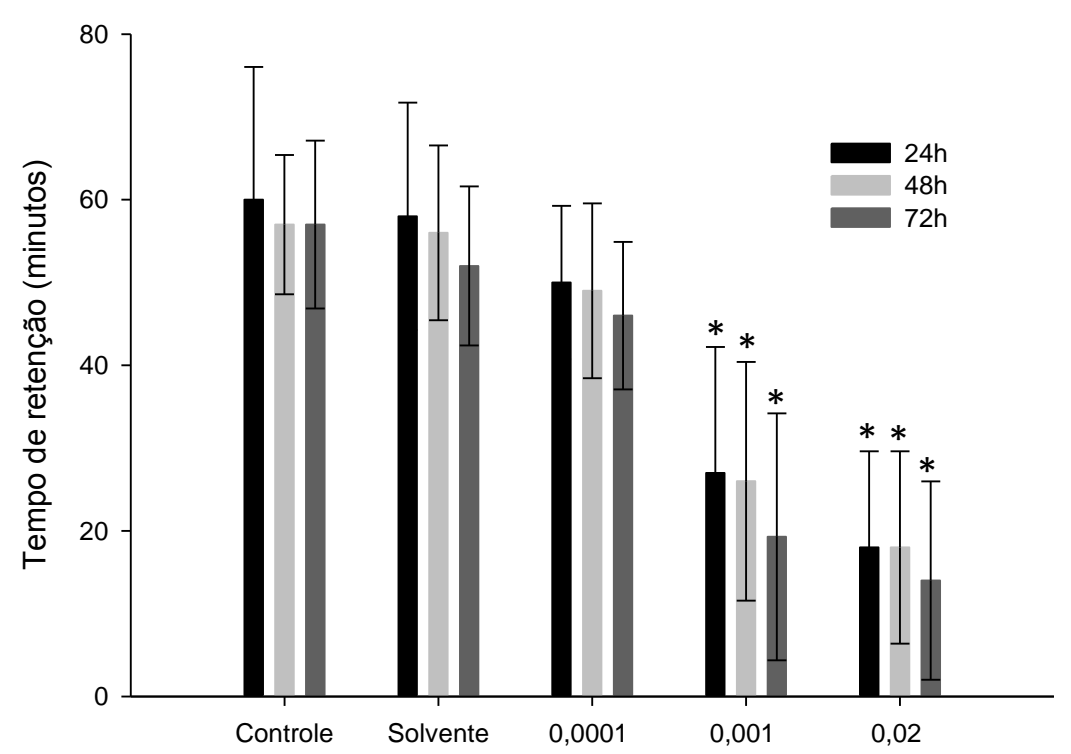

FIGURA 36 - Toxicidade do DEET em hemócitos de Perna perna irradiados (Ensaio III)

(*) Diferença significativa em relação ao controle

Os valores médios do tempo de retenção do corante VN, desvio padrão e coeficiente de variação de cada leitura realizada estão apresentados na TAB. 31.

TABELA 26 - Valores médios do tempo de retenção do corante VN, desvio padrão* e coeficiente de variação* em organismos irradiados com 11 Gy

\begin{tabular}{|c|c|c|c|c|c|c|c|c|c|}
\hline \multirow[b]{2}{*}{$\left(\mathrm{mg} \mathrm{L}^{-1}\right)$} & \multicolumn{3}{|c|}{$24 \mathrm{~h}$} & \multicolumn{3}{|c|}{$48 \mathrm{~h}$} & \multicolumn{3}{|c|}{$72 \mathrm{~h}$} \\
\hline & Média & ${ }^{*} \mathrm{D} P$ & ${ }^{\star \star} \mathrm{C}$ V(\%) & Média & ${ }^{*} \mathrm{D} P$ & ${ }^{\star \star} \mathrm{C} \mathrm{V}(\%)$ & Média & ${ }^{*} \mathrm{D} P$ & ${ }^{* \star} \mathrm{C} \mathrm{V}(\%)$ \\
\hline Controle & 60 & 16,035 & 26,726 & 57 & 8,409 & 14,752 & 57 & 10,141 & 17,792 \\
\hline Solvente & 58 & 13,732 & 23,676 & 56 & 10,556 & 18,85 & 52 & 9,599 & 18,459 \\
\hline 0,0001 & 50 & 9,258 & 18,516 & 49 & 10,556 & 21,542 & 46 & 8,904 & 19,356 \\
\hline 0,001 & 27 & 15,212 & 56,343 & 26 & 14,417 & 55,451 & 19,285 & 14,917 & 77,349 \\
\hline 0,02 & 18 & 11,619 & 64,55 & 18 & 11,619 & 64,55 & 14 & 11,982 & 85,586 \\
\hline
\end{tabular}

Para a avaliação da citotoxicidade do DEET em organismos irradiados calculou-se também a $\mathrm{Cl} 50$ nos ensaios definitivos. Os resultados com as médias, intervalos de confiança, desvios padrão e coeficientes de variação de todos os ensaios estão apresentados nas tabelas abaixo (TAB. 32, 33 e 34) de acordo com as leituras realizadas $(24,48$ e $72 \mathrm{~h}$ ) 
TABELA 27 - Valores calculados para a $\mathrm{Cl}_{(24 \mathrm{~h})}$ em organismos irradiados

\begin{tabular}{ccc}
\hline Ensaio & $\begin{array}{c}\mathbf{C l 5 0}_{(24)} \\
\left(\mathbf{m g ~ L}^{-1}\right)\end{array}$ & $\begin{array}{c}\text { Intervalo de } \\
\text { confiança } \\
\left(\mathbf{m g ~ L}^{-1}\right)\end{array}$ \\
\hline 1 & 0,0067 & $(0,0009-0,0110)$ \\
2 & 0,0087 & $(-)$ \\
3 & 0,0075 & $(-)$ \\
Média & 0,0076 & \\
Desvio padrão & 0,0010 & \\
Coeficiente de variação (\%) & 13,1875 & \\
\hline
\end{tabular}

TABELA 28 - Valores calculados para a $\mathrm{Cl}_{50}(48 \mathrm{~h})$ em organismos irradiados

\begin{tabular}{ccc}
\hline Ensaio & $\begin{array}{c}\mathbf{C l 5 0}_{(48)} \\
\left(\mathbf{m g ~ L}^{-1}\right)\end{array}$ & $\begin{array}{c}\text { Intervalo de } \\
\text { confiança } \\
\left(\mathbf{m g ~ L}^{-1}\right)\end{array}$ \\
\hline 1 & 0,0143 & $(-)$ \\
2 & 0,0086 & $(-)$ \\
3 & 0,0009 & $(-)$ \\
Média & 0,0079 & \\
Desvio padrão & 0,0067 & \\
Coeficiente de variação (\%) & 84,7668 & \\
\hline
\end{tabular}

TABELA 29 - Valores calculados para a $\mathrm{Cl}_{(72 h)}$ em organismos irradiados

\begin{tabular}{ccc}
\hline Ensaio & $\begin{array}{c}\mathbf{C l 5 0}_{(72)} \\
\left(\mathbf{m g ~ L}^{-1}\right)\end{array}$ & $\begin{array}{c}\text { Intervalo de } \\
\text { confiança } \\
\left(\mathbf{m g ~ L}^{-1}\right)\end{array}$ \\
\hline 1 & 0,0008 & $(0,0007-0,0054)$ \\
2 & 0,0009 & $(0,0007-0,0096)$ \\
3 & 0,0008 & $(0,0006-0,0009)$ \\
Média & 0,0008 & \\
Desvio padrão & 0,0001 & \\
Coeficiente de variação (\%) & 6,9282 & \\
\hline
\end{tabular}

Os efeitos biológicos de qualquer contaminante são geralmente dependentes da dose recebida. No caso da radiação ionizante, a dose está relacionada com a energia absorvida no corpo de organismos vivos (FISHER et al., 2013). 
Muitos invertebrados acumulam contaminantes, tais como radionuclídeos, geralmente por serem organismos de hábitos sésseis ou de pouca mobilidade, e filtradores. Eles são indicadores ideais pois podem se acumular radionuclídeos muitas vezes acima as concentrações na identificadas na água do mar (MATISHOV \& MATISHOV, 2004).

Recentes relatórios descreveram a presença de radionuclídeos liberados após o acidente na usina nuclear Fukushima Daiichi na biota do Pacífico, tal fato têm despertado preocupação e atenção em todo o mundo (BUESSELER, et al., 2012; MADIGAN, et al., 2012)

Foram identificadas doses de radiação na biota marinha aproximadamente duas ordens de magnitude acima do valor de referência para a proteção proposta para os ecossistemas $\left(10 \mu \mathrm{Gy} \mathrm{h}^{-1}\right)$ (FISHER et al., 2013).

Em atuns rabilho (Thunnus orientalis) que migraram do Japão para águas de Califórnia foi identificada a presença de ${ }^{134} \mathrm{Cs}$ e ${ }^{137} \mathrm{Cs}$ (MADIGAN, et al., 2012).

No presente estudo a radiação atuou como um fator estressante para os organismos, causando uma diminuição no tempo de retenção do corante vermelho neutro quando comparado com os organismos não irradiados, porém não suficiente para que houvesse um sinergismo entre o composto e a ação da radiação ionizante.

De acordo com Yamamoto (1994) ${ }^{210} \mathrm{Po}$ é um radionuclídeo que ocorre naturalmente da série do ${ }^{238} \mathrm{U}$, e tem meia-vida de 138,4 dias, é um emissor alfa e tende a alcançar suas maiores concentrações ambientais dentro de organismos marinhos.

Dada a constatação de que radionuclídeos artificiais da usina nuclear de Fukushima causaram danos fisiológicos e genéticos, para uma espécie de borboleta residente, e que os efeitos cumulativos de irradiação externa e interna poderiam ter resultado em detrimentos a nível de população, foram avaliada as doses de Fukushima derivadas na biota Marinha e comparadas aos níveis de referência de toxicidade reconhecidos (HIYAMA, et al. 2012).

Os estudos com organismos irradiados e posteriormente expostos à substâncias químicas são escassos, Gimiliani (2013) conduziu um estudo com 
microcrustáceos irradiados à 25 Gy de radiação gama de ${ }^{60} \mathrm{Co}$ e expostos ao DEET avaliando a taxa de reprodução, que diminuiu a partir de $15 \mathrm{mg} \mathrm{L}^{-1}$ do composto. Tais estudos são importantes para a verificação de possíveis interações entre diferentes substâncias, e sobre a toxicidade em organismos que estão sujeitos à receberem doses de radiação maiores que a radiação de "background".

\subsubsection{Exposição dos organismos à radiação ionizante}

Para verificar se houve diminuição no tempo de retenção do corante vermelho neutro em lisossomos de hemócitos do mexilhão Perna perna irradiados à 11 Gy e não expostos ao DEET foram realizados ensaios onde se comparou os tempos de retenção do corante em organismos irradiados e não irradiados por meio do Teste $t$ de Student.

Observou-se diferença significativa em relação ao controle para $\alpha=0,10$ e $\alpha=0,05$ em todas as leituras realizadas ( 24,48 e $72 \mathrm{~h}$ ) para todos os ensaios (I, II e III), exceto para em $72 \mathrm{~h}$ no ensaio I onde não se observou diferença significativa para $\alpha=0,01$. A FIG. 37 apresenta os resultados dos ensaios realizados.

$$
\text { Radiação Gama de }{ }^{60} \mathrm{Co}
$$

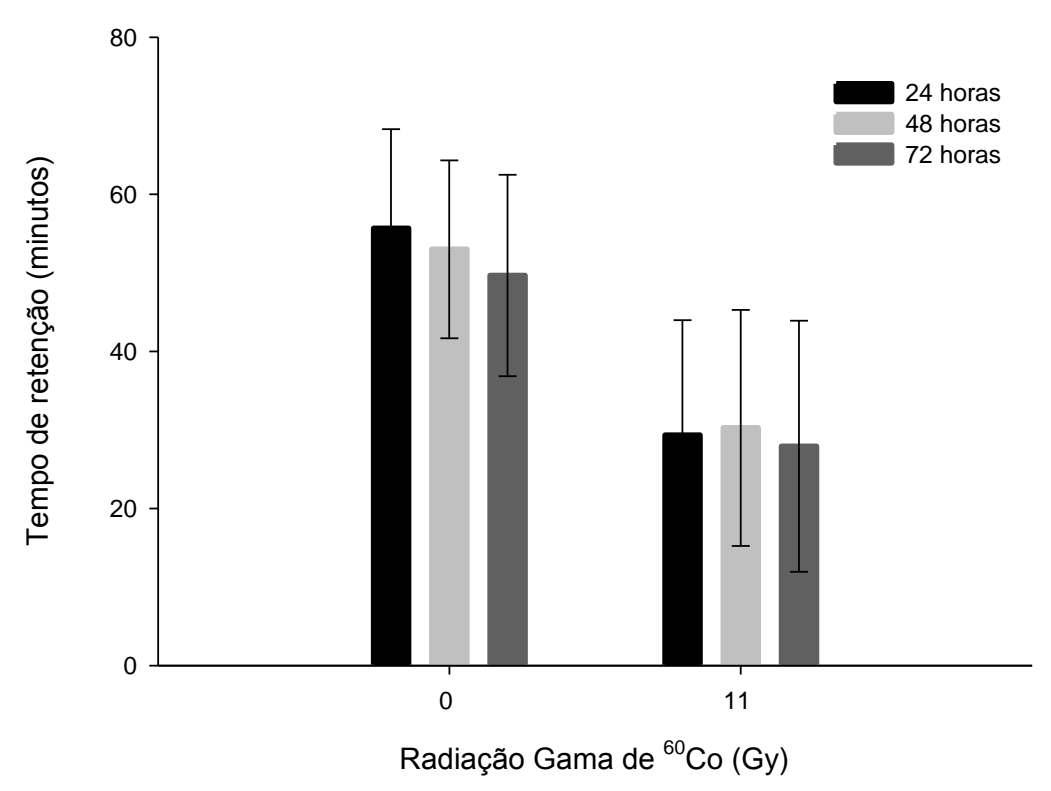

FIGURA 37 - Tempo de retenção do corante vermelho neutro do molusco bivalve Perna perna irradiados em comparação com o controle 
Os valores médios do tempo de retenção do corante VN, desvios padrão e coeficientes de variação de cada leitura realizada estão apresentados na TAB. 35.

TABELA 30 - Valores médios do tempo de retenção do corante, desvio padrão* e coeficiente de variação** de organismos irradiados com 11 Gy e controle

\begin{tabular}{c|ccc|ccc|ccc}
\hline & \multicolumn{3}{|c|}{$\mathbf{2 4 h}$} & \multicolumn{3}{c|}{ 48h } & \multicolumn{3}{c}{$\mathbf{7 2 h}$} \\
(Gy) & Média & ${ }^{*} \mathbf{D} \mathbf{P}$ & ${ }^{* *} \mathbf{C}$ V (\%) & Média & ${ }^{*} \mathbf{D} \mathbf{P}$ & ${ }^{* *} \mathbf{C}$ V (\%) & Média & ${ }^{*} \mathbf{D} \mathbf{P}$ & ${ }^{* *} \mathbf{C}$ V (\%) \\
\hline 0 & 55,666 & 12,630 & 22,689 & 53 & 11,325 & 21,368 & 49,666 & 12,833 & 25,839 \\
11 & 29,333 & 14,648 & 49,938 & 30,261 & 15,031 & 49,670 & 27,923 & 15,98 & 57,228 \\
\hline
\end{tabular}

De acordo com o Conselho Nacional de Proteção Radiológica - NCRP (1991) os estudos dos efeitos da radiação ionizante sobre a biota geralmente são medidos em doses maiores do que o esperado em ambientes aquáticos, pois são associados às atividades nucleares.

A dose de radiação de um organismo é a quantidade total de energia absorvida da radiação ionizante por unidade de massa de tecido (1 Gy $=1 \mathrm{~J} \mathrm{~kg}^{-1}$ de tecido), e a taxa de dose refere-se à energia absorvida ao longo do tempo $\left(\mu \mathrm{Gy} \mathrm{h} \mathrm{h}^{-1}\right.$ ) (FISHER et al., 2013).

De acordo com Fisher e colaboradores (2013) uma fonte é a irradiação externa proveniente da contaminação circundante, tal como sedimentos ou água, principalmente a partir de raios gama, mas também por radiação beta em pequenos organismos $(<1 \mathrm{~cm})$.

O decaimento radioativo resulta em emissões energéticas que variam entre diferentes radionuclídeos, e a eficácia da radiação em causar algum dano biológico, está diretamente relacionada com o tipo de radiação emitida (FISHER et al., 2013).

\subsubsection{Comparação dos resultados dos ensaios de citotoxicidade do DEET com organismos irradiados e não irradiados com radiação gama de ${ }^{60} \mathrm{Co}$}

Com a finalidade de mostrar e comparar a diferença no tempo de retenção do corante vermelho neutro em lisossomos de hemócitos do molusco bivalve Perna perna, os resultados dos ensaios em organismos irradiados e em organismos não irradiados foram apresentados nas FIG. 38, 39 e 40. 
24 horas

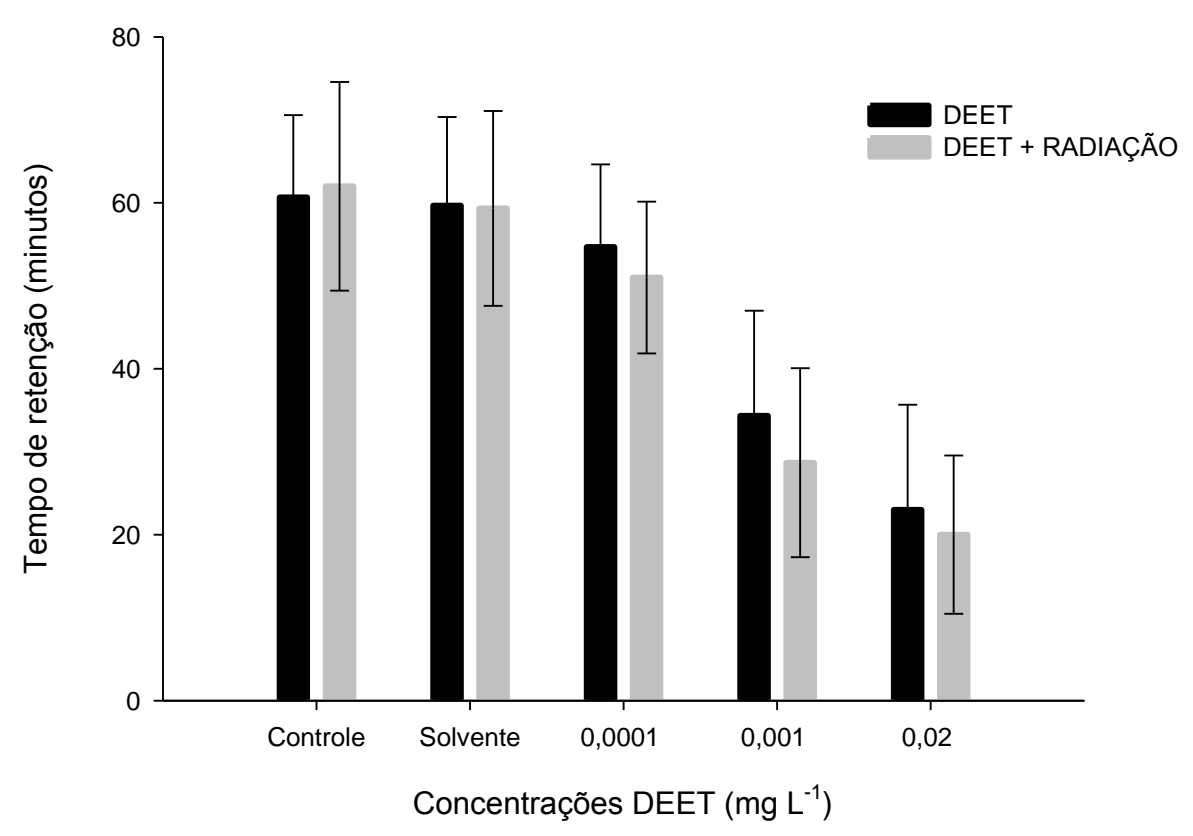

FIGURA 38 - Tempo de retenção do corante VN em função da concentração de DEET para organismos irradiados e não irradiados (24h).

Os valores médios do tempo de retenção do corante $\mathrm{VN}$, desvios padrão e coeficientes de variação de cada leitura realizada estão apresentados na TAB. 36.

TABELA 31 - Valores médios do tempo de retenção do corante, desvio padrão* e coeficiente de variação** de organismos irradiados e não irradiados (24h)

\begin{tabular}{|c|c|c|c|c|c|c|}
\hline \multirow[b]{3}{*}{$\left(\mathrm{mg} \mathrm{L}^{-1}\right)$} & \multicolumn{6}{|c|}{$24 \mathrm{~h}$} \\
\hline & \multicolumn{3}{|c|}{ Não irradiados } & \multicolumn{3}{|c|}{ Irradiados } \\
\hline & Média & *D P & ${ }^{* *} \mathrm{C}$ V (\%) & Média & *D P & ${ }^{* *} \mathrm{C} V(\%)$ \\
\hline Controle & 60,666 & 9,910 & 16,335 & 62 & 12,58 & 20,290 \\
\hline Solvente & 59,666 & 10,683 & 17,904 & 59,333 & 11,736 & 19,780 \\
\hline 0,0001 & 54,666 & 9,967 & 18,233 & 51 & 9,140 & 17,921 \\
\hline 0,001 & 34,333 & 12,656 & 36,864 & 28,666 & 11,392 & 39,741 \\
\hline 0,02 & 23 & 12,668 & 55,079 & 20 & 9,541 & 47,705 \\
\hline
\end{tabular}


48 horas

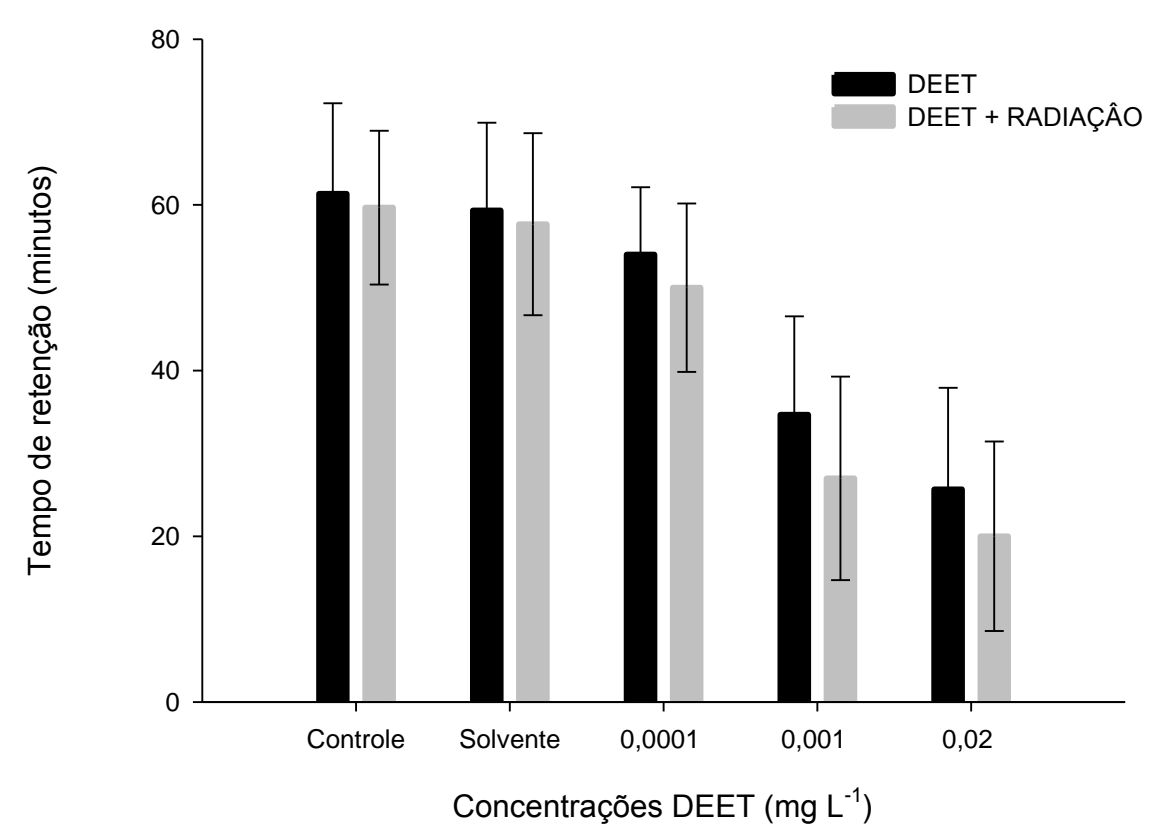

FIGURA 39 - Tempo de retenção do corante VN em função da concentração de DEET para organismos irradiados e não irradiados (48h)

Os valores médios do tempo de retenção do corante $\mathrm{VN}$, desvios padrão e coeficientes de variação de cada leitura realizada estão apresentados na TAB. 37.

TABELA 32 - Valores médios do tempo de retenção do corante, desvio padrão* e coeficiente de variação** de organismos irradiados e não irradiados (48h)

\begin{tabular}{|c|c|c|c|c|c|c|}
\hline \multirow[b]{3}{*}{$\left(\mathrm{mg} \mathrm{L}^{-1}\right)$} & \multicolumn{6}{|c|}{$48 \mathrm{~h}$} \\
\hline & \multicolumn{3}{|c|}{ Não irradiados } & \multicolumn{3}{|c|}{ Irradiados } \\
\hline & Média & *D P & ${ }^{\star \star}$ C V (\%) & Média & ${ }^{*} \mathrm{D} P$ & ${ }^{* \star} \mathrm{C}$ V (\%) \\
\hline Controle & 61,333 & 10,927 & 17,816 & 59,666 & 9,289 & 15,569 \\
\hline Solvente & 59,333 & 10,576 & 17,825 & 57,666 & 10,987 & 19,052 \\
\hline 0,0001 & 54 & 8,132 & 15,059 & 50 & 10,163 & 20,327 \\
\hline 0,001 & 34,666 & 11,876 & 34,259 & 27 & 12,286 & 45,506 \\
\hline 0,02 & 25,666 & 12,249 & 47,726 & 20 & 11,433 & 57,167 \\
\hline
\end{tabular}




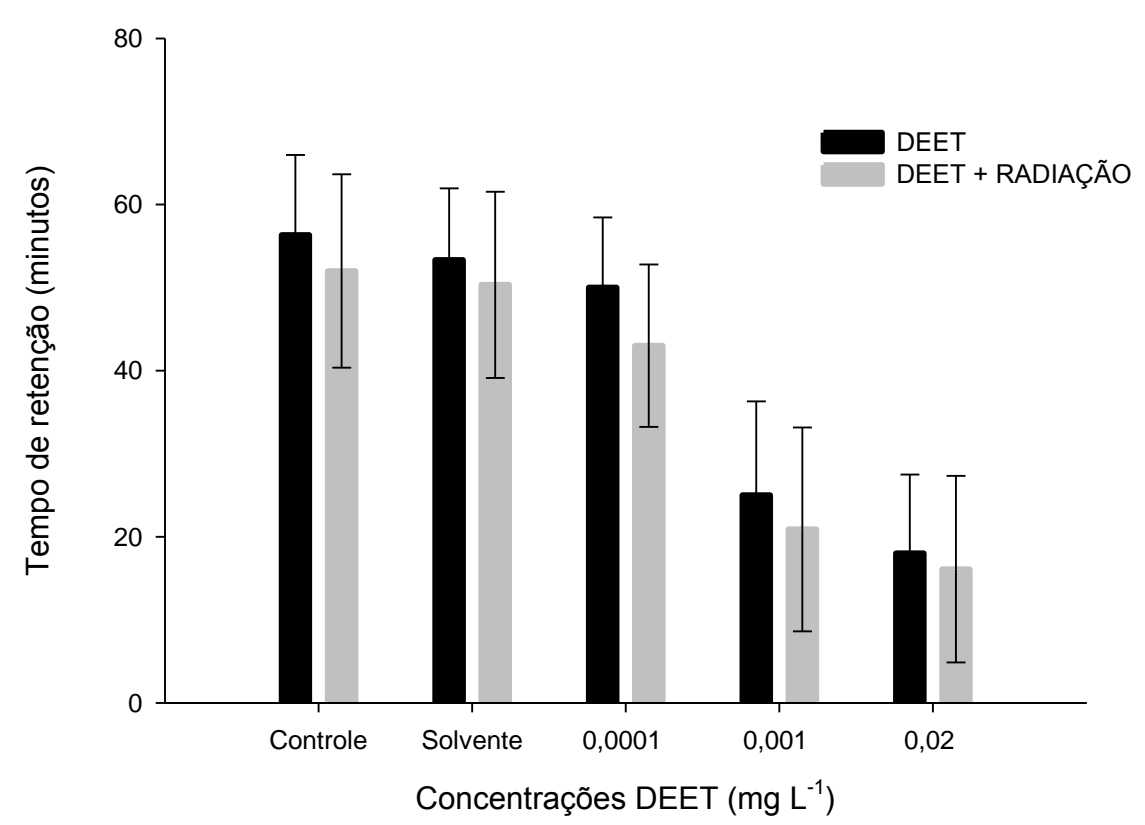

FIGURA 40 - Tempo de retenção do corante VN em função da concentração de DEET para organismos irradiados e não irradiados $(72 \mathrm{~h})$

Os valores médios do tempo de retenção do corante VN, desvios padrão e coeficientes de variação de cada leitura realizada estão apresentados na TAB. 38.

TABELA 33 - Valores médios do tempo de retenção do corante, desvio padrão* e coeficiente de variação** de organismos irradiados e não irradiados $(72 \mathrm{~h})$

\begin{tabular}{|c|c|c|c|c|c|c|}
\hline \multirow[b]{3}{*}{$\left(\mathrm{mg} \mathrm{L}^{-1}\right)$} & \multicolumn{6}{|c|}{$72 \mathrm{~h}$} \\
\hline & \multicolumn{3}{|c|}{ Não irradiados } & \multicolumn{3}{|c|}{ Irradiados } \\
\hline & Média & ${ }^{*} \mathrm{D} P$ & ${ }^{\star \star \star}$ C V (\%) & Média & ${ }^{*} \mathrm{D} P$ & ${ }^{\star \star} \mathrm{C} V(\%)$ \\
\hline Controle & 56,333 & 9,632 & 17,098 & 52 & 11,630 & 22,366 \\
\hline Solvente & 53,333 & 8,611 & 16,147 & 50,333 & 11,217 & 22,282 \\
\hline 0,0001 & 50 & 8,456 & 16,913 & 43 & 9,770 & 22,721 \\
\hline 0,001 & 25 & 11,290 & 45,161 & 20,886 & 12,270 & 58,748 \\
\hline 0,02 & 18 & 9,487 & 52,707 & 16,095 & 11,236 & 69,809 \\
\hline
\end{tabular}




\section{CONCLUSÕES}

> A concentração letal de DEET para o molusco bivalve Perna perna foi de $114,27 \mathrm{mg} \mathrm{L}^{-1}$;

$>$ A dose letal de radiação gama de ${ }^{60}$ Co para mexilhões Perna perna foi de 1068 Gy;

As concentrações de DEET na faixa de 0,001 à $0,02 \mathrm{mg} \mathrm{L}^{-1}$ apresentaram citotoxicidade para lisossomos de hemócitos do mexilhão Perna perna;

> A concentração de $0,0001 \mathrm{mg} \mathrm{L}^{-1}$ de DEET não apresentou citotoxicidade para os lisossomos de hemócitos dos mexilhões;

> A radiação gama de ${ }^{60} \mathrm{Co}$ diminuiu em $47 \%$ o tempo de retenção do corante vermelho neutro em lisossomos de hemócitos do organismo teste;

Observou-se efeito sinérgico em organismos irradiados com 107 Gy e expostos à 0,001 e $0,02 \mathrm{mg} \mathrm{L}^{-1}$ de DEET a partir da análise da integridade da membrana lisossômica, foi observado rompimento celular e mortalidade de organismos;

> A concentração letal de DEET encontrada para mexilhões Perna perna foi de $114,27 \mathrm{mg} \mathrm{L}^{-1}$, porém concentrações na ordem de $1-20 \mu \mathrm{g} \mathrm{L}^{-1}$ apresentaram-se citotóxicas para o organismo, o que mostra que o composto causa efeito sobre a biota aquática. $\mathrm{O}$ que implica em maior rigor quanto às concentrações utilizadas em produtos comercialmente disponíveis, e o monitoramento do descarte do composto. 


\section{REFERÊNCIAS BIBLIOGRÁFICAS}

ABESSA, D. M. S. Avaliação da qualidade de sedimento do Sistema Estuarino de Santos, SP, Brasil. . 2002. 322 Doutorado USP - : Universidade de São Paulo

ANDERSON, P. G.-L., J.; BERESFORD, N. A.; COPPLESTONE,; D.; HOWARD, B. J. H., P.; OUGHTON, D.; WHITEHOUSE, P. Protection of the environment from ionizing radiation in a regulatory context (protect): proposed numerical benchmark values. Journal of Environmental Radioactivity., v. 100, p. 100-1108, 2009.

ANDERSON, S. L., HARRISON, F.L.,. Effects of radiation on aquatic organisms and radiobiological methodologie for effects assessment. Office of Radiation Programs, United States Environmental Protection Agency (USEPA) 1986

ANTONOPOULOU, M. G., A.; DELIGIANNAKIS, Y.; KONSTANTINOU I. Kinetic and mechanistic investigation of photocatalytic degradation of the N,Ndiethyl-mtoluamide. . Chemical Engineering Journal., 2013.

ANTONOPOULOU, M. K., I. Optimization and modeling of the photocatalytic degradation of the insect repellent, DEET in aqueous TiO2 suspensions, Clean Soil, Air, Water. 2013.

ANVISA. Agência Nacional de Vigilância Sanitária - Câmara Técnica de Cosméticos. Utilização do DEET em preparações de repelentes para insetos. 2006

ARAGÃO, M. A. A., R. P. A. . Ecotoxicologa Aquática: Princípios e Aplicações. Métodos de Ensaios de Toxicidade com Organismos Aquáticos. In: ZAGATTO, P. A. \& BERTOLETTI, E. (Editores). . 2006.

BALONOV, M. L., G.; LOUVAT, D.; ROBINSON, C.; CABIANCA, T. The IAEA standards for the radioactive discharge control: Present status and future development. Radioprotection, v. 40, p. S721-S726, 2005. 
BARBER, L. B. K., STEFFANIE H.; BROWN, GREG K.; FURLONG, EDWARD T.; GRAY, JAMES L.; KOLPIN, DANA W.; MEYER, MICHAEL T.; SANDSTROM, MARK W.; ZAUGG, STEVEN D. Persistence and Potential Effects of Complex Organic Contaminant Mixtures in Wastewater-Impacted Streams. Environmental Science \& Technology, v. 47, n. 5, p. 2177-2188, 2013.

BAYNE, B. L. Marine mussels: their ecology and physiology. Cambridge: Cambridge University Press, 1976. 506.

BERGONIE, J., TRIBONDEAU, L. Interpretation de quelques resultats de la radiotherapie et essai de fixation d'une technique rationelle. CR Acad. Sci., n. 143, p. 983-985., 1906.

BIDWELL JR FAU - BECKER, C. B. C. F.-H., STEVE; HENSLEY S FAU - STARK, RICHARD; STARK R FAU - MEYER, MICHAEL T.; MEYER, M. T. Occurrence of organic wastewater and other contaminants in cave streams in northeastern Oklahoma and northwestern Arkansas. Arch Environ Contam Toxicol., n. 14320703 (Electronic), p. 286-98., 2010.

BIRD, A. Perceptions of epigenetics. Nature., n. 447, p. 396-398., 2007.

BLAISE, C. Introduction to ecotoxicological concepts. Proceedings of Biological Testing and Harzard Assessment. . Environmental Canada, p.11-47. 1982

BLAYLOCK, B. G., FRANK, M.L., O'NEAL, B.R. Methodology for estimating radiation dose rates to freshwater biota exposed to radionuclides in the environment. United States Dept. of Energy (USDOE). 1993

BOUTONNET, J.-C., THOMPSON, R.S., DE ROOIJ, C., GARNY, V., LECLOUX, A., VAN WIJK, D. 1,4-dichlorobenzene marine risk assessment with special reference to the osparcom region: north Sea. Environ. Monit. Assess., n. 97, p. 103-117, 2004. 
BRAUSCH, J. M. G., RAND, M. A review of personal care products in the aquatic environment: Environmental concentrations and toxicity. Chemosphere., v. 82, p. 1518-1532, 2011.

BRAUSCH, J. M. R., G. M. A review of personal care products in the aquatic environment: Environmental concentrations and toxicity. Chemosphere., v. 82, p. 1518-1532, 2011.

BROOKE, L. T., CALL, D.J., GEIGER, D.L., NORTHCOTT, C.E.,. Acute Toxicities of Organic Chemicals to Fathead Minnows (Pimephales promelas). Center for Lake Superior Environmental Studies, Superior, WI. 1984.

BROOKE, W. B. R., R. M. Review: Tick repellents: Past, present, and future. Pesticide Biochemistry and Physiology, v. 96, p. 63-79, 2010.

BROOKS, A. L. Developing a scientific basis for radiation risk estimates: goal of the DOE low dose research program. Health Phys., n. 85 (1), p. 85-93., 2003.

BROWN M FAU; HEBERT, A. A. Insect repellents: an overview. n. 0190-9622 p. 243-9., 1997.

BRUNST, V. V. Effects of ionizing radiation on the development of amphibians. $\mathbf{Q}$. Rev. Biol., n. 40, p. 1-67, 1965.

BUDAVARI, S. The Merck Index - An Encyclopedia of Chemicals, Drugs, and Biologicals. Whitehouse Station, NJ: Merck and Co., p.584. 1996

BURATINI, S. V. B., E. Análise estatística. In: Ecotoxicologia aquática: Princípios e aplicações. ZAGATTO, P. A.; BERTOLETTI, E. 2006.

CAIRNS, J. J. N., B. R. Ecological Toxicity Testing. Boca Raton: Lewis Publishers: 228 p. 1995.

CALZA, P. M., C.; RASO, E.; GIANCOTTI, V.; MINERO, C. N,N-diethyl-mtoluamide transformation in river waters. Sci. Total Environ. , v. 409, p. 38943901., 2011. 
CETESB. Companhia Ambiental do Estado de São Paulo - Relatórios de Balneabilidade de Praias 2013. Disponível em:

< http://www.cetesb.sp.gov.br/agua/praias/25-publicacoes-/-relatorios >. Acesso em: 19 de Fevereiro.

CHANEY, L. A., WINEMAN, R.W., ROCKHOLD, R.W., HUME, A.S.,. Acute effects of an insect repellant, N,N-diethyl-m-toluamide, on cholinesterase inhibition induced by pyridostigmine bromide in rats. Toxicol. Appl. Pharmacol., n. 165, p. 107-114., 2000.

CHEUNG, V. V., WEDdERBURN, R.J. \& DEPLEDGE, M.H. . Molluscan lysossomal responses as a diagnostic tool for the detection of a pollutian gradient in Tolo Harbor,Hong Kong. . Mar. Env. Res., n. 46, p. 273-241. , 1997.

COMMITTEE., I. I. M. W. International Mussel Watch Project: Initial Implementation Phase, final report

Woods Hole Oceanographic Institution, Coastal Research Center, Woods Hole, MA., 1995

CORDY, G. E. D., NORMA L.; BOUWER, HERMAN; RICE, ROBERT C.; FURLONG, EDWARD T.; ZAUGG, STEVEN D.; MEYER, MICHAEL T.; BARBER, LARRY B.; KOLPIN, DANA W. Do Pharmaceuticals, Pathogens, and Other Organic Waste Water Compounds Persist When Waste Water Is Used for Recharge? Ground Water Monitoring \& Remediation, v. 24, n. 2, p. 58-69, 2004.

COSGRove, G. E. Reptilian radiobiology. J. Am. Vet. Med. Assoc., n. 159, p. 1678-1684., 1971.

COSTANZO, S. D., WATKINSON, A.J., MURBY, E.J., KOLPIN, D.W., SANDSTROM, M.W.,. Is there a risk associated with the insect repellant DEET (N,N-diethyl-mtoluamide) commonly found in aquatic environments? Sci. Total Environ., n. 384, p. 214-220., 2007.

DELISTRATY, D. Radioprotection of nonhuman biota. Journal of Environmental Radioactivity, n. 99, p. 1863-1869, 2008. 
DEPLEDGE, M. H. Nondestructive Biomarkers in Vertebrates (M. C. Fossi \& C. Leonzio, eds.) Boca Raton, FL, USA. : Lewis Publishers, 1993. 271-285. .

DOGAN EB FAU - AYRES, J. W. A. J. F.-R., P. A.; ROSSIGNOL, P. A. Behavioural mode of action of deet: inhibition of lactic acid attraction. 1999.

DONOHUE, D. L. Strengthening IAEA safeguards through environmental sampling and analysis. Journal of Alloys and Compounds, v. 271-273, p. 11-18, 1998.

DOWD, S. B. T., E.R. Practical radiation protection and applied radiobiology. Philadelphia, P.A.: Saunders Company. 1999

DOWNS, J. A., NUSSENZWEIG, M.C., NUSSENZWEIG, A.,. Chromatin dynamics and the preservation of genetic information. Nature., n. 447, p. 951-958., 2007.

ECHA. European Chemicals Agency - Guidance on information requirements and chemical safety assessment. 2010

EDITORIAL. The international conference on radioecology and environmental radioactivity. Journal of Environmental Radioactivity., n. 100

p. 999-1001., 2009.

EISLER, R. Radiation Hazards to Fish, Wildlife, and Invertebrates: A Synoptic Review. National Biological Service, United States Department of Interior, Washington, DC, USA. Contam. Haz. Rev. Rep. 29. 1994

FAJARDO, L. F. N., M.; ANDERSON, R. E. Radiation pathology. New York. NY. Oxford. 2001

FERREIRA, J. F. M., A. R. M. . Desenvolvimento de cultivo de mexilhões em Santa Catarina (sul do Brasil). . In: CONGRESSO LATINOAMERICANO DE CIÊNCIAS DEL MAR. Mar del Plata, Argentina.: 80 p. 1995.

FOSSI, M. C. S., C.; CASINI, S. . Mixed function oxidase induction in Carcinus aestuarii. Field and experimental studies for the evaluation of toxicological risk due to Mediterranean contaminants. . Comp. Biochem. Physiol. , v. 121, p. 321-331. 1998. 
FOWLER, S. W. Radionuclide bioaccumulation patterns in marine organisms. . In: AGENCY., I. I. A. E., Protection of the environment from the effects of ionizing radiation., 2003, Proceedings of an International Conference Stockholm, 6 -10 October.p.548.

FRADIN, M. S. D., J. F. . Comparative Efficacy of Insect Repellents against Mosquito Bites. The New England Journal of Medicine, v. 347, n. 1, p. 13-18, 2002.

FREIRE, M. M. S., V. G.; GINUINO, I. S. F.; ARIAS, A. R. L. . Biomarcadores na avaliação da saúde ambiental dos ecossistemas aquáticos. . Oecol. Bras. , v. 12, n. 3, p. 347-354, 2008.

GERASKIN, S. A., EVSEEVA, T.I., BELYKH, E.S., MAJSTRENKO, T.A., MICHALIK, B., TASKAEV, A.I. Effects on non-human species inhabiting areas with enhanced level of natural radioactivity in the north of Russia: a review. J. Environ. Radioact, n. 94, p. 151-182., 2007.

GETOFF, N. Radiation-induced degradation of water pollutants-state of the art. Radiation Physics and Chemistry., v. 47., p. 581-593., 1996.

GHERARDi-GOldstein, E. B., E.; ZAGATtO, P. A.; ARAÚJO, R. P. A.; RAMOS, M. L. L. C. Procedimentos para Utilização de Testes de Toxicidade no Controle de Efluentes Líquidos. CETESB: Companhia de Tecnologia de Saneamento Ambiental São Paulo, SP. 1990

GLASSMEYER, S. T. F., E.T.; KOLPIN, D.W.; CAHILL, J.D.; ZAUGG,; S.D.; WERNER, S. L. Transport of chemical and microbial compounds from known wastewater discharges: potential for use as indicators of human fecal contamination. Environmental Science Technology., v. 39, p. 5157-5169., 2005.

GRYIBOSKI, J. W., D.; ORDWAY. N. K. . Toxic encephalopathy apparently related to the use of insect repellent. . N. Engl. J. Med., v. 264, p. 289-291, 1961. 
HALL, S. A. G., N.; BEROZA, M. Insect repellent. J. Agr. Food. Chem., v. 5, p. 663-667, 1957.

HAMILTON, M. A., RUSSO, R.C., THURSTON, R.V. Trimmed SpearmanKarber method for estimating median lethal concentrations in toxicity bioassays. Environmental Science \& Technology., p.714-719. 1977

HIGLEY, K. A. Effects of radioactivity on plants and animals. CRC Press, Boca Raton, FL, USA, p.209-224. 2007

HINTON, T. G. Risks from exposure to radiation. 2nd ed. CRC Press/ Lewis Publishers. Boca Raton, FL., p.303-304. 2003

HODGSON, E. A Textbook of Modern Toxicology. John Wiley \& Sons, 2004.

HOFFMAN, D. J. B., A.; RATTNER, G.; BURTON, A. J.; CAIRNS, J. J. Handbook of Ecotoxicology. 2nd ed. CRC Press., 2002.

HOFFMANN, E. J. M., J. R. . Reassessment of the role and utility of wind in suppression of mosquito (Diptera: Culicidae) host finding: stimulus dilution supported over flight limitation. 2003.

IAEA. International Atomic Energy Agency - Effects of ionizing radiation on aquatic organisms and ecosystems. Vienna, Austria. 1976

IAEA. International Atomic Energy Agency - Methodology for assessing impacts of radioactivity on aquatic ecosystems. 1979

IAEA. International Atomic Energy Agency - Effects of ionizing radiation on plants and animals at levels implied by current radiation protection standards. 1992

IAEA. International Atomic Energy Agency - Measures to strengthen international cooperation in nuclear, radiation and transport safety and waste management. 2005 
ICRP. International Commission on Radiological Protection Recommendations of the International Commission on Radiological Protection. 1991

ICRP. International Commission on Radiological Protection - A framework for assessing the impact of ionizing radiation on non-human species. 2003

ICRP. International Commission on Radiological Protection - Draft recommendations of the international commission on radiological protection. 2007

IRVINE, C., SAMPLE, B. A Review and Analysis of Ecological Dose-effects from Radiation Exposure. DOE/RL-2005-40, Draft A, Richland, WA, USA. 2005

KENDALL, R. J. A., T. A.; BAKER, R. J.; BENS, C. M.; CARR, J. A.; CHIODO, L. A.; COB III, G. P.; DICKERSON, R. L.; DIXON, K. R.; FRAME, L. T.; HOOPER, M. J.; MARTIN, C. F.; MCMURRY, S. T.; PATINO, R.; SMITH, E. E.; THEODORAKIS, W. Casarett and Doull's Toxicology - The Basic Science of Poisons. 6th ed., MacGraw-Hill: New York: 2001.

KING, R. Rapid assesment of marine pollution - Biological techniques. . Plymouth Environmental Research Center, p. 37, 2000.

KOLPIN, D. W., FURLONG, E.T., MEYER, M.T., THURMAN, E.M., ZAUGG, S.D., BARBER, L.B., BUXTON, H.T. Pharmaceuticals, hormones and other organic wastewater contaminants in US streams, 1999-2000: a national reconnaissance. Environ. Sci. Technol., v. 36, p. 1202-1211., 2002.

KOLPIN, D. W. S., M.; MEYER, M.T.; FURLONG, E.T.; ZAUGG, S.D. Urban contribution of pharmaceuticals and other organic wastewater contaminants to streams during differing flow conditions. Science of the Total Environment., $\mathrm{n}$. 328, p. 119-130., 2004.

KOTURBASH, I., RUGO, R.E., HENDRICKS, C.A., LOREE, J., THIBAULT, B., KUTANZI, K., POGRIBNY, I., YANCH, J.C., ENGLEWARD, B.P., KOVALCHUK, 
O. Irradiation induces DNA damage and modulates epigenetic effectors in distant bystander tissue in vivo. Oncogene 25, p. 4267-4275., 2006.

LEBOWITZ, H., YOUNG, R., KIDWELL, J., MCGOWAN, J., LANGLOSS, J., BRUSICK, D. DEET (N,N-diethyltoluamide) does not affect sperm number, viability, and head morphology in male rats treated dermally. Drug Chem. Toxicol., v. 6, p. 379-395., 1983.

LEONZIO, C. F., M. C. . Nondestructive biomarkers strategy: perspectives and applications. Lewis Publ., London, p.297-312. . 1993

LITTLE, A. D. Development of Candidate Chemical Simulant List: The Evaluation of Candidate Chemical Simulants Which May Be Used in Chemically Hazardous Operations. . Air Force Aero Med Res Lab, WrightPatterson AFB, OH, AFAMRL-TR-82-87. . 1982

LOWE, D. M. Alterations in cellular structure of Mytilus edullis resulting from exposure to environmental contaminants under field and experimental conditions. . Mar. Ecol. Prog. Ser., n. 46, p. 91-100., 1988.

LOWE, D. M., FOSSATO, V.U, \& DEPledGE, M.H. Contaminant -induced lysosomal membrane damage in blood cells of mussels Mytilus galloprovincialis from Venice lagoon: an in vitro study. Mar. Ecol. Prog. Ser., n. 129, p. 189-196, 1995.

LOWE, D. M. M., M. N. \& EVANS, B. M. . Contaminant impact on interactions of molecular probes with lisosomes in living hepatocytes from Lab. Limanda limanda. Marine Ecology Progress Series, n. 91, p. 135-140. , 1992.

LOWE, D. M. P., R. K. . Contaminant induced lysossomal membrane damage in marine mussel digestive cells: an in vitro study. . Aquatic Toxicology, v. 30, p. 357-365, 1994.

MAGNUSSON, M. H., K.; RIDD, M.; NEGRI, A. P. Pesticide contamination and phytotoxicity of sediment interstitial water to tropical benthic Microalgae. . Water Research, 2013. 
MAYER FLJ, E. M. Manual of acute toxicity: interpretation and data base for 410 chemicals and 66 species of freshwater animals. U.S.Dep.Interior, Fish Wildl.Serv. (USGS Data File). 1986

MELLINGER, P. J., SCHULTZ, V. Ionizing radiation and wild birds: a review. Crit. Rev. Environ. Control 5, p. 397-421, 1975.

METTLER JUNIOR, F. A. U., A.C. Medical effects of ionizing radiation. 2nd ed. Philadelphia, P.A. Saunders Company, 1995.

MICHAEL A. G., G. G. S. Toxicity of the repellent DEET (N,N-Diethyl Metatoluamide) to Gambusia affinis (Baird and Girard). . Mosq News n. 34, p. 3235, 1974.

MILLER, J. D. Anaphylaxis associated with insect repellent. . N. Engl. J. Med., v. 307, p. 1341-1342, 1982.

MIRANDA, M. C. Desenvolvimento de lipossoma com produto repelente de insetos e metodologia analítica. 2005. UFRJ/ FF, Rio de Janeiro.

MOORE, M. N. Cellular responsesto pollutants. Mar Pollut Bull, v. 16, p. 134-139, 1985.

MOORE, M. N., VIARENGO, A. Lysosomal membrane fragility and catabolism of cytosolic proteins: evidence for a direct relationship. Experientia n. 43, p. 320 323.1987.

MOTHERSILL, C., BUCKING, C., SMITH, R.W., AGNIHOTRI, N., O'NEILL, A., KILEMADE, M., SEYMOUR, C.B. Communication of radiation-induced stress or bystander signals between fish in vivo. Environ. Sci. Technol., v. 40, p. 68596864., 2006.

NCRP. National Council on Radiation Protection and Measurements. Effects of ionizing radiation on aquatic organisms. Bethesda, MD. Report $\mathrm{n} N$ 109., p.115. 1991 
NICHOLSON, S. Ecotoxicological and toxicological responses to cooper in Perna viridis (L.) (Bivalvia: Mytilidae) haemocyte lysossomal membranes. . Chemosphere. , v. 45, p. 339-407, 2001.

O'BRIEN, R. D., WOLFE, L.S. Nongenetic effects of radiation. In: Radiation. Radioactivity and Insects. New York, USA. Academic Press, p.23-54. 1964

OLIVI, P. C., C. R.; BOTTA, C. M. R.; ESPINDOLA, E. L. G. . A TOXICIDADE EM AMBIENTES AQUÁTICOS: DISCUSSÃO E MÉTODOS DE AVALIAÇÃO.

Quimica Nova, v. 31, n. 7, p. 1820-1830, 2008.

PALUCH, G. B., L.; COATS J. Mosquito repellents: a review of chemical structure diversity and olfaction. . Society of Chemical Industry, 2010.

PEDROSA, R. C. G., R.; WILHELM FILHO, D. Time-dependent oxidative stress caused by benznidazole. Redox Report, Associação Brasileira de Divulgação Científica, p. 265- 271. , 2001.

PENTREATH, R. J. Radioecology, radiobiology and radiological protection: frameworks and fractures. Journal of Environmental Radioactivity, v. 100, p. 1019-1026., 2009.

PEREIRA, C. D. S. A., D. M. DE S.; BAINY, A. C. D.; ZARONI, L. P.; GASPARRO, M. R.; BÍCEGO, M. C.; TANIGUCHI, S.; FURLEY, T. H.; SOUSA, E. C. P. M. Integrated assessment of multilevel biomarker responses and chemical analysis in mussels from São Sebastião, São Paulo, Brazil. . Environmental toxicology and chemistry - SETAC, v. 26(3), p. 462-469. , 2007.

PLAA, G. L. Present status: toxic substances in the environment. . Can J. Physiol. Pharmacol., v. 60, p. 1010-1016., 1982.

POLIKARPOV, G. G. Conceptual model of responses of organisms, populations, and ecosystems to all possible dose rates of ionising radiation in the environment. Radiat. Prot. Dosimet, v. 75, n. (1-4), p. 181-185., 1998.

QIU, J. Epigenetics: unfinished symphony. Nature., v. 441, p. 143-145, 2006. 
RAND, G. M. W., P. G.; MCCARTY, L. S. Fundamentals of Aquatic Toxicology: Effects, Environmental Fate and Risk Assessment. 2nd. Ecological Services Inc. North Palm Beach, FL., 1995. 1125.

RESGALLA JR., C. L., K. S. . Sensibilidade dos Organismos Marinhos Utilizados em Testes de Toxicidade no Brasil. . NOTAS TÉC. FACIMAR, v. 6, n. 153-163, 2002.

RIBO, J. M. Environ. Toxicol. Water Qual. v. 12, p. 283, 1997.

ROSE, K. S. B. Lower limits of radiosensitivity in organisms excluding man. J. Environ. Radioact., v. 15, n. 113-133, 1992.

SALOMÃO, L. C. M., A. R. M.; LUNETTA, J. E. Influência da salinidade na sobrevivência de Perna perna. Bol. Fisiol. Animal Univ. São Paulo, v. 4, p. 143152, 1980.

SANDSTROM, M. W. K., D.W.; THURMAN, E.M.; ZAUGG, S.D. Widespread detection of N,N-diethyl-m-toluamide in U.S. Streams: Comparison with concentrations of pesticides, personal care products, and other organic wastewater compounds. Environ. Toxicol. Chem. , v. 24, p. 1029-1034., 2005.

SCHLENK, D. Necessity of defining biomarkers for use in ecological risk assessment. Marine Pollution Bulletim, v. 39, p. 48-53, 1999.

SEO, J., LEE, Y.G., KIM, S.D., CHA, C.J., AHN, J.H., HUR, H.G. Biodegradation of the insecticide N,N-diethyl-m-toluamide by fungi: identification and toxicity of metabolites. Arch. Environ. Contam. Toxicol., v. 48, p. 323-328., 2005.

SHERMAN, J. L. J. Development of a systemic insect repellent. J. Amer. Med. Assoc., v. 196, p. 256-258, 1966.

SINGH, S. P. A., A.; CHAUDHARY, A.; KHAN, S.; WILLETT, K.L.; GARDINALI, P.R. Occurrence and distribution of steroids, hormones and selected pharmaceuticals in South Florida coastal environments. Ecotoxicology., n. 19, p. 338-350., 2010. 
SPURGEON, D. J., RICKETTS, H., SVENDSEN, C., MORGAN, A.J., KILLE, P. Hierarchical responses of soil invertebrates (earthworms) to toxic metal stress. Environ. Sci. Technol., v. 39, p. 5327-5334., 2005.

TAY, K. S. R., N.A.; ABAS, M.R. Degradation of DEET by ozonation in aqueous solution. Chemosphere., v. 76, p. 1296-302., 2009.

TRUHAUT, R. Ecotoxicology: Objectives, principles and perspectives. . Ecotoxicology and Environmental Safety, n. 1, p. 151-173, 1977.

UNEP. United Nations Environment Programme - Report of the meeting of experts to review the MEDPOL biomonitoring programme. Athens, Greece: UNEP- (OCA) / MEDWG., p.132-137. . 1997

UNSCEAR. Sources and Effects of lonizing Radiation. Scientific Annex: Effects of Radiation on the Environment. United Nations, New York, USA. 1996

USEPA. United States Environmental Protection Agency. Reregistration Eligibility Decision (RED) DEET. Prevention, pesticides and toxic substances., p.134. 1998

USEPA. United States Environmental Protection Agency. Methods for measuring the acute toxicity of effluents and receiving waters to freshwater and marine organisms., p.266. 2002

USEPA. United States Environmental Protection Agency. Short-term methods for estimating the chronic toxicity of effluents and receiving waters to freshwater and marine organisms., p.335. 2002

VOLKLE, H. Radiation protection of environment under the light of the new concept of radiation protection of non-human species. ICRP Second European Congress, Paris, France., 2006.

WALKER, C. H. H., S. P.; SIBLY, R. M. \& PEAKALL, D. B. . Principles of ecotoxicology. . London, UK: Taylor \& Francis., 1996. 321. 
WEEKS, J. A. G., P. D.; NIKIFOROV, A. I. . Assessment of the Environmental Fate and Ecotoxicity of N,N-Diethyl-m-toluamide (DEET). . Integrated Environmental Assessment and Management. , v. 8, n. 1, p. 120-134., 2011.

WEIGEL, S. B., U.; JENSEN, E.; KALLENBORN, R.; THORESEN, H.; HUHNERFUSS, $\mathrm{H}$. Determination of selected pharmaceuticals and caffeine in sewage and sweater from Tromso/ Norway with emphasis on ibuprofen and its metabolites. Chemosphere., n. 56, p. 583-592., 1994.

WEIGEL, S. K., JAN; HÜHNERFUSS, HEINRICH Drugs and personal care products as ubiquitous pollutants: occurrence and distribution of clofibric acid, caffeine and DEET in the North Sea. Science of The Total Environment, v. 295, n. 1-3, p. 131-141, 2004.

WEST, I. G., D. Western Ecosystems Technology. TOXSTAT 3.41994.

WHICKER, F. W. Impacts on plant and animal populations. In: Health Impacts of Large Releases of Radionuclides. Ciba Foundation Symposium 203. John Wiley \& Sons, p.74-88. 1997

WHICKER, F. W. S., V. Radioecology: Nuclear energy and environment. CRC Press. Boca Raton, FL., n. 212(1), p. 228, 1982.

WICHTERMAN, R. Biological effects of ionizing radiation on protozoa: some discoveries and unsolved problems. Bioscience, v. 22, p. 281-289., 1972.

WILSON, D. C. J.-L., T. L. Emerging Contaminant Sources and Fate in Recharged Treated Wastewater, Lake Havasu City, Arizona. U.S. Environmental Protection Agency. Office of Research and Development, National Exposure Research Laboratory. Las Vegas, NV 2013

YU, M.-H. Environmental Toxicology. CRC Press. Boca Raton. 2005

ZAGATtO, P. A. B., E. . Ecotoxicologia Aquática: Princípios e Aplicações. . São Carlos, SP. : Rima, 2006. 
ZAKRZEWSKI, S. F. Principles of Environmental Toxicology. American Chemical Society: Washington, 1994.

ZARONI, L. P. A., D. M. S.; RACHID, B. R. F. AND SOUSA, E. C. P. M. Diferenças no estado fisiológico de adultos e na viabilidade de embriões do mexilhão Perna perna provenientes de duas populações coletadas em Ubatuba - SP. . São Paulo: Arte \& Ciência Villipres., p.15-25. 2001 


\section{APÊNDICES}

APÊNDICE A - Resultados dos ensaios de ecotoxicidade aguda para o DEET obtidos a partir do software Trimmed Spearman-Karber (HAMILTON et al., 1977).

Ensaio 1 CL50 $(72)$ para o DEET
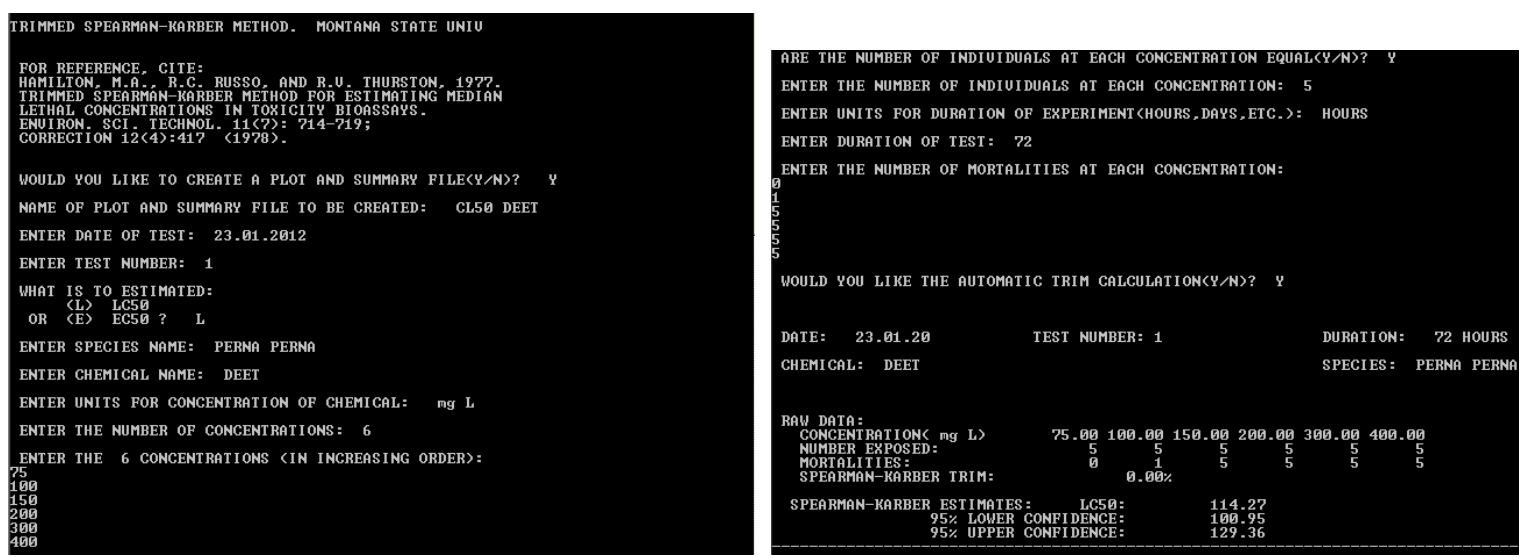

\section{Ensaio 2 CL50 $(72)$ para o DEET}
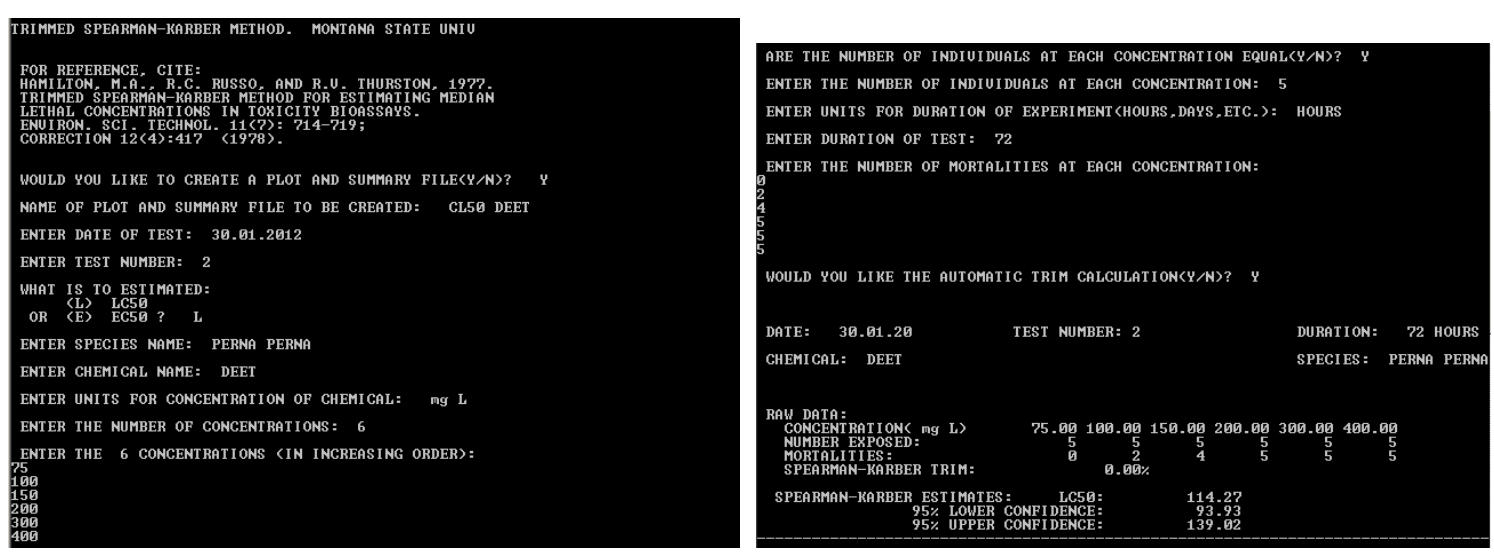

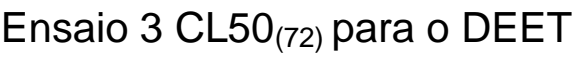
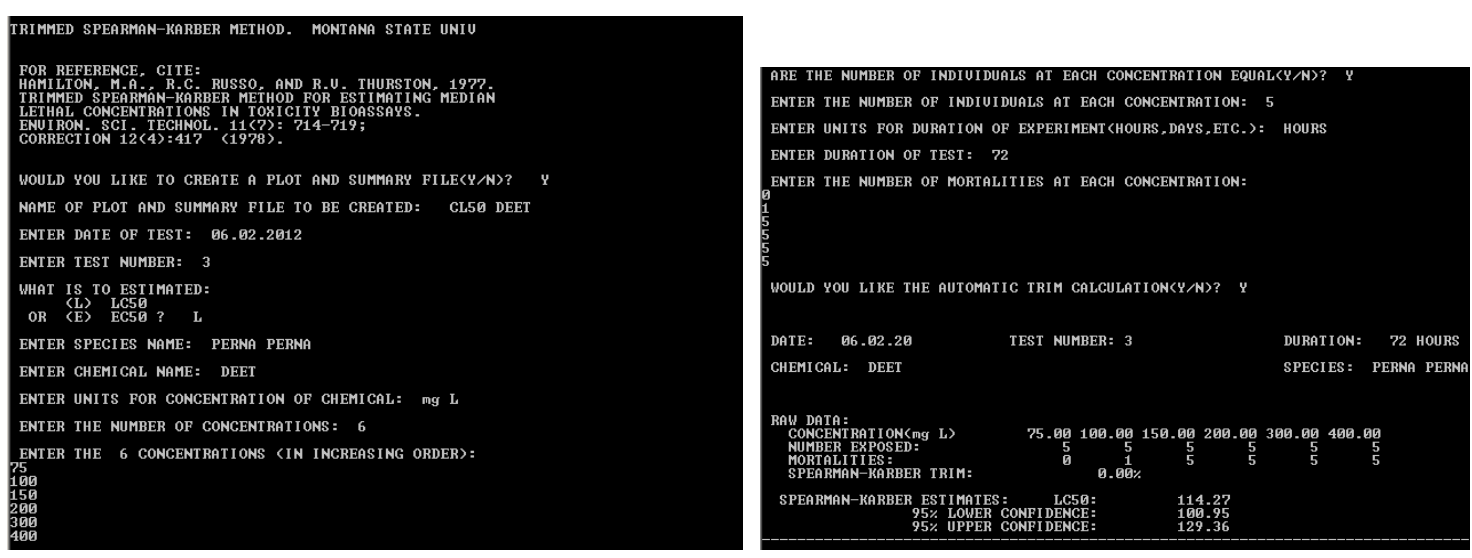
APÊNDICE B - Resultados dos ensaios de ecotoxicidade aguda para o DEET obtidos a partir do software Trimmed Spearman-Karber (HAMILTON et al., 1977).

Ensaio $1 \mathrm{DL50}_{(72)}$ para organismos irradiados com radiação gama de ${ }^{60} \mathrm{Co}$
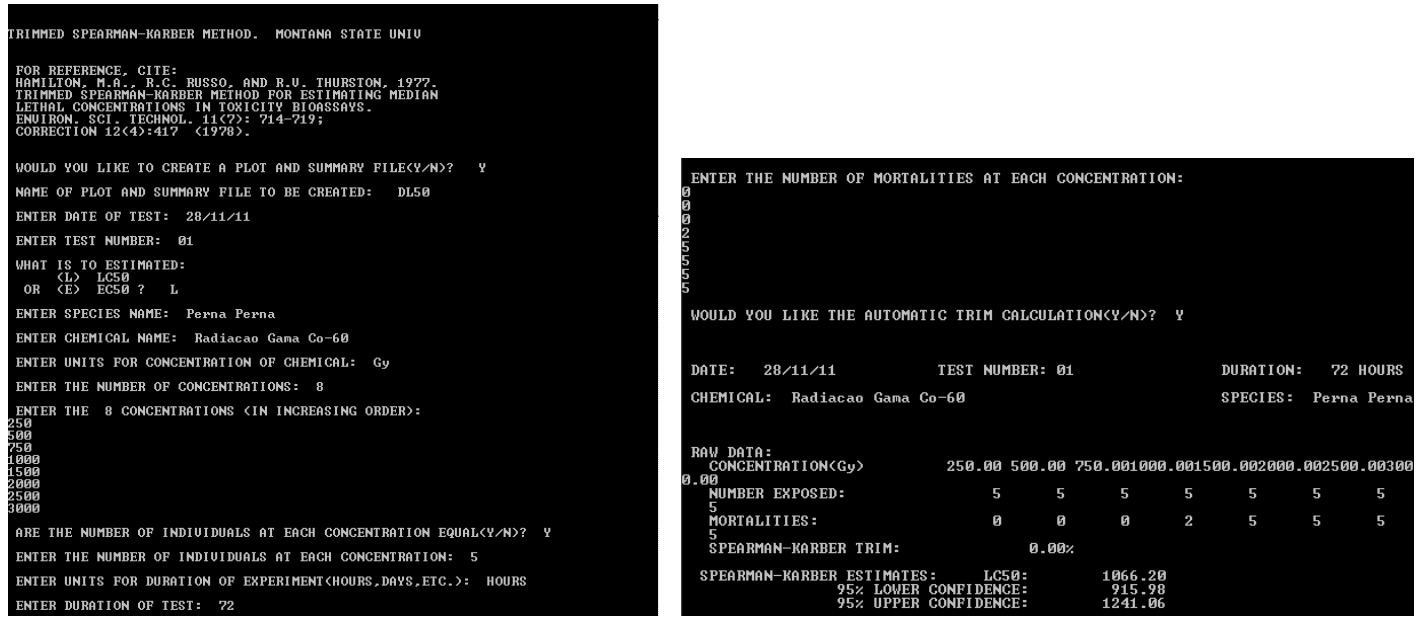

Ensaio $2 \mathrm{DL50}_{(72)}$ para organismos irradiados com radiação gama de ${ }^{60} \mathrm{Co}$
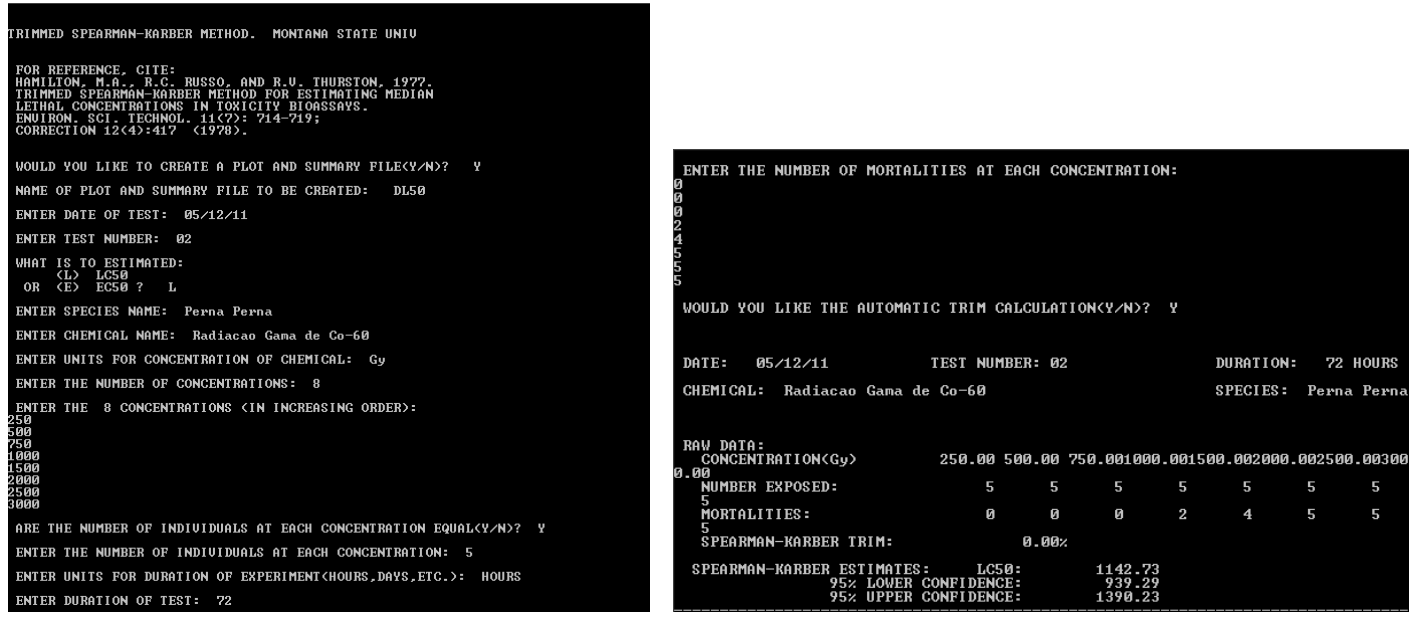

Ensaio $3 \mathrm{DL50}_{(72)}$ para organismos irradiados com radiação gama de ${ }^{60} \mathrm{Co}$
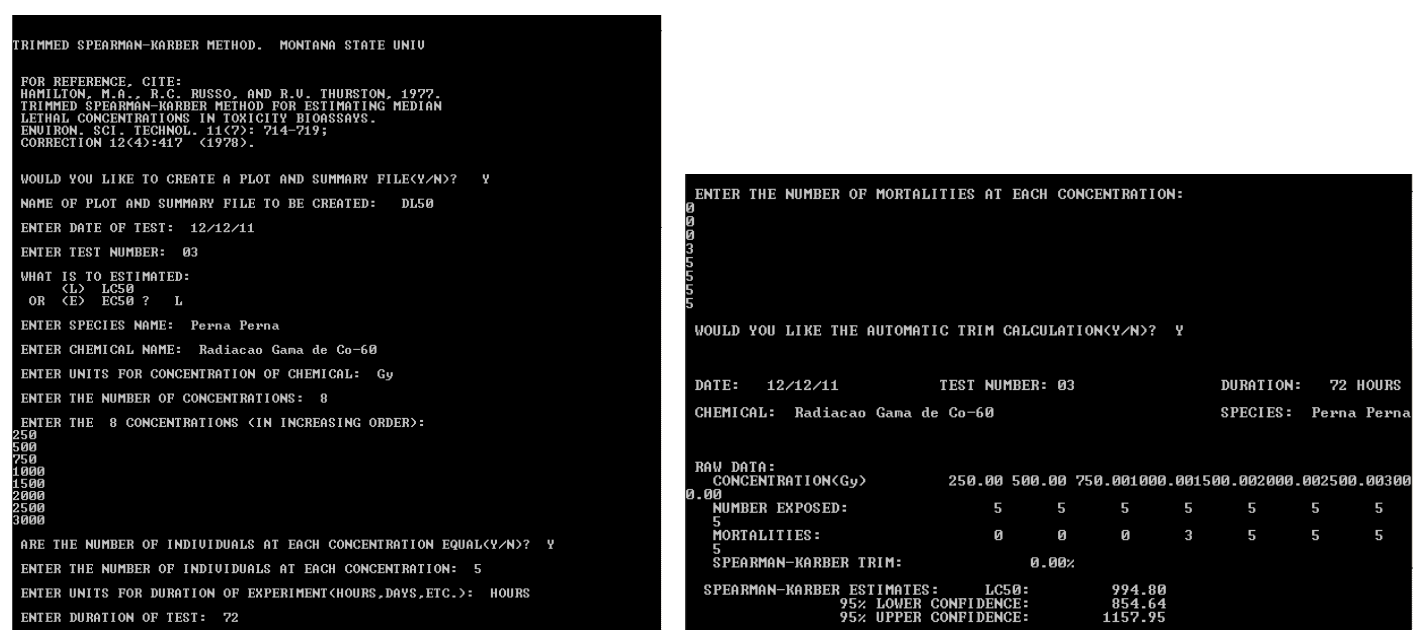
APÊNDICE C - Resultados dos ensaios preliminares de citotoxicidade do DEET em organismos não irradiados obtidos por meio do software TOXSTAT 3.4 (GULLEY, D.D. et al. 1991).

I ensaio preliminar tempo de retenção do corante vermelho neutro - 24 horas

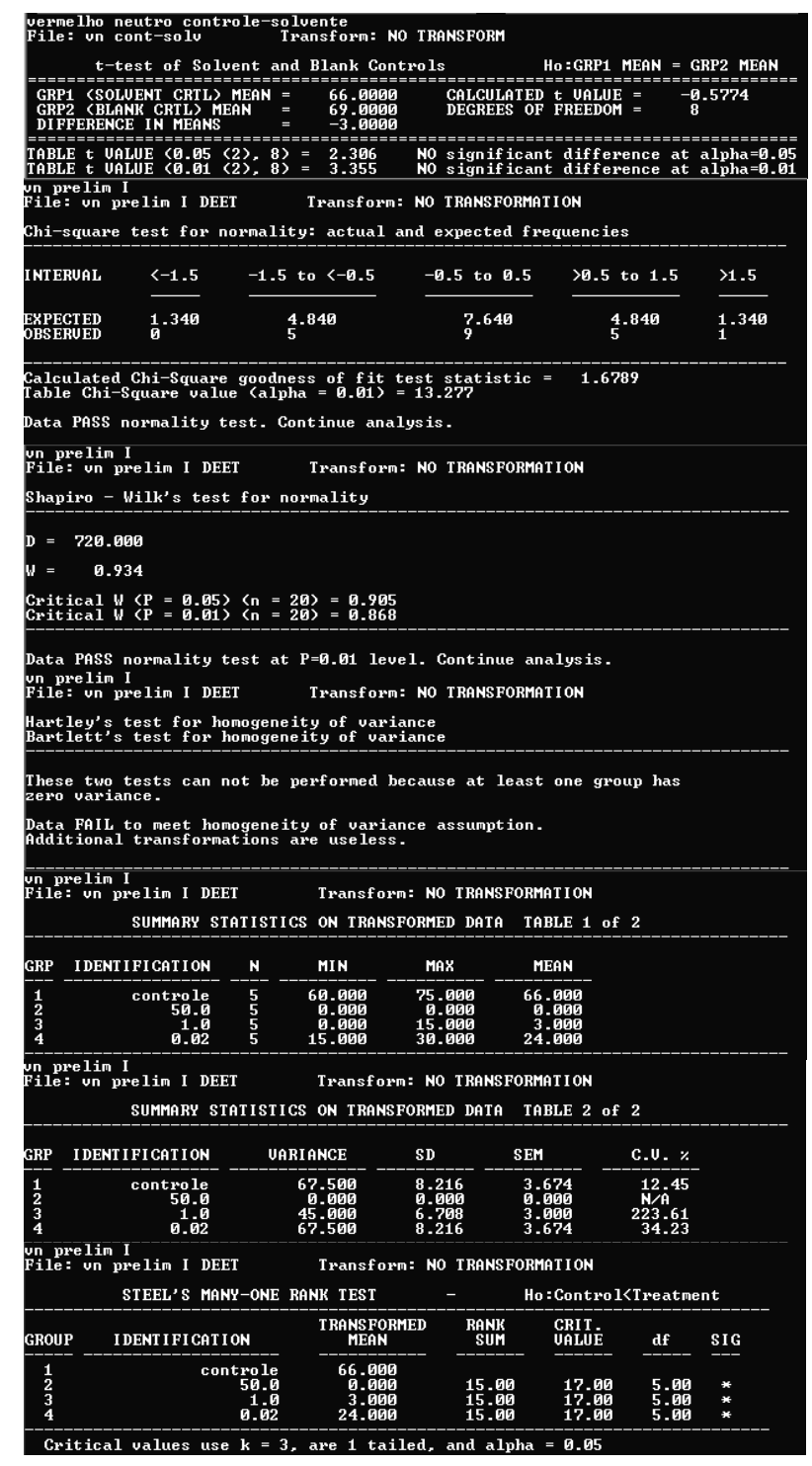

I ensaio preliminar tempo de retenção do corante vermelho neutro - 48 horas

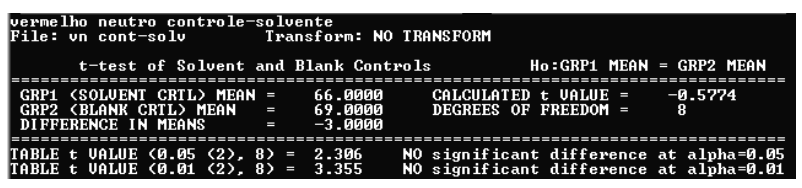




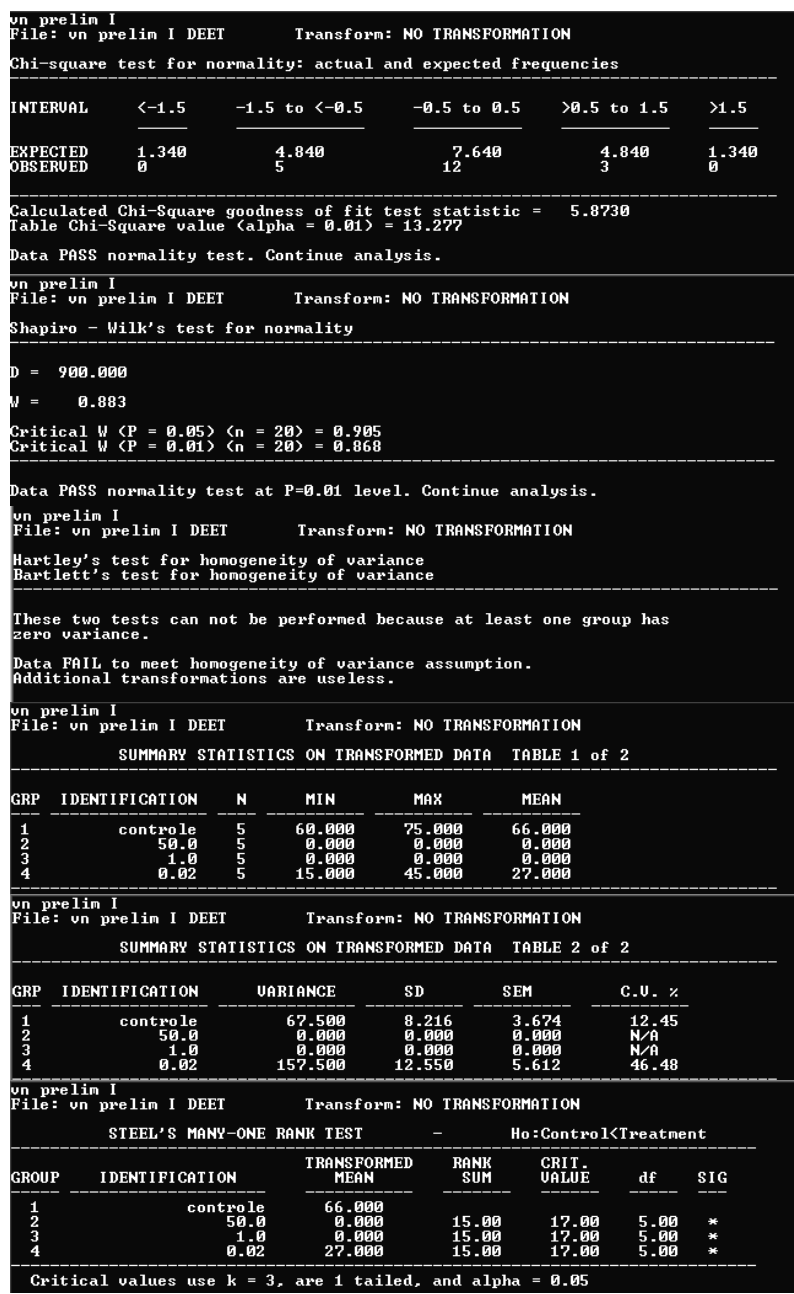

I ensaio preliminar tempo de retenção do corante vermelho neutro -72 horas

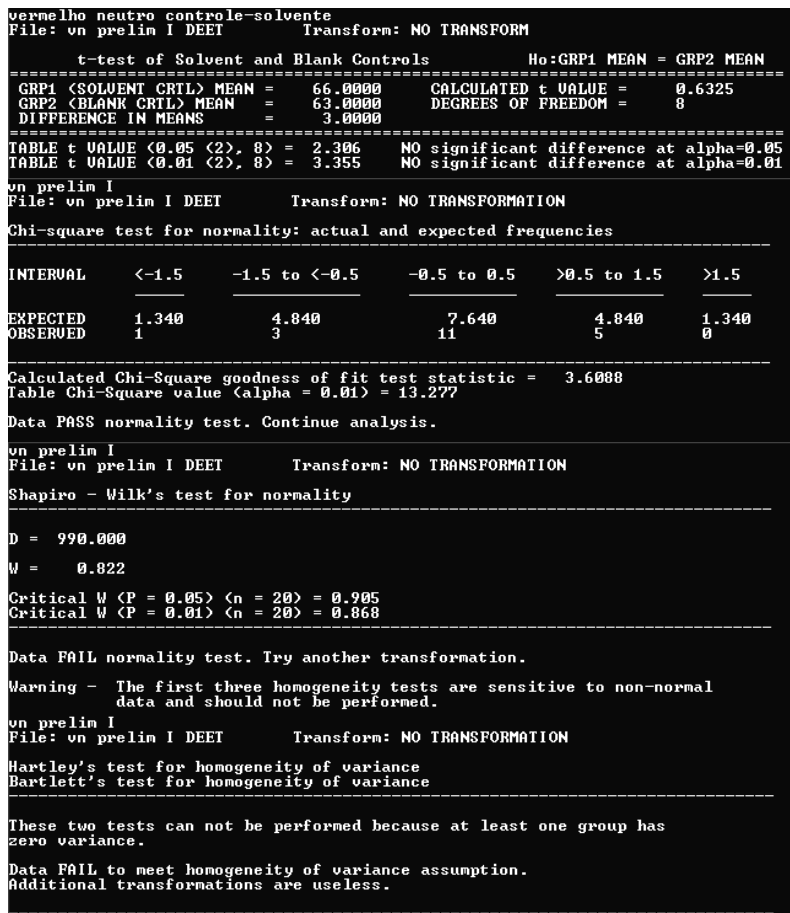




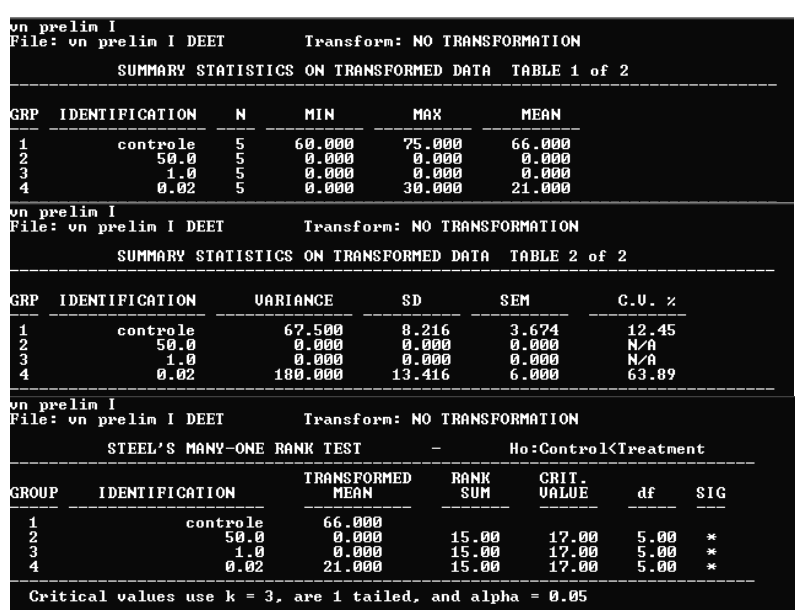

II ensaio preliminar tempo de retenção do corante vermelho neutro - 24 horas

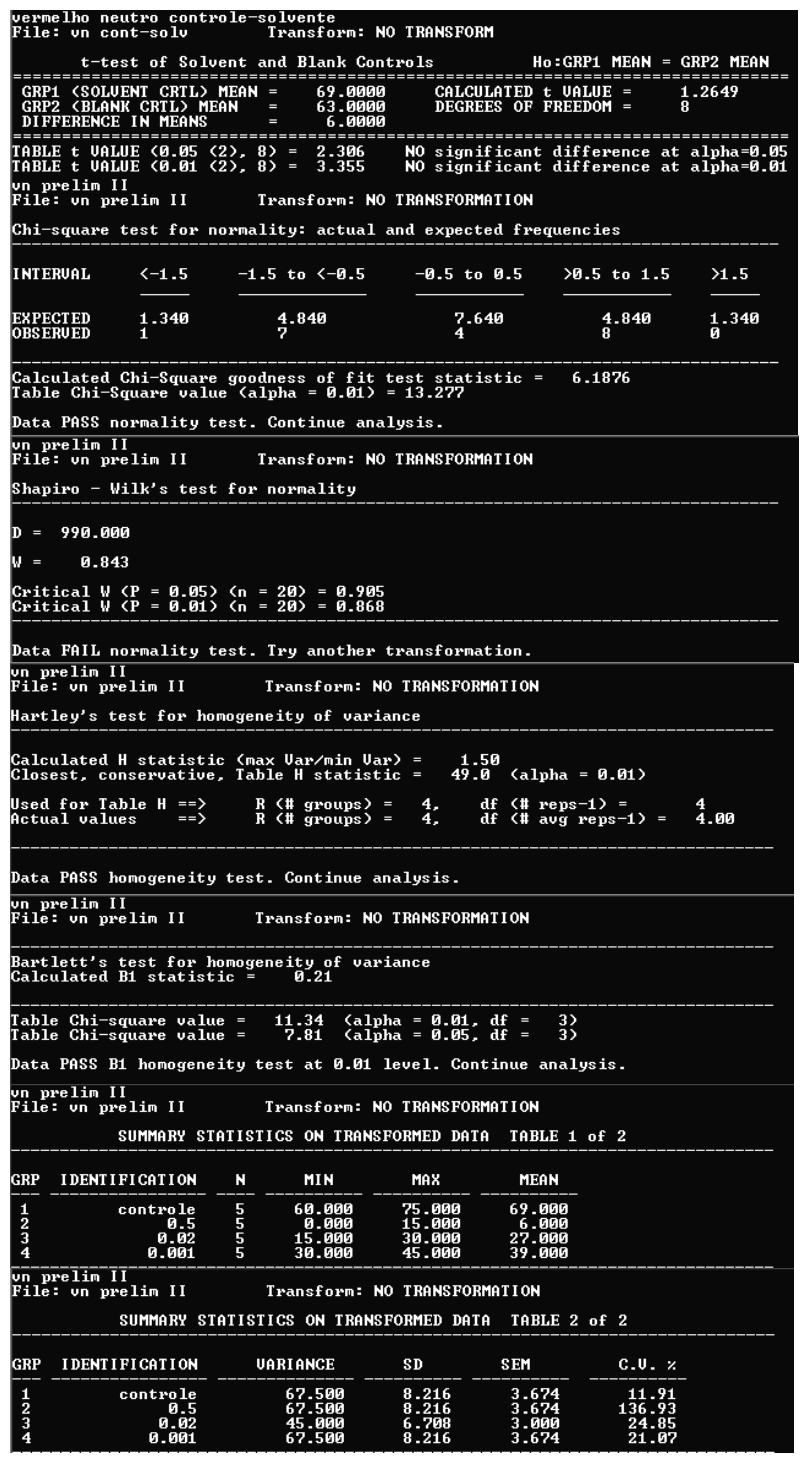




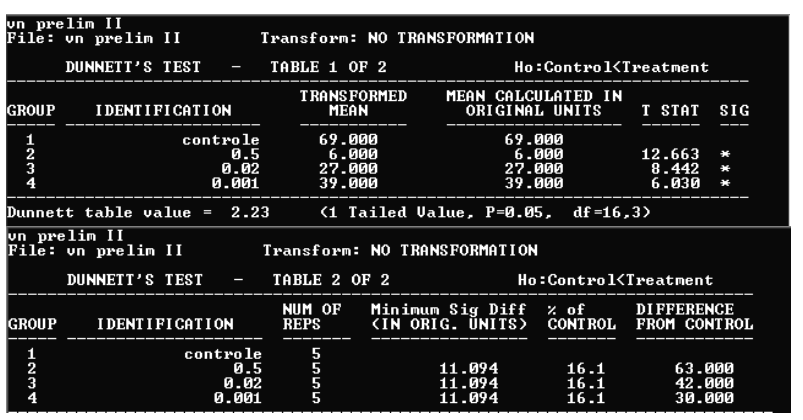

II ensaio preliminar tempo de retenção do corante vermelho neutro - 48 horas

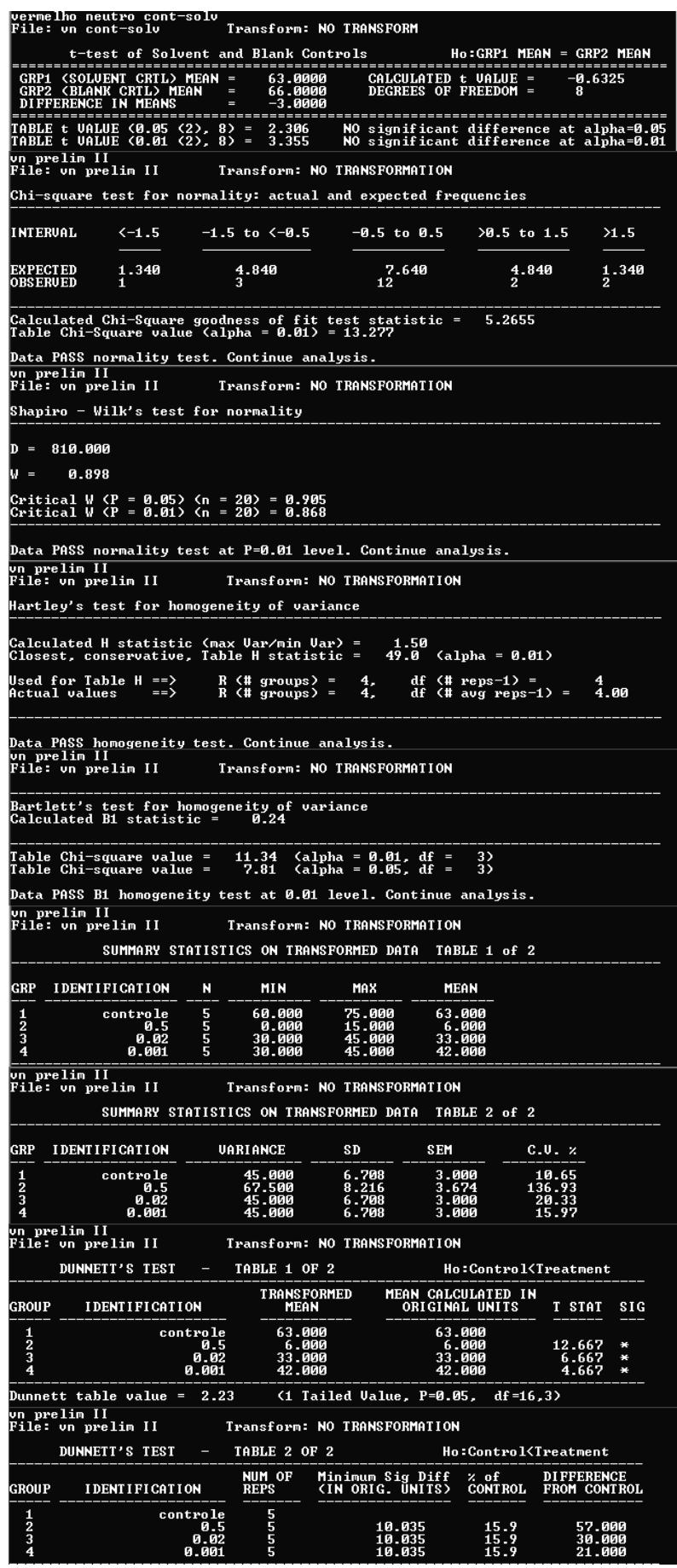

II ensaio preliminar tempo de retenção do corante vermelho neutro - 72 horas 


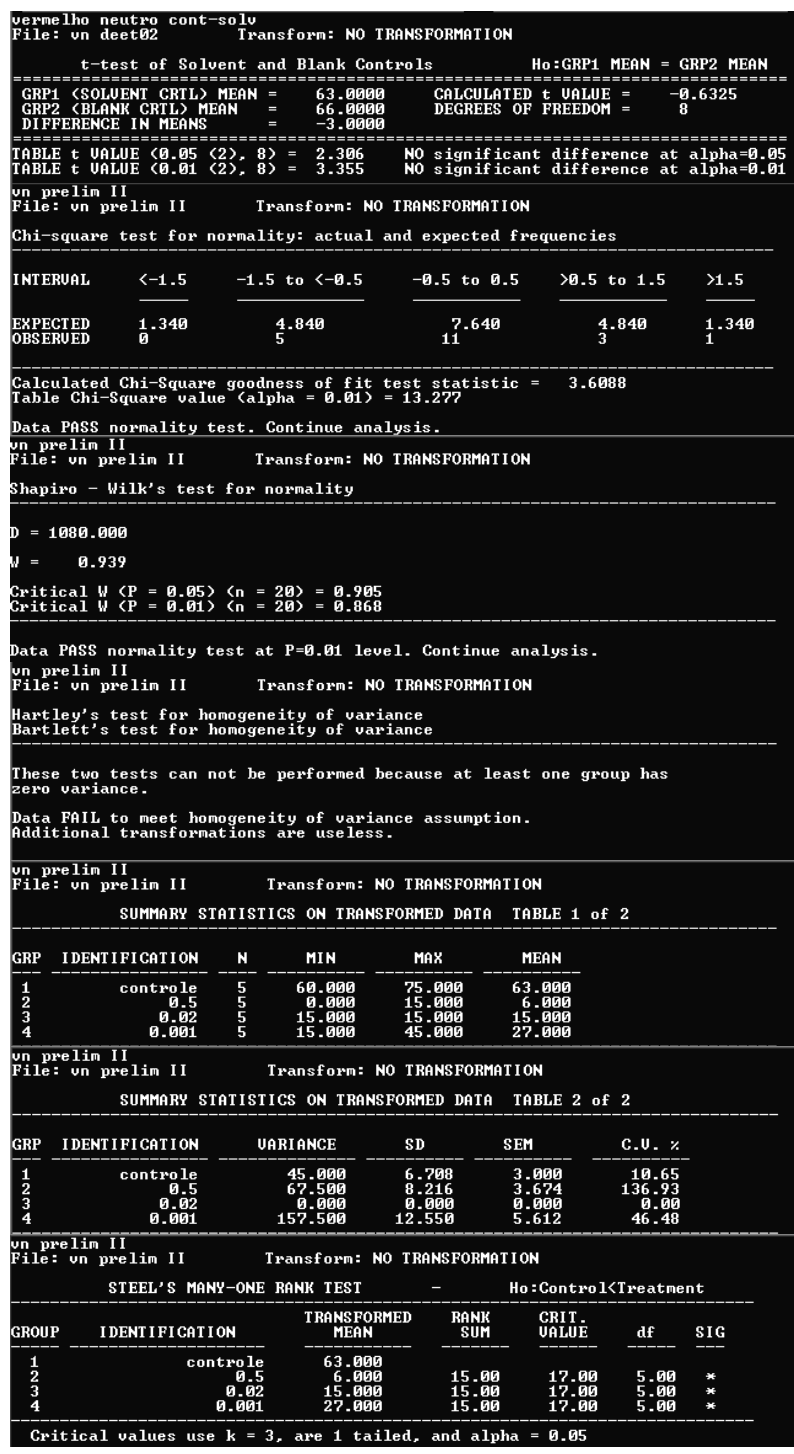

III ensaio preliminar tempo de retenção do corante vermelho neutro - 24 horas

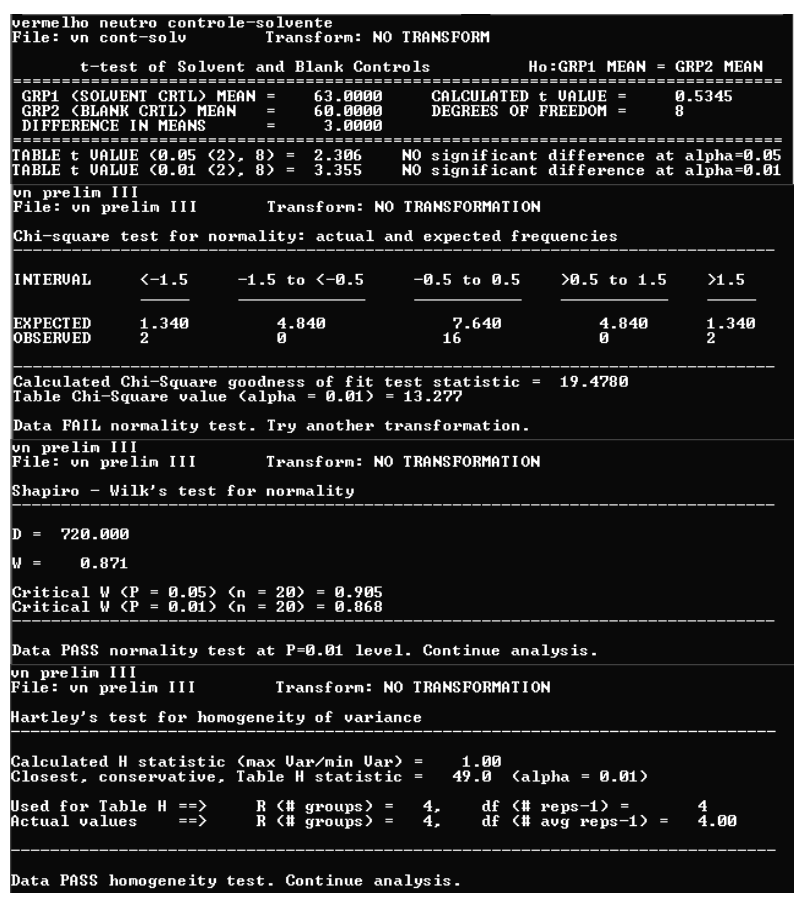




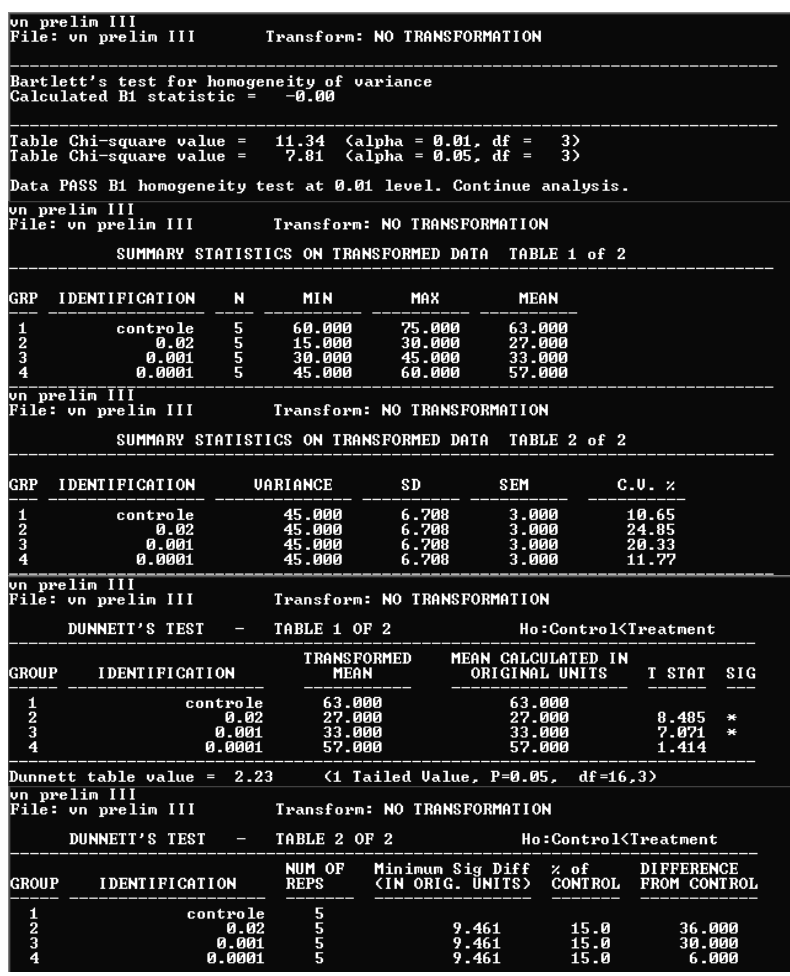

III ensaio preliminar tempo de retenção do corante vermelho neutro - 48 horas

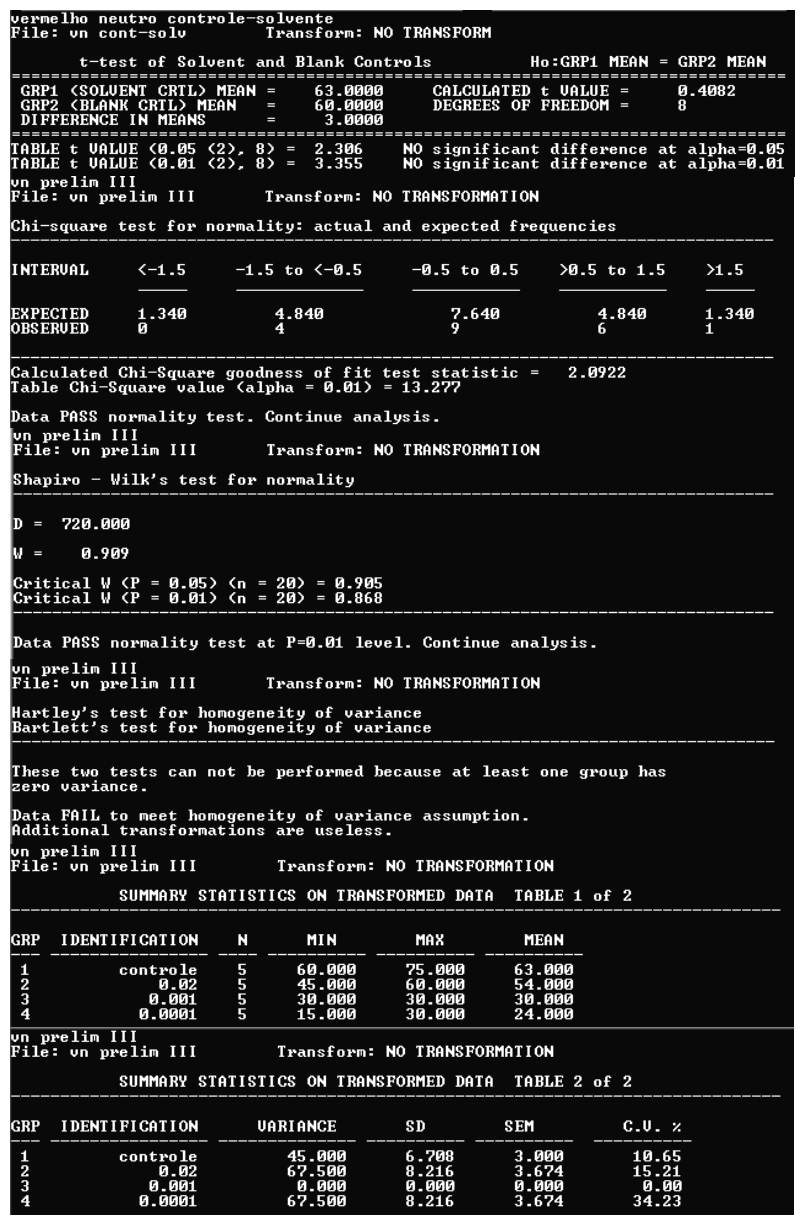




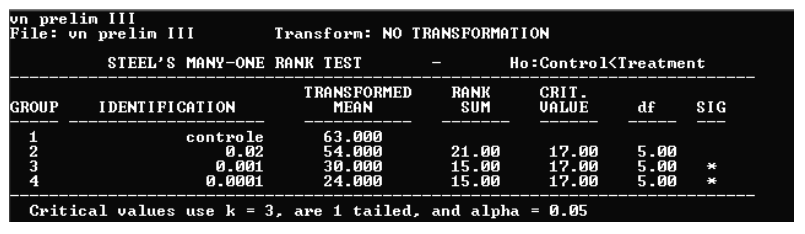

III ensaio preliminar tempo de retenção do corante vermelho neutro - 72 horas

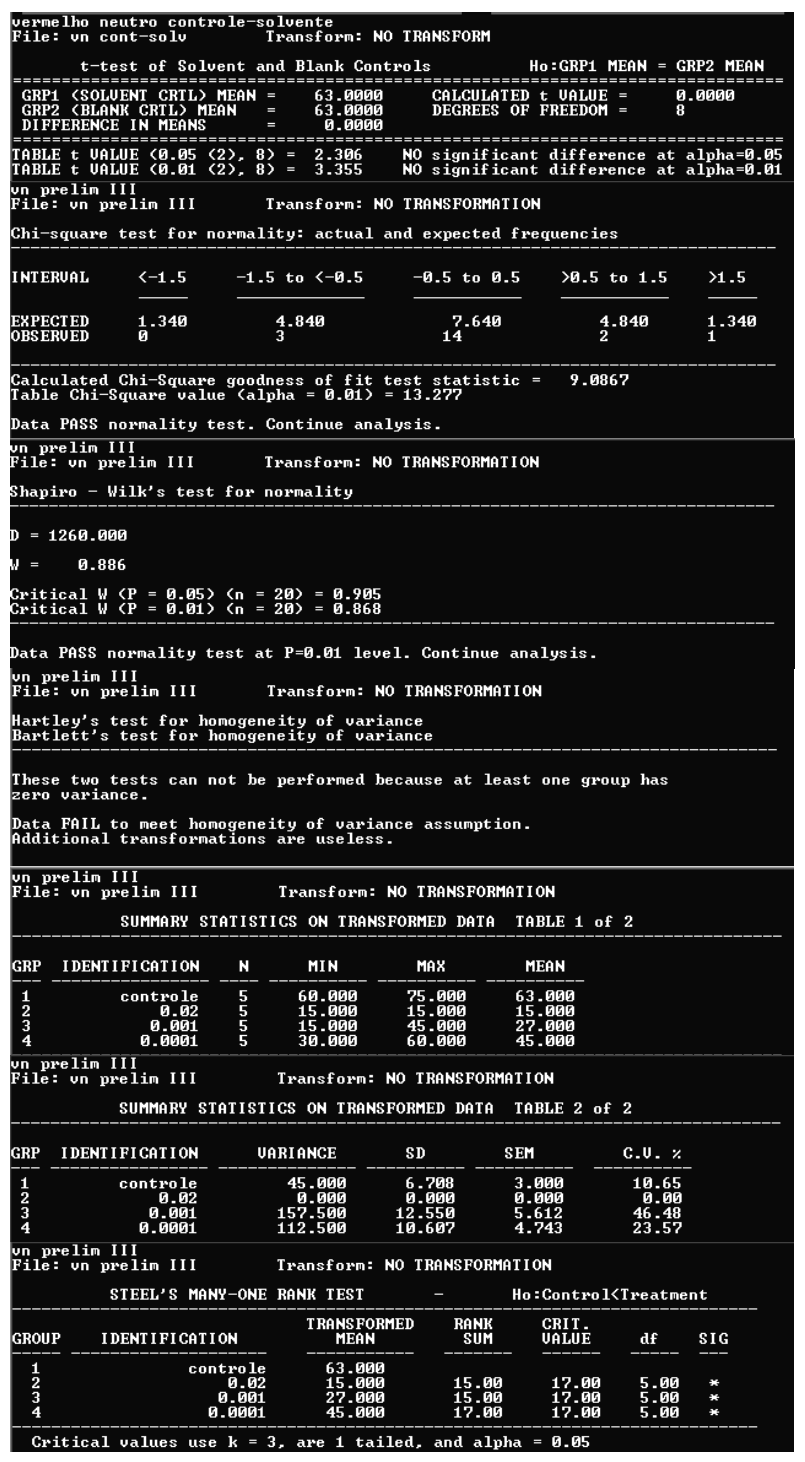

IV ensaio preliminar tempo de retenção do corante vermelho neutro -24 horas

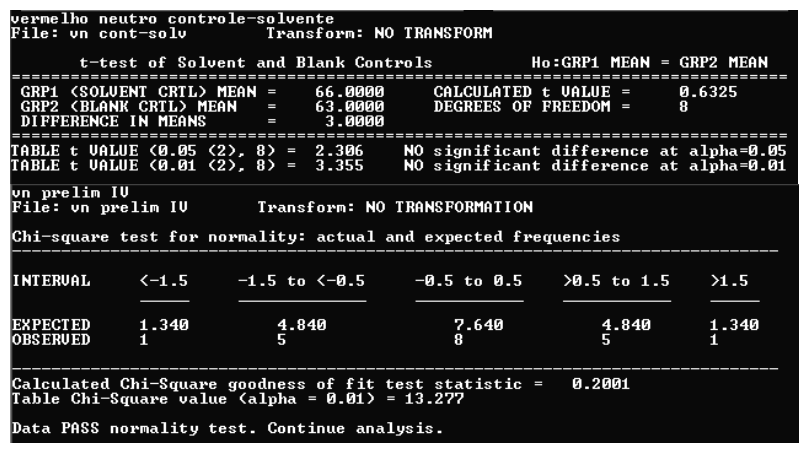




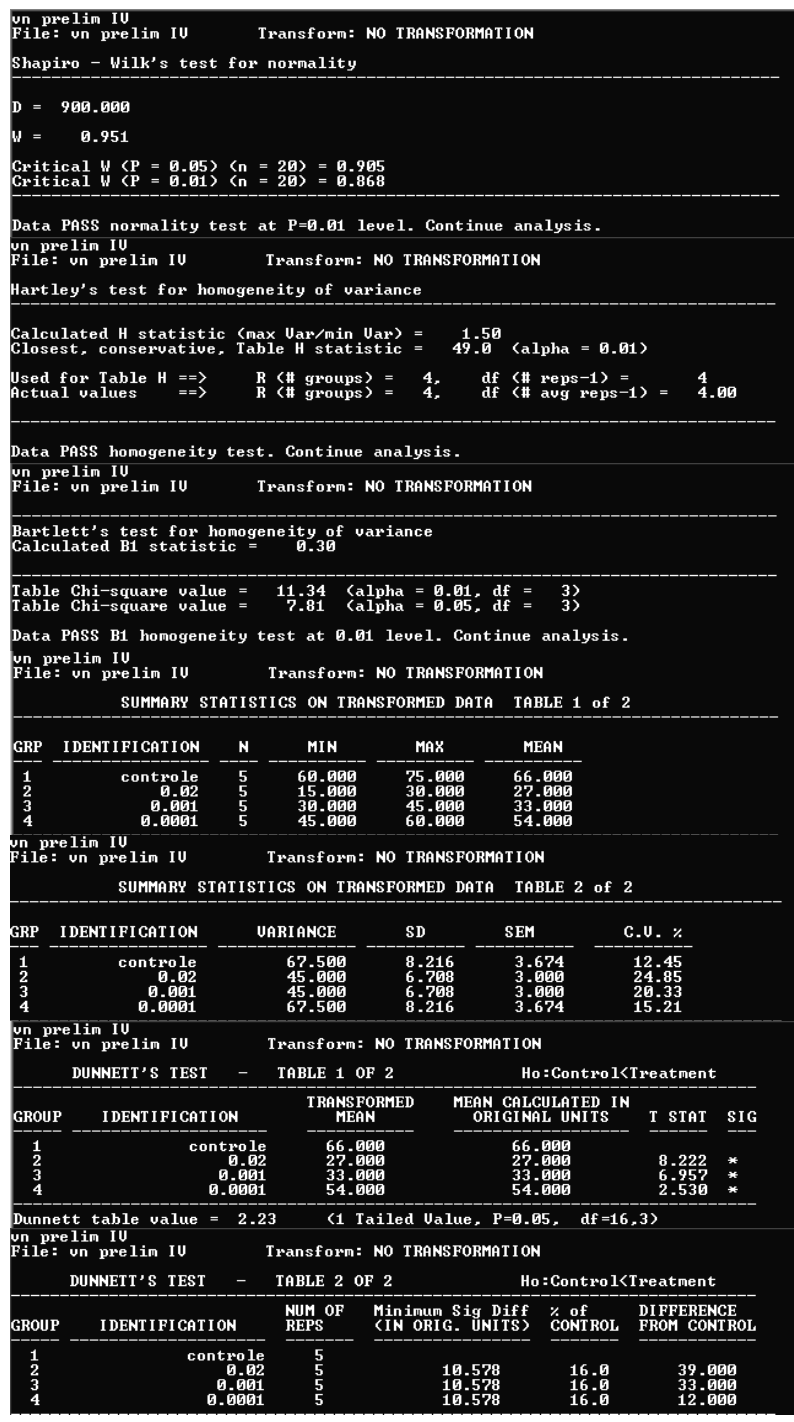

IV ensaio preliminar tempo de retenção do corante vermelho neutro - 48 horas

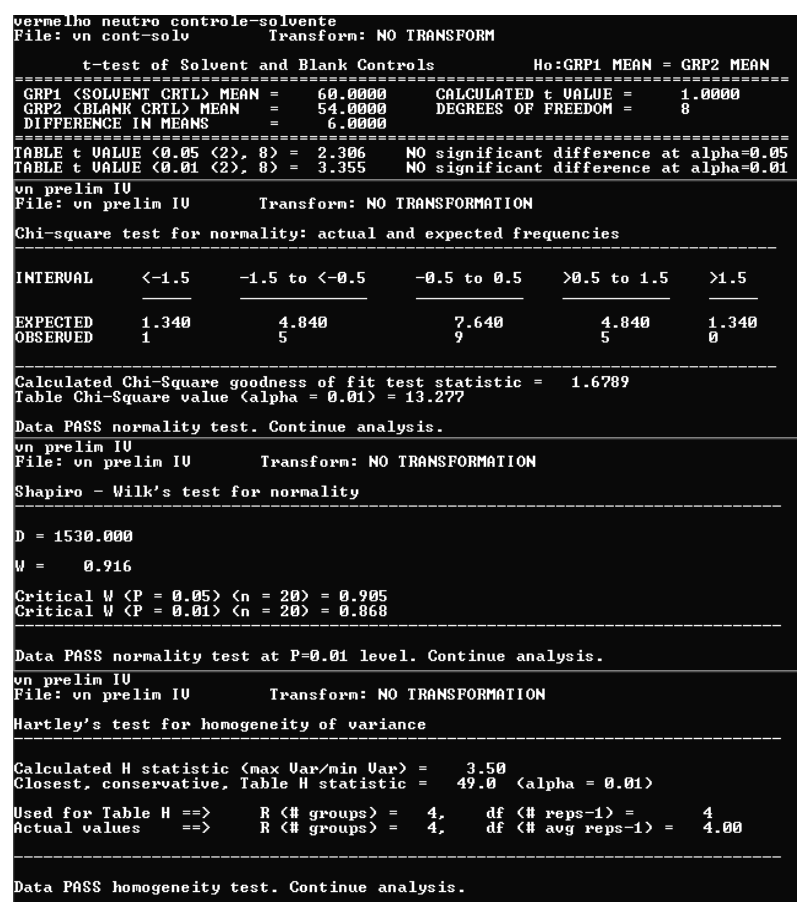




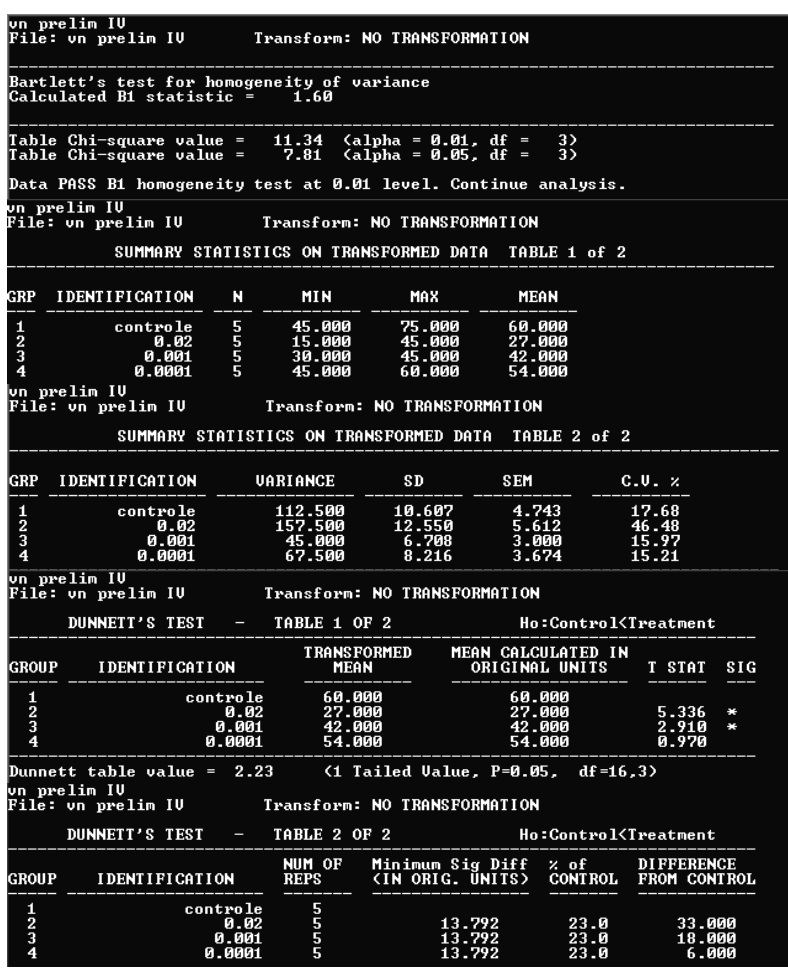

IV ensaio preliminar tempo de retenção do corante vermelho neutro - 72 horas

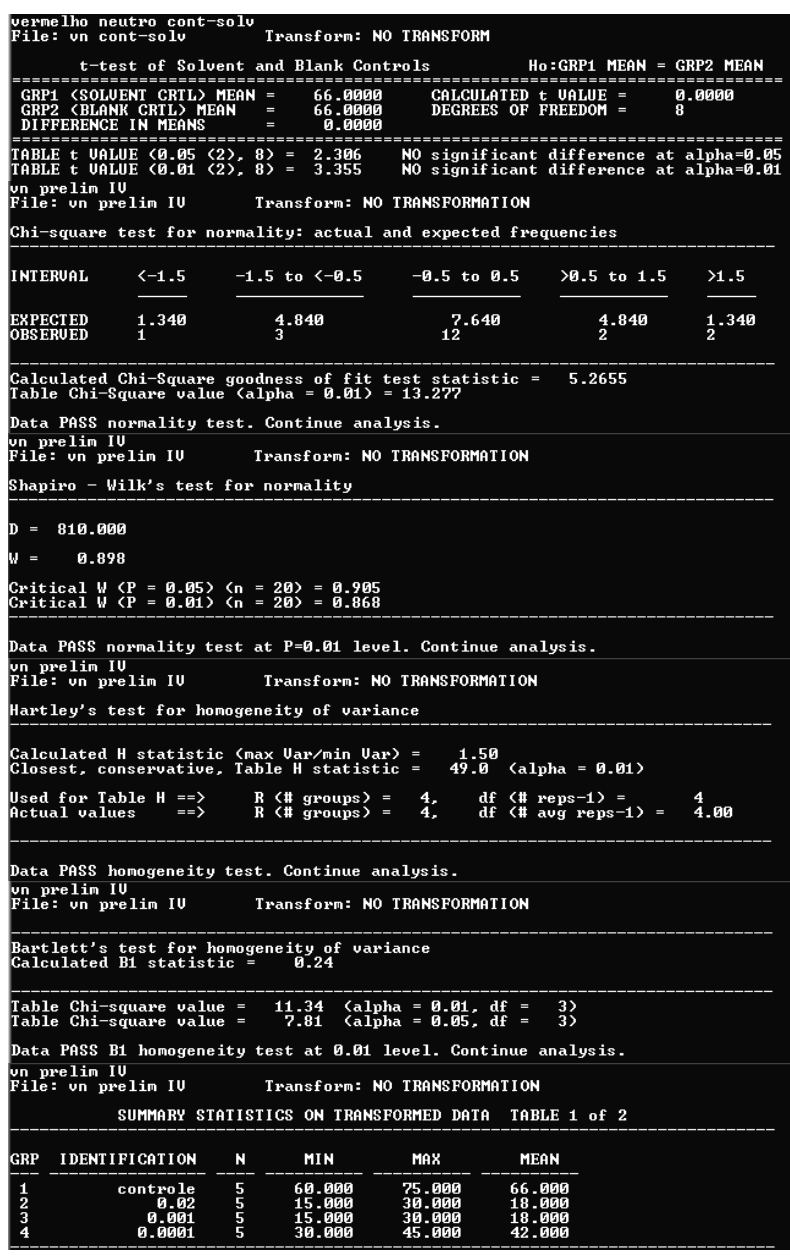




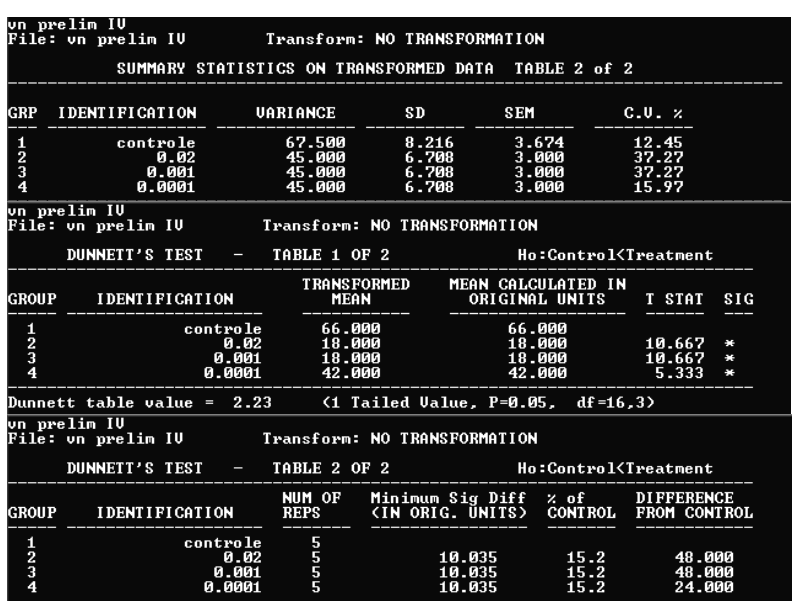

V ensaio preliminar tempo de retenção do corante vermelho neutro - 24 horas

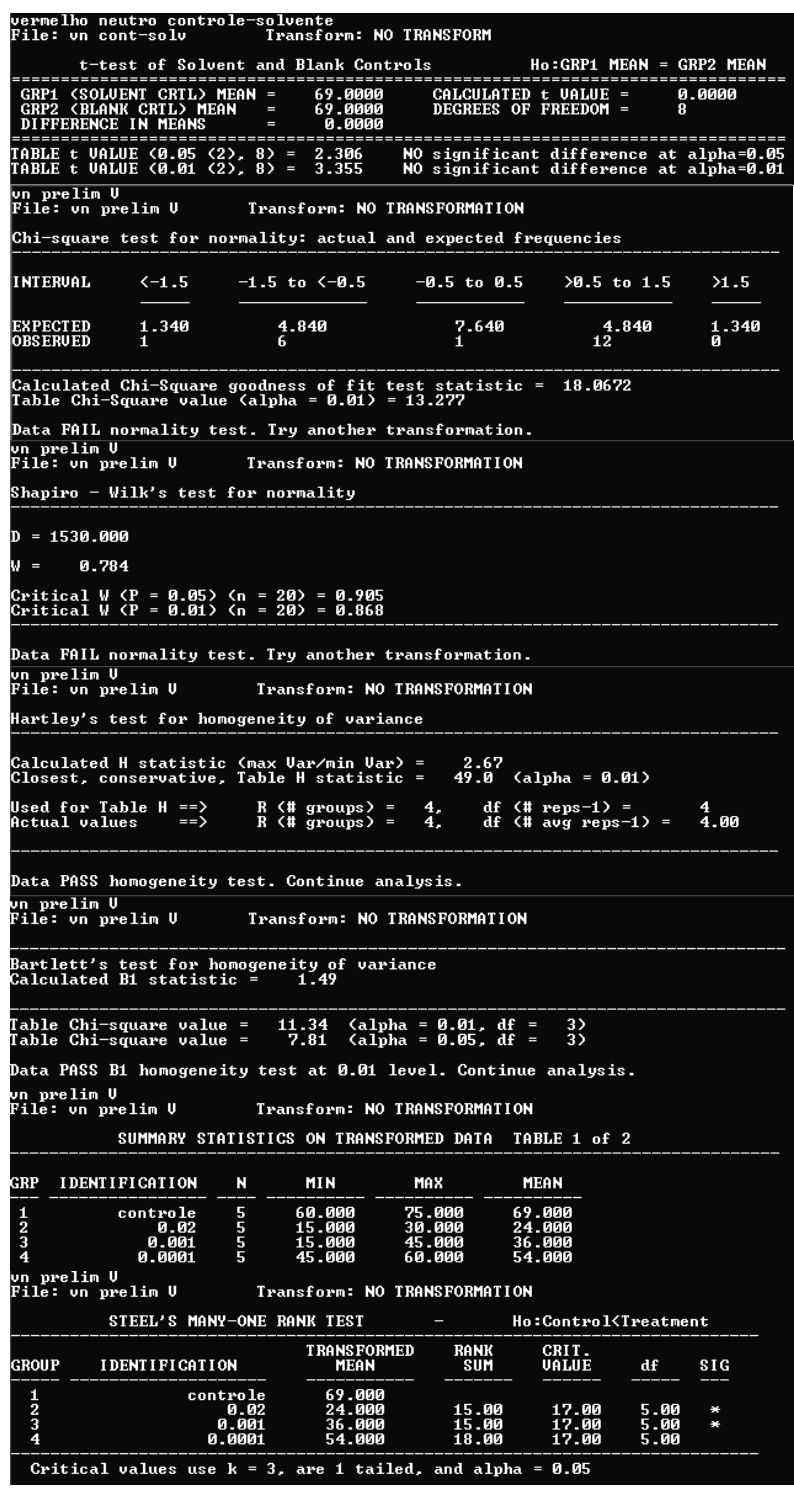

V ensaio preliminar tempo de retenção do corante vermelho neutro - 48 horas 


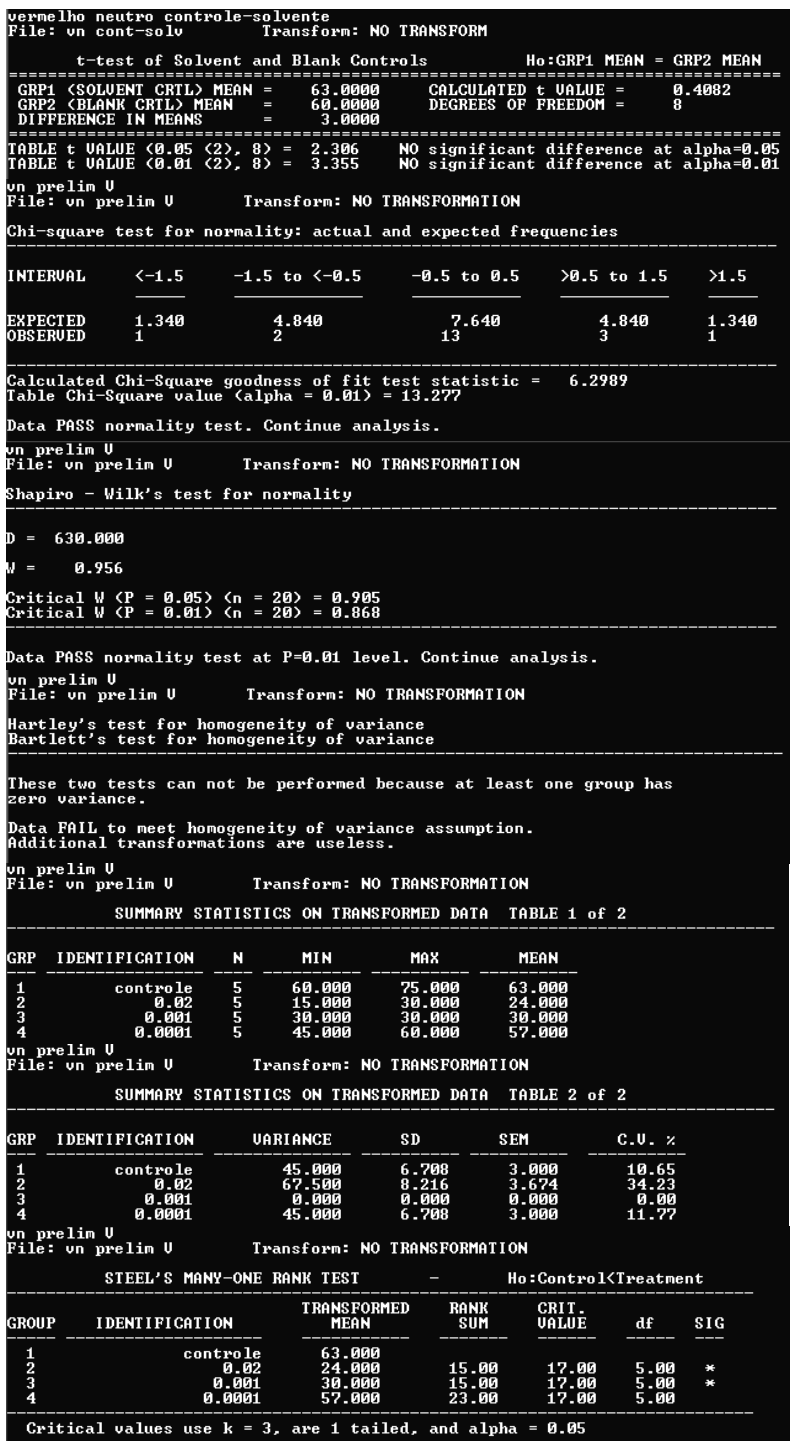

V ensaio preliminar tempo de retenção do corante vermelho neutro - 72 horas

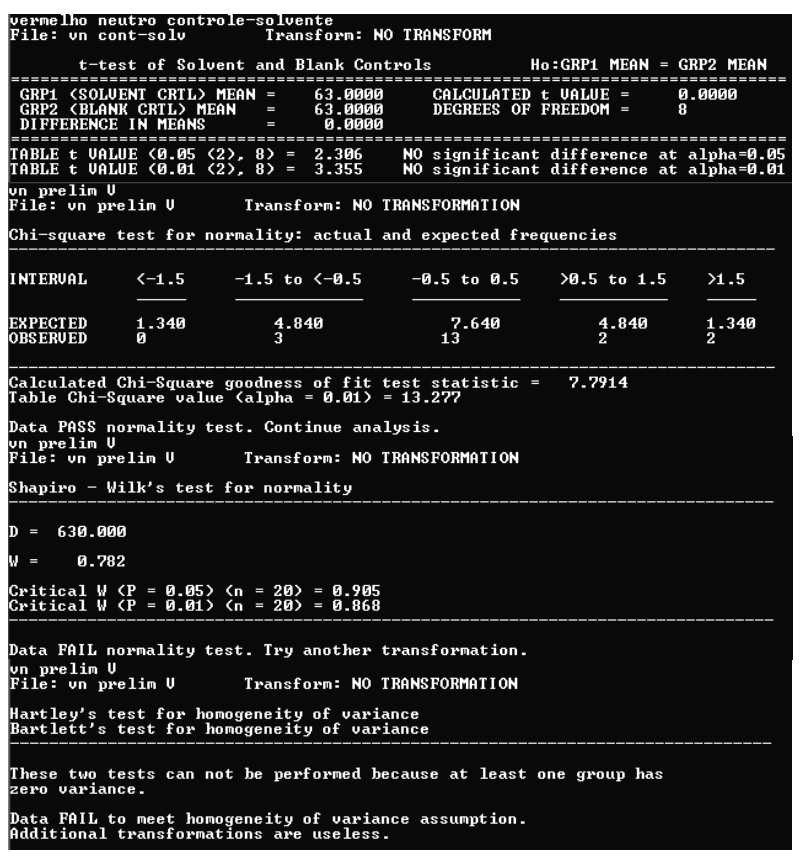




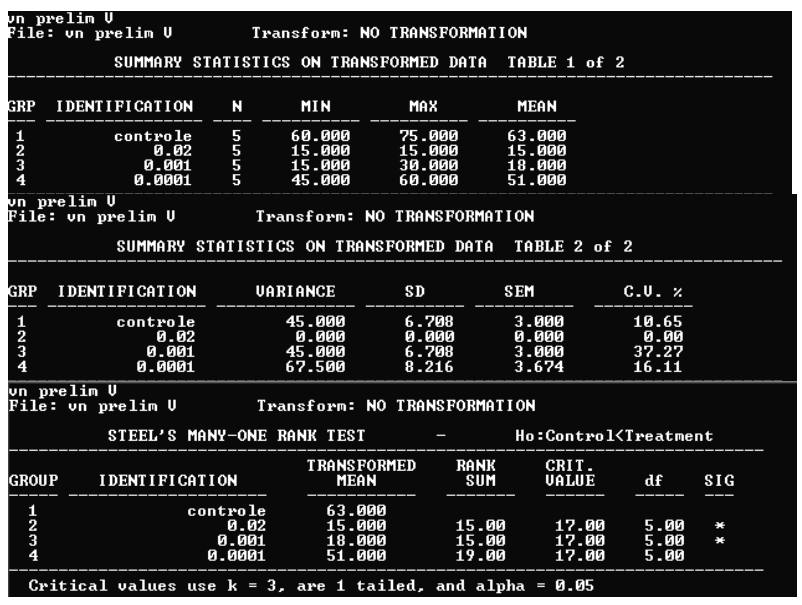

APÊNDICE D - Resultados dos ensaios de citotoxicidade do DEET em organismos não irradiados obtidos por meio do software TOXSTAT 3.4 (GULLEY, D.D. et al. 1991).

\section{Ensaio - 24 horas}

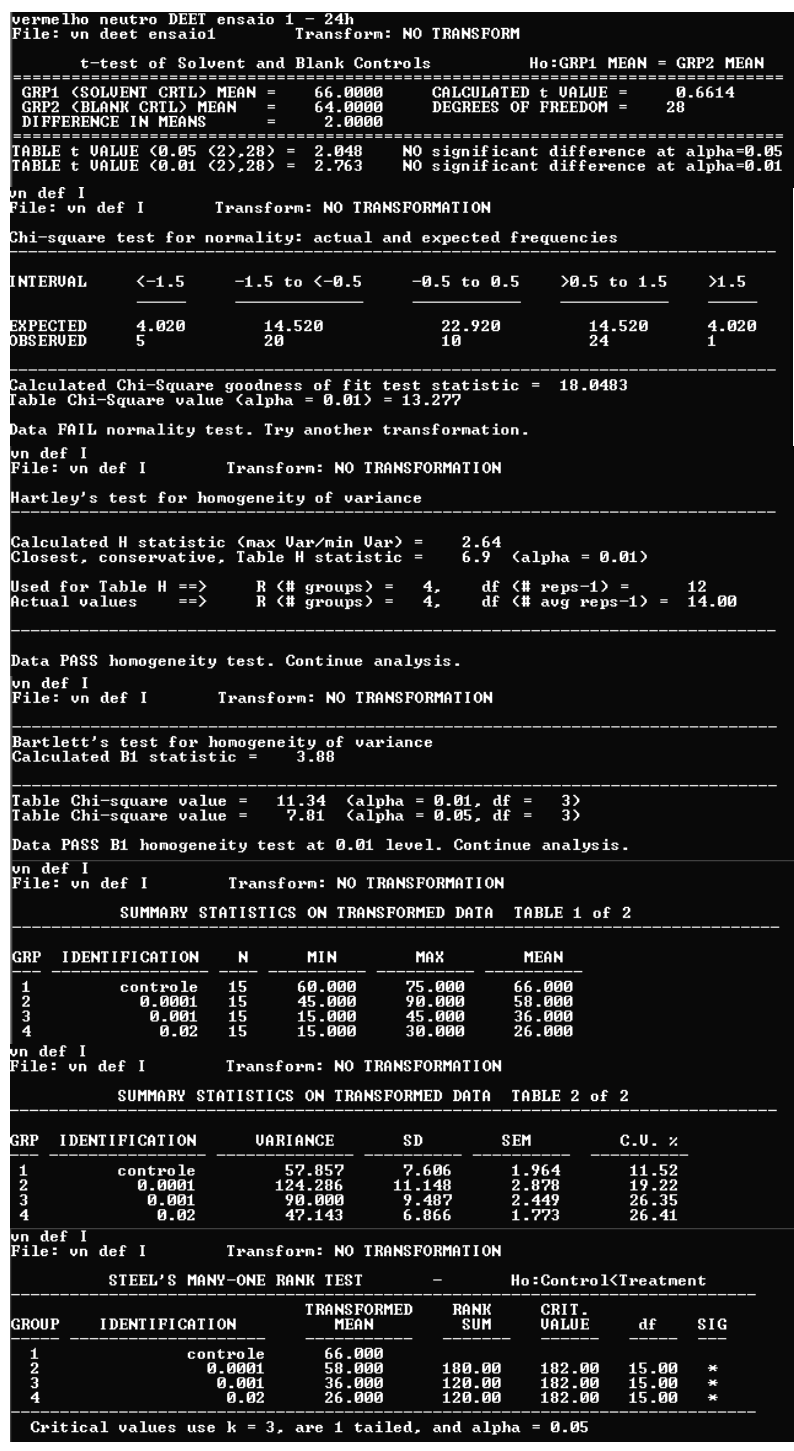

I Ensaio - 48 horas 


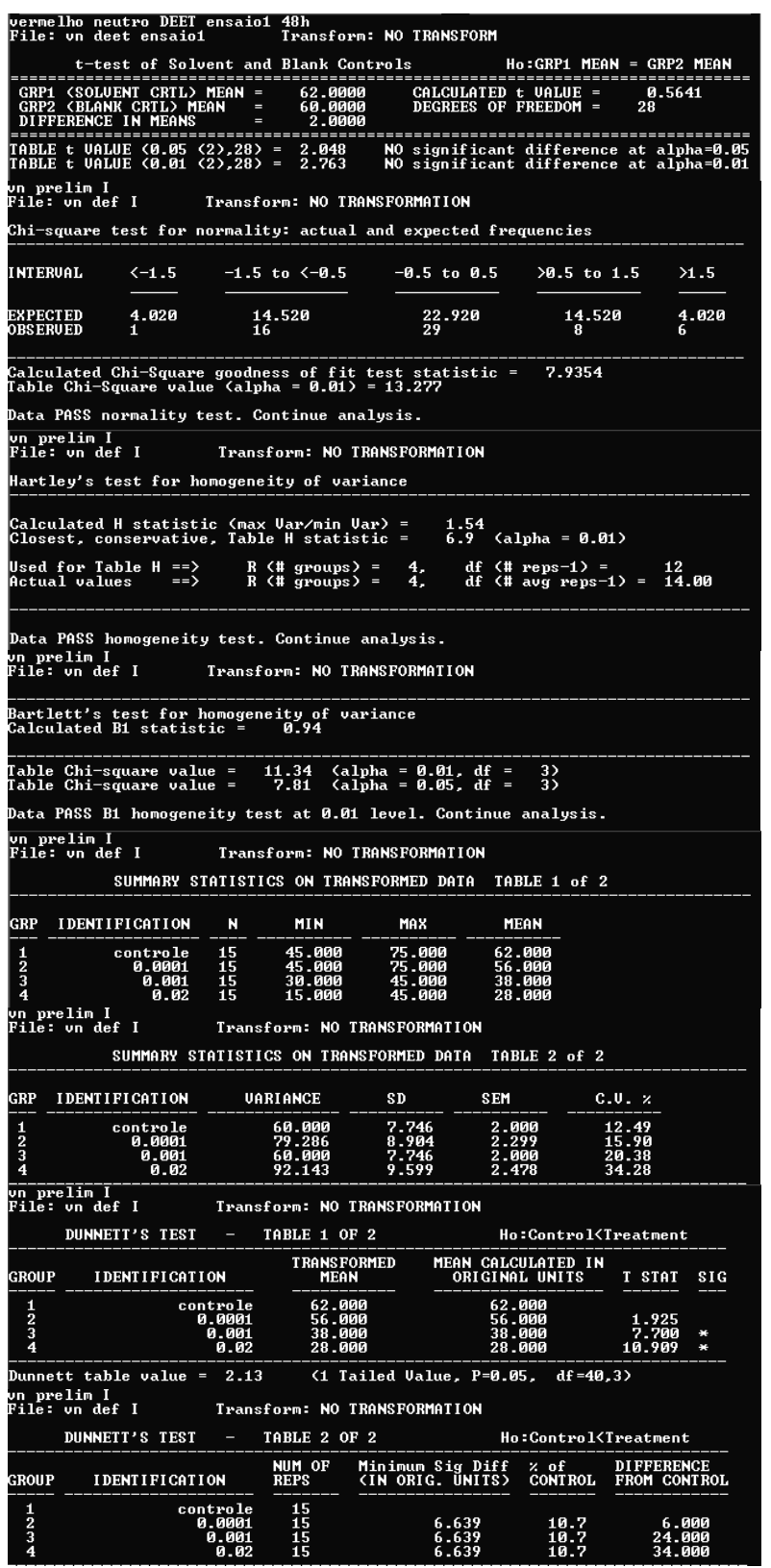

\section{Ensaio - 72 horas}

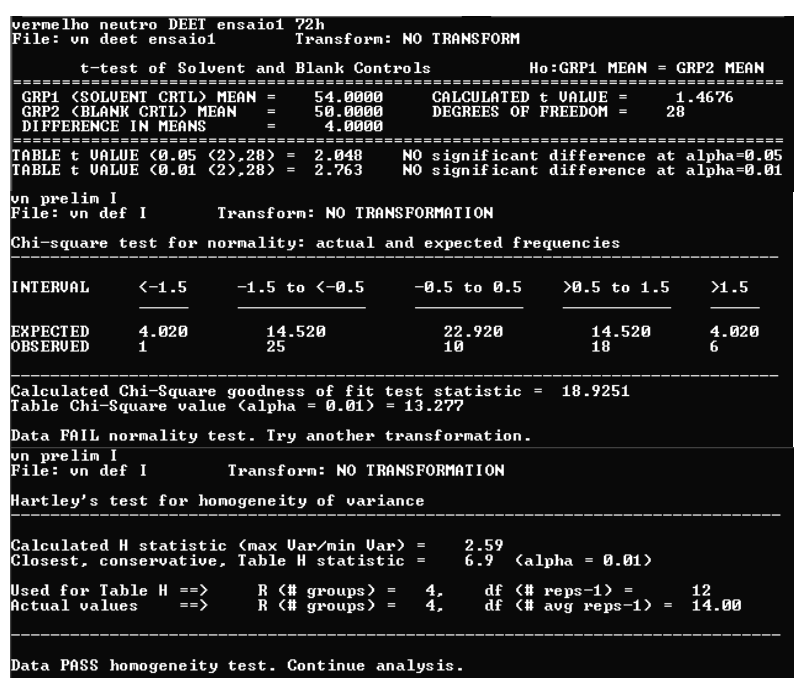




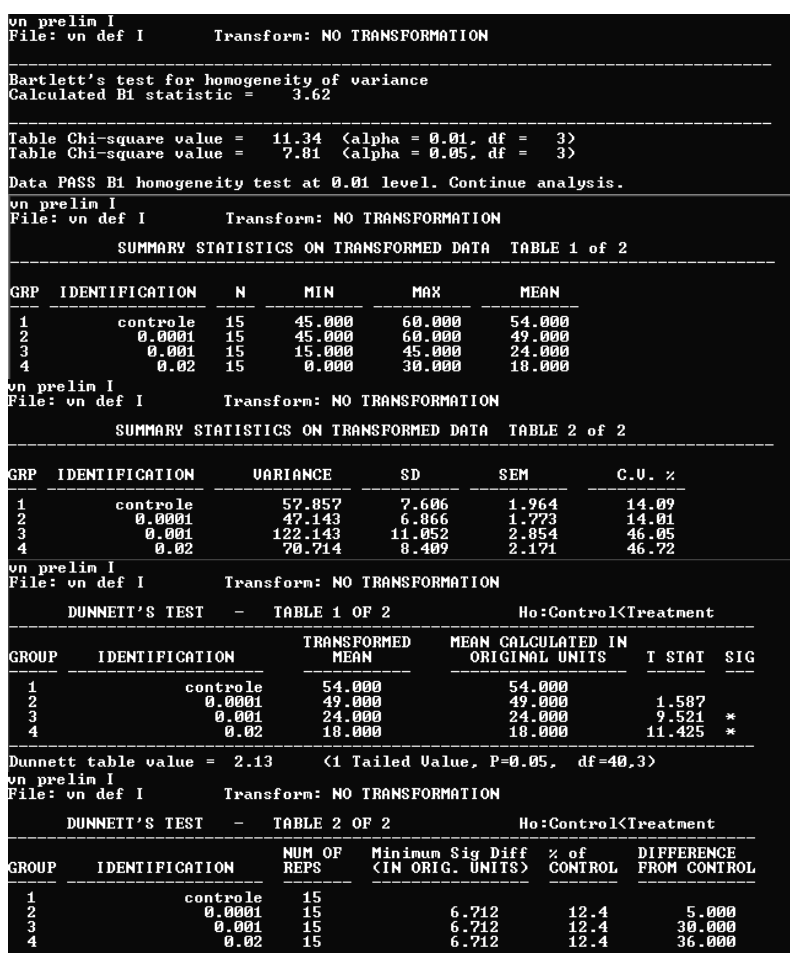

\section{Ensaio - 24 horas}

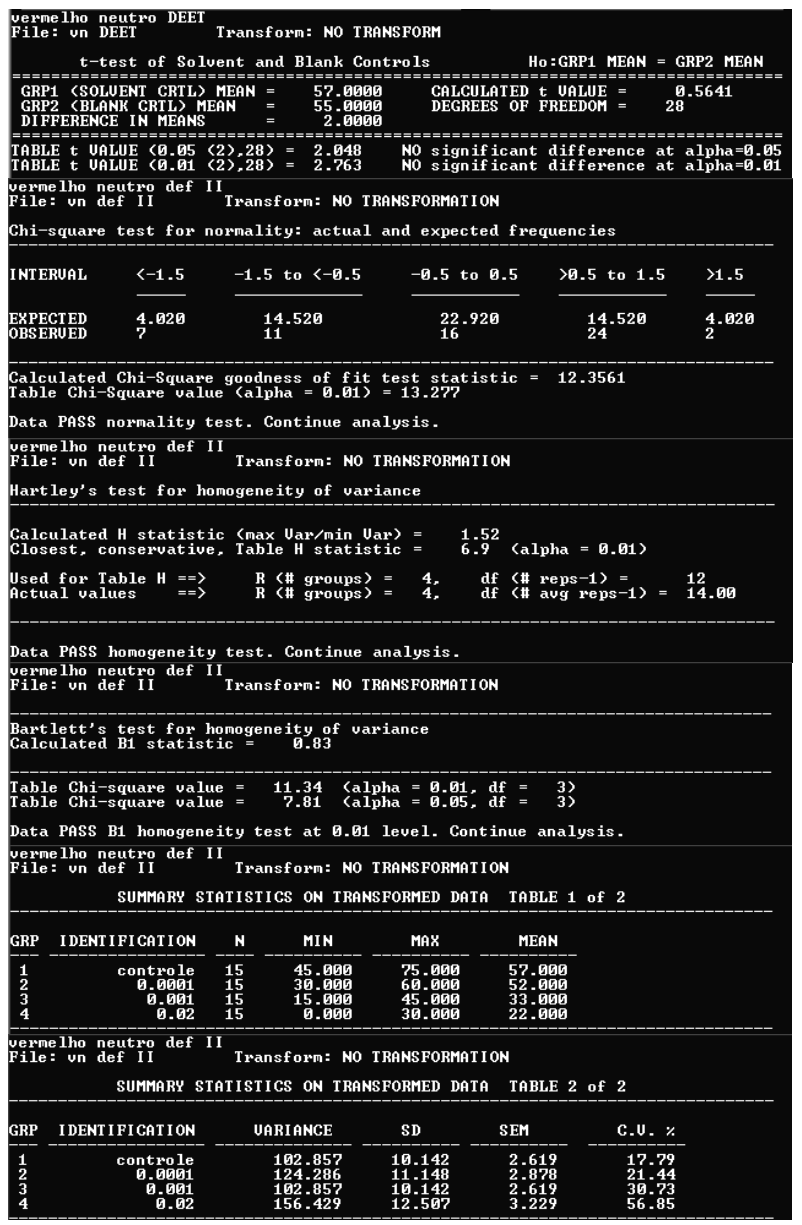




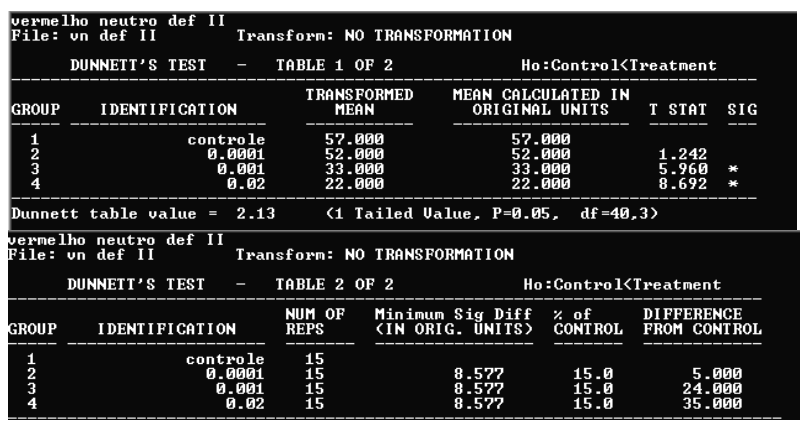

\section{Ensaio - 48 horas}

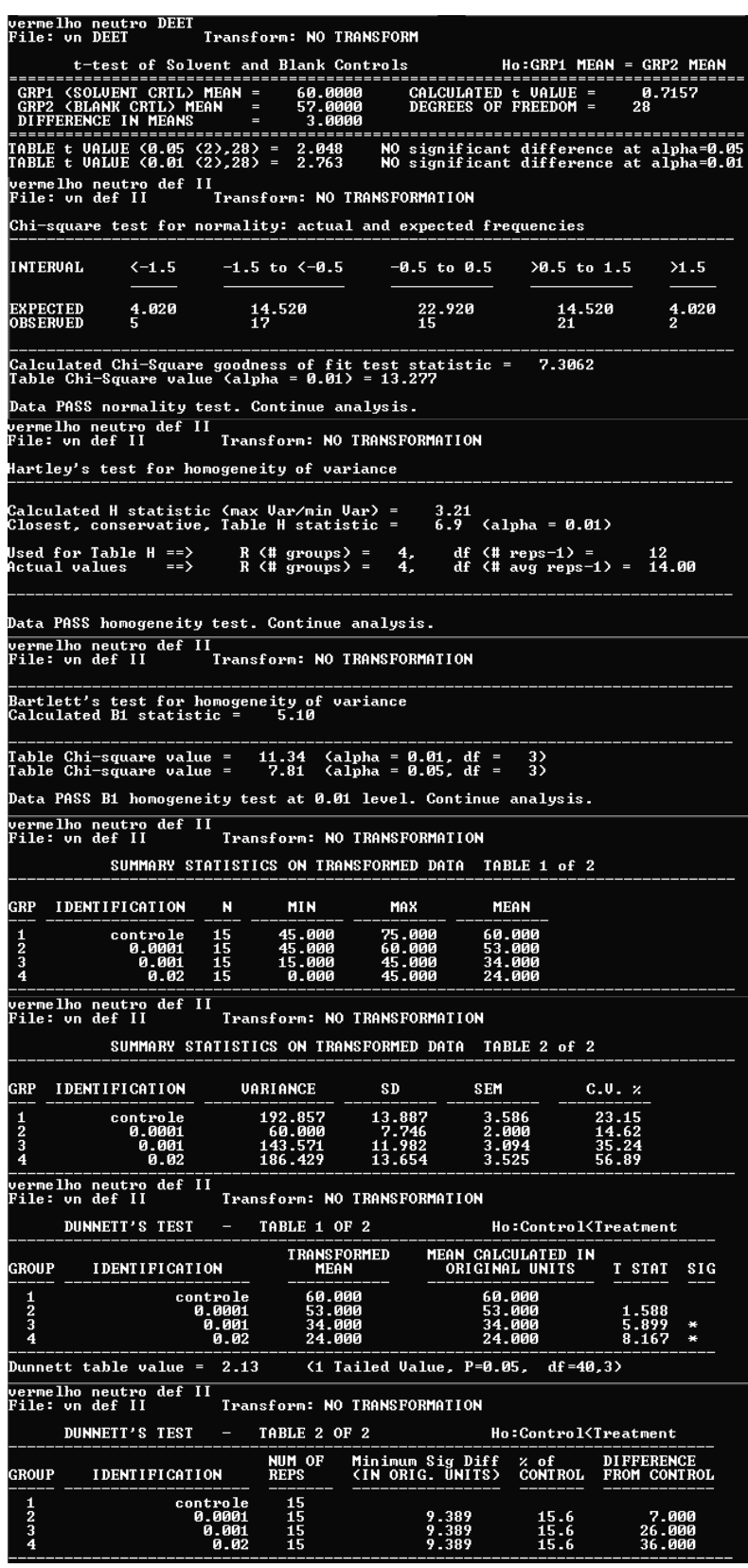

II Ensaio - 72 horas 


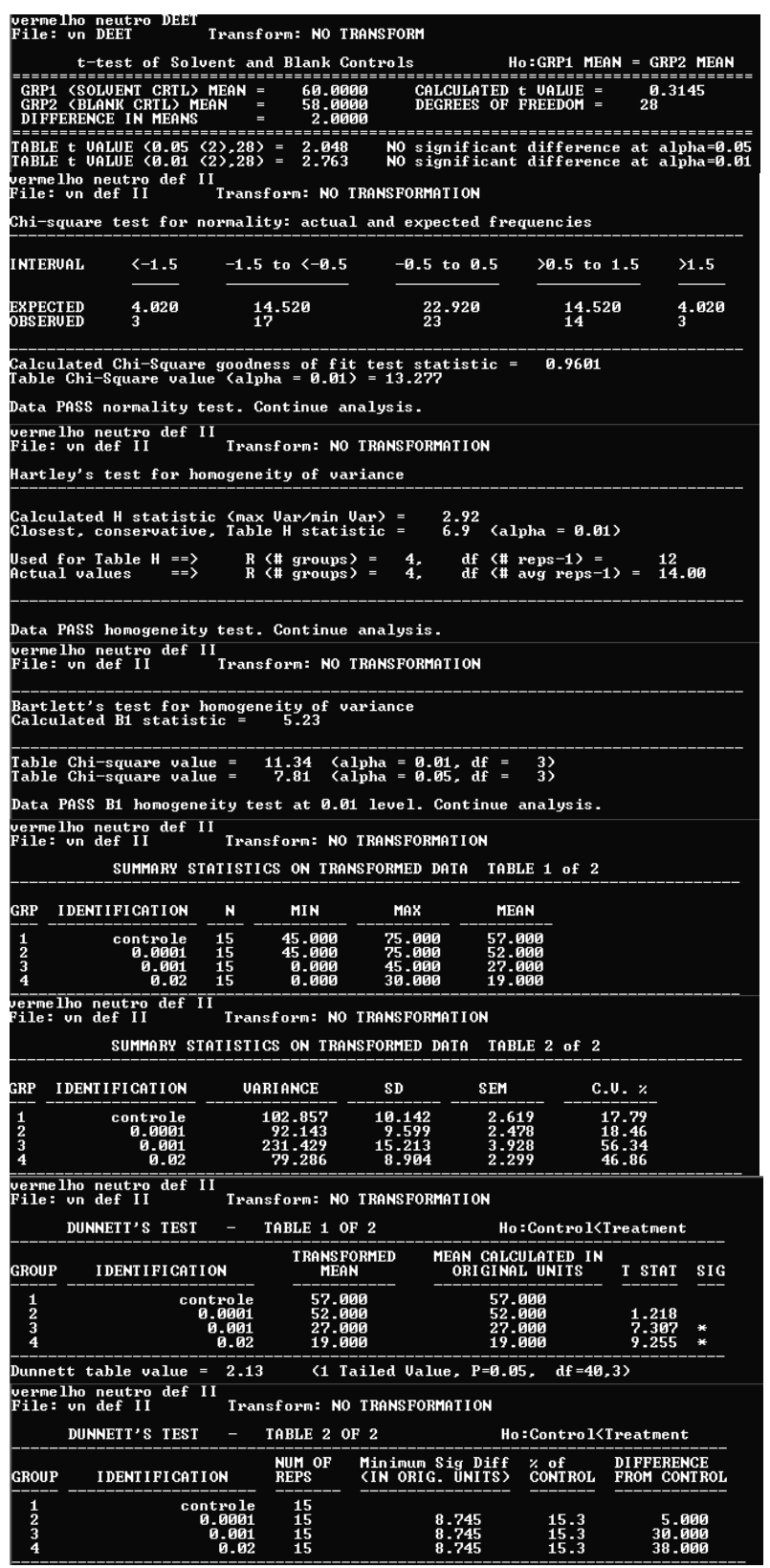

\section{Ensaio - 24 horas}

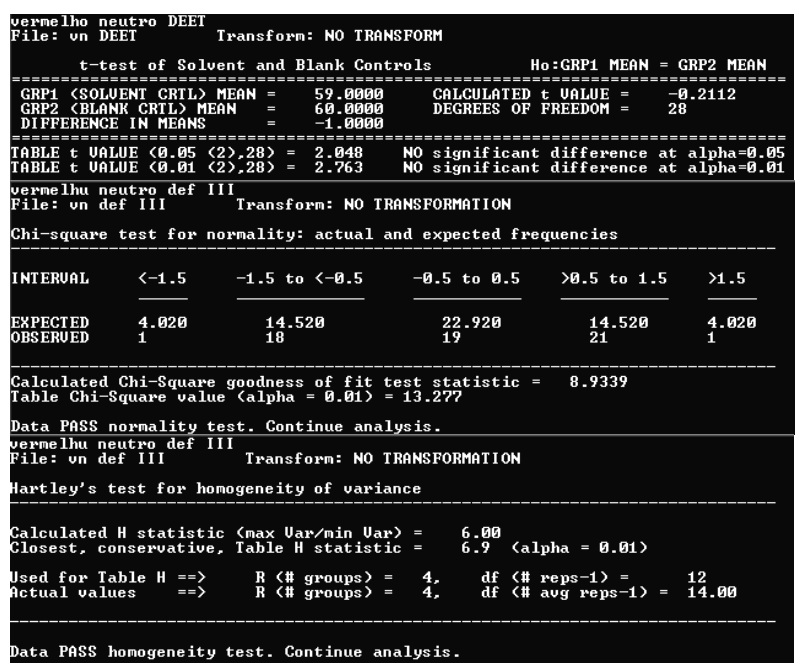




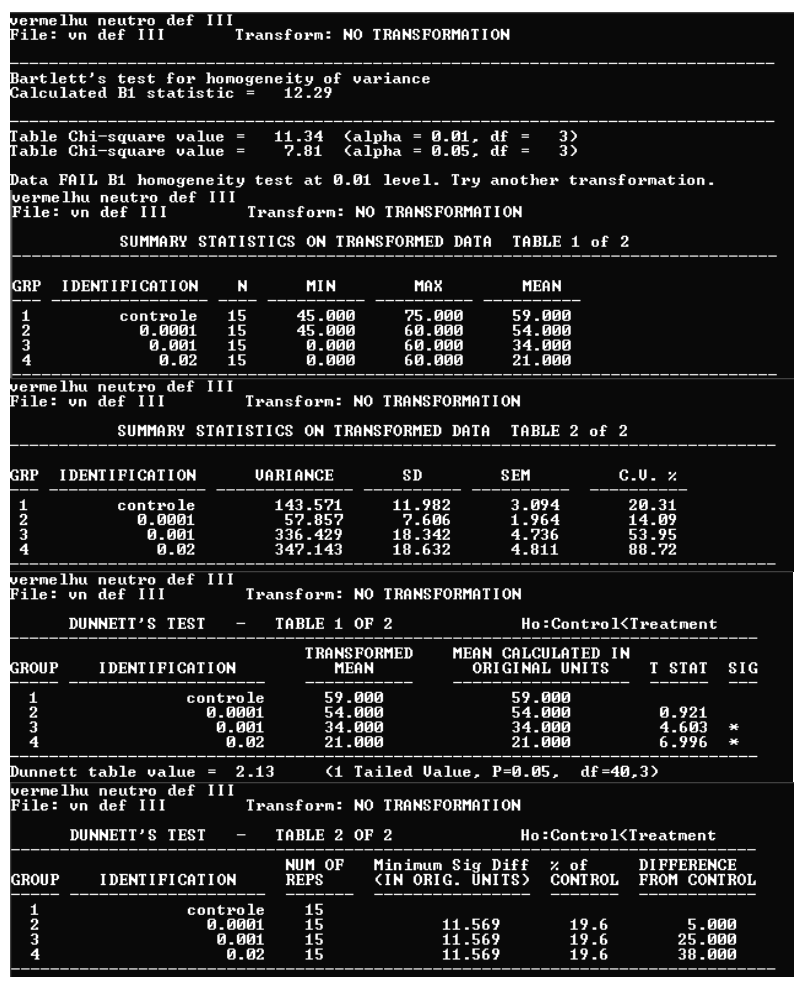

\section{Ensaio - 48 horas}

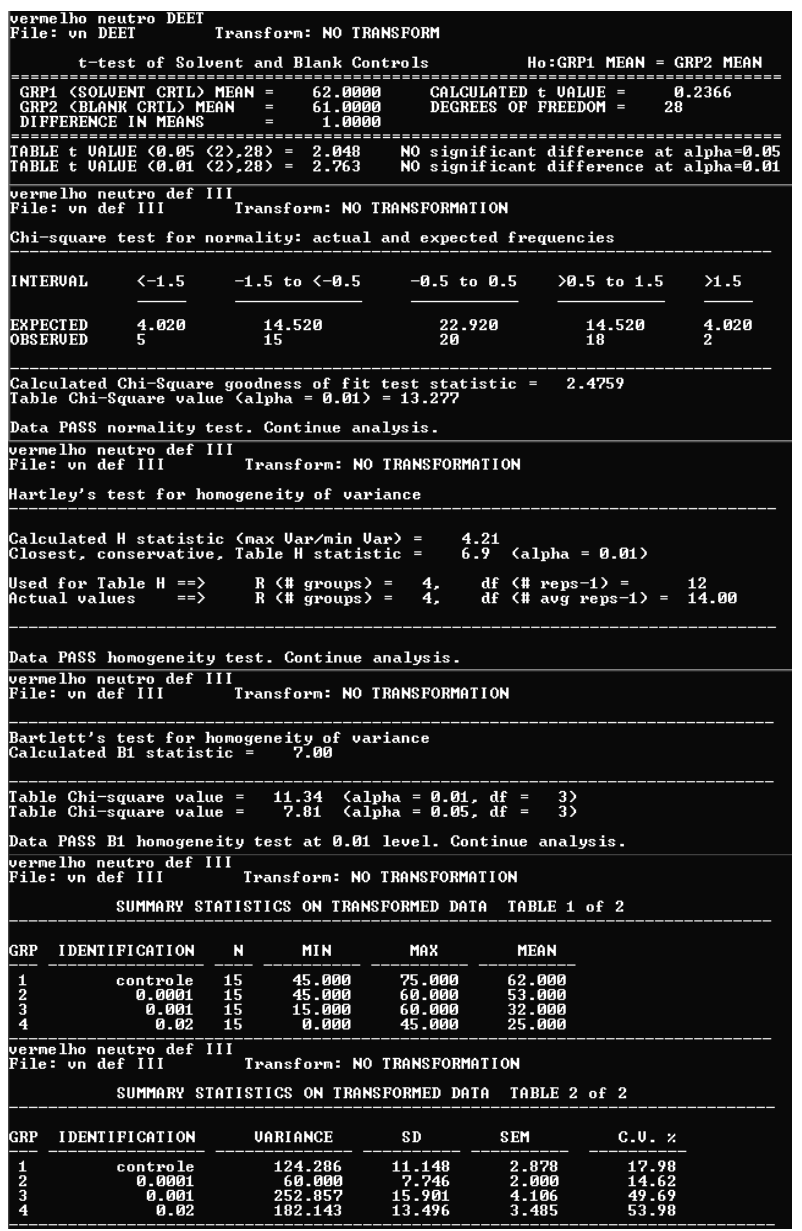




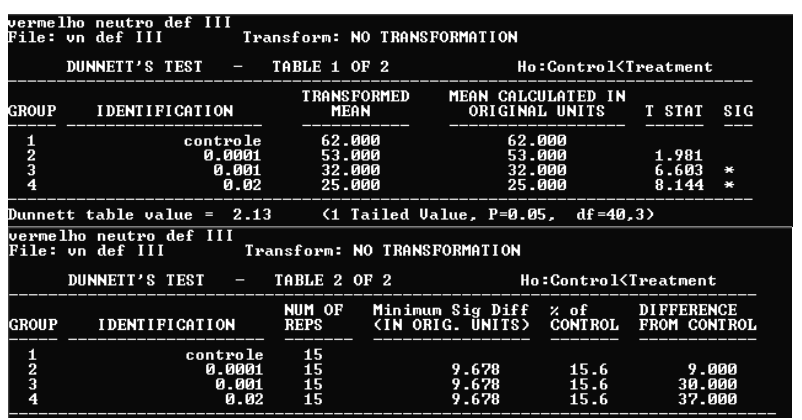

III Ensaio - 72 horas

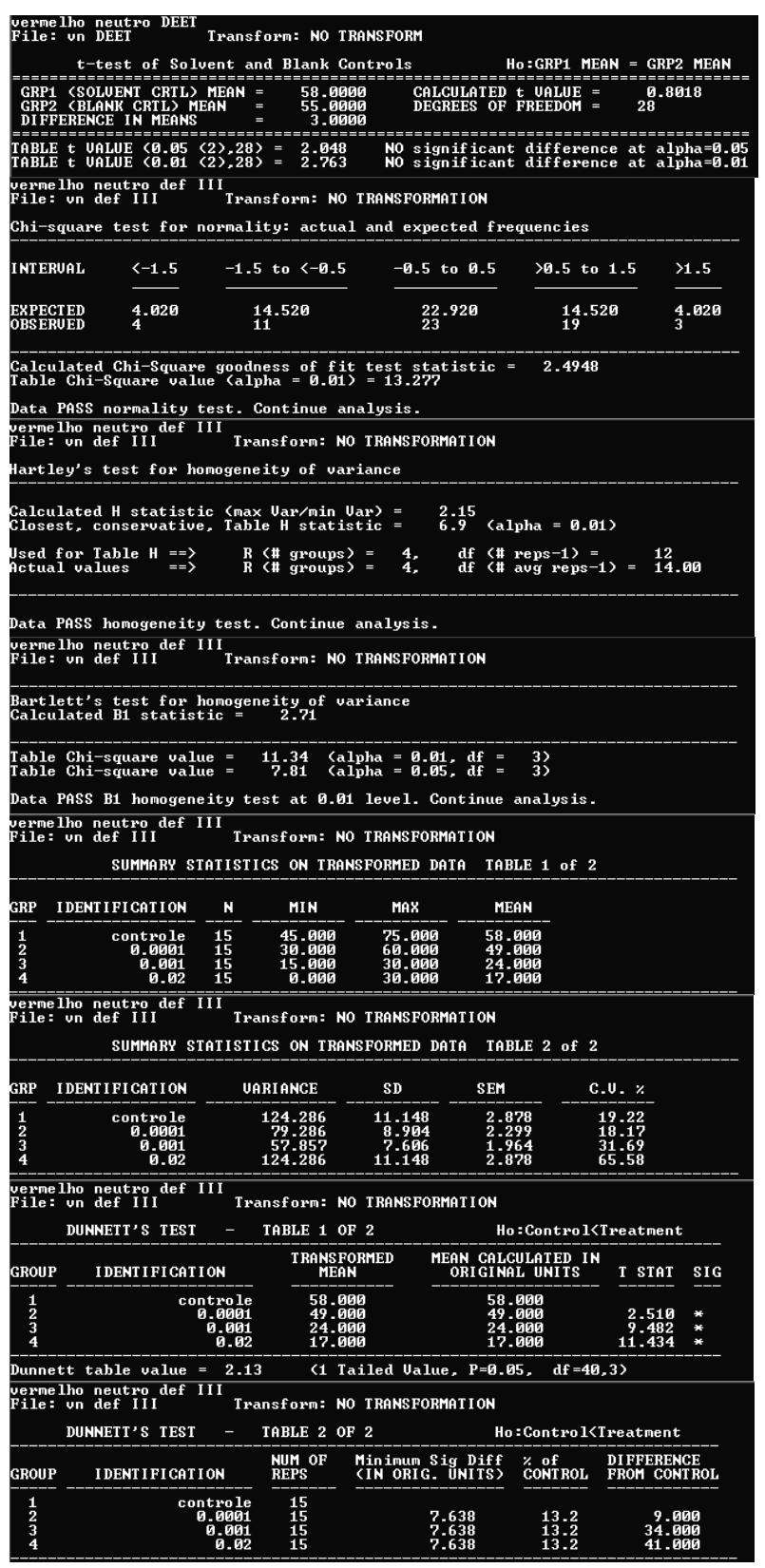

APÊNDICE E - Resultados dos ensaios preliminares de citotoxicidade do DEET em organismos irradiados obtidos por meio do software TOXSTAT 3.4 (GULLEY, D.D. et al. 1991).

I ensaio preliminar $107 \mathrm{~Gy}-24$ horas 


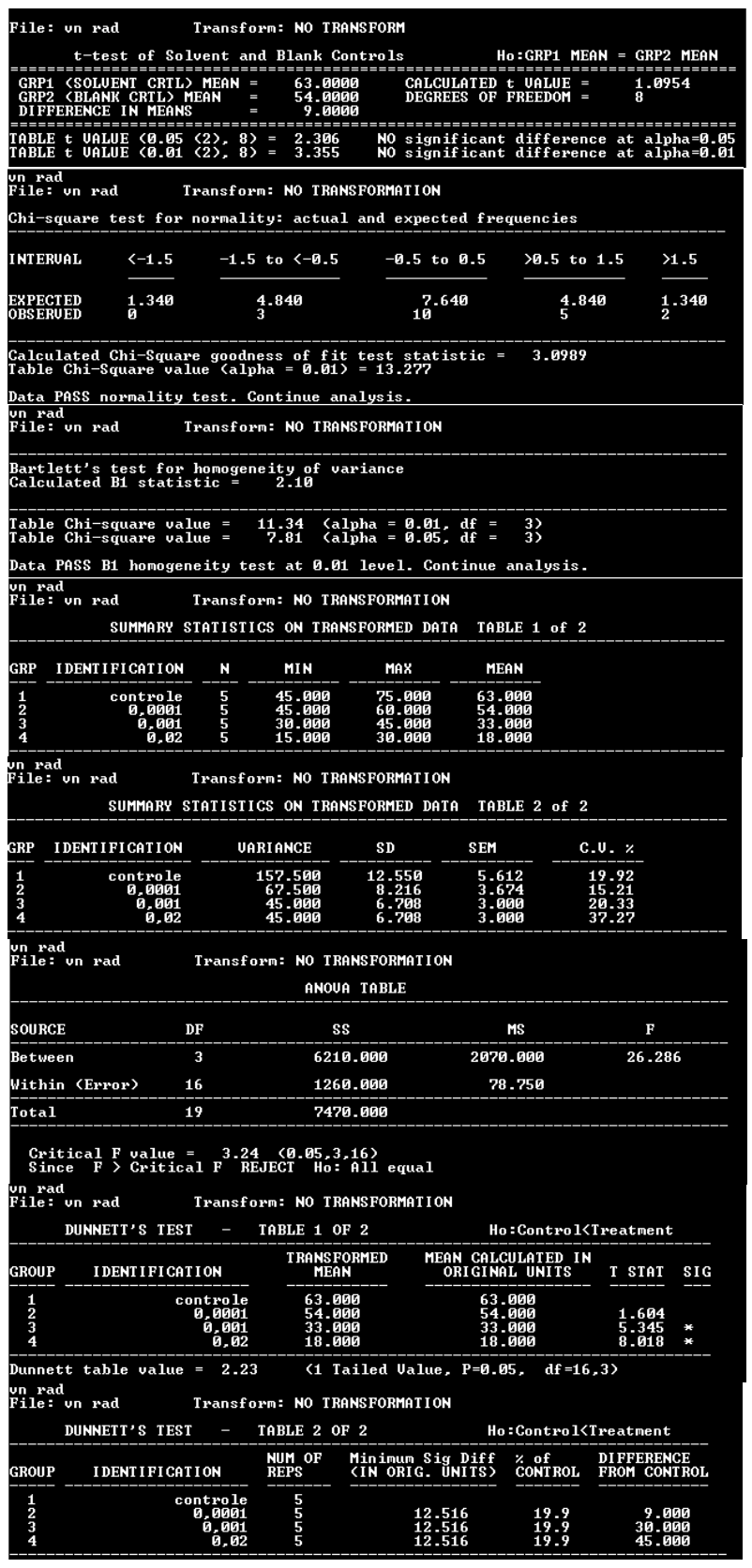

I ensaio preliminar 107 Gy - 48 horas

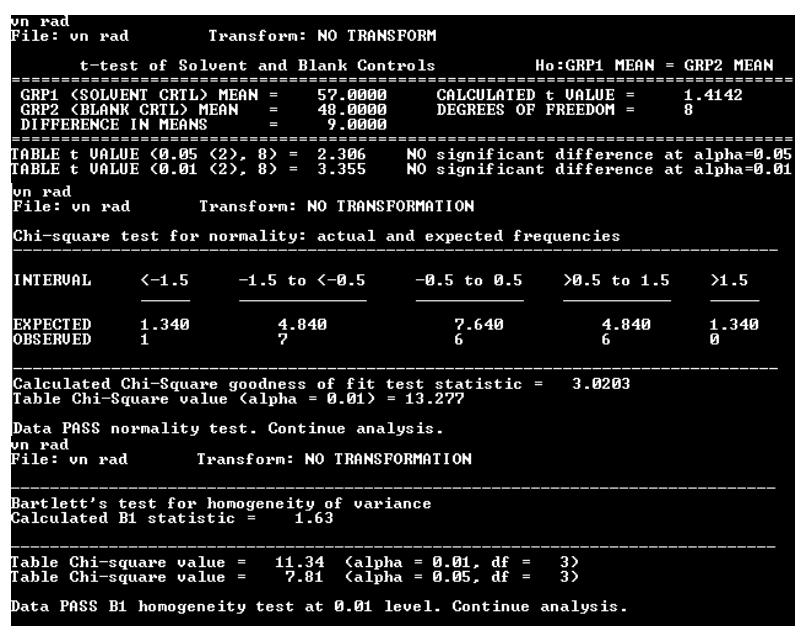




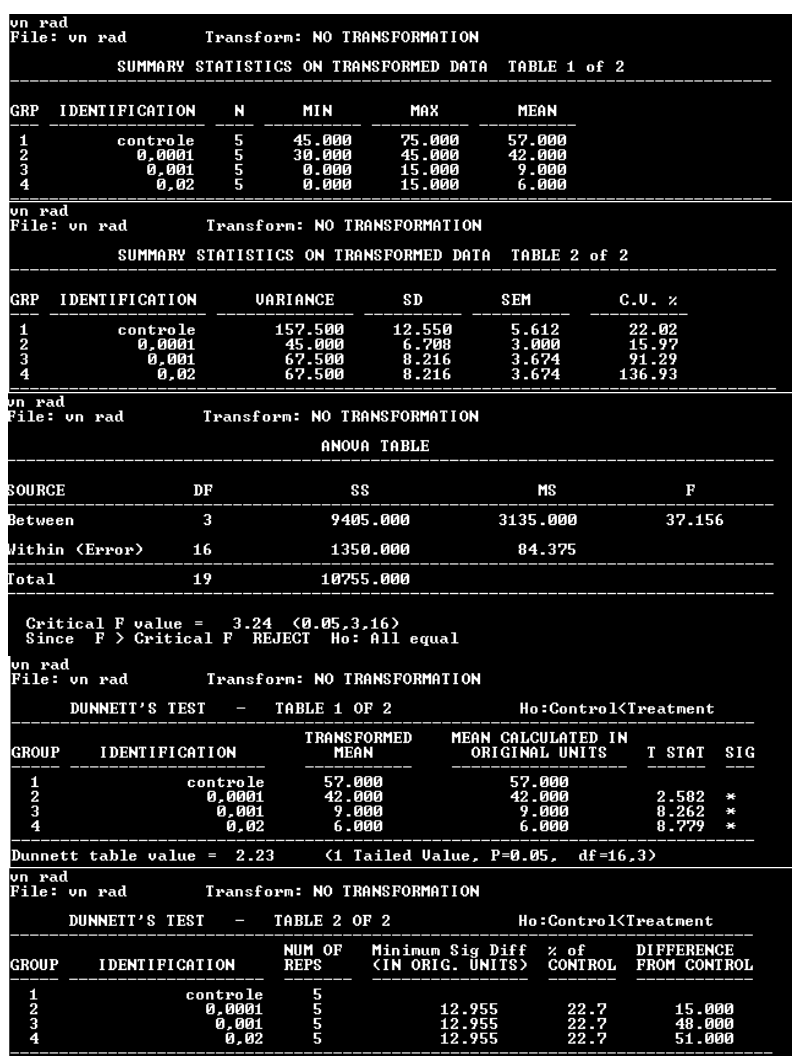

I ensaio preliminar $107 \mathrm{~Gy}-72$ horas

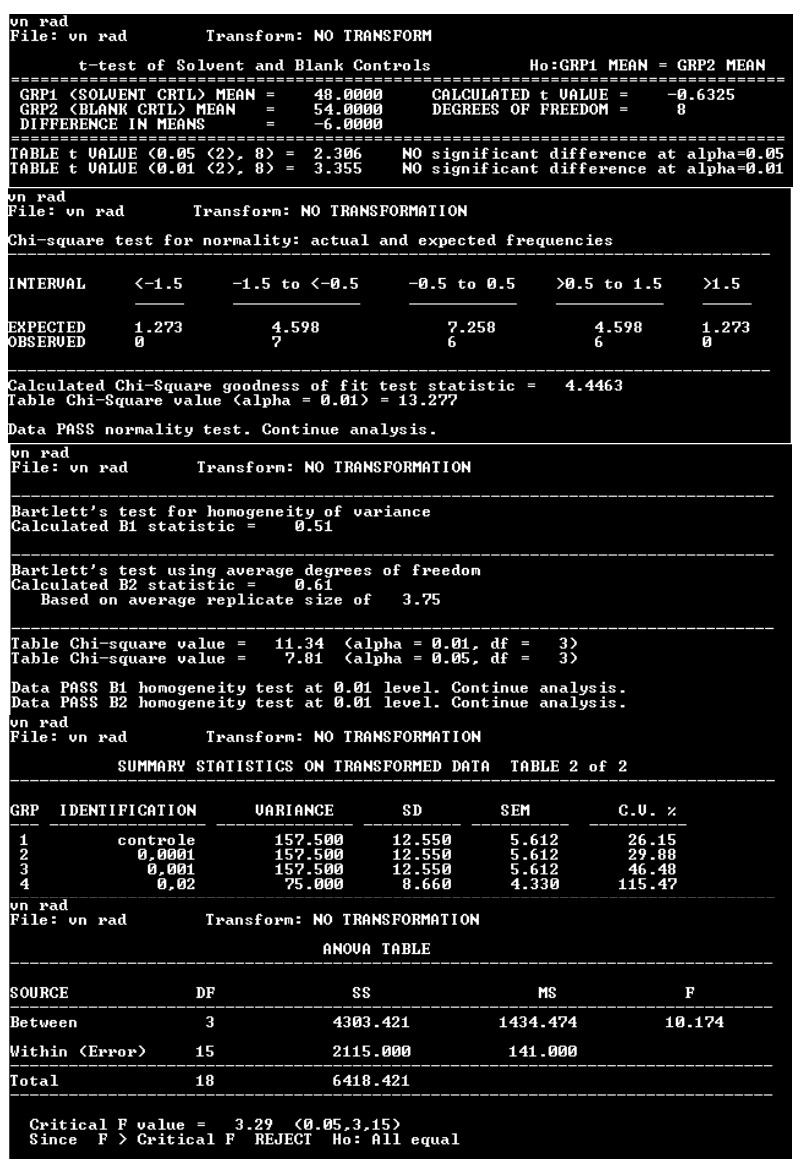




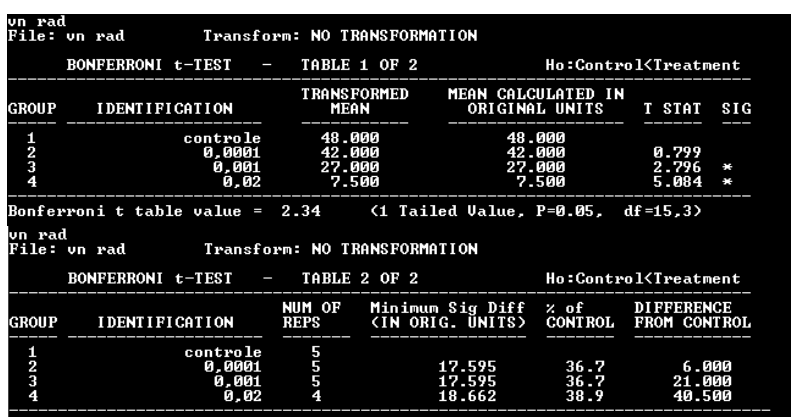

II ensaio preliminar $107 \mathrm{~Gy}-24$ horas

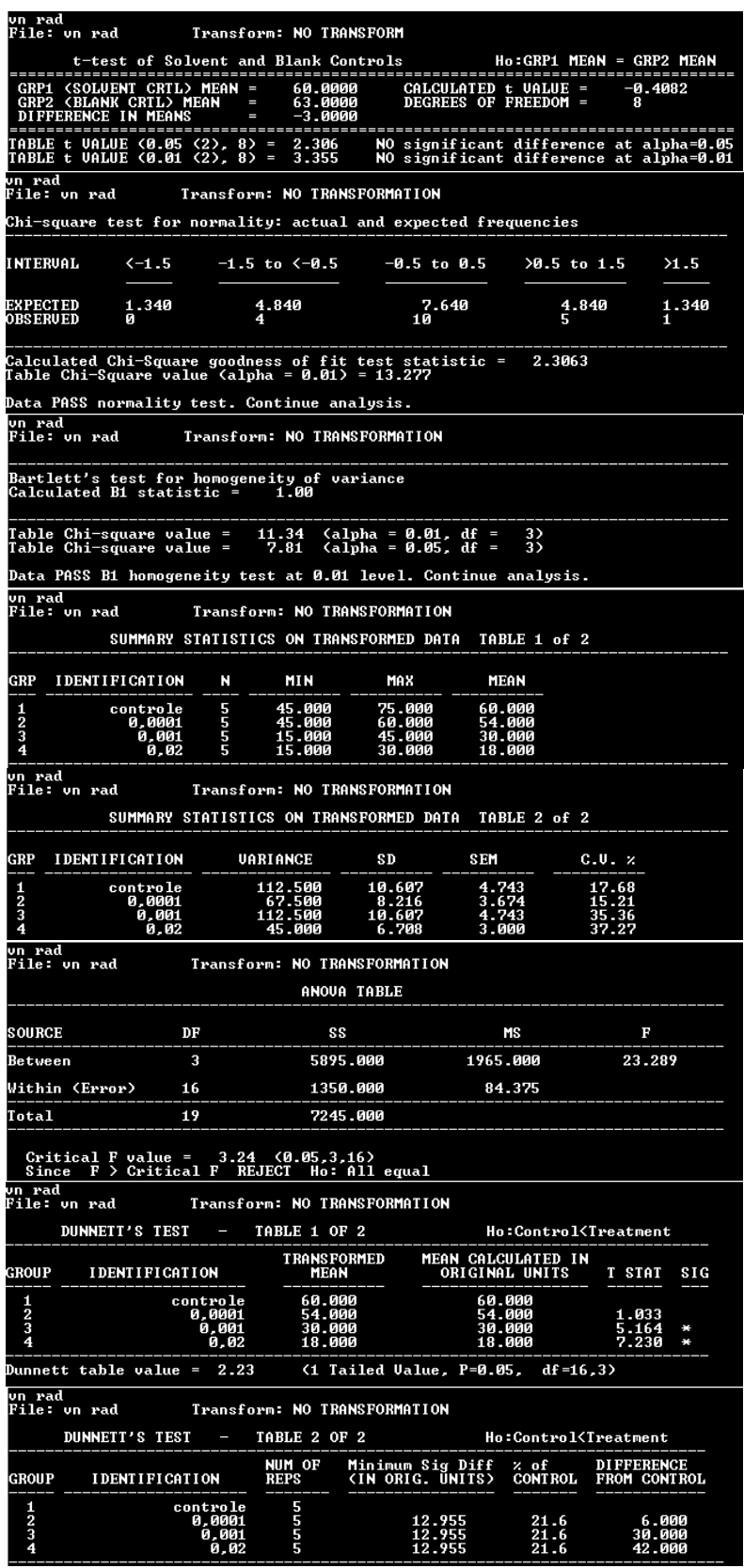

II ensaio preliminar $107 \mathrm{~Gy}-48$ horas 


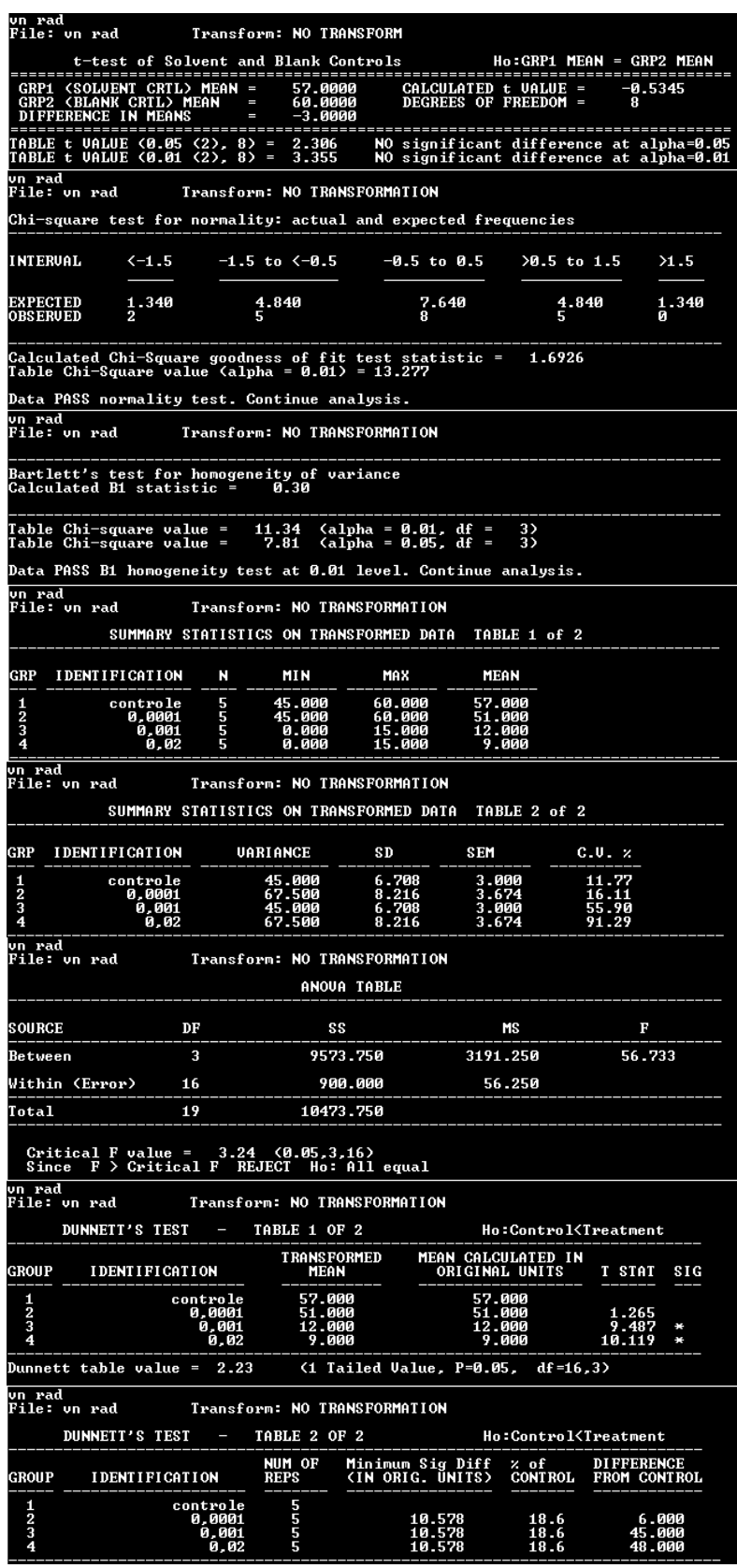

II ensaio preliminar 107 Gy - 72 horas

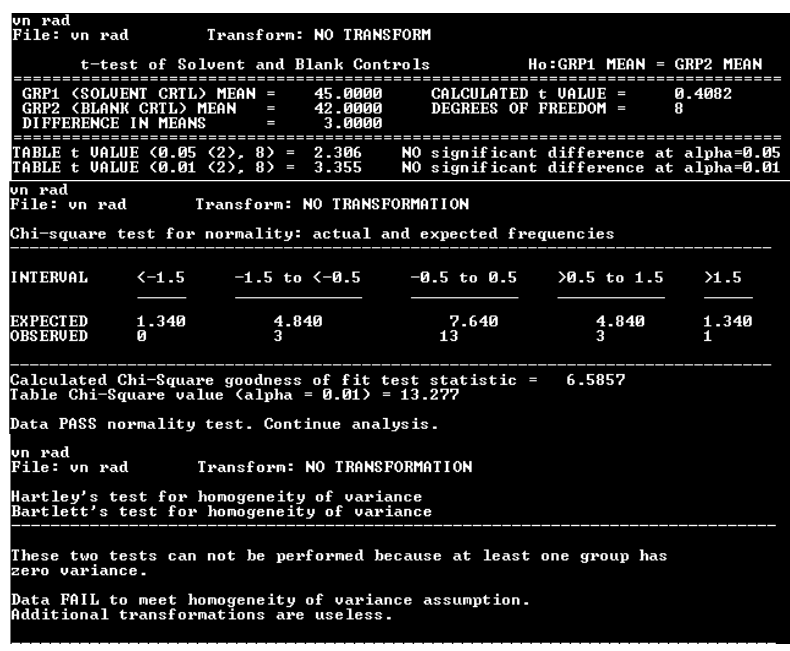




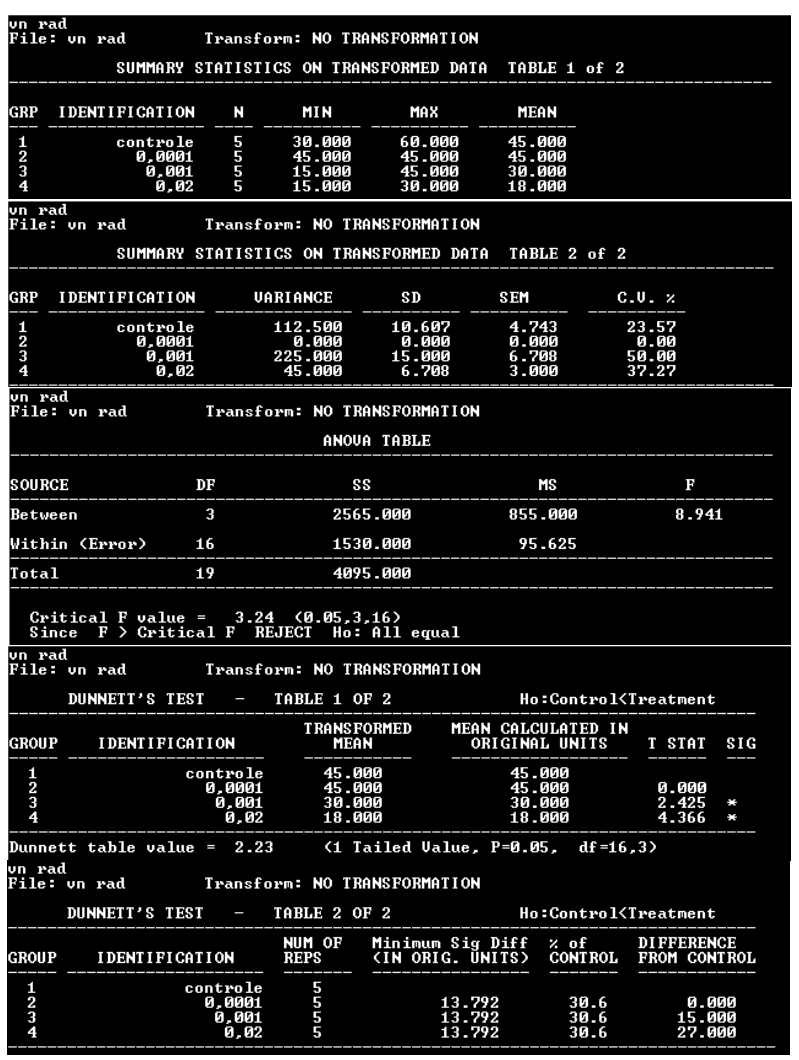

III ensaio preliminar $107 \mathrm{~Gy}-24$ horas

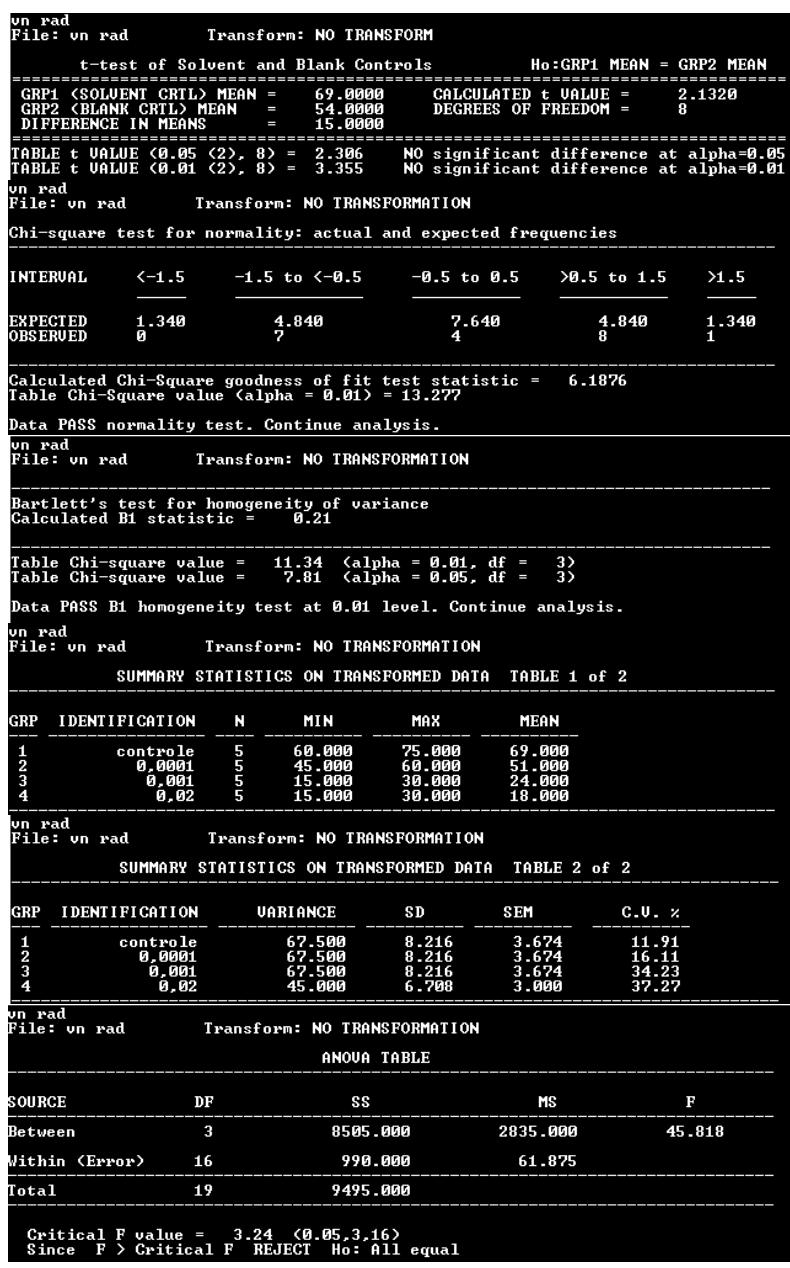




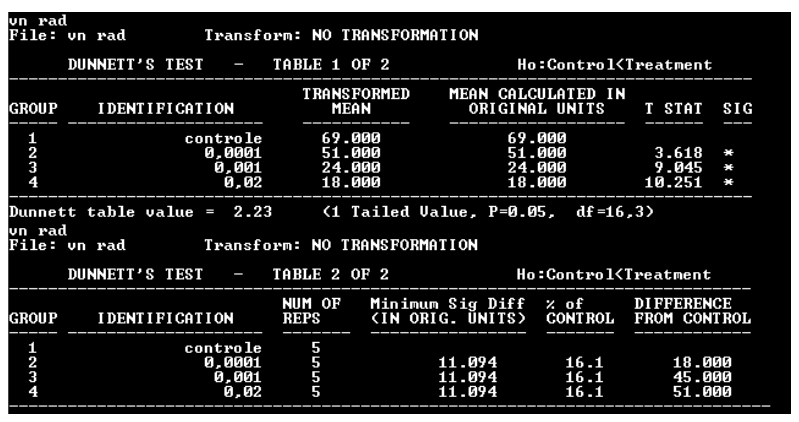

III ensaio preliminar 107 Gy - 48 horas

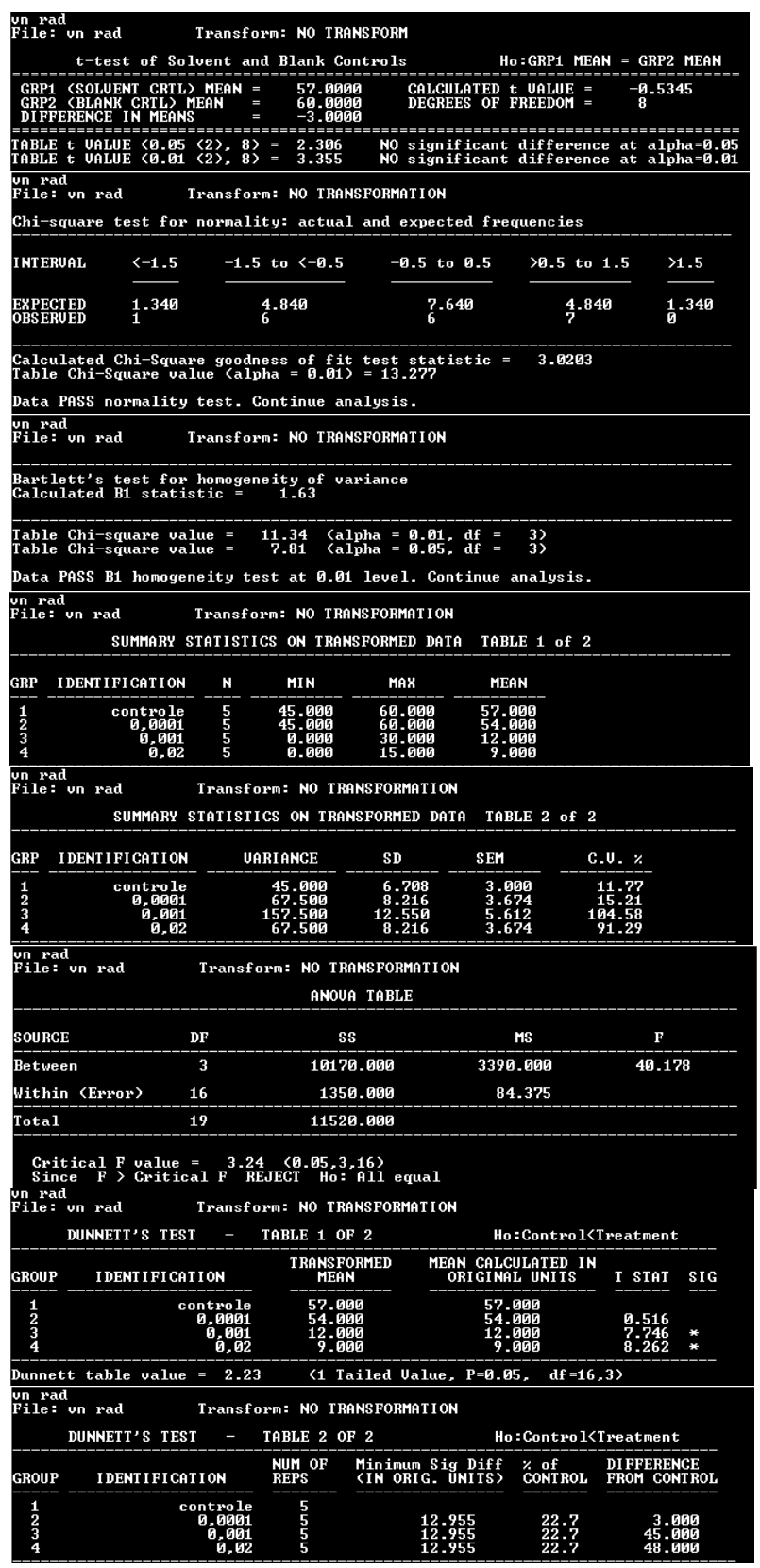

III ensaio preliminar 107 Gy - 72 horas 


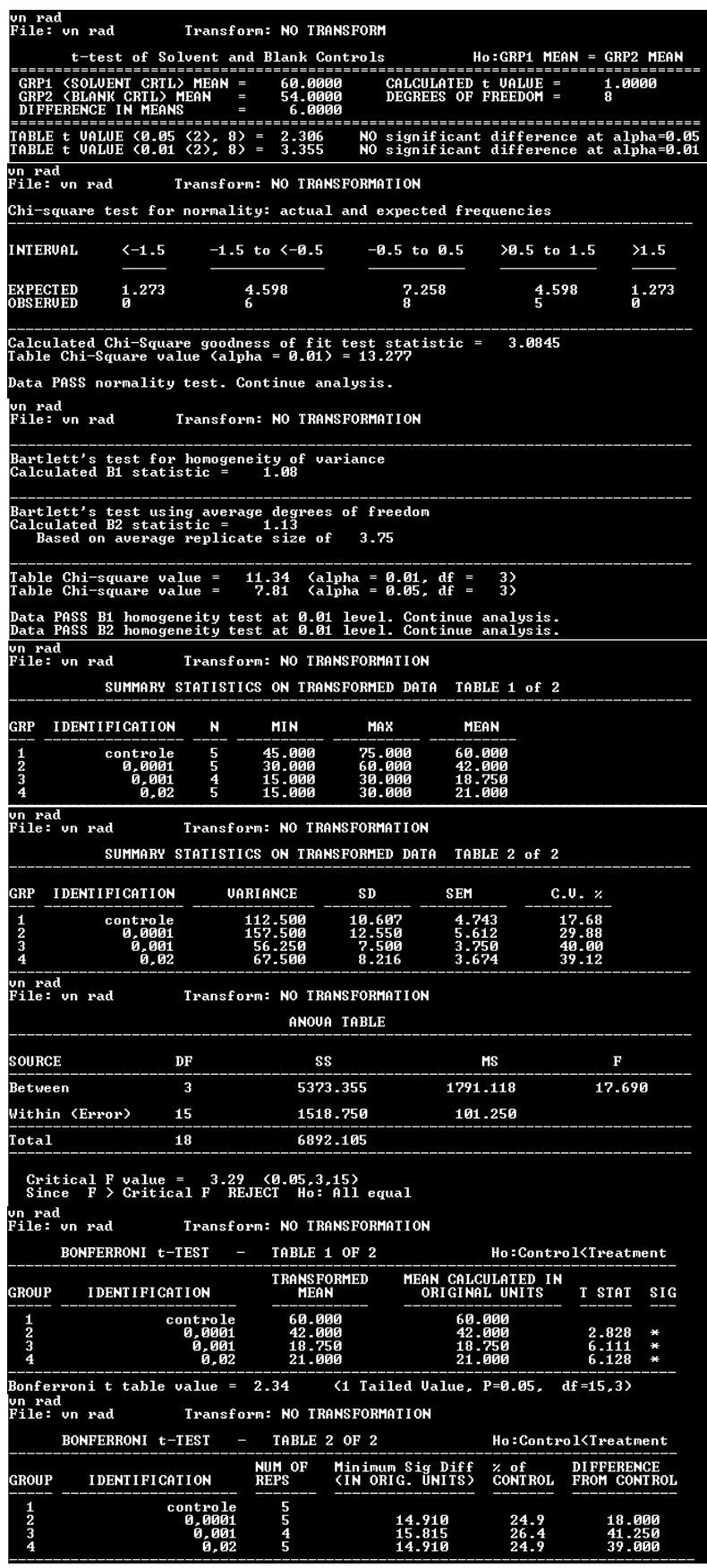

I ensaio preliminar 11 Gy - 24 horas

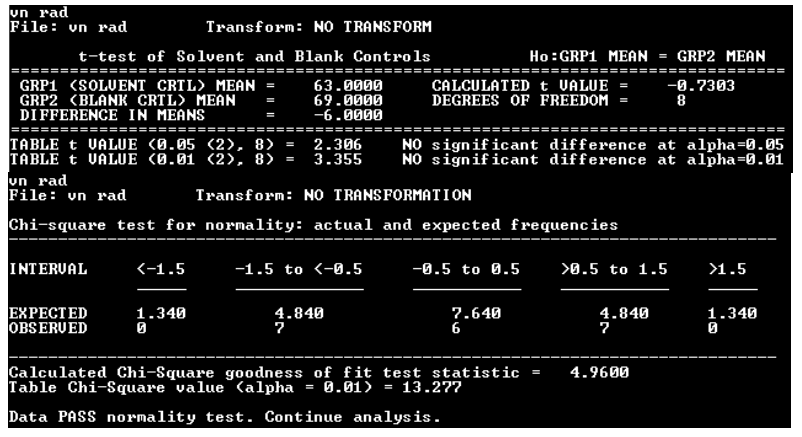




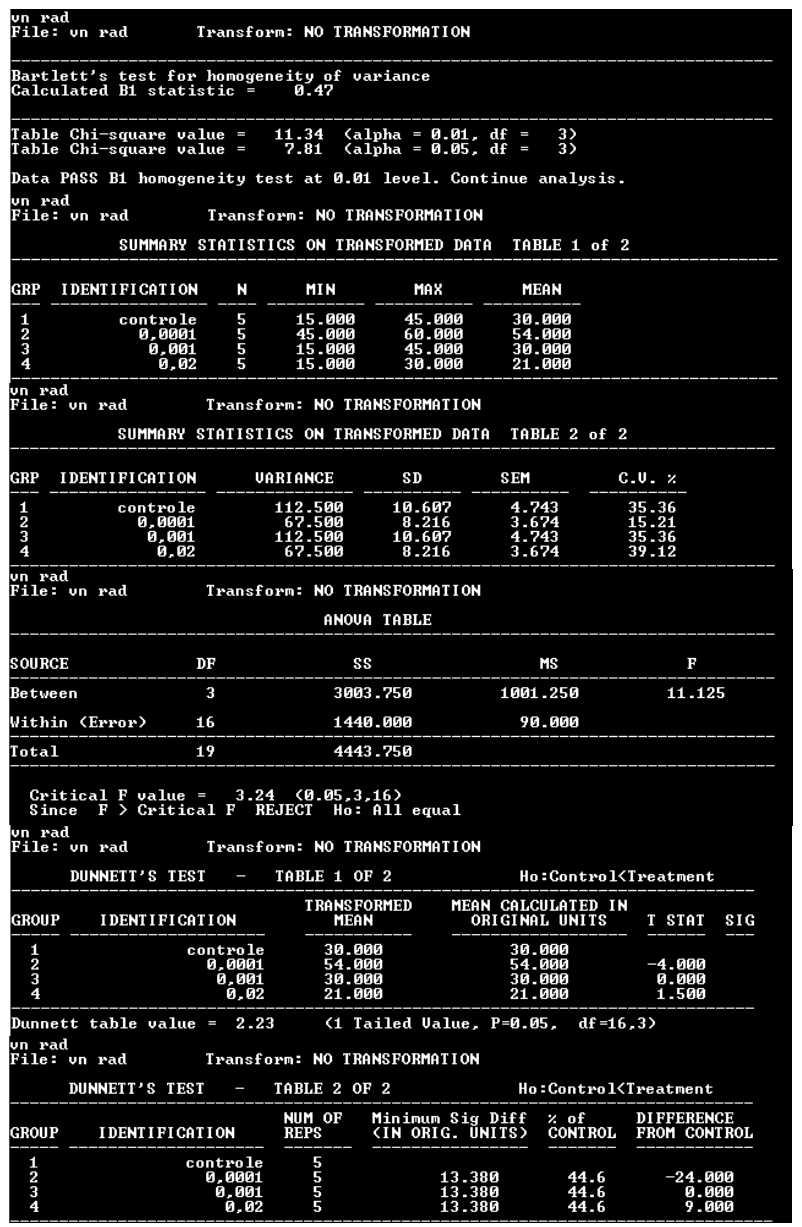

I ensaio preliminar $11 \mathrm{~Gy}-48$ horas

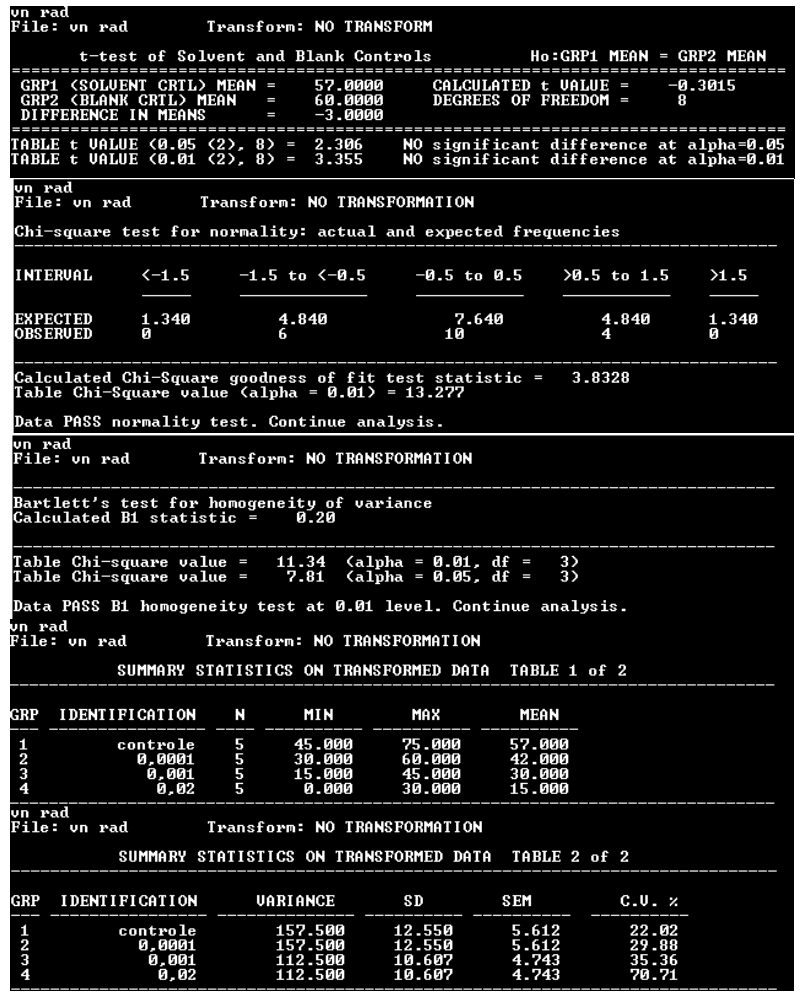




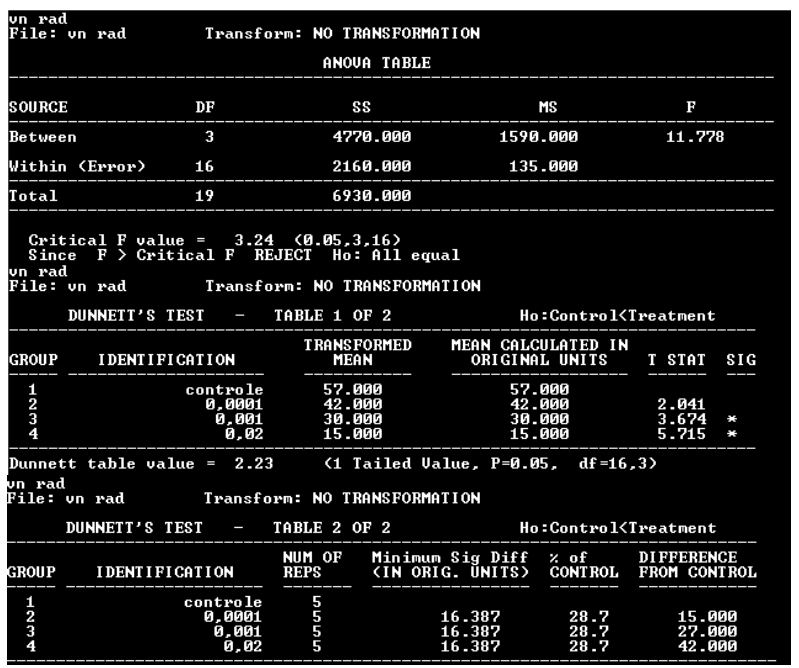

I ensaio preliminar $11 \mathrm{~Gy}-72$ horas

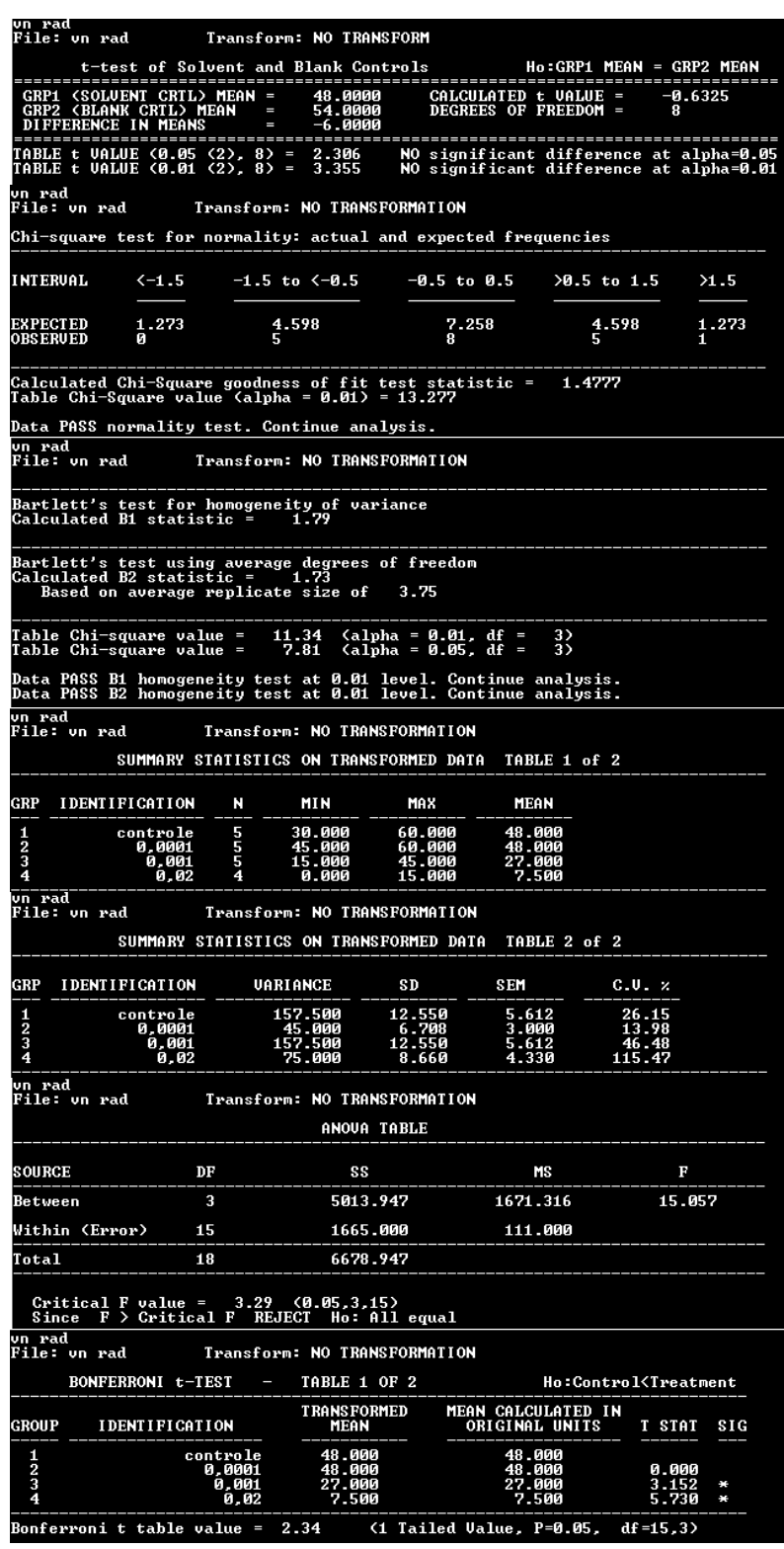




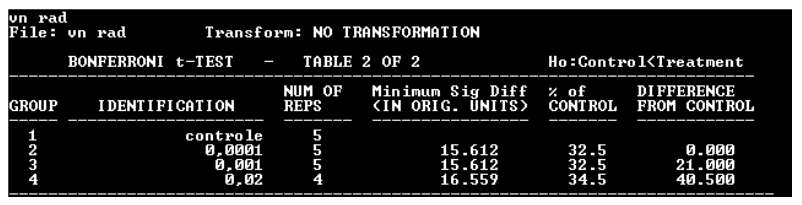

II ensaio preliminar 11 Gy - 24 horas

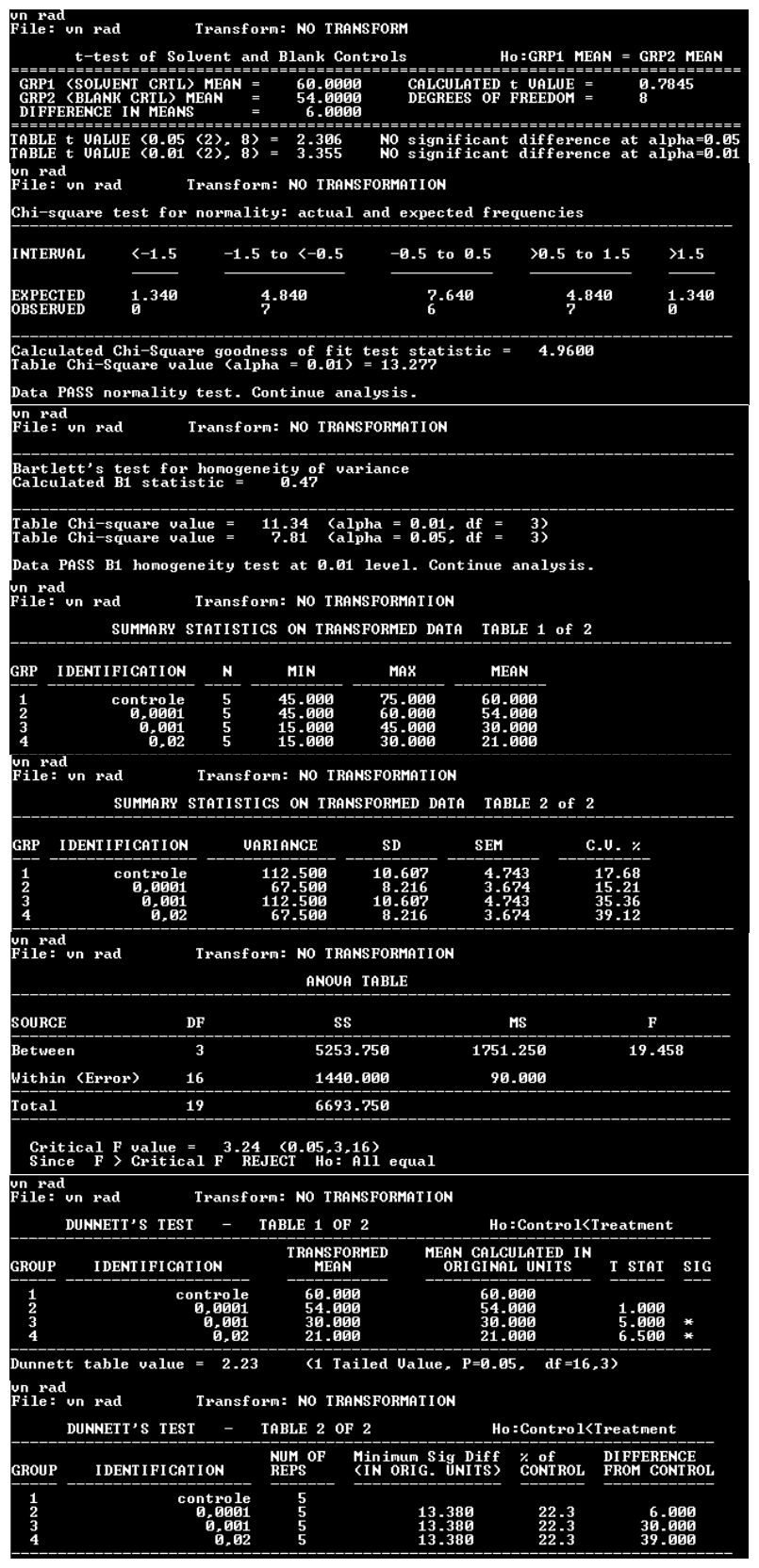

II ensaio preliminar $11 \mathrm{~Gy}-48$ horas 


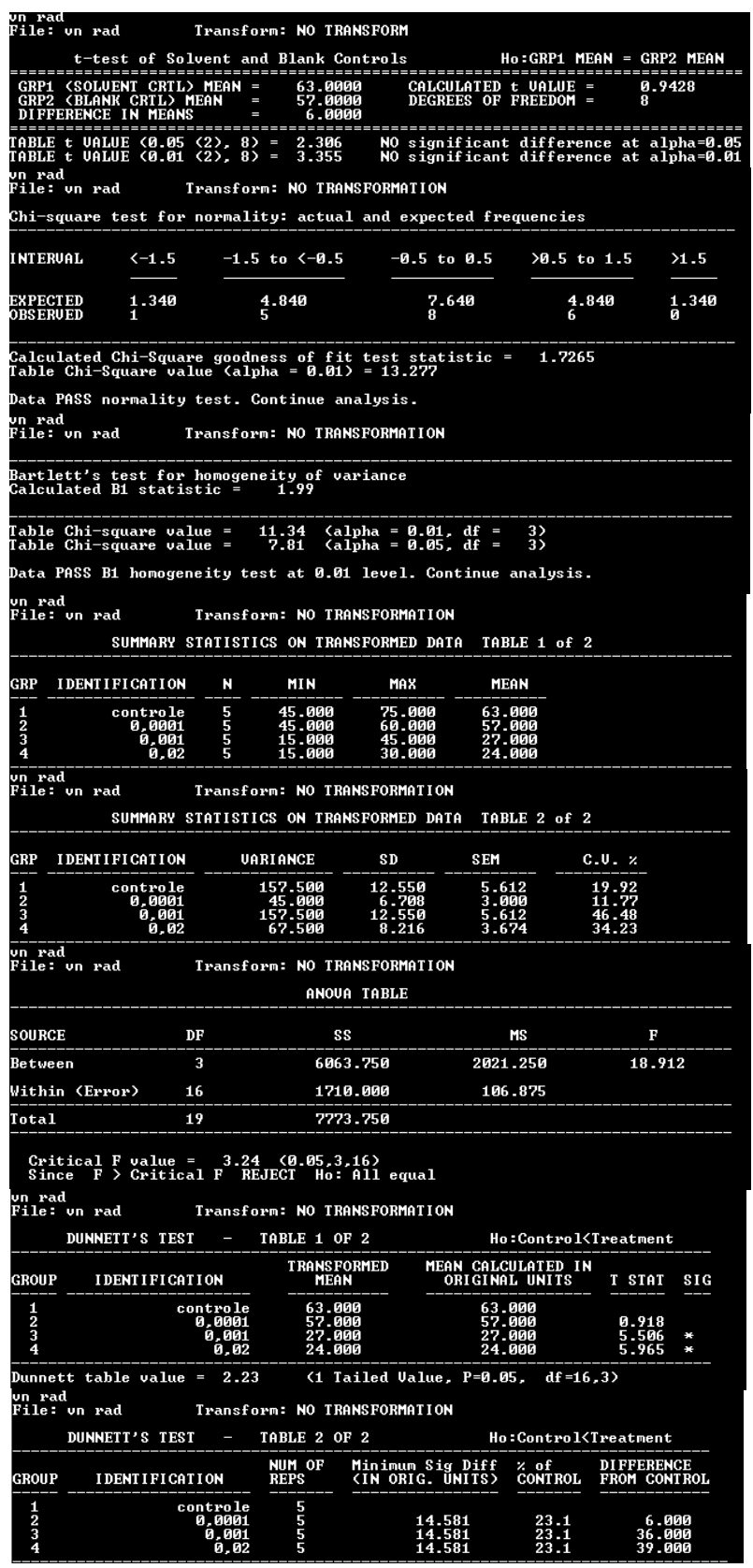

\section{II ensaio preliminar 11 Gy - 72 horas}

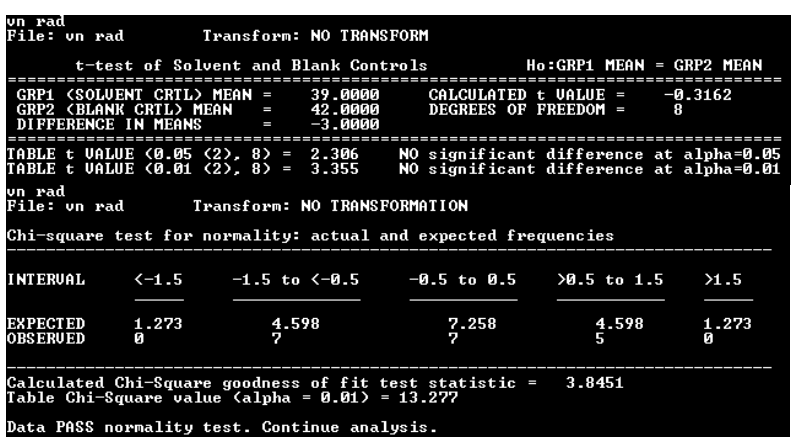




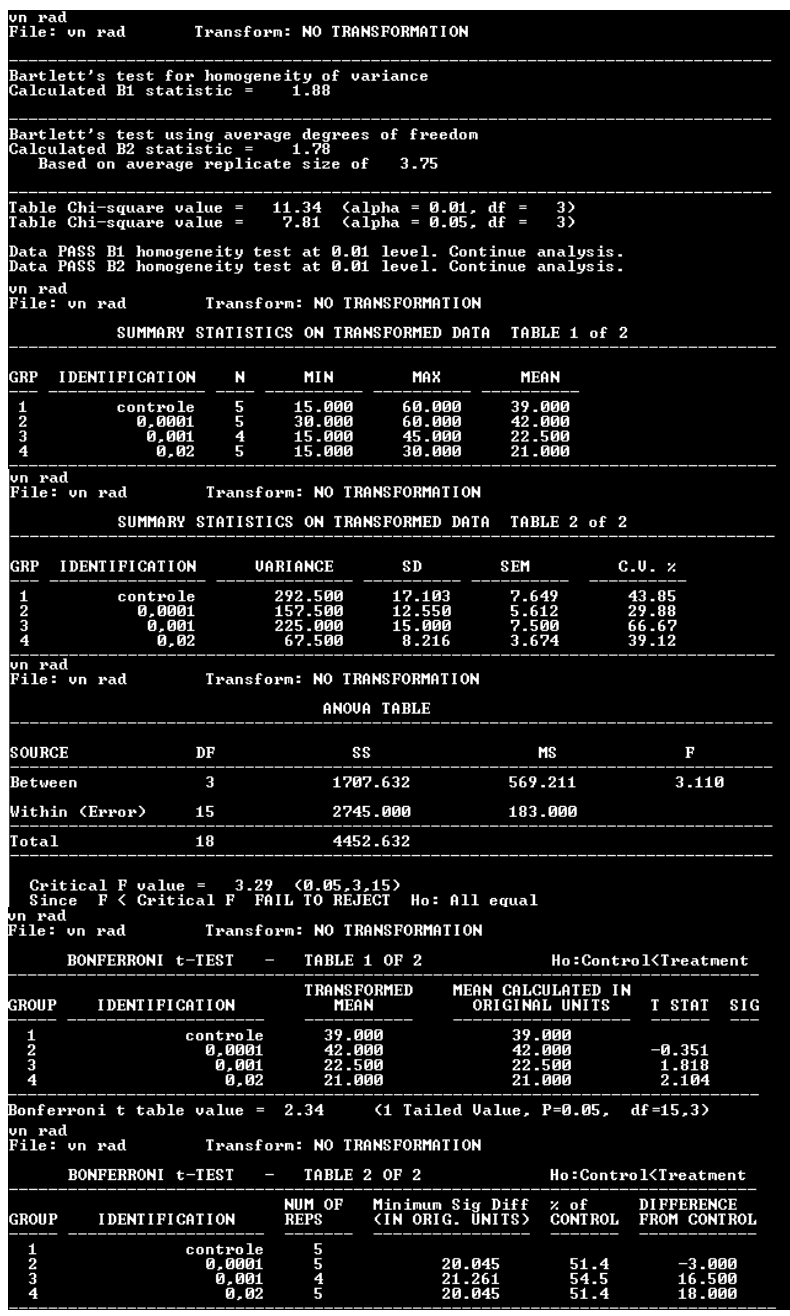

III ensaio preliminar $11 \mathrm{~Gy}-24$ horas

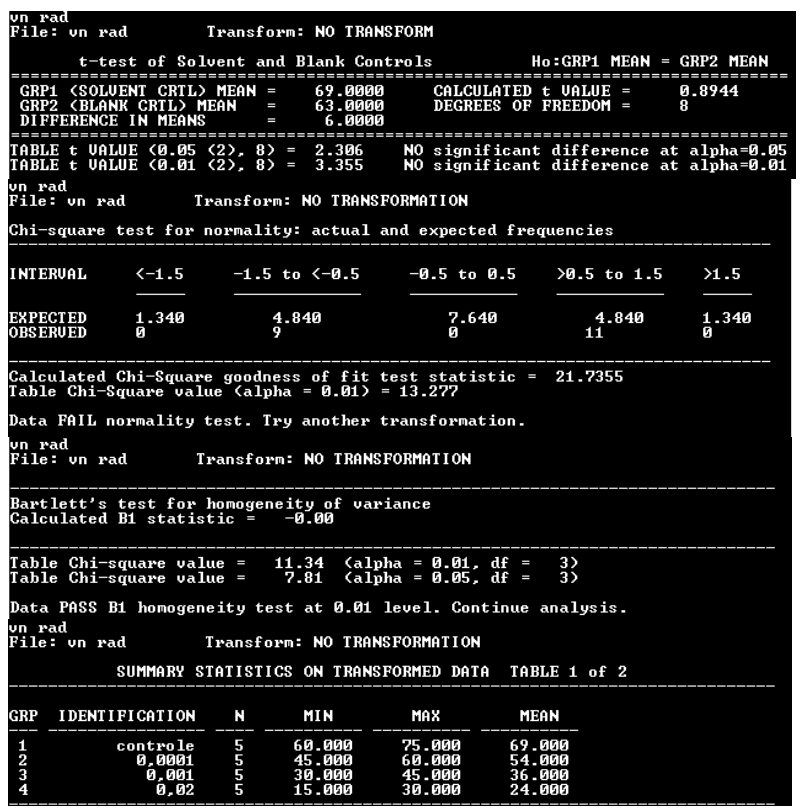




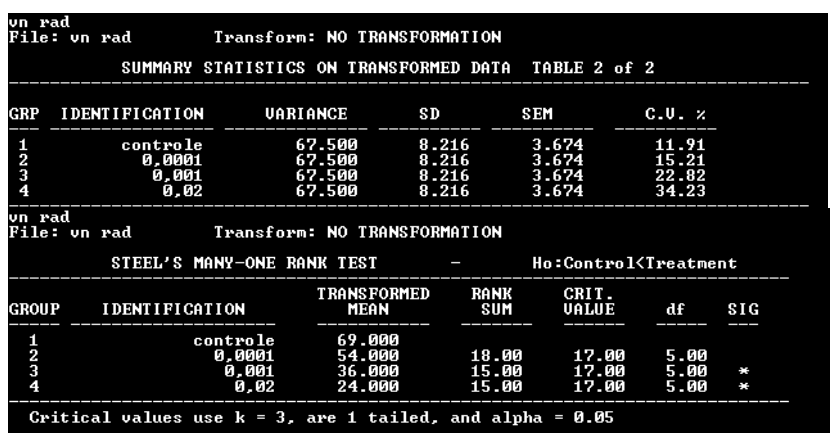

III ensaio preliminar $11 \mathrm{~Gy}-48$ horas

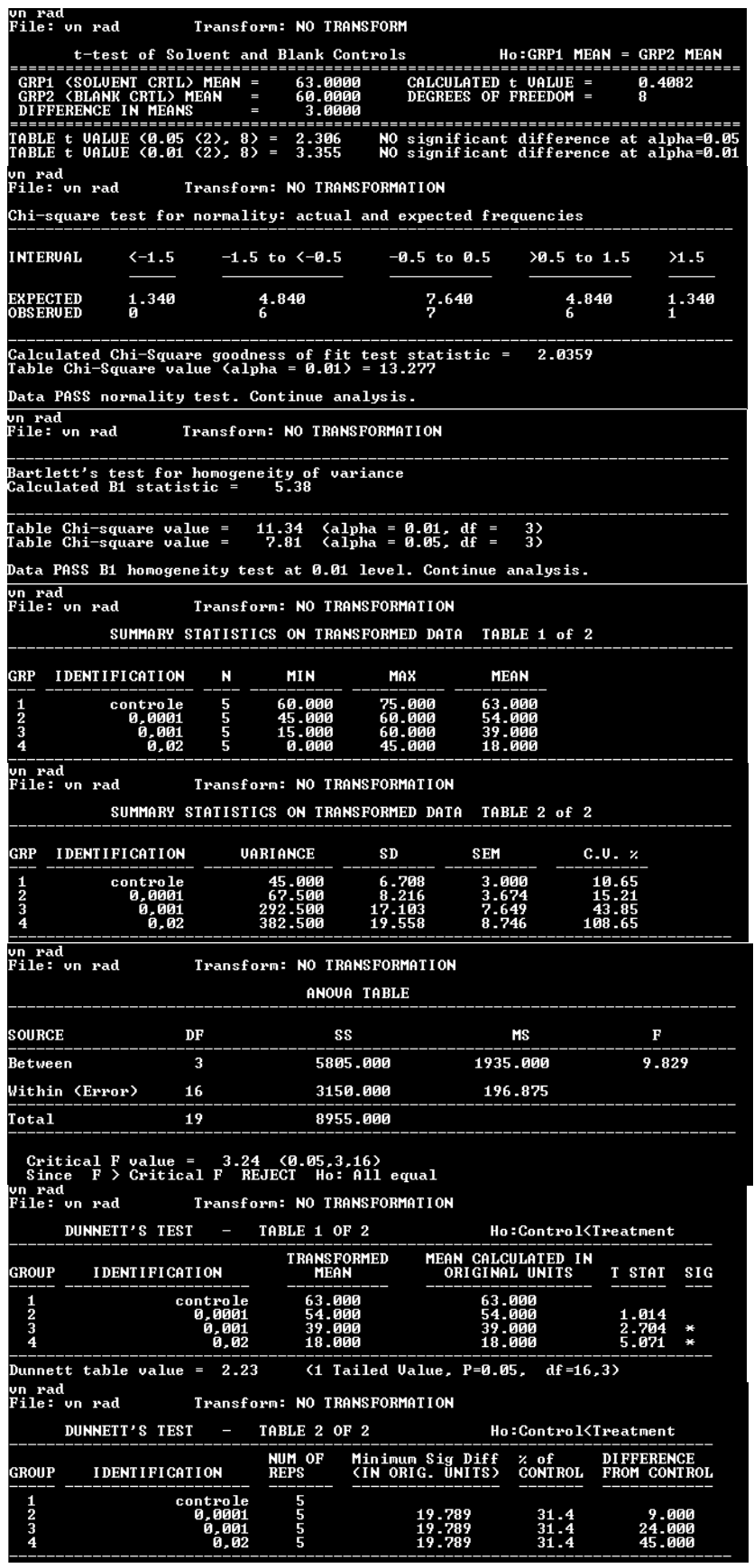

III ensaio preliminar $11 \mathrm{~Gy}-72$ horas 


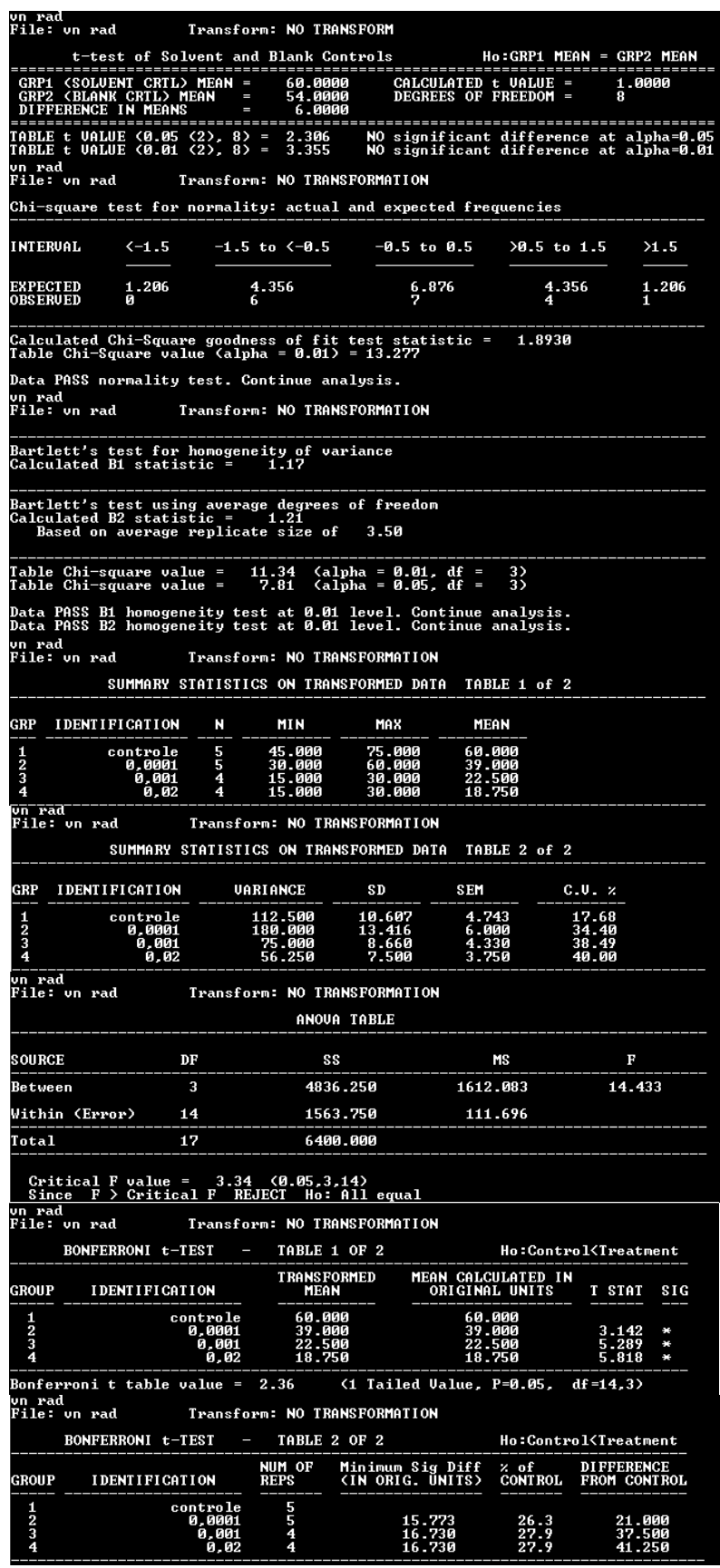

I ensaio preliminar $3 \mathrm{~Gy}-24$ horas

\begin{tabular}{|c|c|c|c|c|c|}
\hline \multicolumn{4}{|c|}{$\begin{array}{l}\text { Transforn: NO IRANSFORM } \\
\text { File: }\end{array}$} & \multicolumn{2}{|c|}{ o:GRP1 MEAN = GRP2 MEAN } \\
\hline \multicolumn{3}{|c|}{ 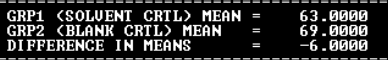 } & \multicolumn{3}{|c|}{ 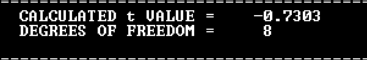 } \\
\hline \multicolumn{6}{|c|}{ 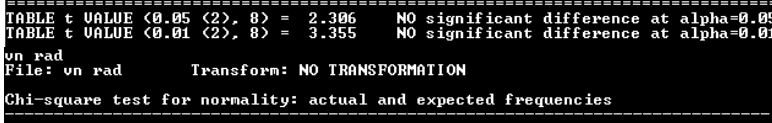 } \\
\hline NTERUAL & $<-1.5$ & -1.5 to $<-8.5$ & -0.5 to 0.5 & $>0.5$ to 1.5 & $>1.5$ \\
\hline $\begin{array}{l}\text { EXPECIED } \\
\text { OBSERUEED }\end{array}$ & $\frac{1.340}{8}$ & $\frac{4.840}{3}$ & $10^{7.640}$ & $\begin{array}{l}4.840 \\
5\end{array}$ & $\frac{1.348}{2}$ \\
\hline
\end{tabular}




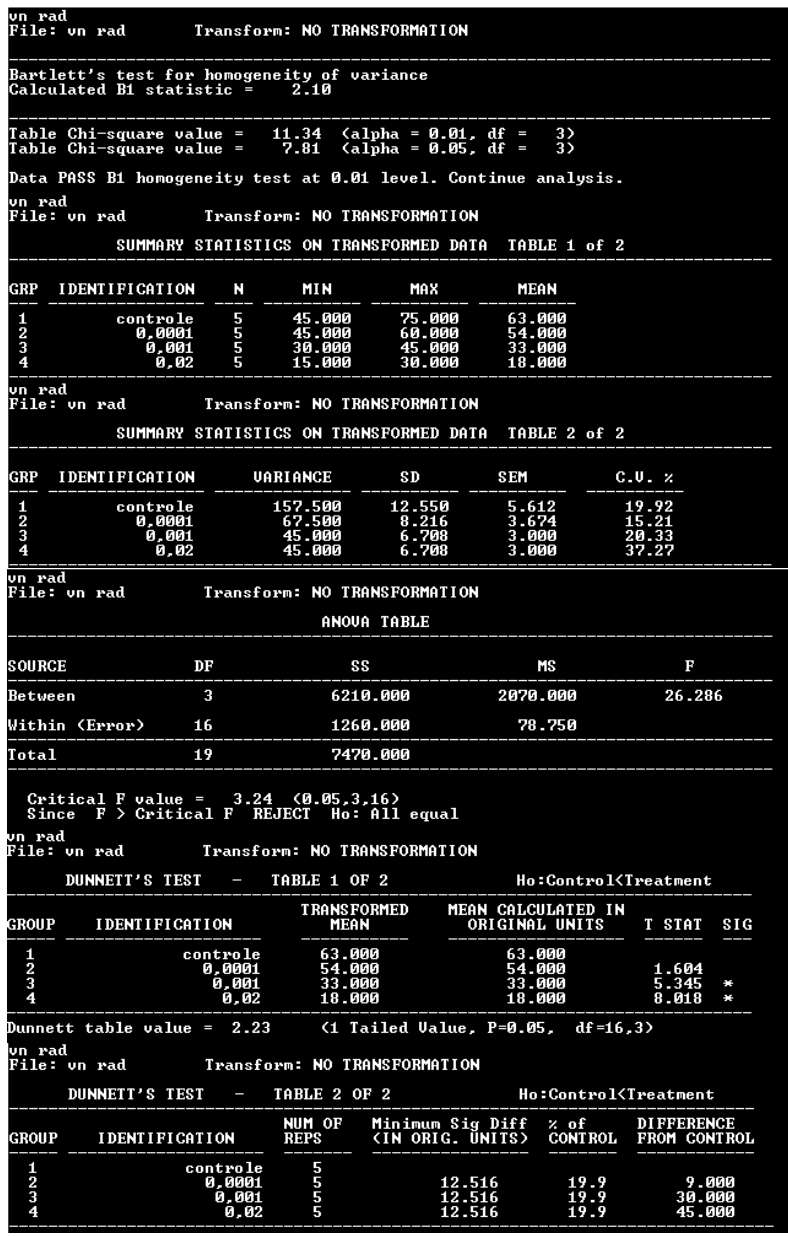

I ensaio preliminar $3 \mathrm{~Gy}-48$ horas

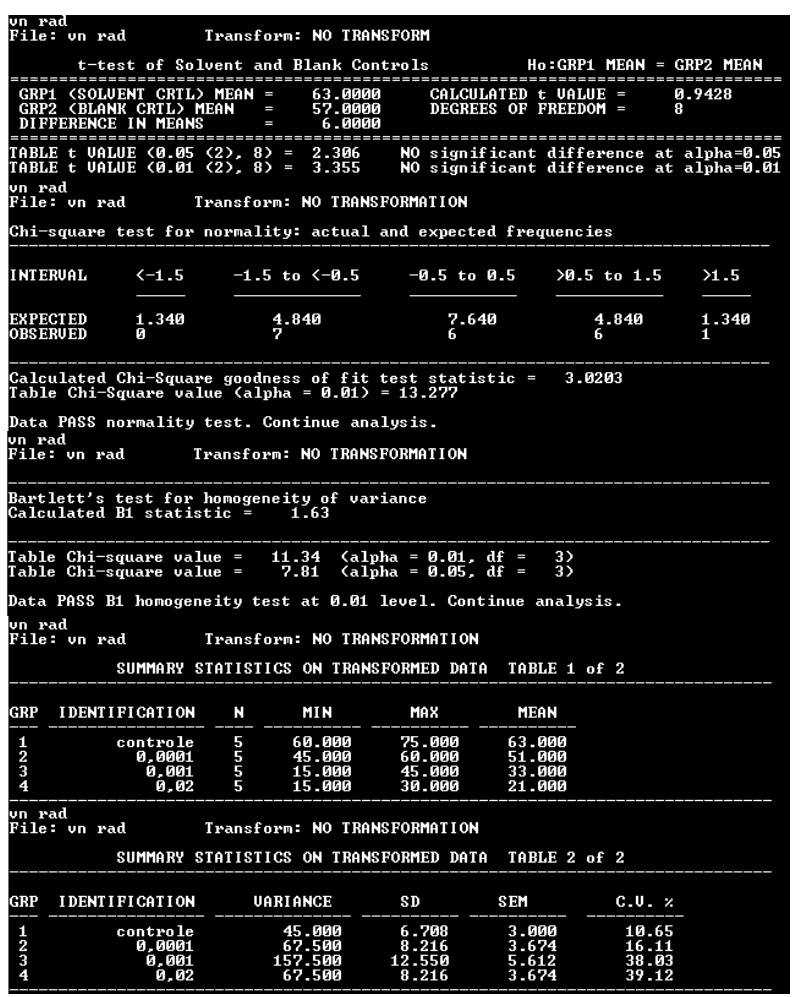




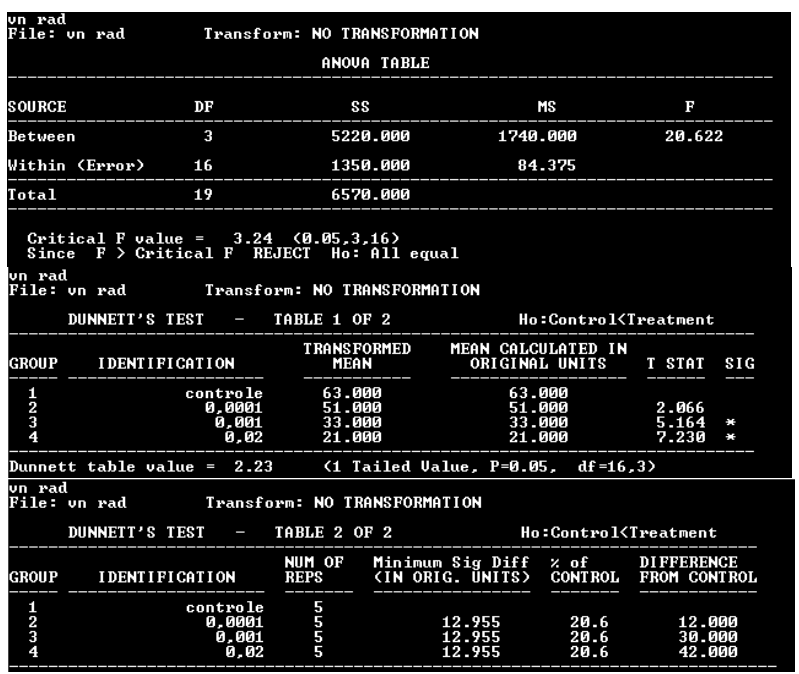

I ensaio preliminar $3 \mathrm{~Gy}-72$ horas

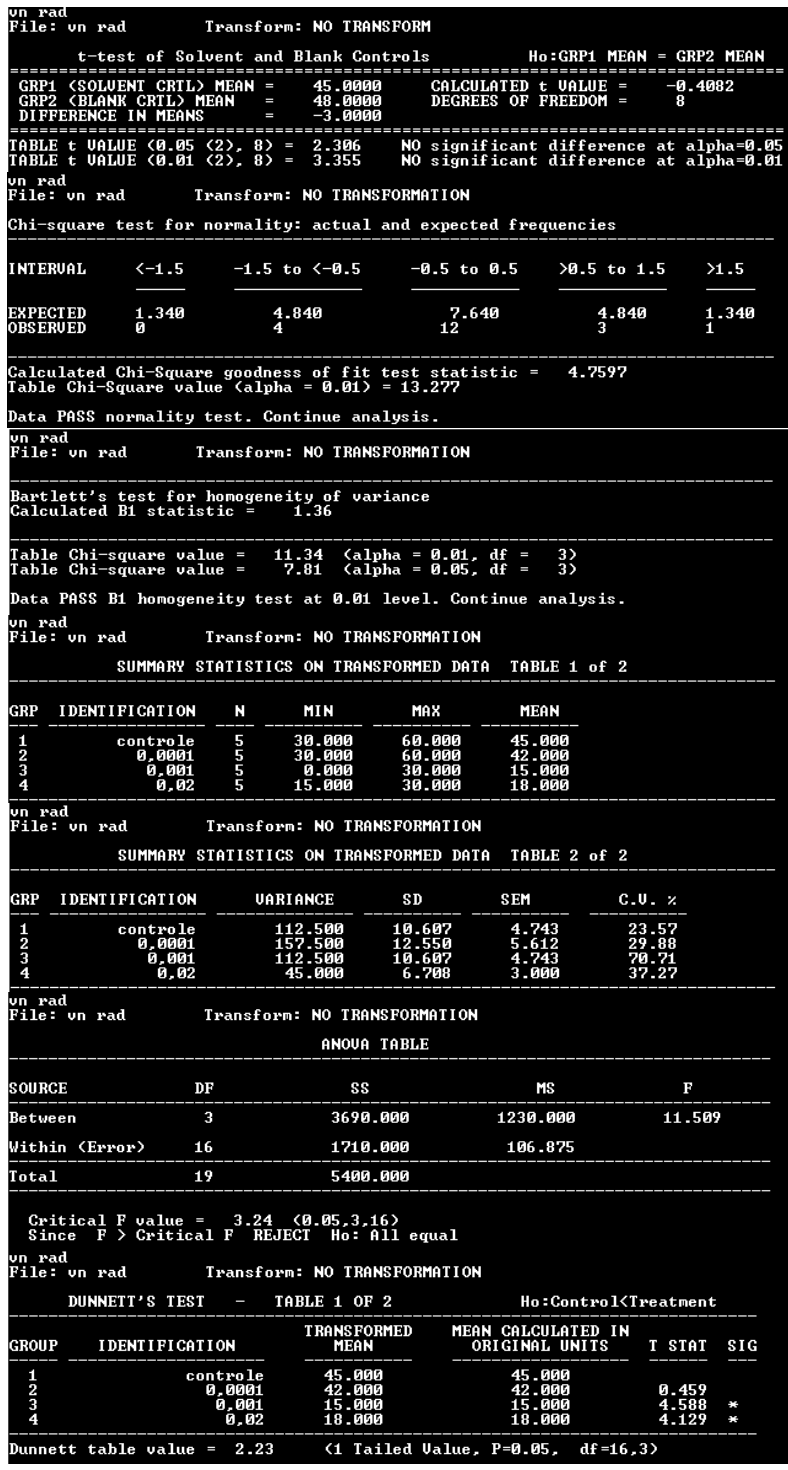




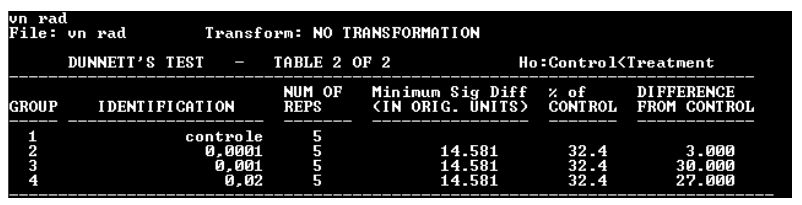

II ensaio preliminar $3 \mathrm{~Gy}-24$ horas

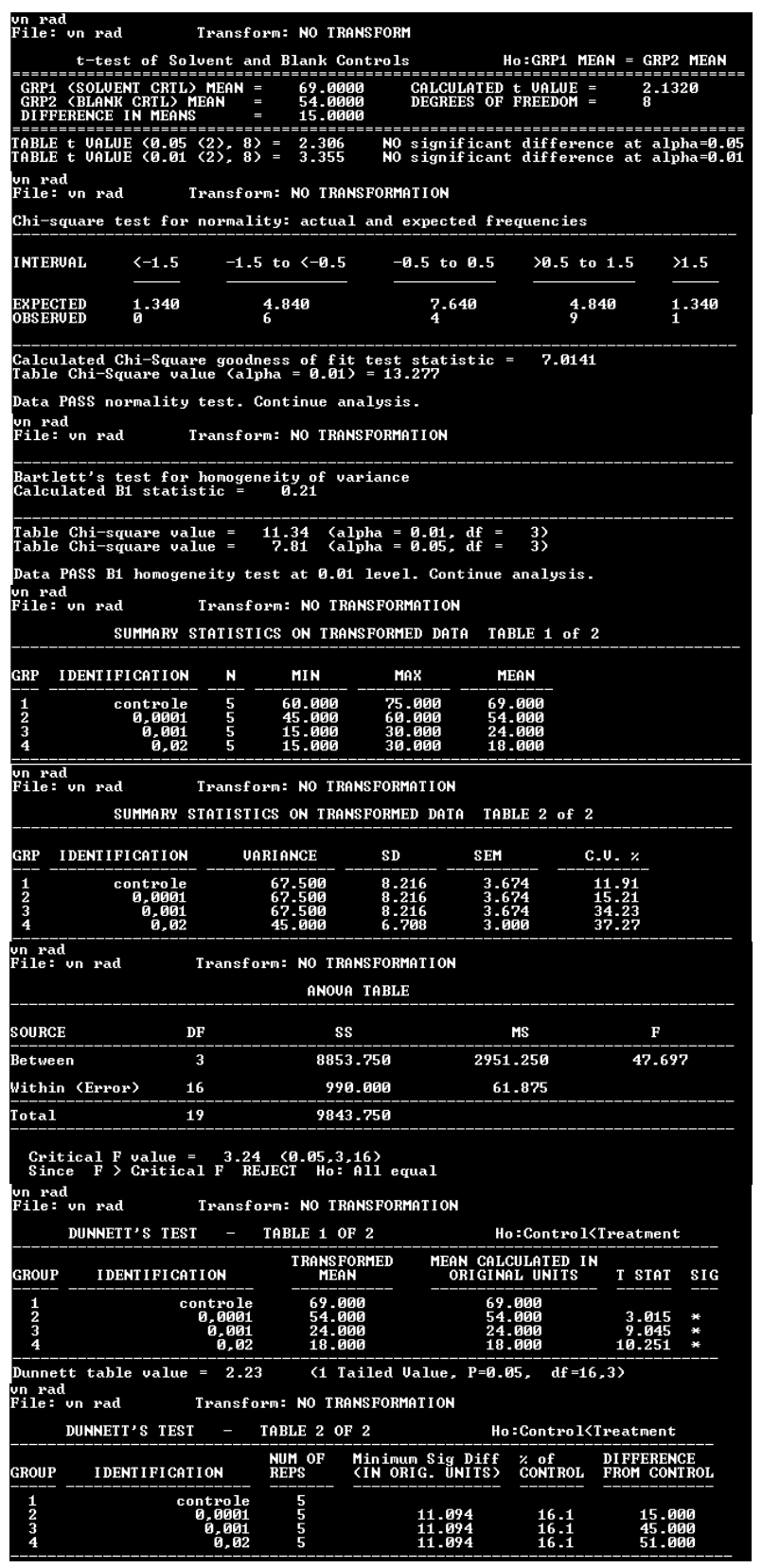

II ensaio preliminar 3 Gy -48 horas

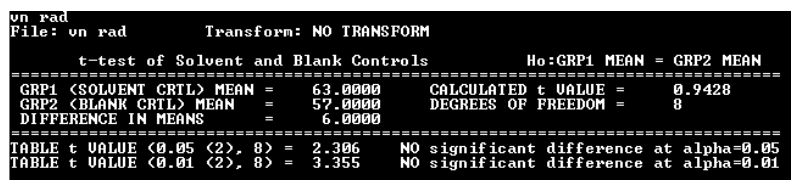




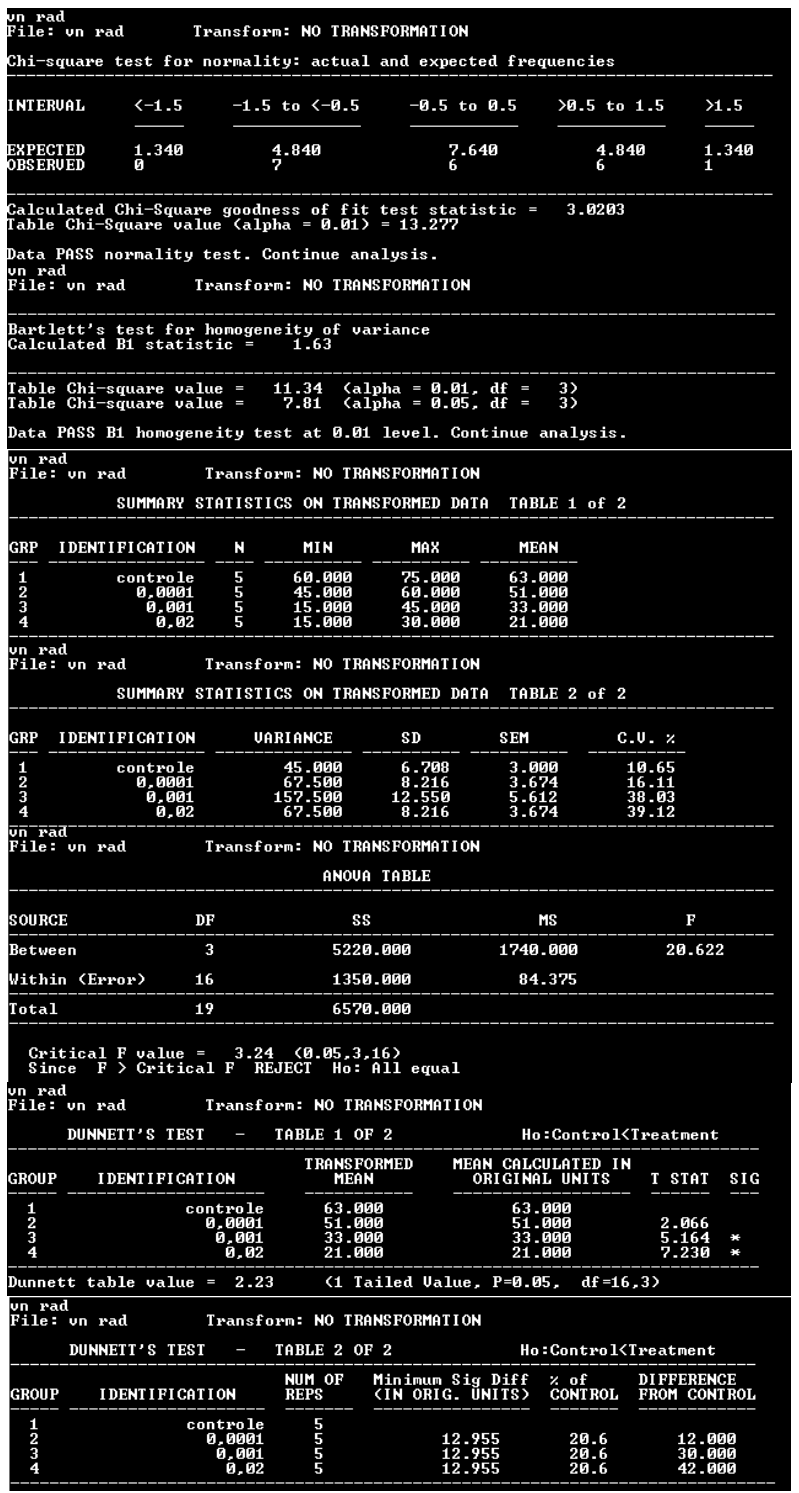

II ensaio preliminar 3 Gy - 72 horas

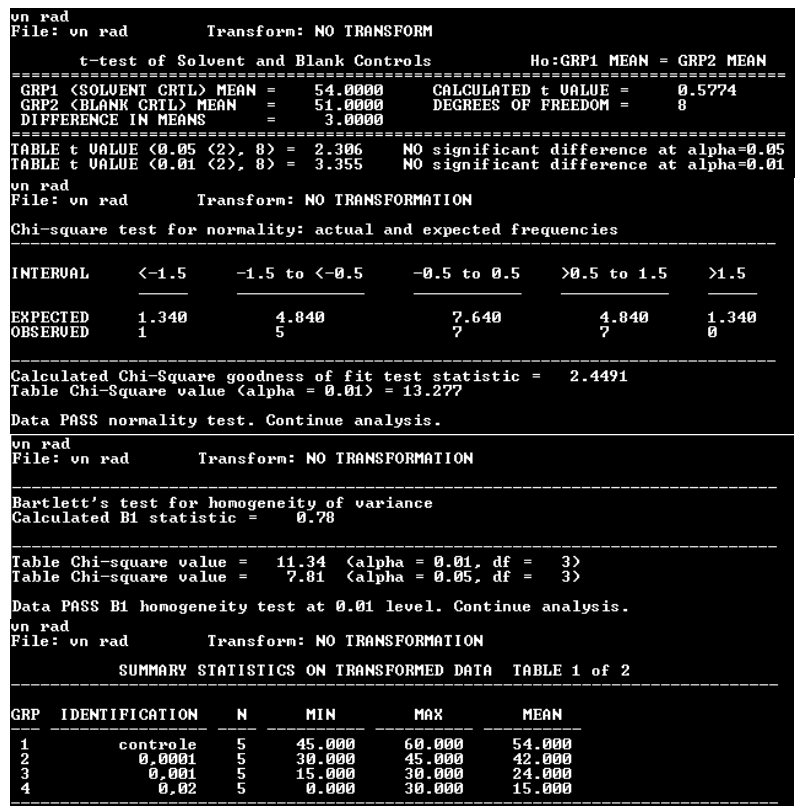




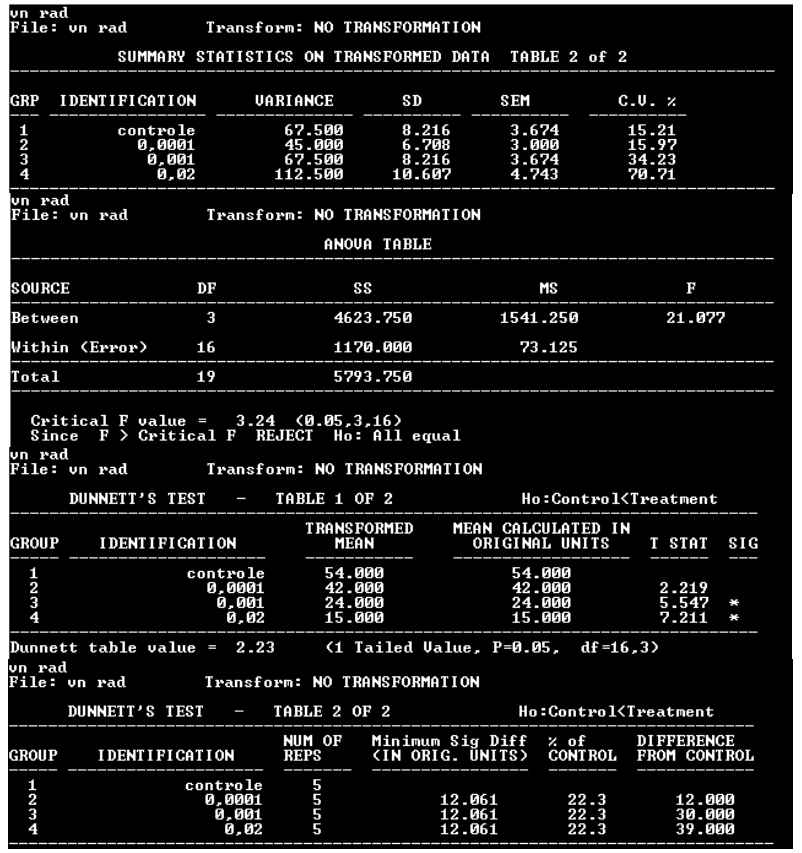

III ensaio preliminar 3 Gy -24 horas

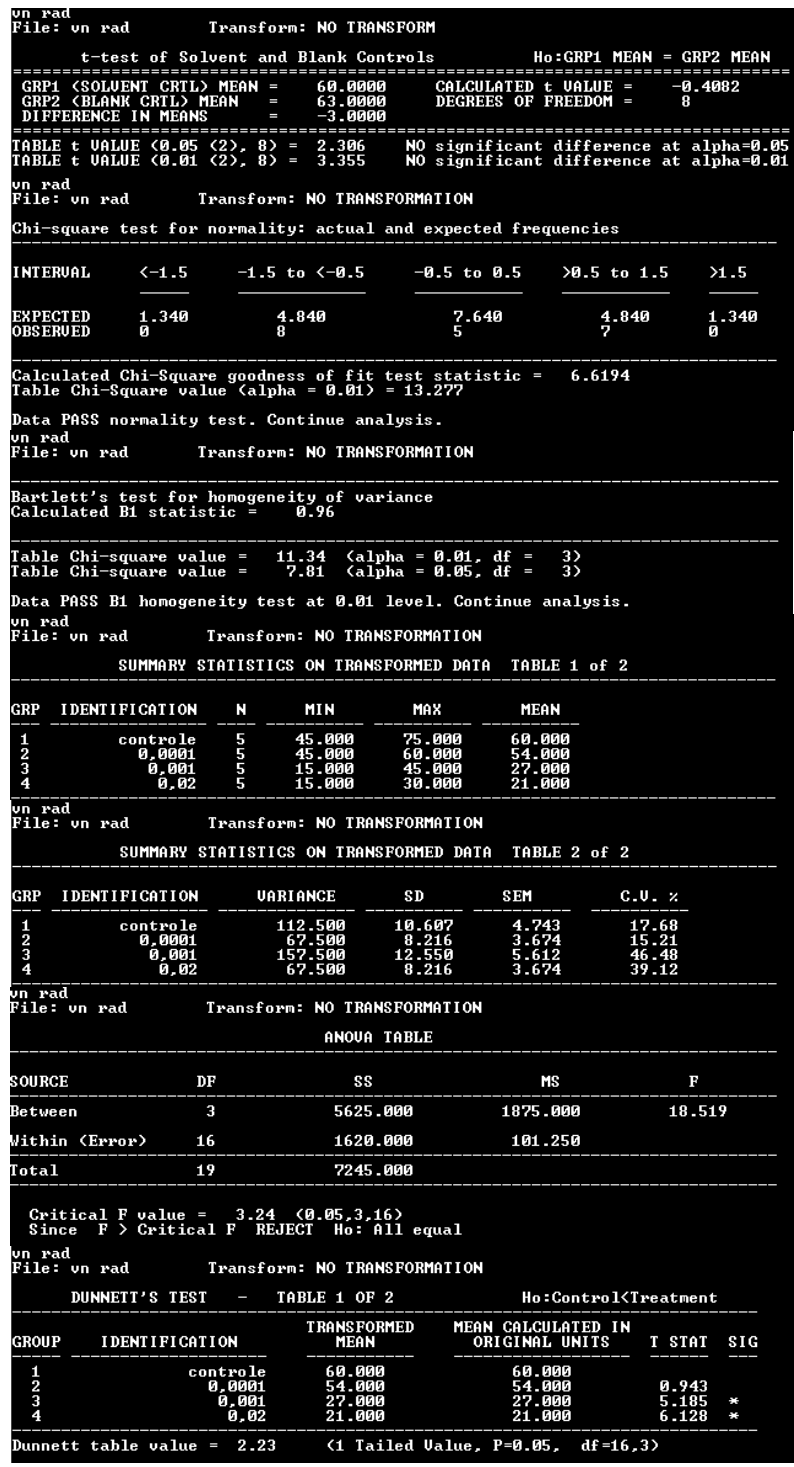




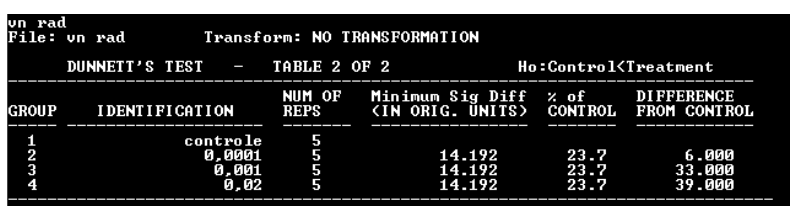

III ensaio preliminar $3 \mathrm{~Gy}-48$ horas

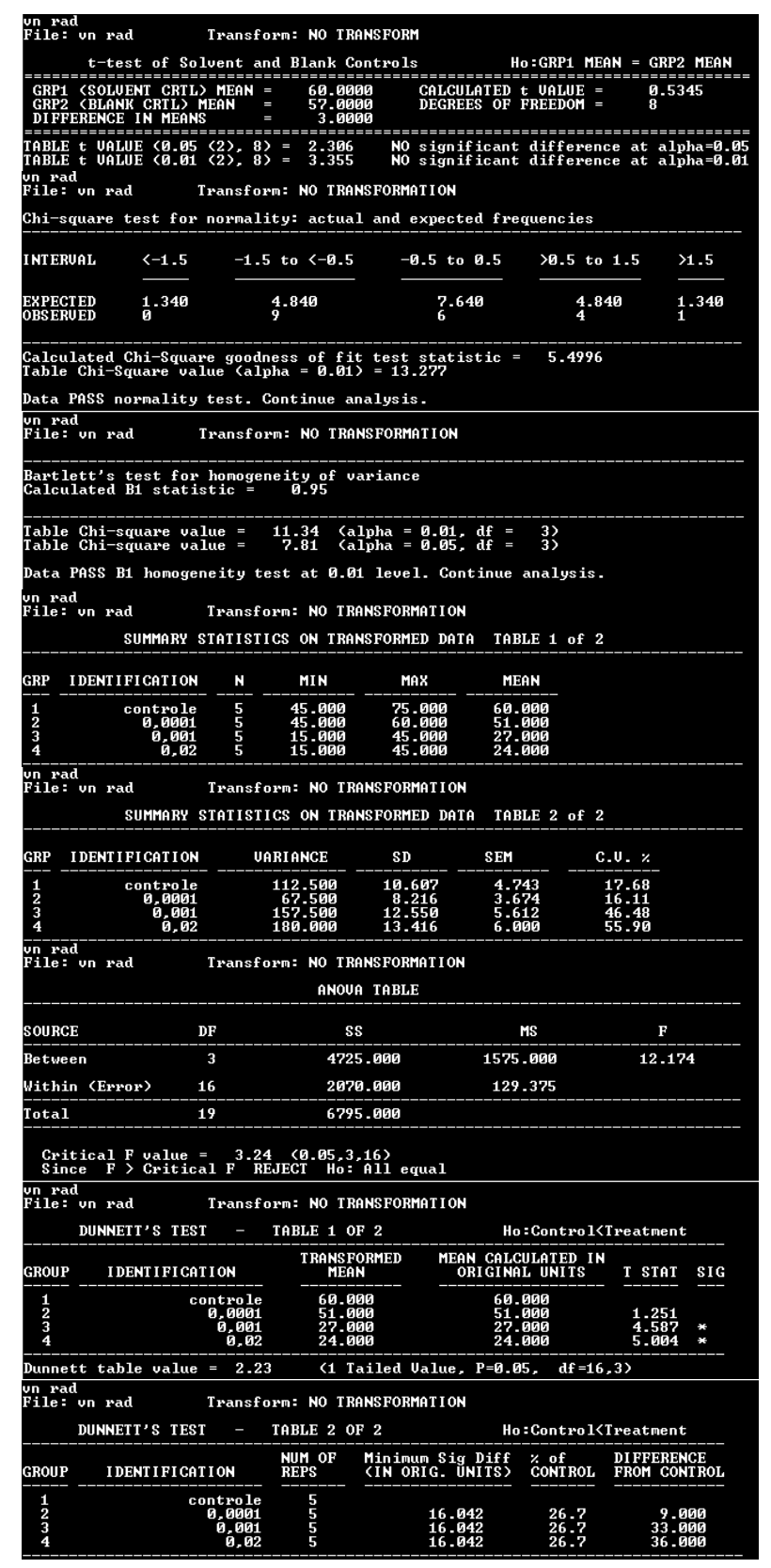

III ensaio preliminar $3 \mathrm{~Gy}-72$ horas 


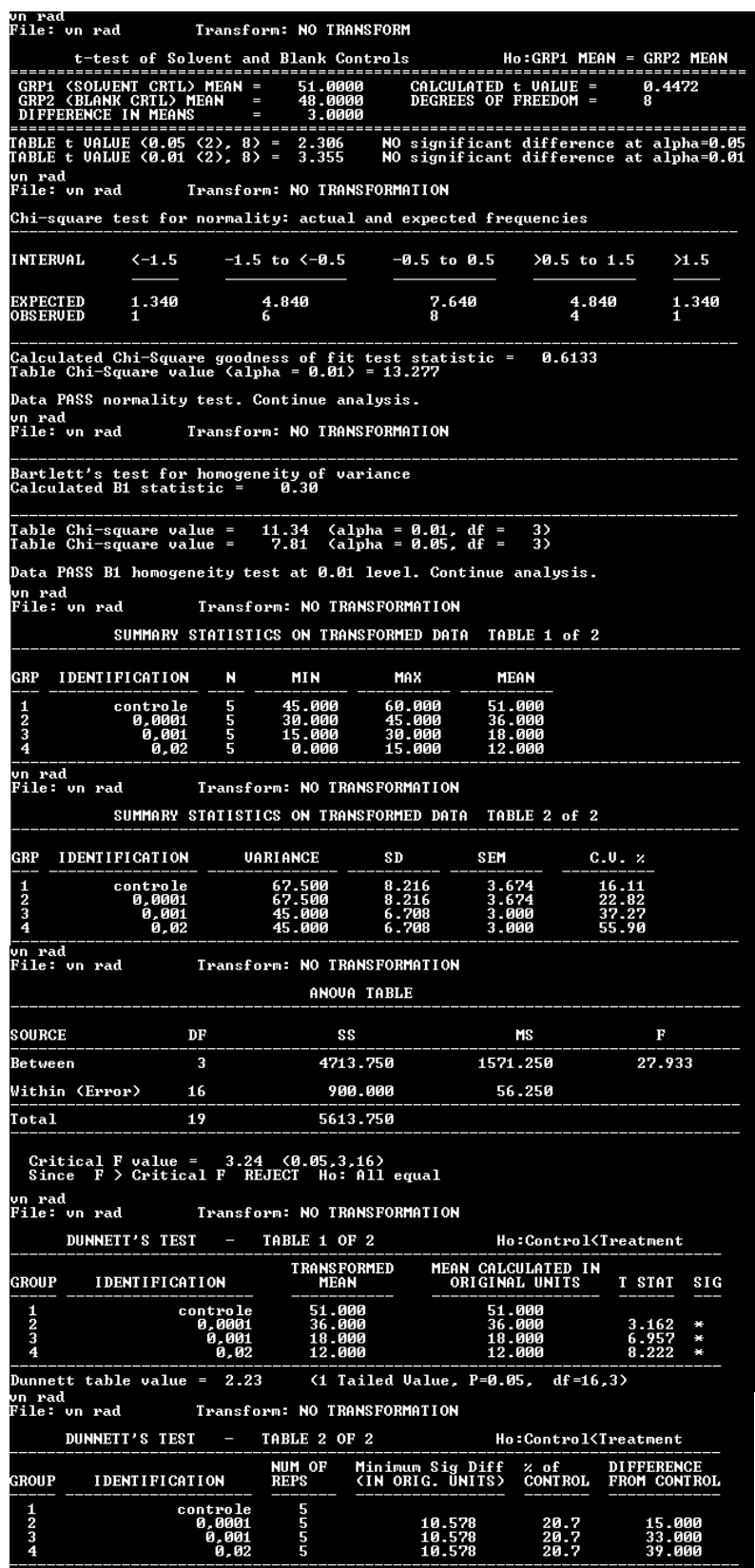


APÊNDICE F - Resultados dos ensaios de citotoxicidade do DEET em organismos irradiados obtidos por meio do software TOXSTAT 3.4 (GULLEY, D.D. et al. 1991).

\section{Ensaio - 24 horas}

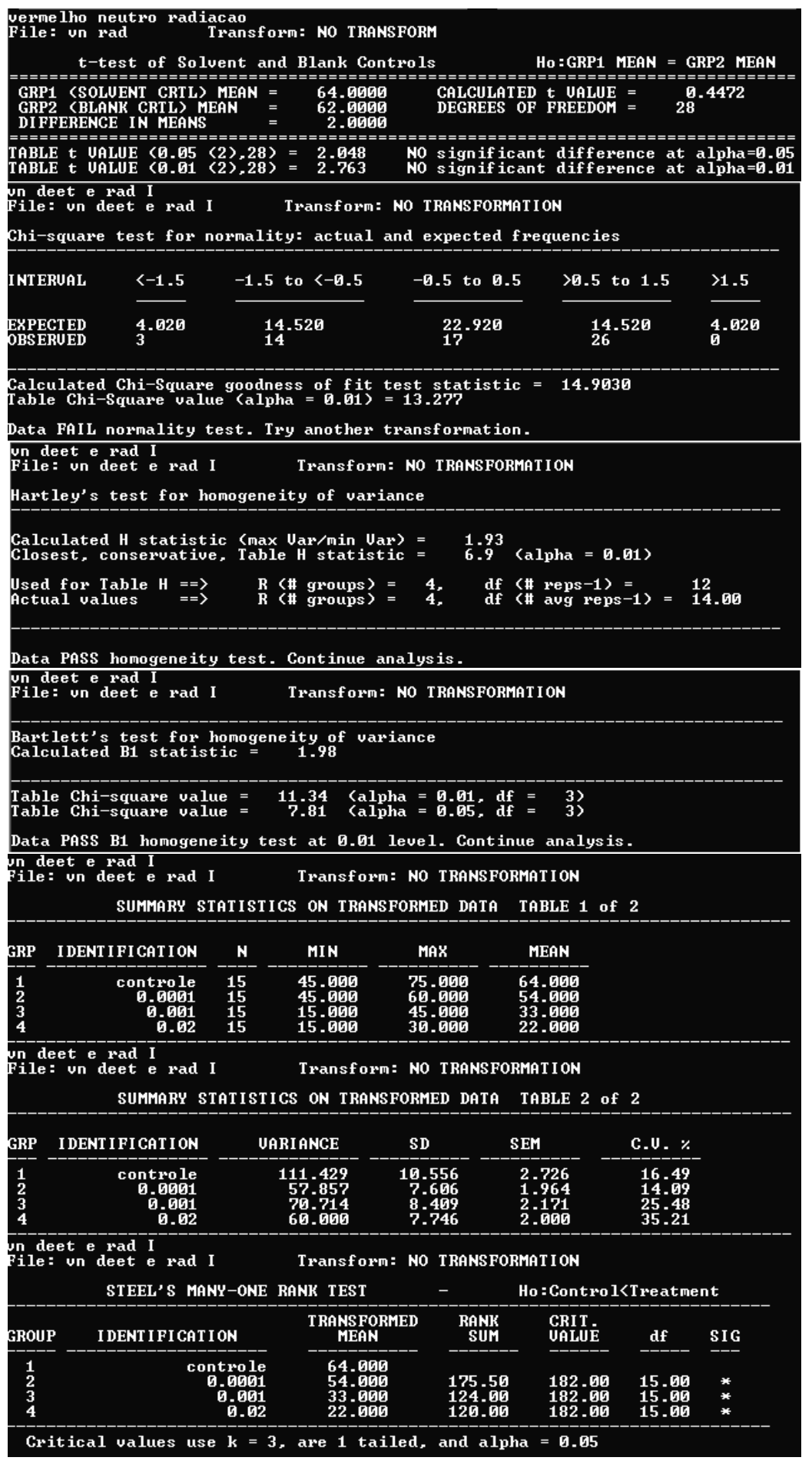




\section{Ensaio - 48 horas}

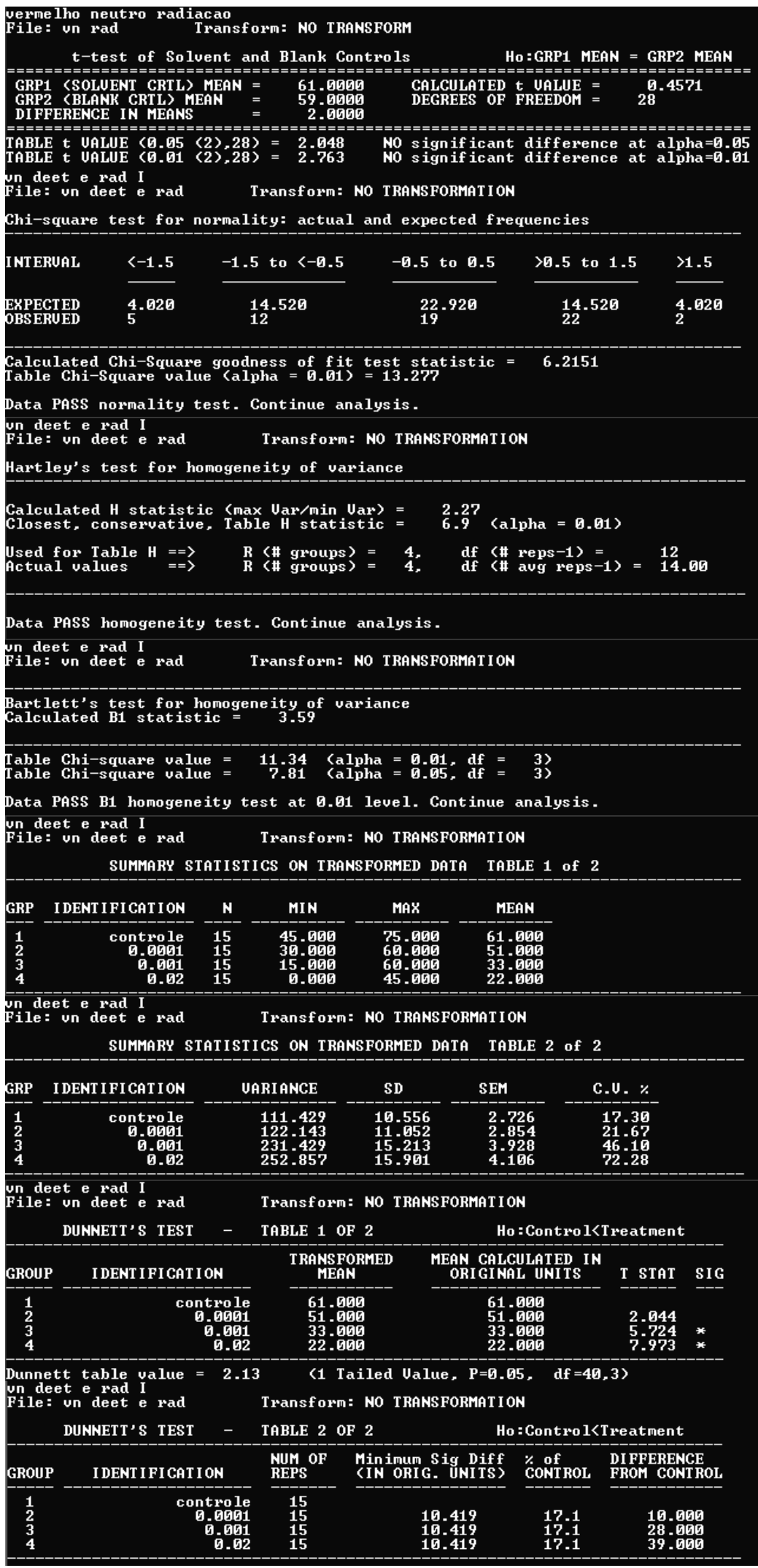




\section{Ensaio - 72 horas}

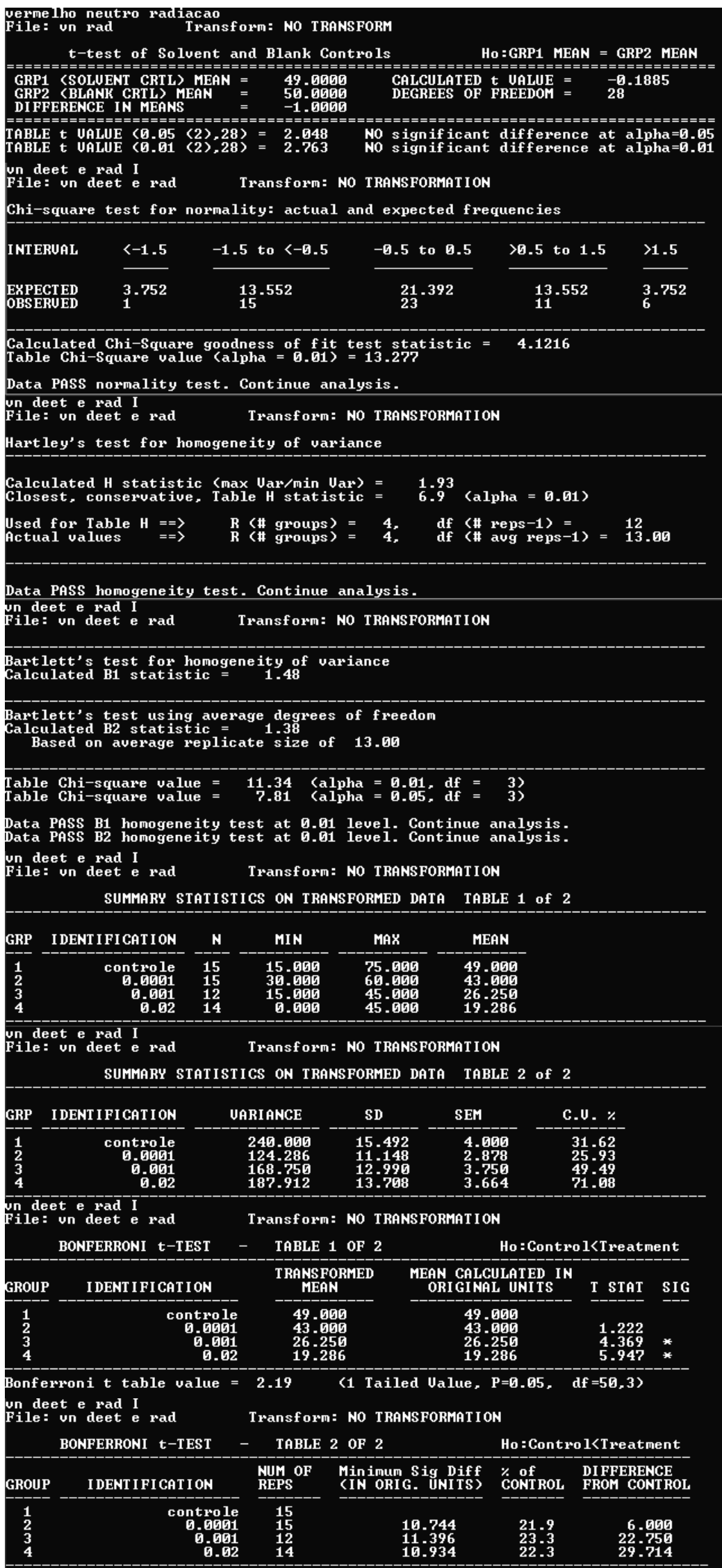


II Ensaio - 24 horas

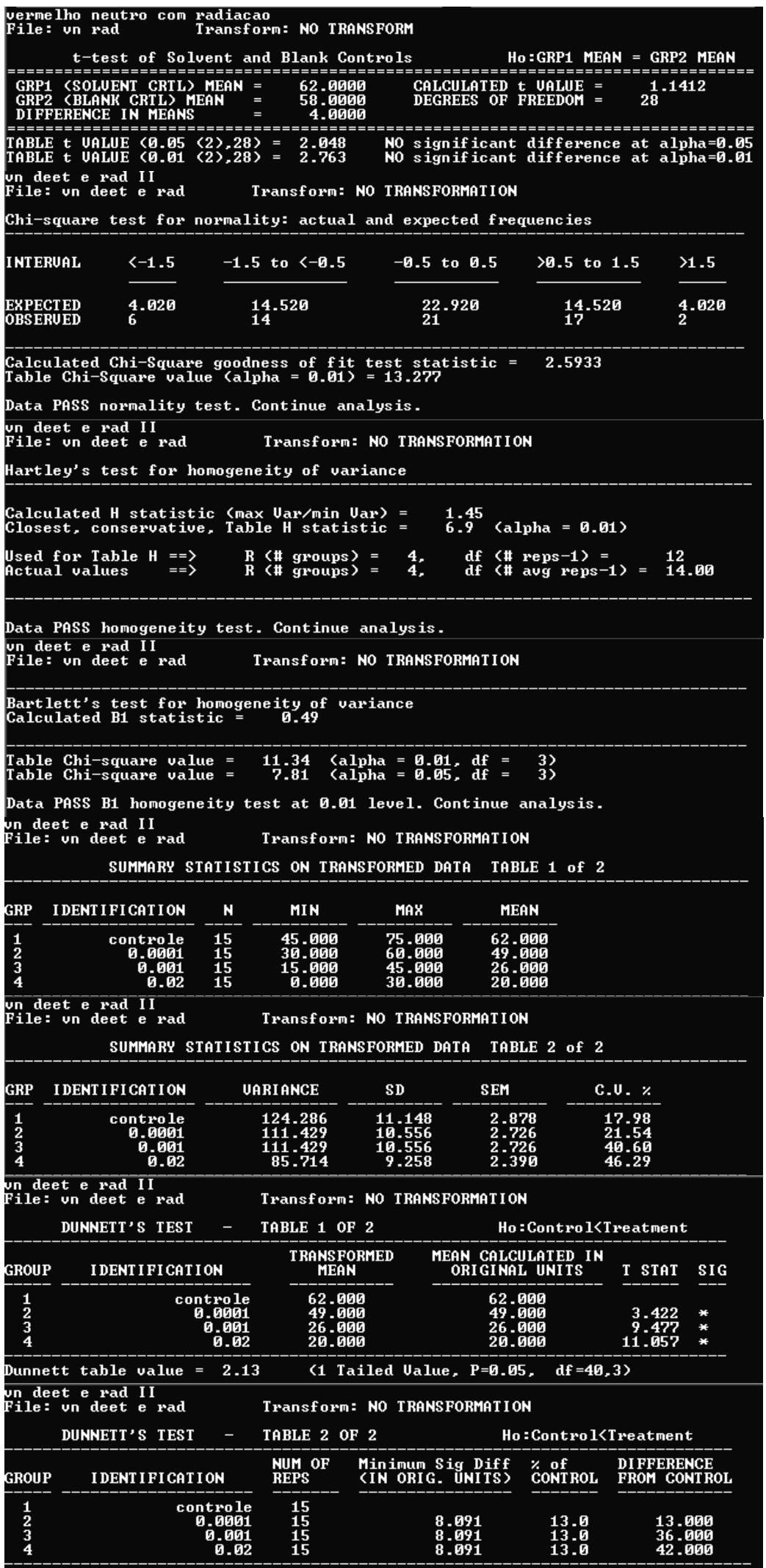


II Ensaio - 48 horas

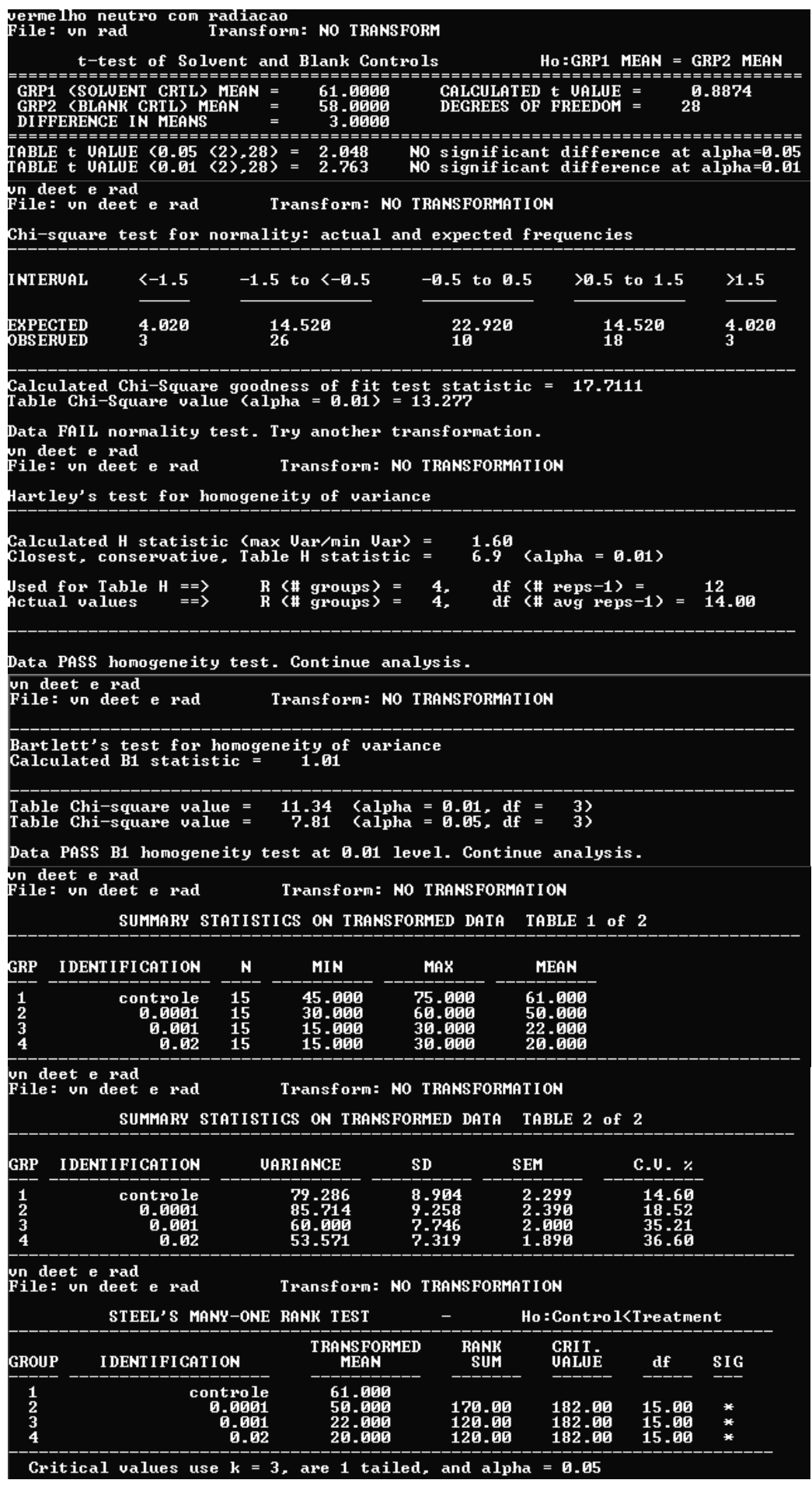


II Ensaio - 72 horas

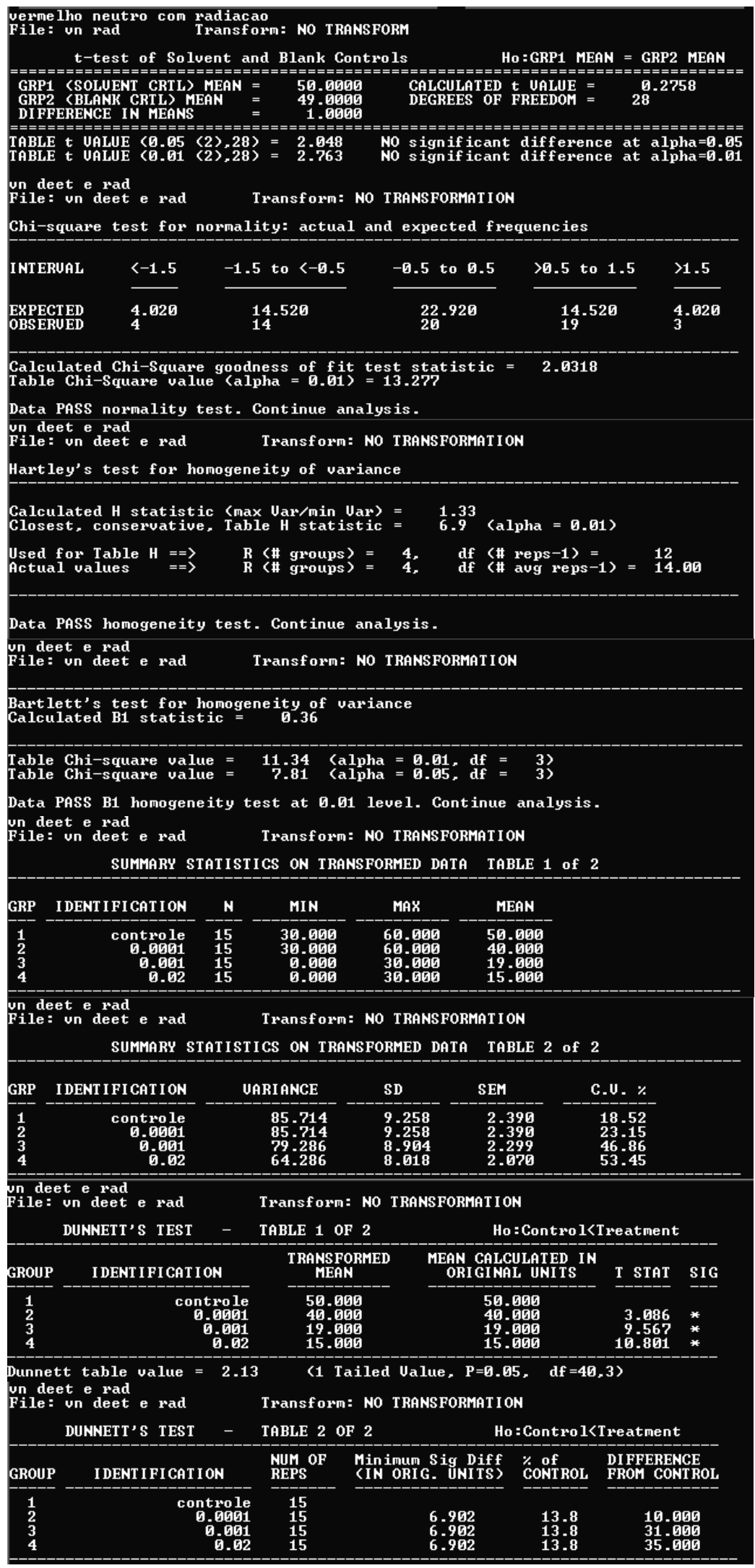




\section{Ensaio - 24 horas}

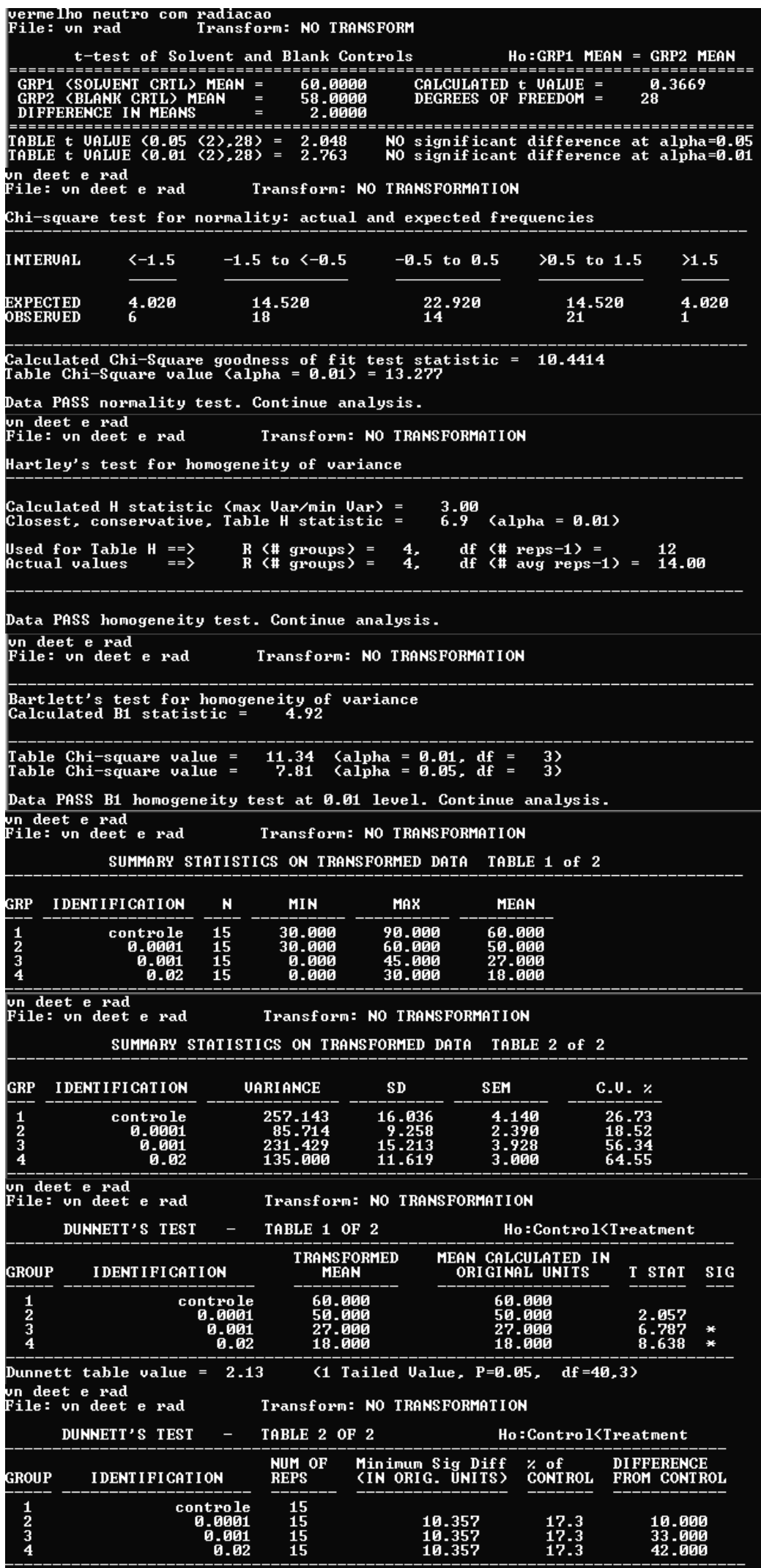




\section{Ensaio - 48 horas}

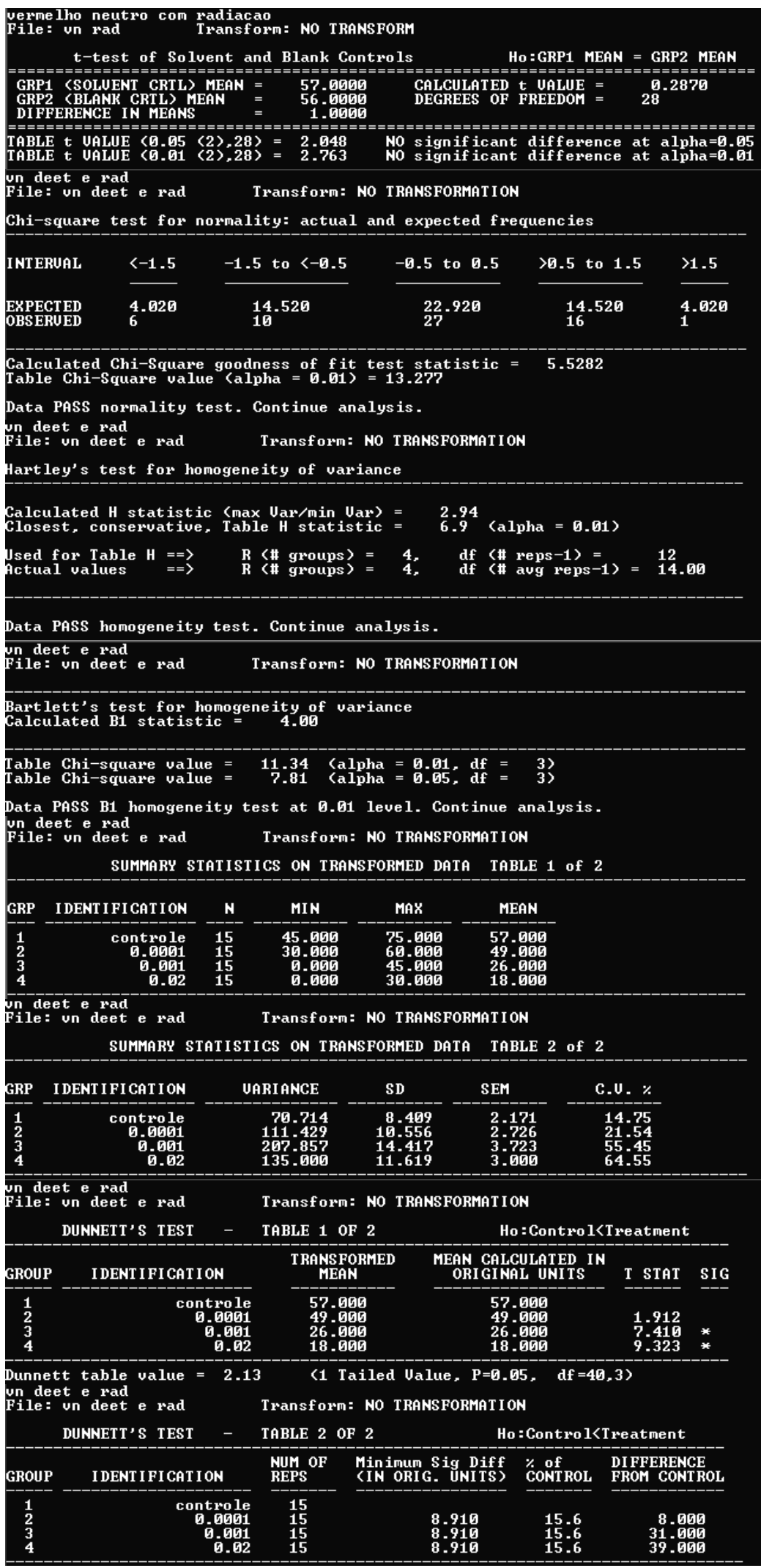




\section{Ensaio - 72 horas}

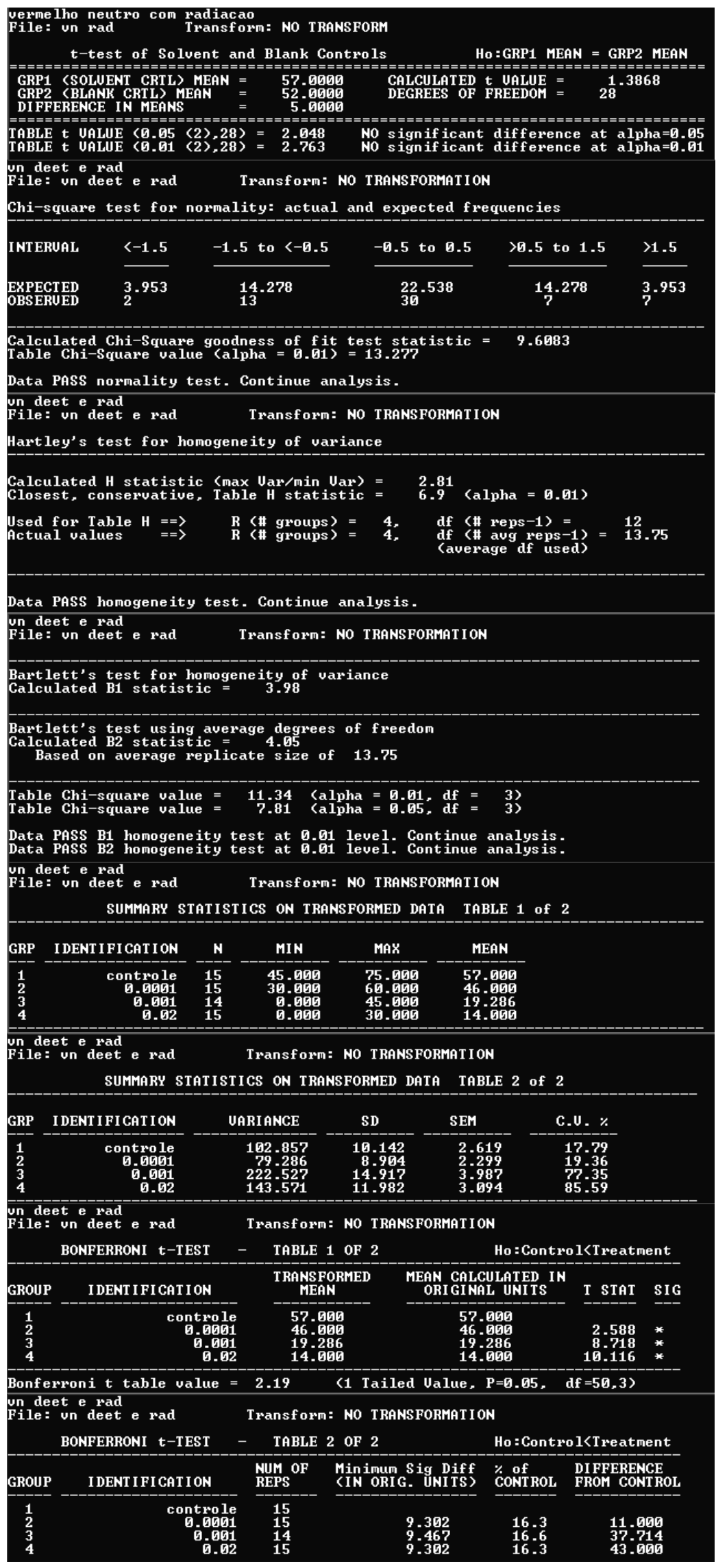


APÊNDICE G - Resultados dos ensaios de citotoxicidade em organismos irradiados e não irradiados obtidos por meio do software TOXSTAT 3.4 (GULLEY, D.D. et al. 1991).

\section{Ensaio}

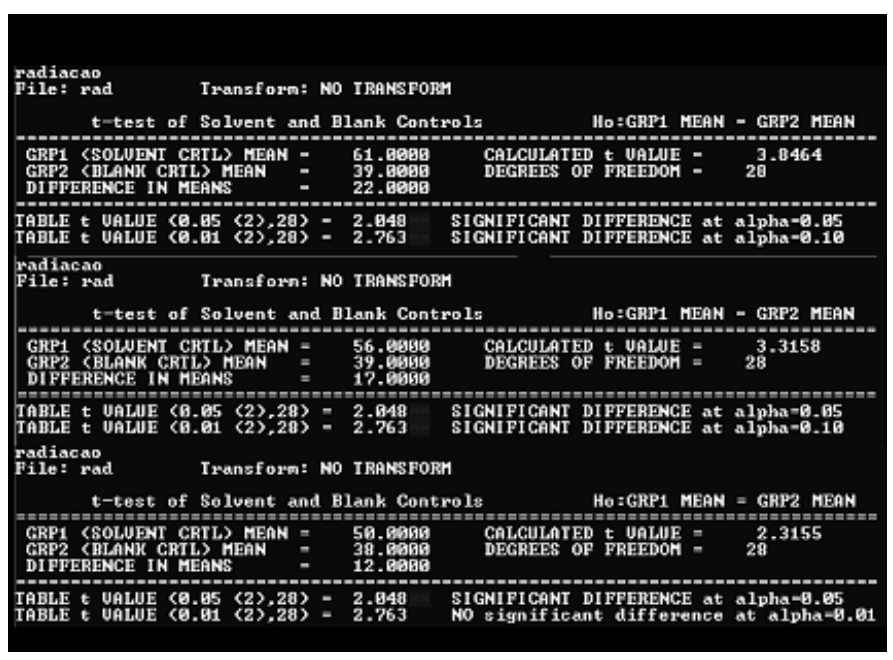

II Ensaio

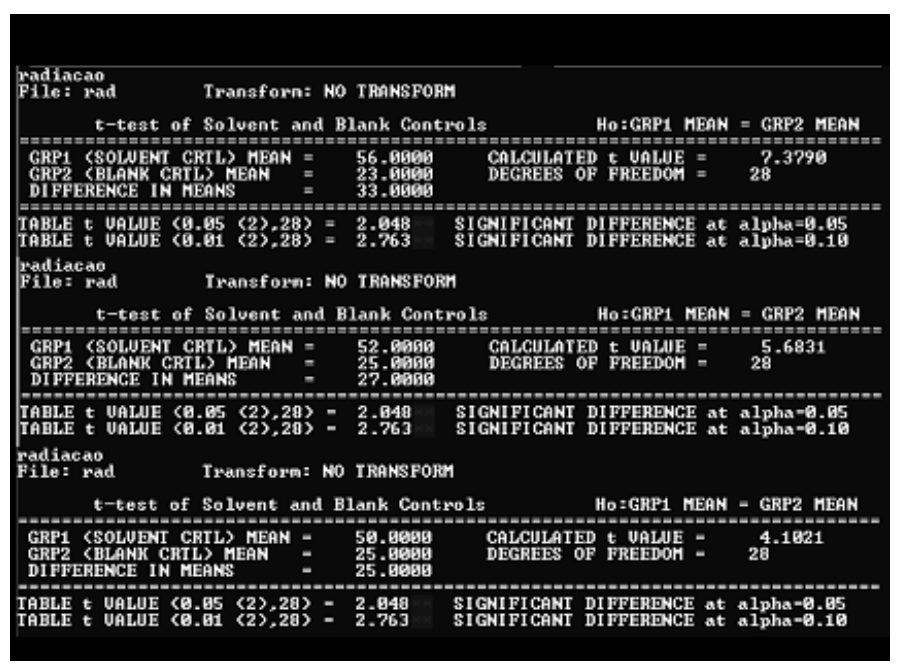

III Ensaio

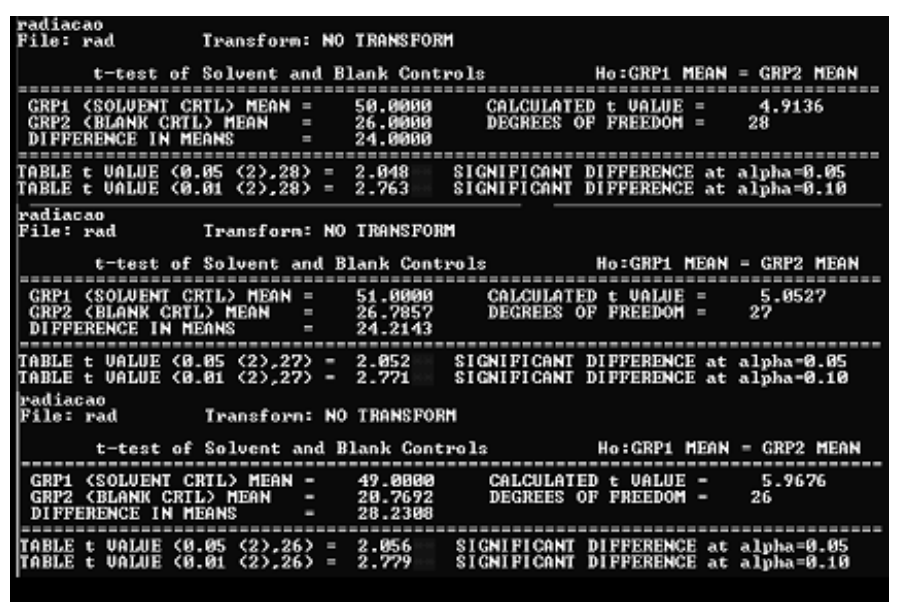


APÊNDICE H - Resultados dos testes de estimativa pontual para cálculo da $\mathrm{Cl} 25$ e Cl50 em organismos irradiados e não irradiados obtidos por meio do software ICP.

Ensaio I - Organismos não irradiados

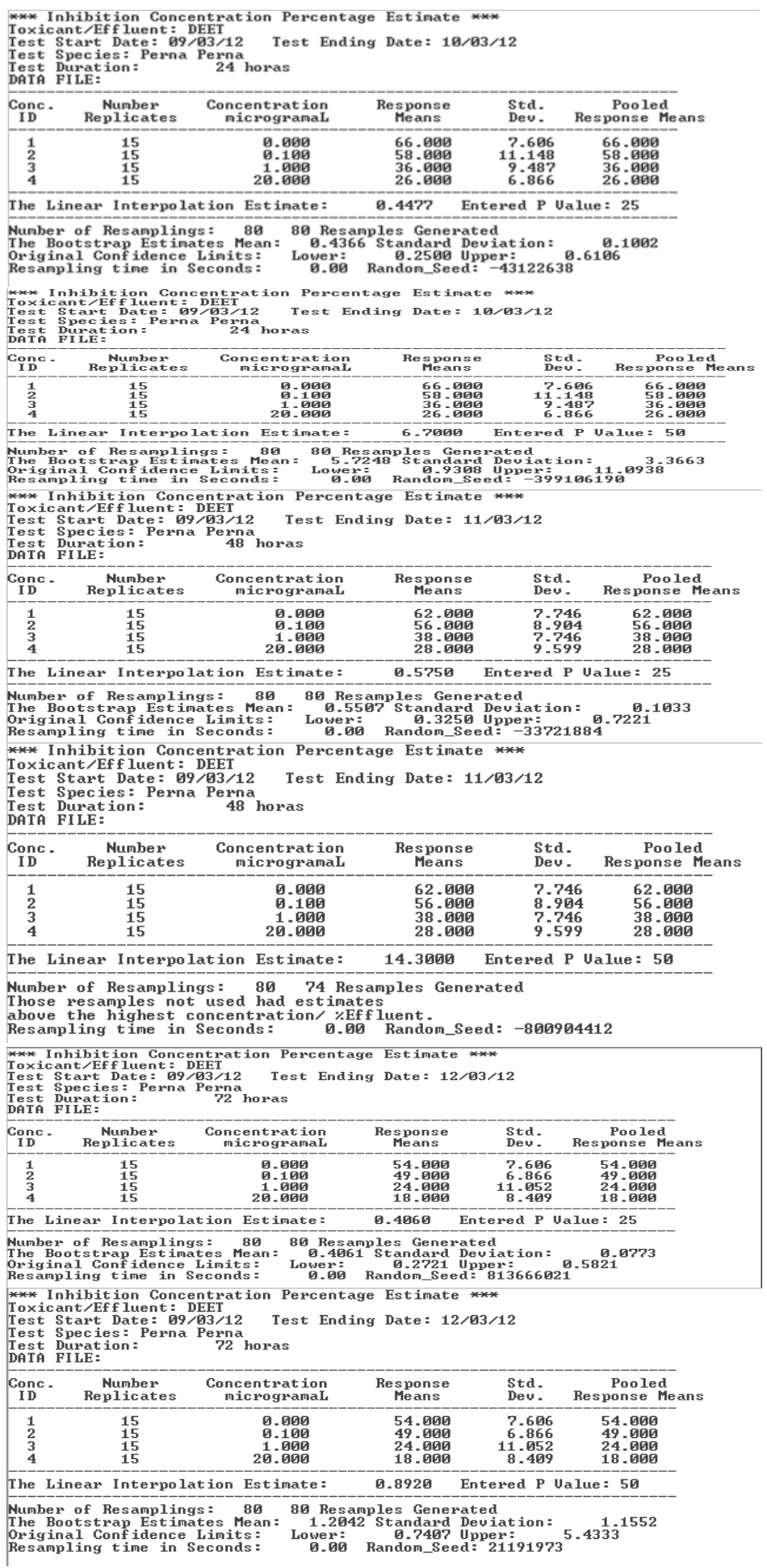

Ensaio II - Organismos não irradiados 
*** Inhibition Concentration Percentage Estimate **** Toxicant/Effluent: DEET
Test Start Date: 13/03/12 Test Ending Date: 14/03/12 Test Start Date: $13 / 63 / 12$ Test
Test Species: Perna Perna
Test Duration: 24 horas
DAT FILE:

\begin{tabular}{|c|c|c|c|c|c|}
\hline Conc. & $\begin{array}{c}\text { Number } \\
\text { Replicates }\end{array}$ & $\begin{array}{c}\text { Concentration } \\
\text { microgramaL }\end{array}$ & $\begin{array}{l}\text { Response } \\
\text { Means }\end{array}$ & $\begin{array}{l}\text { Std. } \\
\text { Dev. }\end{array}$ & $\begin{array}{r}\text { Pooled } \\
\text { Response M }\end{array}$ \\
\hline $\begin{array}{l}1 \\
2 \\
3 \\
4 \\
\end{array}$ & $\begin{array}{l}15 \\
15 \\
15 \\
15\end{array}$ & $\begin{array}{r}0.000 \\
0.100 \\
1.000 \\
20.000\end{array}$ & $\begin{array}{l}57.090 \\
52.000 \\
33.000 \\
22.000\end{array}$ & $\begin{array}{l}10.142 \\
11.148 \\
10.142 \\
12.507\end{array}$ & $\begin{array}{l}57.000 \\
52.000 \\
33.096 \\
22.000\end{array}$ \\
\hline The $\mathrm{Li}$ & ear Interpola & tion Estimate: & 0.5382 & Entered $P$ & Value: 25 \\
\hline
\end{tabular}

\begin{tabular}{|c|c|c|c|c|c|}
\hline $\begin{array}{l}\text { Toxica } \\
\text { Test S } \\
\text { Test S } \\
\text { Test D D } \\
\text { DeTh F }\end{array}$ & $\begin{array}{l}\text { t/Effluent: } \\
\text { art Date= } \\
\text { acties: Perna } \\
\text { ration: } \\
\text { LE: }\end{array}$ & $\begin{array}{l}\text { EET } \\
\text { Perna }^{3 / 2} \text { Test Er } \\
24 \text { horas }\end{array}$ & g Date $=14$ & & \\
\hline $\begin{array}{l}\text { Conc - } \\
\text { ID }\end{array}$ & $\begin{array}{c}\text { Number } \\
\text { Replicates }\end{array}$ & $\begin{array}{l}\text { Concentration } \\
\text { microgramaL }\end{array}$ & $\begin{array}{c}\text { Response } \\
\text { Means }\end{array}$ & $\begin{array}{l}\text { Std. } \\
\text { Deu: }\end{array}$ & $\begin{array}{c}\text { Pooled } \\
\text { Response Mear }\end{array}$ \\
\hline $\begin{array}{l}1 \\
2 \\
3 \\
4 \\
\end{array}$ & $\begin{array}{l}15 \\
15 \\
15 \\
15 \\
\end{array}$ & 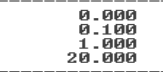 & $\begin{array}{l}57.696 \\
52.606 \\
33.606 \\
22.006\end{array}$ & $\begin{array}{l}10-142 \\
11.148 \\
10: 142 \\
12.567\end{array}$ & 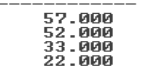 \\
\hline
\end{tabular}

Number of Resamplings: 8975 Resamples Generated

The
The Bootstraphstimates Mean:

No Confidence Limits can be produced since the number of resamples
generated is not a multiple of 4 .

Resampling time in seconds:

**** Inhibition Concentrat

Test Start Date: $13 /{ }^{2} / 12$ Test Ending Date: $15 / 03 / 12$

Test Species: Perna Perna
Test Duration:

DAT PILE:

\begin{tabular}{|c|c|c|c|c|c|c|}
\hline $\begin{array}{l}\text { Conc. } \\
\text { ID }\end{array}$ & $\begin{array}{c}\text { Number } \\
\text { Replicates }\end{array}$ & $\begin{array}{r}\text { Concentrat } \\
\text { microgra }\end{array}$ & $\begin{array}{l}\text { ation } \\
\text { amal }\end{array}$ & $\begin{array}{c}\text { Response } \\
\text { Means }\end{array}$ & $\begin{array}{l}\text { Std. } \\
\text { Deu. }\end{array}$ & $\begin{array}{c}\text { Pooled } \\
\text { Response Mean }\end{array}$ \\
\hline $\begin{array}{l}1 \\
2 \\
3 \\
4\end{array}$ & $\begin{array}{l}15 \\
15 \\
15 \\
15\end{array}$ & $\begin{array}{r}0.00 \\
0.16 \\
1.06 \\
20.06\end{array}$ & $\begin{array}{l}300 \\
100 \\
300 \\
300\end{array}$ & $\begin{array}{l}60.000 \\
53.060 \\
34.006 \\
24.000\end{array}$ & $\begin{array}{r}13.887 \\
7.746 \\
11.982 \\
13.654\end{array}$ & $\begin{array}{l}60.000 \\
53.006 \\
34.006 \\
24.000\end{array}$ \\
\hline The $\mathrm{L}$ & near Interpol & ation Estima & nate: & 0.4789 & \multicolumn{2}{|c|}{ Entered $P$ Value: 25} \\
\hline \multicolumn{7}{|c|}{ 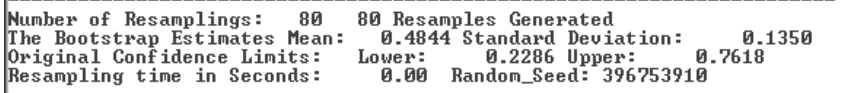 } \\
\hline
\end{tabular}
Toxicant/Ef fluent: DEET

Date: 13/03/12 Test Ending Date: 15/03/12

Test Species: Perna Perna
Test Duration: 48 horas

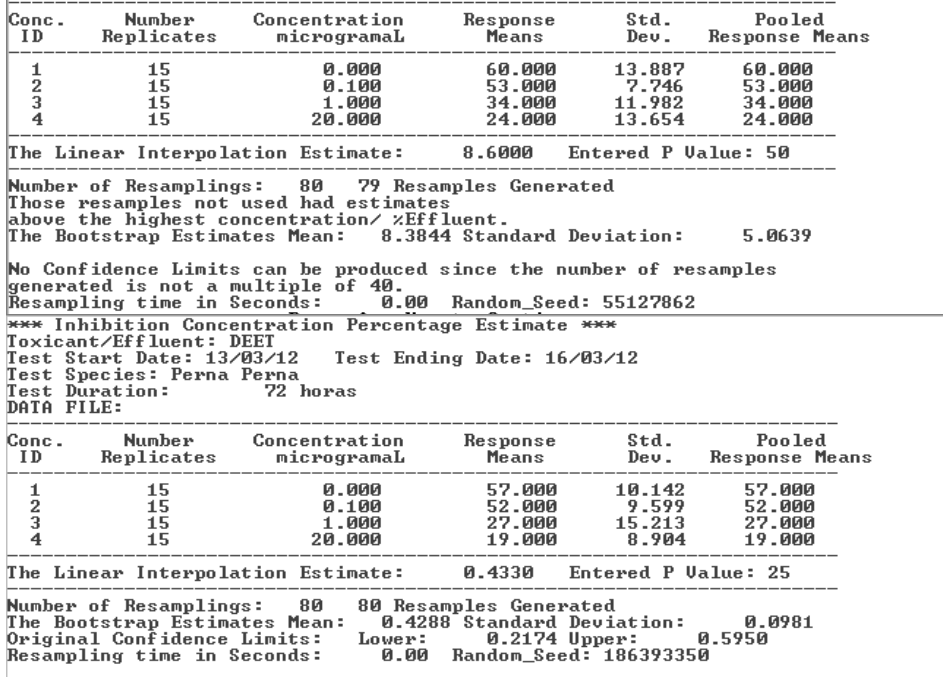

*** Inhibition Concentration Percentage Estimate ***

Test Start Date: 13/03/12 Test Ending Date: 16/03/12

Test Species: Perna Perna 72 horas

\begin{tabular}{|c|c|c|c|c|c|}
\hline Conc & $\begin{array}{c}\text { Number } \\
\text { Replicates }\end{array}$ & $\begin{array}{c}\text { Concentration } \\
\text { microgramaL }\end{array}$ & $\begin{array}{l}\text { Response } \\
\text { Means }\end{array}$ & $\begin{array}{l}\text { Std. } \\
\text { Dev. }\end{array}$ & $\begin{array}{c}\text { Pooled } \\
\text { Response Means }\end{array}$ \\
\hline $\begin{array}{l}1 \\
2 \\
3 \\
4\end{array}$ & $\begin{array}{l}15 \\
15 \\
15 \\
15\end{array}$ & $\begin{array}{r}0.000 \\
0.1006 \\
1 . .6060 \\
20.000\end{array}$ & $\begin{array}{l}57.000 \\
52.006 \\
27.060 \\
19.000\end{array}$ & $\begin{array}{r}10.142 \\
9.599 \\
15.213 \\
8.964\end{array}$ & $\begin{array}{l}57.900 \\
52.000 \\
27.000 \\
19.000\end{array}$ \\
\hline The 1 & Linear Interpol & tion Estimate: & 0.9460 & Entered $P$ & Value: 50 \\
\hline \multicolumn{6}{|c|}{ 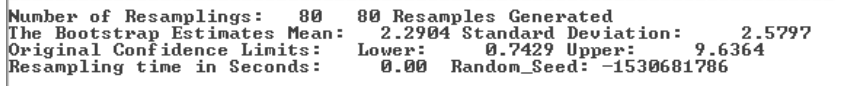 } \\
\hline
\end{tabular}

Ensaio III - Organismos não irradiados 


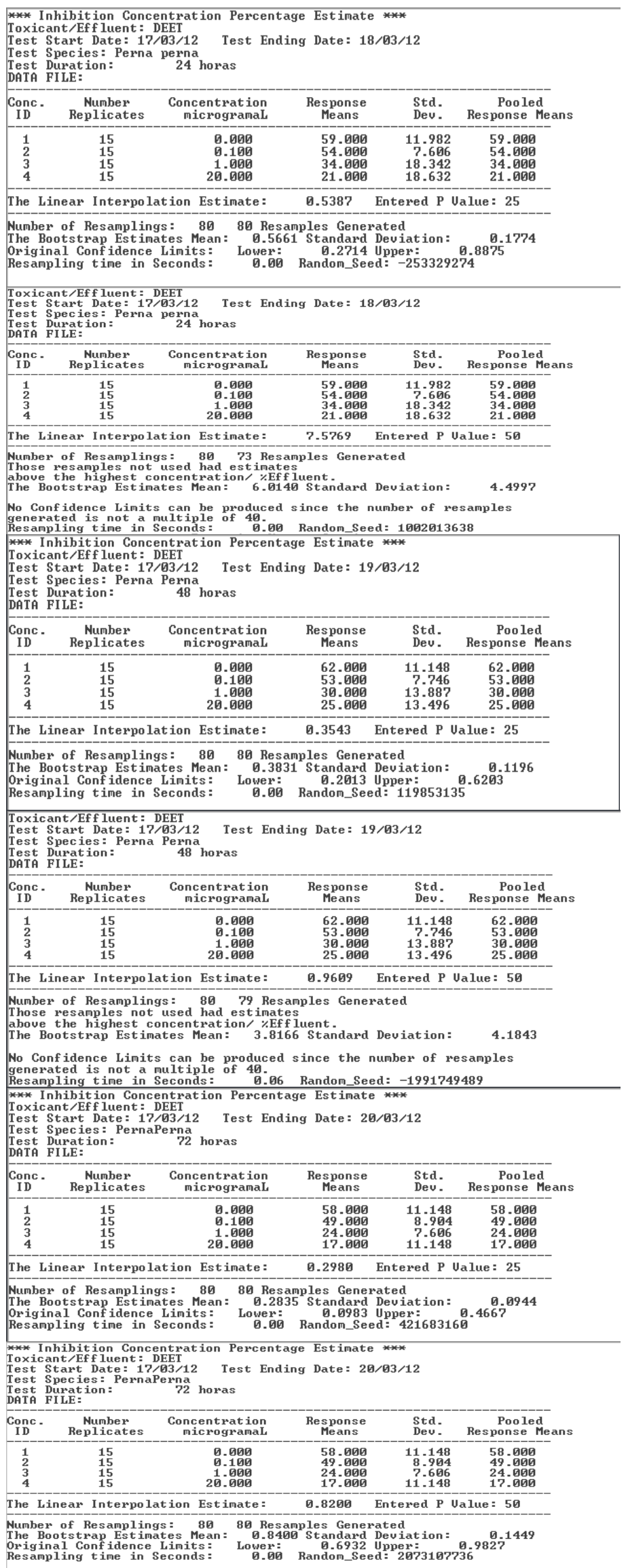

\section{Ensaio I-Organismos irradiados}




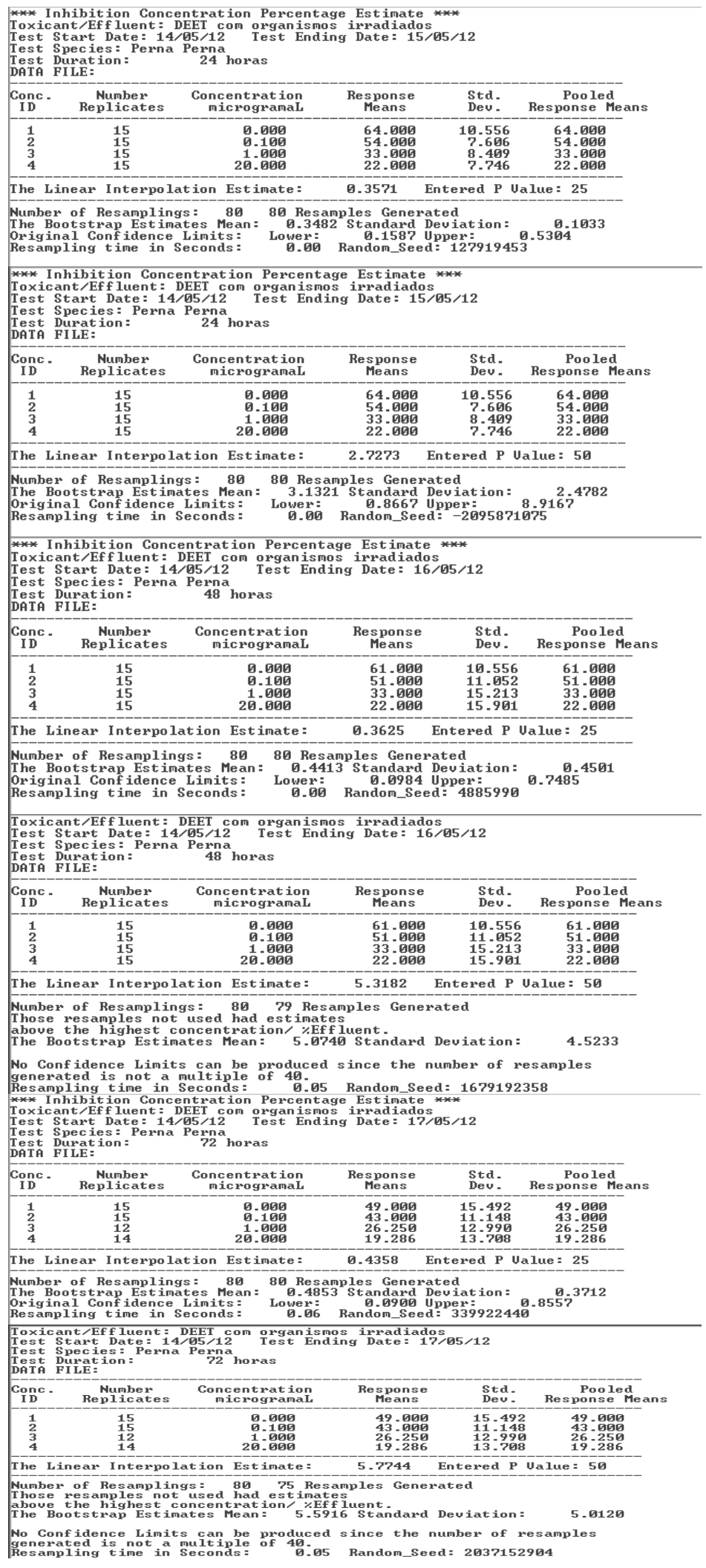

Ensaio II - Organismos irradiados 
*** Inhibition Concentration Percentage Estimate ***

$\begin{array}{ll}\text { Toxicant/Ef luent: DEET com organismos irradiados } \\ \text { Test Start Date: } 21 / 65 / 12 & \text { Test Ending Date: } 22 / 05 / 12\end{array}$

Test Species: Perna Perna
Test Duration: 24 horas

Test Duratior

\begin{tabular}{|c|c|c|c|c|c|}
\hline $\begin{array}{l}\text { Conc. } \\
\text { ID }\end{array}$ & $\begin{array}{l}\text { Number } \\
\text { Replicates }\end{array}$ & $\begin{array}{l}\text { Concentration } \\
\text { microgramaL }\end{array}$ & $\begin{array}{l}\text { Response } \\
\text { Means }\end{array}$ & $\begin{array}{l}\text { Std. } \\
\text { Dev. }\end{array}$ & $\begin{array}{c}\text { Pooled } \\
\text { Response Mea }\end{array}$ \\
\hline 1 & 15 & 0.000 & 62.000 & 11.148 & 62.000 \\
\hline 2 & 15 & 0.100 & 49.000 & 10.556 & 49.000 \\
\hline 3 & 15 & 1.000 & 26.000 & 10.556 & 26.000 \\
\hline 4 & 15 & 20.000 & 20.000 & 9.258 & 20.000 \\
\hline
\end{tabular}

The Lntered

Number of Resamplings: 80 80 Resamples Generated

The Bootstrap Estimates Mean: 0.2088 Standard Deviation: 0.1082

$\begin{array}{lll}\text { Original Confidence Limits: } & \text { Lower: } & 0.0813 \text { Upper: } \\ \text { Resampling time in Seconds: } & 0.00 & \text { Random_Seed: }-12186416\end{array}$

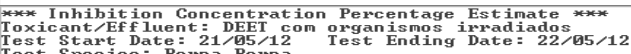

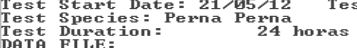

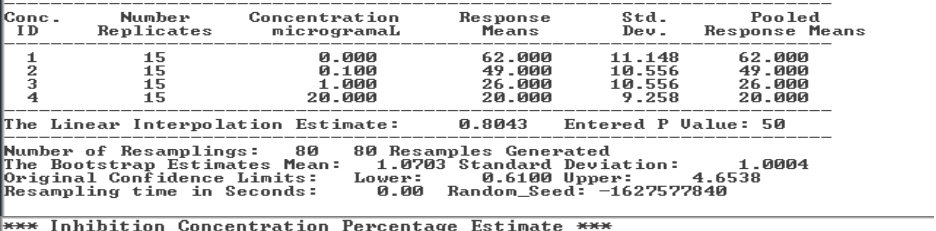

*** Inhibition Concentration Percentage Estimate ***
Toxicant/Ef fuent ${ }^{*}$ DEET com organismos irradiados
Test Start Date: 21/65/12
Test species: Perna Perna
Test Ending Date: $23 / 05 / 12$

Test Species: Perna Perna
TeTt PILE:

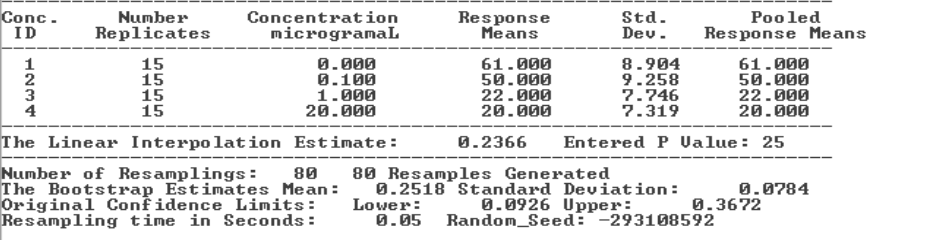

*** Inhibition Concentration Percentage Estimate ***

Toxicant Ef luent: DEET com organismos irradiados

Test Species: Perna Perna
Test Duration:

Test Durat

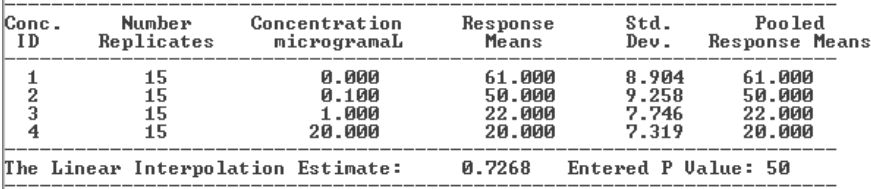

Number of Resamplings: 80 80 Resamples Generated

The Bootstrap Estimates Mean: 0.7370 Standard Deviation: 0.0670

Original Confidence Limits: $\quad$ Lower: 0.6162 Upper: 0.8833

*** Inhibition Concentration Percentage Estimate ***

Toxicant/Eff luent: DEET com organismos irradiados

Test Start Date: 21/05/12 Test Ending Date : 24/05/12

Test Species: Perna Perna 72 horas

Test Duration:
DATA FILE:

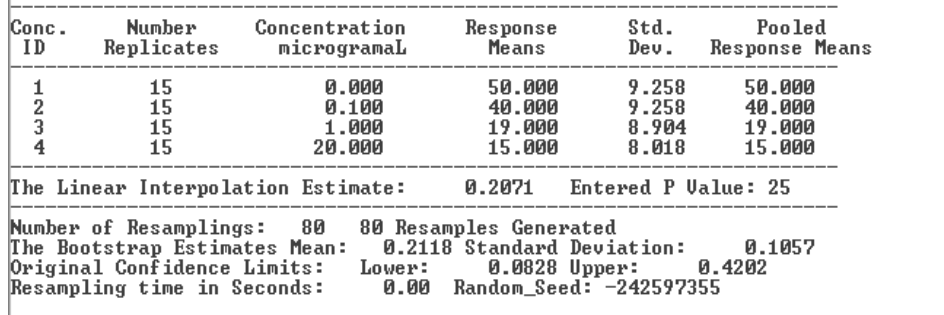

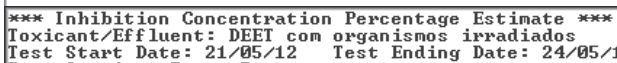

Test Start Date: 21/95/12 Test
Test Species: Perna Perna
Test Duration:

Test Durat

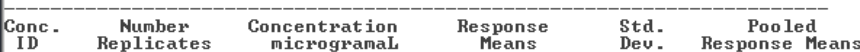

\begin{tabular}{|c|c|c|c|c|c|}
\hline & & 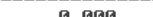 & 59.900 & & \\
\hline$\overline{3}$ & $\begin{array}{l}15 \\
15 \\
15\end{array}$ & O.19日 & $\begin{array}{l}50.600 \\
49.969\end{array}$ & $\begin{array}{l}7.258 \\
9.258 \\
8.904\end{array}$ & 40.6日日 \\
\hline & 15 & 20.ตอด & 15.600 & 8.018 & 15.ตอด \\
\hline
\end{tabular}

The Linear Interpolation Estimate : 0.7429 Entered $P$ Ualue : 50

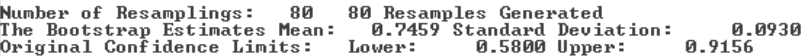

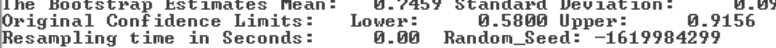

\section{Ensaio III - Organismos irradiados}




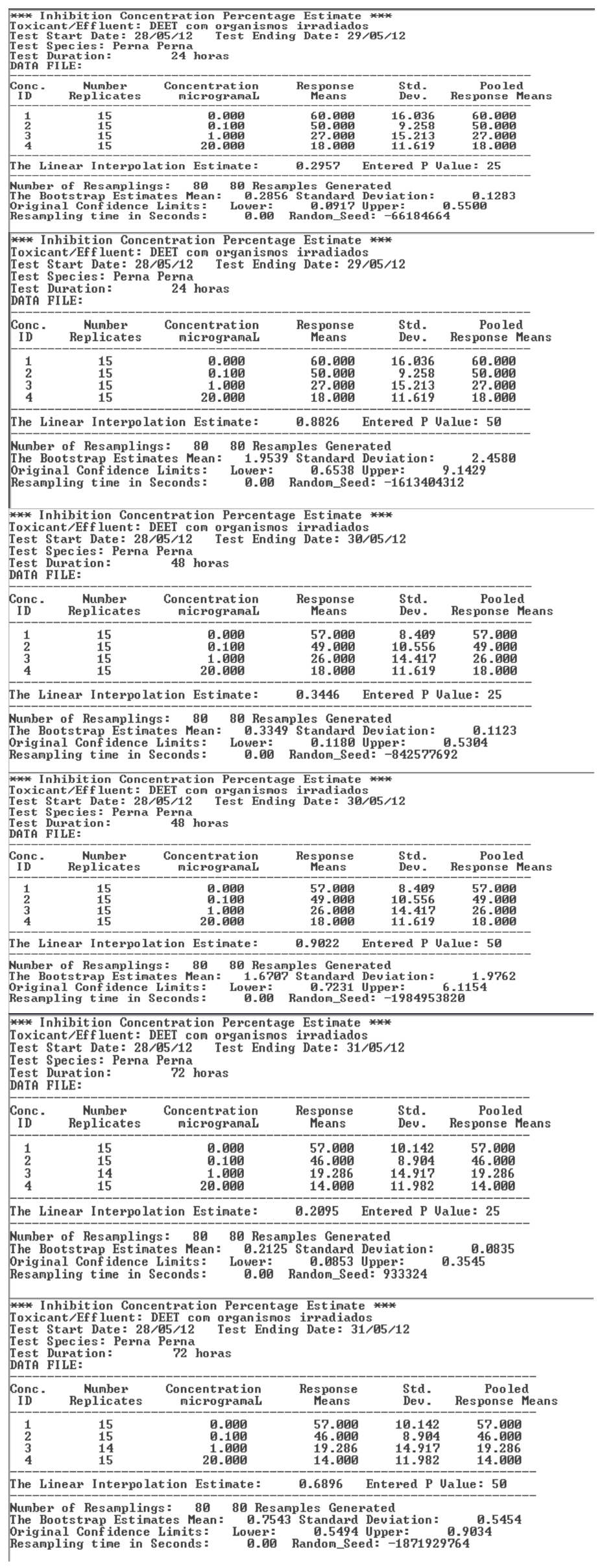




\section{Ensaio I - Organismos irradiados (sem DEET)}

*** Inhibition Concentration Percentage Estimate ***

Toxicant/Ef luent: Radiacao gana de 6b-Co
Test Start Date: 26/03/12
Test Ending Date: $27 / 63 / 12$

Test Species: Perna Perna

Test Species:
Test Duratio
DAT PILE:

\begin{tabular}{|c|c|c|c|c|c|}
\hline $\begin{array}{l}\text { Conc. } \\
\text { ID }\end{array}$ & $\begin{array}{c}\text { Nunber } \\
\text { Replicates }\end{array}$ & $\begin{array}{r}\text { Concentration } \\
6 y\end{array}$ & $\begin{array}{l}\text { Response } \\
\text { Means }\end{array}$ & $\begin{array}{l}\text { Std. } \\
\text { Deu. }\end{array}$ & $\begin{array}{c}\text { Pooled } \\
\text { Response Mea }\end{array}$ \\
\hline$\frac{1}{2}$ & $\begin{array}{l}15 \\
15\end{array}$ & $\begin{array}{r}0.000 \\
10.700\end{array}$ & 61.000 & $\begin{array}{r}15.492 \\
15.834\end{array}$ & 61.000 \\
\hline
\end{tabular}

*** Inhibition Concentration Percentage Estinate ***

Toxicant/Eff luent: Radiacao gana de 60-Co
Test Start Date: $26 / 93 / 12$ Test Ending Date: 27/63/12

Test Species: Perna Pera lest

Test Species: Perna Perna

Test Duration:

\begin{tabular}{|c|c|c|c|c|c|}
\hline $\begin{array}{l}\text { Conc. } \\
\text { ID }\end{array}$ & $\begin{array}{c}\text { Nunber } \\
\text { Replicates }\end{array}$ & $\begin{array}{r}\text { Concentration } \\
6 y\end{array}$ & $\begin{array}{c}\text { Response } \\
\text { Means }\end{array}$ & $\begin{array}{l}\text { Std. } \\
\text { Deu. }\end{array}$ & $\begin{array}{c}\text { Pooled } \\
\text { Response Mean }\end{array}$ \\
\hline$\frac{1}{2}$ & $\begin{array}{l}15 \\
15\end{array}$ & $\begin{array}{r}0.000 \\
10.700\end{array}$ & $\begin{array}{l}61.000 \\
39.000\end{array}$ & $\begin{array}{l}15.492 \\
15.834\end{array}$ & $\begin{array}{l}61.0000 \\
39.0000\end{array}$ \\
\hline The I & ar Interpol & tion Estimate: & 7.4170 & Entered P & alue: 25 \\
\hline
\end{tabular}

Nunber of Resamplings: 8073 Resamples Generated

Those resamples not used had estinates

above the highest concentration/ ':Eff luent.

No Confidence Linits can be produced since the nunber of resamples

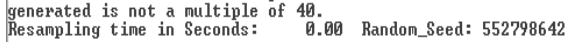

\begin{tabular}{|c|c|c|c|c|c|}
\hline \multicolumn{6}{|c|}{ 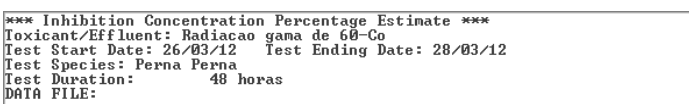 } \\
\hline $\begin{array}{l}\text { Conc. } \\
\text { ID }\end{array}$ & $\begin{array}{c}\text { Number } \\
\text { Replicates }\end{array}$ & $\begin{array}{r}\text { Concentration } \\
\text { Gy }\end{array}$ & $\begin{array}{l}\text { Response } \\
\text { Means }\end{array}$ & $\begin{array}{l}\text { std. } \\
\text { Deu. }\end{array}$ & $\begin{array}{c}\text { Pooled } \\
\text { Response Means }\end{array}$ \\
\hline$\frac{1}{2}$ & $\begin{array}{l}15 \\
15\end{array}$ & $\begin{array}{r}0.006 \\
10.700\end{array}$ & $\begin{array}{l}56.000 \\
39.000\end{array}$ & $\begin{array}{l}11.982 \\
15.834\end{array}$ & $\begin{array}{l}56.9069 \\
39.900\end{array}$ \\
\hline
\end{tabular}

input data since none of the (possibly pooled) group response means
were less than $50 \%$ of the control response mean.

\begin{tabular}{|c|c|c|c|c|c|}
\hline \multicolumn{6}{|c|}{ 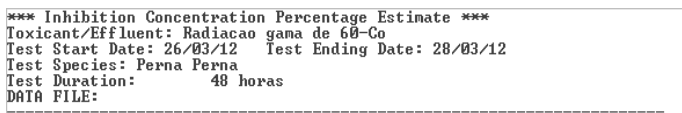 } \\
\hline Conc. & $\begin{array}{c}\text { Number } \\
\text { Replicates }\end{array}$ & $\begin{array}{r}\text { Concentration } \\
\text { Gy }\end{array}$ & $\begin{array}{c}\text { Response } \\
\text { Means }\end{array}$ & $\begin{array}{l}\text { Std. } \\
\text { Deu. }\end{array}$ & $\begin{array}{c}\text { Pooled } \\
\text { Response Means }\end{array}$ \\
\hline$\frac{1}{2}$ & $\begin{array}{l}15 \\
15\end{array}$ & $\begin{array}{c}0.000 \\
10.700\end{array}$ & $\begin{array}{l}56.000 \\
39.000\end{array}$ & $\begin{array}{l}11.982 \\
15.834\end{array}$ & $\begin{array}{l}56.000 \\
39.000\end{array}$ \\
\hline \multicolumn{3}{|c|}{ The Linear Interpolation Estimate: } & 8.8118 & Entered P U & Jalue: 25 \\
\hline \multicolumn{5}{|c|}{$\begin{array}{l}\text { Number of Resanplings: } 80 \quad 58 \text { Resamples Generated } \\
\text { Those resanples not used had estinates } \\
\text { above the highest concentration/ \%Eff luent. } \\
\text { The Bootstrap Estinates Mean: } 7.9023 \text { Standard Deviation: }\end{array}$} & 1.1858 \\
\hline
\end{tabular}

\begin{tabular}{|c|c|c|c|c|c|}
\hline Conc. & $\begin{array}{c}\text { Nunber } \\
\text { Replicates }\end{array}$ & $\begin{array}{r}\text { Concentration } \\
G y\end{array}$ & $\begin{array}{l}\text { Response } \\
\text { Means }\end{array}$ & $\begin{array}{l}\text { Std. } \\
\text { Deu. }\end{array}$ & $\begin{array}{c}\text { Pooled } \\
\text { Response Mean }\end{array}$ \\
\hline$\frac{1}{2}$ & $\begin{array}{l}15 \\
15\end{array}$ & $\begin{array}{r}0.000 \\
10.700\end{array}$ & $\begin{array}{l}50.0000 \\
38.000\end{array}$ & $\begin{array}{l}12.247 \\
15.901\end{array}$ & $\begin{array}{l}50.000 \\
38.0000\end{array}$ \\
\hline
\end{tabular}

*** Inhibition Concentration Percentage Estinate ***
Toxicant/Effluent: Radiacao gama de 6ด-Co

Toxicant/Eff luent: Radiacao gana de 6Q-Co
Test Start Date: 26/03/12 Test Ending Date: 29/63/12

Test Start Date: $26 / 03 / 12$
Test Species: Perna Perna

Test Duration: 72 horas

\begin{tabular}{cccccc}
\hline $\begin{array}{c}\text { Conc. } \\
\text { ID }\end{array}$ & $\begin{array}{c}\text { Nunber } \\
\text { Replicates }\end{array}$ & $\begin{array}{c}\text { Concentration } \\
\text { Gy }\end{array}$ & $\begin{array}{c}\text { Response } \\
\text { Means }\end{array}$ & $\begin{array}{c}\text { Std. } \\
\text { Dev. }\end{array}$ & $\begin{array}{c}\text { Pooled } \\
\text { Response Means }\end{array}$ \\
\hline 1 & 15 & 0.000 & 50.000 & 12.247 & 50.000 \\
2 & 15 & 10.700 & 38.000 & 15.901 & 38.000 \\
\hline
\end{tabular}

*** No Linear Interpolation Estinate can be calculated from the

input data since none of the (possibly pooled) group response mean 


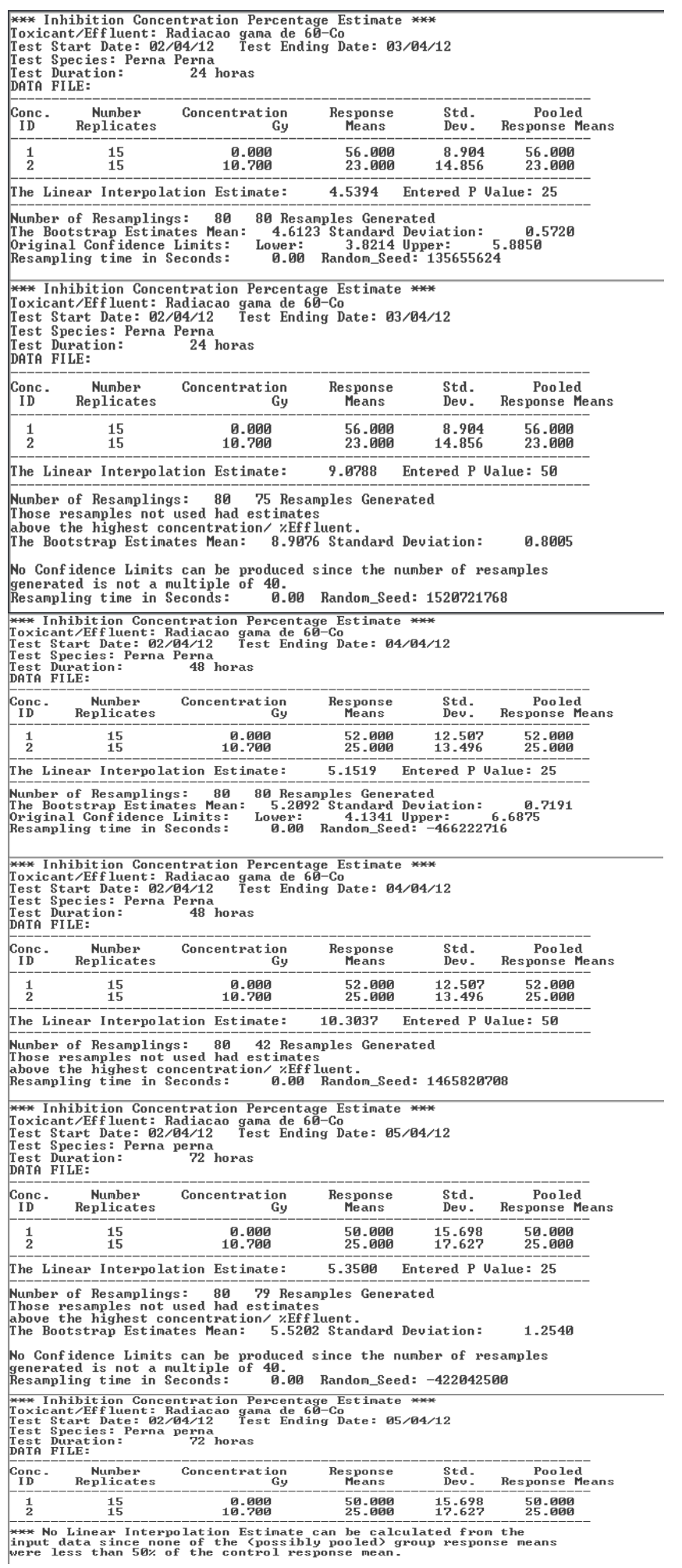

Ensaio III - Organismos irradiados (sem DEET) 
*** Inhibition Concentration Percentage Estimate ***

Toxicant/Effluent: Radiacao gama de 60-Co

Test Start Date: 09/04/12 Te
Test Species: Perna Perna

Test Duration: 24 horas

\begin{tabular}{|c|c|c|c|c|c|}
\hline $\begin{array}{l}\text { Conc. } \\
\text { ID }\end{array}$ & $\begin{array}{c}\text { Number } \\
\text { Replicates }\end{array}$ & $\begin{array}{r}\text { Concentration } \\
\text { Gy }\end{array}$ & $\begin{array}{l}\text { Response } \\
\text { Means }\end{array}$ & $\begin{array}{l}\text { Std. } \\
\text { Dev. }\end{array}$ & $\begin{array}{c}\text { Pooled } \\
\text { Response Mean }\end{array}$ \\
\hline $\begin{array}{l}1 \\
2\end{array}$ & $\begin{array}{l}15 \\
15\end{array}$ & $\begin{array}{r}0.000 \\
10.700\end{array}$ & $\begin{array}{l}50.090 \\
26.000\end{array}$ & $\begin{array}{l}13.496 \\
13.256\end{array}$ & $\begin{array}{l}50.090 \\
26.000\end{array}$ \\
\hline \multicolumn{3}{|c|}{ The Linear Interpolation Estimate: } & 5.5729 & \multicolumn{2}{|c|}{ Entered P Ualue: 25} \\
\hline \multicolumn{6}{|c|}{ 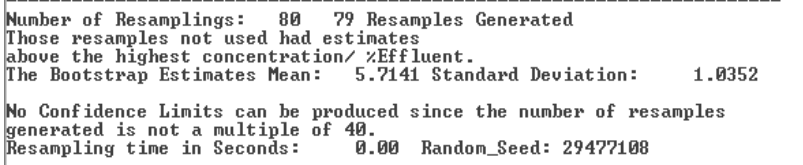 } \\
\hline \multicolumn{6}{|c|}{$\begin{array}{l}\text { *** Inhibition Concentration Percentage Estimate *** } \\
\text { Toxicant/Effluent: Radiacao gama de } 69-C o \\
\text { Test Start Date: } 99 / 94 / 12 \text { Test Ending Date }: 19 / 94 / 12 \\
\text { Test Species: Perna Perna } \\
\text { Test Duration: } \quad 24 \text { horas }\end{array}$} \\
\hline $\begin{array}{l}\text { Conc. } \\
\text { ID }\end{array}$ & $\begin{array}{c}\text { Number } \\
\text { Replicates }\end{array}$ & $\begin{array}{r}\text { Concentration } \\
G y\end{array}$ & $\begin{array}{l}\text { Response } \\
\text { Means }\end{array}$ & $\begin{array}{l}\text { Std. } \\
\text { Dev. }\end{array}$ & $\begin{array}{c}\text { Pooled } \\
\text { Response Mear }\end{array}$ \\
\hline$\frac{1}{2}$ & $\begin{array}{l}15 \\
15\end{array}$ & $\begin{array}{r}\text { 9. } 000 \\
10.700\end{array}$ & $\begin{array}{l}50.000 \\
26.000\end{array}$ & $\begin{array}{l}13.496 \\
13.256\end{array}$ & $\begin{array}{l}50.000 \\
26.000\end{array}$ \\
\hline
\end{tabular}

** No Linear Interpolation Estimate can be calculated from the

input data since none of the (possibly pooled) group response means

*** Inhibition Concentration Percentage Estimate ***

Toxicant/Effluent: Radicao gama de 66-Co

Test Species: Perna Perna
Test Duration: $\quad 48$ hora

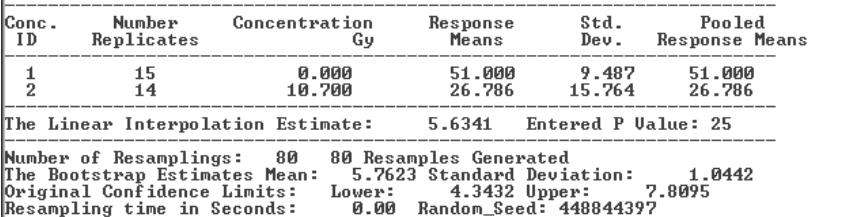

*** Inhibition Concentration Percentage Estimate ***

Test Start Date: 99/04/12 Test Ending Date : 11/04/12

Test Species: Perna Perna
Test Duration: $\quad 48$ horas

\begin{tabular}{|c|c|c|c|c|c|}
\hline $\begin{array}{l}\text { Conc. } \\
\text { ID }\end{array}$ & $\begin{array}{c}\text { Number } \\
\text { Replicates }\end{array}$ & $\underset{G y}{\underset{G}{C}}$ & $\begin{array}{l}\text { Response } \\
\text { Means }\end{array}$ & $\begin{array}{l}\text { Std. } \\
\text { Dev: }\end{array}$ & $\begin{array}{c}\text { Pooled } \\
\text { Response Mea }\end{array}$ \\
\hline$\frac{1}{2}$ & $\begin{array}{l}15 \\
14\end{array}$ & $\begin{array}{r}0.000 \\
10.700\end{array}$ & $\begin{array}{l}51.006 \\
26.786\end{array}$ & $\begin{array}{r}9.487 \\
15.764\end{array}$ & $\begin{array}{l}51.000 \\
26.786\end{array}$ \\
\hline
\end{tabular}

*** No Linear Interpolation Estimate can be calculated from the
input data since none of the (possibly pooled) group response means
were less than $5 \mathrm{~g} \%$ of the control response mean.

*** Inhibition Concentration Percentage Estimate ***

Toxicant/Eff luent: Radiacao gama de $60-C$

Test Start Date: $09 / 04 / 12$ Test Ending Date: 12/04/12

est Species: Perna Perna

DATA FILE:

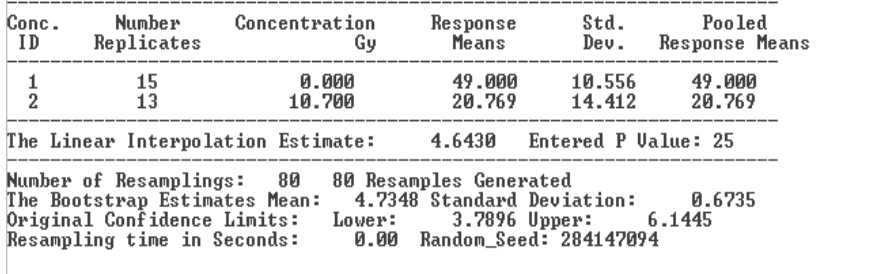

*** Inhibition Concentration Percentage Estimate ***

Toxicant/Ef luent: Radiacao gama de 60-Co
Test Start Date: $99 / 94 / 12$ Test Ending Date: 12/04/12

Test Species: Perna Perna 72 horas

Test Durat:

\begin{tabular}{|cccccc}
$\begin{array}{c}\text { Conc. } \\
\text { ID }\end{array}$ & $\begin{array}{c}\text { Number } \\
\text { Replicates }\end{array}$ & $\begin{array}{c}\text { Concentration } \\
\text { Gy }\end{array}$ & $\begin{array}{c}\text { Response } \\
\text { Means }\end{array}$ & $\begin{array}{c}\text { Std. } \\
\text { Dev. }\end{array}$ & $\begin{array}{c}\text { Pooled } \\
\text { Response Means }\end{array}$ \\
\hline 1 & 15 & 0.000 & 49.000 & 10.556 & 49.000 \\
2 & 13 & 10.700 & 20.769 & 14.412 & 20.769 \\
\hline The Linear Interpolation Estimate : & 9.2860 & Entered P Value: & 50 \\
\hline
\end{tabular}

Number of Resamplings: 8065 Resamples Generated

Those resamples not used had estimates

aboue the highest concentration/ \%Effluent.
The Bootstrap Estimates Mean: 9.1312 Standard Deviation:

No Confidence Limits can be produced since the number of resamples

generated is not a multiple of 40 .
Resampling time in Seconds: 
